\title{
A fatigue-based model for the droplet impingement erosion incubation period
}





\section{A fatigue-based model for the droplet impingement erosion incubation period}

Henk Slot

2021 
The results presented in this thesis have been obtained partly within the European Union's Seventh Framework Programme (FP7/2007-2013), project WALID, under grant agreement no. 309985.

De promotiecommissie is als volgt opgesteld:

prof.dr.ir. H.F.J.M. Koopman, Universiteit Twente, voorzitter en secretaris prof. dr. ir. E. van der Heide, Universiteit Twente, promotor dr. D.T.A. Matthews, Universiteit Twente, co-promotor prof.dr.ir. R. Akkerman, Universiteit Twente prof.dr.ir. J. Maljaars, Technische Universiteit Eindhoven dr.ir. J.J.E. Teuwen, Technische Universiteit Delft prof.dr.ir. T. Tinga, Universiteit Twente

Slot, Henk

A fatigue-based model for the droplet impingement erosion incubation period PhD Thesis, University of Twente, Enschede, The Netherlands, June 2021.

ISBN: 978-90-365-5191-5

DOI: $10.3990 / 1.9789036551915$ 


\title{
A fatigue-based model for the droplet impingement erosion incubation period
}

\author{
PROEFSCHRIFT
}

\author{
ter verkrijging van \\ de graad van doctor aan de Universiteit Twente, \\ op gezag van de rector magnificus, \\ prof. dr. ir. A. Veldkamp, \\ volgens besluit van het College voor Promoties \\ in het openbaar te verdedigen \\ op vrijdag 4 juni 2021 te 14:45 uur
}

door

Henk Slot

Geboren op 20 maart 1961

te Wanneperveen 
DIT PROEFSCHRIFT IS GOEDGEKEURD DOOR

Promotor: prof. dr. ir. E. van der Heide

Co-promotor: dr. D.T.A. Matthews 
Dedicated to my grandfather Hendrik Arendshorst - † April 1945, Buchenwald/Theresienstadt In one of his letters from the concentration camp he wrote:

"... Jesus Christ is the same yesterday, and today, and forever..." (Hebrews 13:8) 


\section{Foreword}

My introduction to the fascinating world of fatigue and fracture mechanics took place during my Metals Engineering study, at the lectures of Prof. J.L. Overbeeke of the University of Eindhoven. A visit to his fatigue laboratory at the university, combined with his trouble-shooting lectures, awoke a special interest for these material properties.

Some years later, during my time at the Mechanical Testing department of the Metals Research Institute of TNO, a firm base for my fatigue and fracture knowledge of metals and welded structures was laid.

In about 1995, I entered the Tribology group of TNO, where I worked for nearly 20 years. During this time, I developed a special interest in the application of materials, and in material selection for optimised performance in such areas as the abrasive wear of materials, and solid particle erosion especially in wear by sand - water slurry mixtures, as in dredging applications. Furthermore, I conducted research in rolling contact fatigue such as occurring in bearings and camshafts.

One of my projects was the "Wet steam injection spool" as used in the Schoonebeek oil field in the Netherlands. I discovered that a wear mechanism new to us, erosion by droplet impact, was responsible for the lifetime of this structural part. Due to this droplet erosion lifetime evaluation study in 2009, my interest for the relation between the mechanical properties of materials and the erosion incubation period and erosion rate was born.

Soon after this exciting experience with the exploration of the mechanism of droplet impact erosion, we acquired the European projects WALID and NATURAL, both focusing on the leading-edge erosion of wind turbine blades by rain drops.

From 2015, I worked in the Building, Infrastructure and Maritime Unit of TNO and one of the subjects I continued to work on was the tribology of the wheel - rail contact and rolling contact fatigue of rails in the railway network in the Netherlands.

Looking back at the work I performed for TNO, it is the physical relation between mechanical properties of materials, such as strength, stiffness and ductility, and on the other hand, the functional properties such as erosion rate or wear rate, fatigue properties and fatigue crack growth rate, which form the central theme of my research.

A special thanks to all TNO colleagues of the European projects WALID and NATURAL, especially Richard IJzerman and Bert Dillingh for their efforts in realising the droplet impingement test set-up and accurately performing the impingement tests with PBT. 
Great thanks to Prof. Emile van der Heide and Dr. Dave Matthews of the Laboratory for Surface Technology and Tribology of the University of Twente for their supervision, support, and encouragement during the realisation of this thesis.

Henk Slot

Best, March, 2021. 


\section{Samenvatting}

\section{Een model voor de incubatieperiode bij druppelslagerosie gebaseerd op vermoeiing}

Het beoordelen van de levensduur van materiaaloppervlakken, aangetast door druppelslagerosie, was voor de start van dit onderzoek alleen mogelijk met druppelslagerosie-testopstellingen waarbij materialen en coatings relatief ten opzichte van elkaar vergeleken worden.

In dit proefschrift is een op materiaalvermoeiing gebaseerd analytisch model ontwikkeld waarmee de incubatieperiode bij druppelslagerosie (tijdspanne vóór het loskomen van slijtagedeeltjes) kan worden voorspeld. Het doel van dit model is een wetenschappelijk-gebaseerd alternatief te creëren dat de selectie en ontwikkeling van materialen en / of materiaaleigenschappen voor verbetering van de weerstand tegen druppelslagerosie mogelijk maakt.

De inslag van een waterdruppel op een materiaaloppervlak met hoge snelheid resulteert in een hoge waterdruk in het contactoppervlak als gevolg van de lokale compressie van het water in een deel van de druppel (waterhamerdruk). Deze druk hangt voor een deel af van de fysische eigenschappen van het materiaal. Als gevolg van de inslag van de druppel ontstaan er drie verschillende golven in het materiaal. Van deze golven resulteert de Rayleigh-oppervlaktegolf in de hoogste trekspanningscyclus in het gebied rond het contactoppervlak.

Afhankelijk van het type materiaal en de materiaaleigenschappen zijn verschillende soorten faalmechanismen mogelijk, namelijk brosse breuk, oppervlaktevermoeiing en een mengsel van vermoeiingscheurgroei en lokale brosse breukjes. Oppervlaktevermoeiing, zonder lokale brosse breukjes, kan worden beschouwd als het faalmechanisme met de hoogste druppelslagerosielevensduur. In het ontwikkelde voorspellende model is daarom oppervlaktevermoeiing beschouwd als het bepalende slijtagemechanisme, op voorwaarde dat de breuktaaiheden van alle fasen in de microstructuur boven een bepaalde drempelwaarde liggen, die afhankelijk is van de inslagsnelheid en grootte van de druppels.

In het model voor de incubatieperiode bij druppelslagerosie is gebruik gemaakt van de vermoeiingsschade-accumulatie theorie van Palmgren-Miner. De maximale spanningscyclus aan het materiaaloppervlak is een gevolg van de Rayleighoppervlaktegolf. De resulterende vermoeiingsschade mag volgens Palmgren-Miner 
bij dat spanningsniveau berekend worden als verhouding van het aantal opgetreden spanningswisselingen ten opzichte van de vermoeiingslevensduur volgens de standaard $\mathrm{S}$ - $\mathrm{N}$-curve van het materiaal.

Voor de validatie is het model eerst toegepast op het thermoplastische materiaal PBT. Van dit materiaal was een batch geproduceerd door spuitgieten en de andere batch door warmpersen. De voorspellingen van de incubatieperioden op basis van de resultaten van de vermoeiingsproeven, zijn voor beide PBT batches, vergeleken met de resultaten van de druppelslagerosieproeven. Voor beide PBT batches werd een goede overeenkomst in algemene trend gevonden tussen modelvoorspellingen en testresultaten. Voor de spuitgiet PBT was de afwijking 29\%, maar de absolute waarde van de incubatieperiode voorspeld voor de warm geperste PBT verschilde ca. een factor 15 .

In een tweede validatie zijn de modelvoorspellingen van de incubatieperiode vergeleken met een breed scala aan testresultaten van diverse metalen. Het model is toegepast met ferro- en non-ferrometalen, namelijk aluminium en roestvaststaal, de effecten van de hardheidstoename door versteviging aan het oppervlak en de residuele drukspanning aan het oppervlak als gevolg van een waterdruppel "peening-effect" op de vermoeiingseigenschappen zijn in deze modelering meegenomen. De modelvoorspellingen voor roestvaststaal AISI 316 en aluminium 6061-T6, met behulp van $S$ - $N$-vermoeiingscurven uit verschillende literatuurbronnen, inclusief het waterdruppel "peening-effect", toont voor het druppelslagsnelheidsbereik van 140 tot $400 \mathrm{~m} / \mathrm{s}$ een uitstekende overeenkomst met de incubatieperiode volgens de multi regressievergelijking zoals bepaald in een uitgebreid ASTM-testprogramma in meerdere laboratoria. Bijna alle incubatieperiode-voorspellingen lagen binnen de $95 \%$ betrouwbaarheidsgrenzen van de genoemde multi regressievergelijking.

Het uitgevoerde onderzoek heeft voor metalen, thermoplasten en elastomeren geleid tot een sterk verbeterd begrip van de relaties tussen de fysische en mechanische eigenschappen en de incubatieperiode bij druppelslagerosie. De fysische en metallurgische mechanismen die resulteren in het degradatieproces van het metalenoppervlak tijdens de incubatieperiode bestaan uit: 1) kleine plastische deformaties aan het oppervlak en vorming van deukjes, 2) toename van de oppervlaktehardheid door versteviging en residuele drukspanningen als gevolg van deze plastische vervormingen aan het oppervlak, 3) vermoeiingsscheurinitiaties, 4) groei van kleine vermoeiingsscheurtjes. 
Op basis van de geselecteerde golf- en vermoeiingseigenschappen van de verschillende materialen die in het model zijn gebruikt, zijn richtlijnen opgesteld met betrekking tot deze eigenschappen om de incubatieperiode bij druppelslagerosie te verlengen. De relatieve waterhamerdruk, de verhouding van de waterhamerdruk en de druppelslagsnelheid $\left(p_{w h} / v_{d}\right)$, kan worden gebruikt om te bepalen welke materiaalsoorten de waterhamerdruk en de daaruit volgende maximale spanningen als gevolg van de Rayleigh-oppervlaktegolf maximaal kunnen verminderen.

De kennis en het voorspellende model dat in dit onderzoek is ontwikkeld en in dit proefschrift wordt gepresenteerd, kan dienen als hulpmiddel om combinaties van materiaaleigenschappen voor verlenging van de incubatieperiode te bestuderen. 


\section{Summary}

For the lifetime assessment of surfaces affected by droplet impingement erosion, only droplet impact test facilities were available at the start of this research to evaluate and rank materials and coatings.

In this thesis, a fatigue-based analytical model for the prediction of the droplet impingement erosion incubation period (timespan before erosion by detachment of wear particles starts) has been developed with the intention of creating a sciencebased alternative that allows for the selection and development of materials and/or material properties for an enhanced resistance to droplet impingement erosion.

The impact of a water drop on a solid surface at high velocity results in a high water pressure in the contact area due to the local compression of water in a part of the drop (water hammer pressure). This pressure depends partly on the physical properties of the solid material. Upon drop impact, three different waves start travelling in the solid material. The Rayleigh surface wave has been identified as producing the highest stress cycles in the region around the drop impact contact area.

Depending on the type of material and material properties, different types of wear modes have been identified: brittle fracture, surface fatigue and a mixture of the two. Surface fatigue, without any local brittle fracture, can be considered as the wear mode with the highest erosion lifetime. Thus, in the predictive model, surface fatigue has been considered as the wear mechanism, provided that the fracture toughness of all microstructural phases is above a certain threshold value. This depends, however, on the drop impact velocity and the drop size.

As the maximum stress cycle at the surface follows from the Rayleigh surface wave, fatigue properties of the material as given by standard $S-N$ curves, and fatigue damage accumulation based on the Palmgren-Miner, theory have been used for this predictive model for the droplet impingement erosion incubation period.

For an accurate model validation, the predictive model has first been applied to the thermoplastic material PBT, produced by injection moulding and compression moulding, and compared with drop impact erosion results on the same PBTs. For both PBTs a good similarity between test results and model predictions for the injection moulded PBT was found (deviation of $29 \%$ ). However, the absolute value of the incubation period predicted by the model for the compression moulded PBT differed by a factor of 15 .

In a second validation, the analytical model for the prediction of the incubation period of metal surfaces was compared with a wide range of liquid droplet erosion 
incubation period tests. The model was extended for the use of $S-N$ curves for nonferrous and ferrous metals -aluminium and stainless steel respectively - by including the effects of additional surface hardening and residual compressive stress at the surface due to a water drop peening effect. Model predictions were performed for stainless steel AISI 316 and aluminium 6061-T6, using S- $N$ fatigue curves from different literature sources, and including the defined additional surface hardening and a residual compressive stress state at the surface due to "water drop peening effect". For the droplet impact velocity range of 140 to 400 $\mathrm{m} / \mathrm{s}$ they showed excellent agreement with the multi-regression equation as determined from an ASTM interlaboratory test program. Nearly all incubation period predictions were within the $95 \%$ confidence limits of the aforementioned multi-regression equation.

In this research, a strongly enhanced understanding of the relationship between the physical and mechanical properties and the drop impact erosion incubation period of metals, thermoplastics and elastomers has been obtained. The physical and metallurgical mechanisms resulting in the degradation process of the metal surface during the incubation period were identified. These consisted of 1) surface plastic deformation and formation of dents; 2) surface hardening and residual compressive stress as a result of these surface plastic deformations; 3 ) fatigue crack initiation; and 4) fatigue crack growth.

The selected wave properties (dynamic impedance) and fatigue properties of the metals, thermoplastics and elastomers used in the presented analytical model were identified with respect to developing guidelines for enhanced droplet impingement erosion incubation life. The relative impact pressure $\left(p_{w h} / v_{d}\right)$ can be used to identify to what extent certain material classes reduce the water hammer pressure and corresponding maximum stress due to the Rayleigh wave. 


\section{Part I}




\section{Table of Contents}

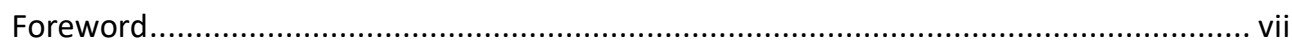

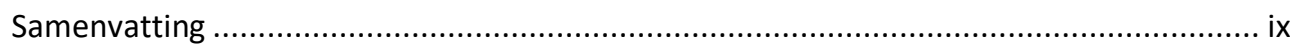

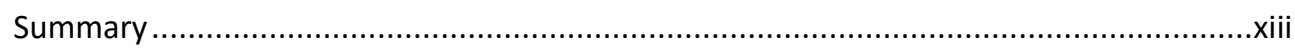

Part I..........................................................................................

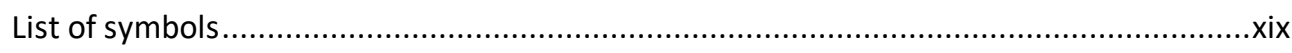

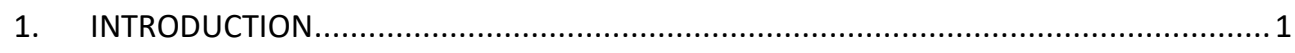

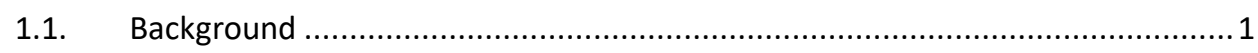

1.2. Droplet impingement erosion................................................................. 1

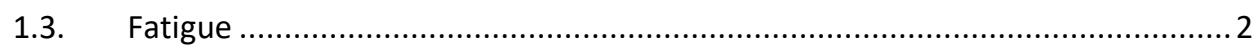

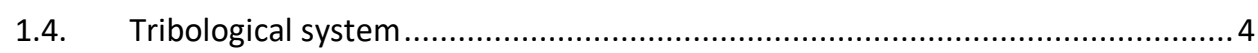

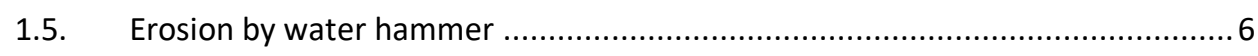

1.6. Experimental results of droplet impingement erosion tests........................... 8

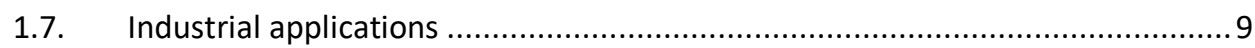

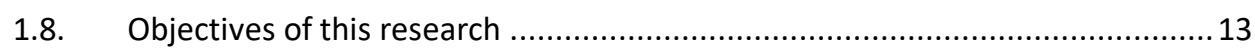

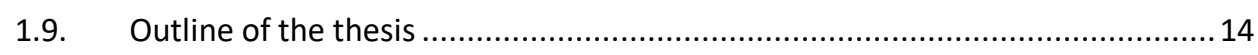

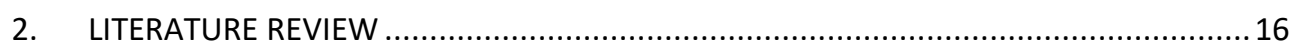

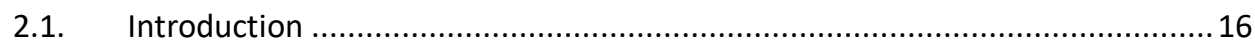

2.2. Modelling the mechanical aspects of droplet impact ...................................17

2.3. Wear mechanisms and droplet impact ....................................................... 23

2.4. Synthesis to material selection for droplet impingement resistance................31

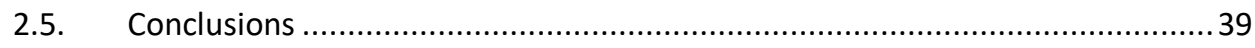

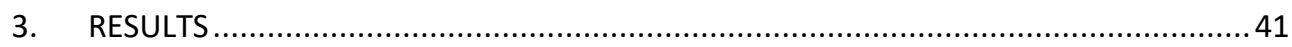

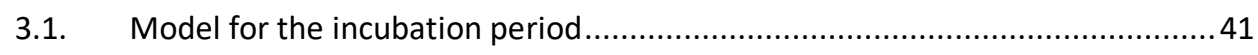

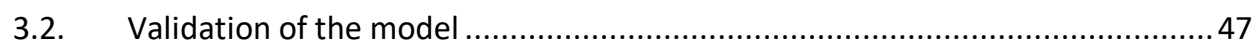

3.3. Guidelines for optimised material properties ........................................... 53

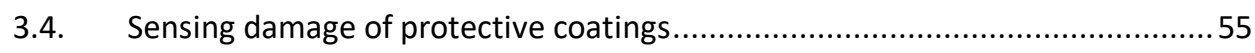

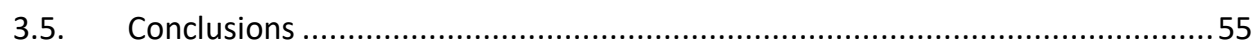




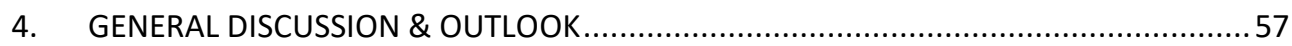

4.1. Droplet impingement erosion \& fatigue modelling aspects .........................57

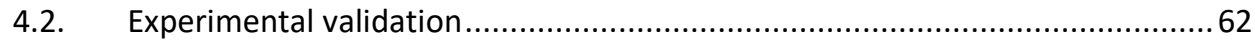

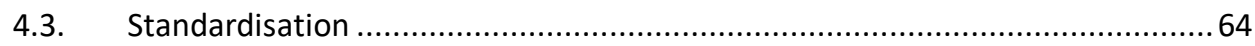

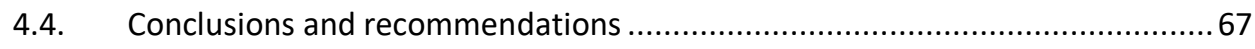

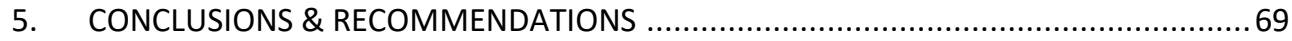

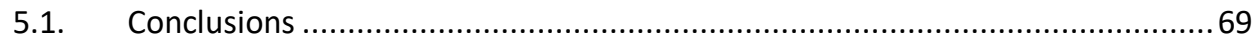

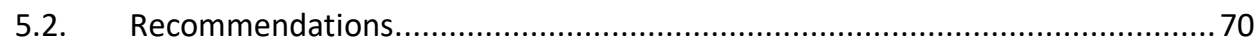

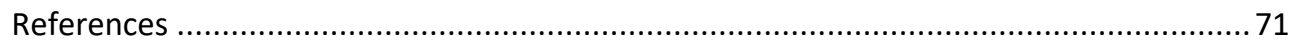

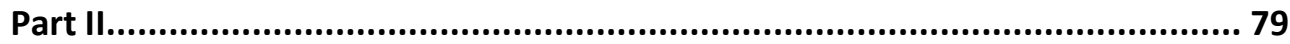

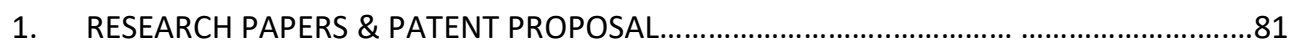

2. FATIGUE RELATED RESEARCH PAPERS - NOT INCLUDED IN THIS THESIS......................81

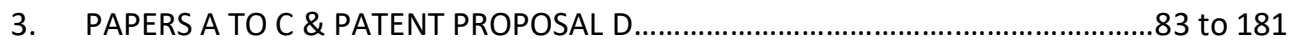




\section{List of symbols}

$A=$ constant in Rayleigh surface wave attenuation $(\mathrm{PaVm})$ or elongation at fracture (\%) $a=$ material parameter of strain hardening $(1 / \mathrm{Pa})$, or radius of contact area $(\mathrm{m})$ $a_{c}=$ critical crack size $(\mathrm{m})$ $b=$ material parameter for the residual stress $(1 / \mathrm{Pa})$

$C_{v}=$ volume concentration of water in air (-)

$c_{l, m}=$ longitudinal wave velocity of a material $(\mathrm{m} / \mathrm{s})$

$c_{R}=$ Rayleigh surface wave velocity of a material $(\mathrm{m} / \mathrm{s})$

$c_{t}=$ transverse wave velocity of a material $(\mathrm{m} / \mathrm{s})$

$c_{w}=$ speed of sound in water at the pressure $p_{w h}(\mathrm{~m} / \mathrm{s})$

$c_{w 0}=$ speed of sound in water at a pressure of 1 bar $(\mathrm{m} / \mathrm{s})$

$D_{h}=$ cumulative fatigue damage per hour $(1 / \mathrm{h})$

$D_{f}=$ cumulative fatigue damage at failure (-)

$d_{d}=$ water drop diameter $(\mathrm{m})$

$E=$ Young's modulus $(\mathrm{Pa})$

$f=$ fatigue cycle frequency $(\mathrm{Hz})$

$H=$ surface hardness after peening at a certain impact velocity $(\mathrm{Pa})$

$H_{0}=$ material hardness when stress free and without strain hardening $(\mathrm{Pa})$

$h_{\text {tot }}=$ product of correction factors for differences between fatigue test and drop impact conditions (-)

$I_{p}=$ droplet impingement erosion incubation period $(\mathrm{h})$

$I_{r}=$ rain intensity $(\mathrm{mm} / \mathrm{h})$

$K_{c}=$ fracture toughness $(\mathrm{PaVm})$

$k=$ constant for the pressure influence on the speed of sound in water (-)

$m=$ material parameter in fatigue tests $(-)$

$N_{f}=$ fatigue life (number of cycles to failure)

$N_{f, i}=$ number of fatigue cycles to failure at level $i(-)$

$N_{i}=$ number of fatigue cycles of the incubation period (-)

$N_{0}=$ number of specific impacts for incubation (-)

$N O R=$ incubation resistance number $(-)$

$n=$ number of tests, or exponent for the Rayleigh wave attenuation (-)

$n_{i}=$ number of cycles due to multiple drop impact at stress level $i(-)$

$n_{r}=$ radial distribution of density of drop impacts (impacts $/ \mathrm{m} . \mathrm{s}$ )

$n_{S}=$ distribution of drop impacts as a function of stress (impacts/Pa.s)

$p_{w h}=$ water hammer pressure $(\mathrm{Pa})$

$p_{w h, t h}=$ threshold water hammer pressure $(\mathrm{Pa})$

$R=$ stress ratio in the fatigue test (-) 
$R_{d}=$ maximum erosion rate $(\mathrm{m} / \mathrm{s})$

$R_{e}=$ rationalised erosion rate (-)

$R_{m}=$ tensile strength of material $(\mathrm{Pa})$

$R_{p 0.2}=$ yield strength of material $(\mathrm{Pa})$

$r=$ radial coordinate $(\mathrm{m})$

$r_{0}=$ radius of contact area when Rayleigh wave starts $(\mathrm{m})$

$r_{1}=$ radial coordinate where the maximum stress is attenuated $S_{\max (r 1)}(\mathrm{m})$

$r_{w h}=$ radius of maximum contact area with the water hammer pressure $(\mathrm{m})$

$S_{a}=$ stress amplitude $(\mathrm{Pa})$

$S_{D}=$ fatigue limit $(\mathrm{Pa})$

$S_{D, d}=$ fatigue limit for the actual drop impact conditions $(\mathrm{Pa})$

$S_{f}=$ material parameter in fatigue tests $(\mathrm{Pa})$

$S_{f 0}=$ fatigue strength coefficient for as received material $(\mathrm{Pa})$

$S_{m}=$ mean stress $(\mathrm{Pa})$

$S_{\text {max }}=$ maximum stress in a fatigue cycle $(\mathrm{Pa})$

$S_{\text {max }, i}=$ maximum fatigue stress at level i $(\mathrm{Pa})$

$S_{\max (r 0)}=$ maximum stress due to Rayleigh wave at location $r_{0}(\mathrm{~Pa})$

$S_{\max (r 1)}=$ maximum stress due to Rayleigh wave at location $r_{1}(\mathrm{~Pa})$

$s=$ standard deviation $(-)$

$v_{a}=$ radial velocity of contact area boundary $(\mathrm{m} / \mathrm{s})$

$v_{d}=$ water droplet impact velocity on the specimen surface $(\mathrm{m} / \mathrm{s})$

$v_{d, t h}=$ fatigue threshold water droplet impact velocity $(\mathrm{m} / \mathrm{s})$

$v_{d, t h, K}=$ brittle fracture threshold water droplet impact velocity $(\mathrm{m} / \mathrm{s})$

$t=$ time $(\mathrm{s})$

$Z=$ reduction of area (\%)

$\Phi_{v}=$ volume of impacting water drops per unit area $(\mathrm{m} / \mathrm{s})$

$v=$ Poisson's ratio (-)

$\rho_{m}=$ density of material $\left(\mathrm{kg} / \mathrm{m}^{3}\right)$

$\rho_{w}=$ density of water $\left(\mathrm{kg} / \mathrm{m}^{3}\right)$

$\sigma_{R}=$ residual (compressive) stress at the surface after peening $(\mathrm{Pa})$ 


\section{Chapter 1}

\section{INTRODUCTION}

\subsection{Background}

For the lifetime assessment of surfaces affected by droplet impingement erosion, droplet impact test facilities are available only to evaluate and rank materials and coatings. For wind turbine blade surfaces suffering from rain erosion and for steel steam turbines blades loaded by water drops, a predictive analytical model based on mechanical and physical materials properties would signal a breakthrough in these fields. As a result, a trial-and-error based strategy would no longer need to be adopted in optimising the lifetime of components that suffer from droplet impingement erosion, as this is the current state of the art. Clearly, this leads to sub-optimal solutions and costly experimental work and ultimately limits the applications in which droplet impingement is dominant, including offshore wind energy. In this thesis, a fatigue-based analytical model for the prediction of the droplet impingement erosion incubation period has been developed; the purpose of this is to create a science-based alternative that allows for the selection and development of materials and/or material properties for an enhanced resistance to droplet impingement erosion.

\subsection{Droplet impingement erosion}

In the current work the term erosion [1] is used to indicate the loss of material from the solid surface due to relative motion in contact with air which contains solid particles or fluid droplets. The term impingement is added frequently to indicate that the relative motion of the particles or droplets is nearly normal to the solid surface.

Droplet impingement erosion of material surfaces is often the result of the impact of slowly moving drops which hit the surface of a solid moving at high velocity, as shown schematically in Figure 1.1a. The resulting damage caused by severe droplet impingement erosion of the leading edge of a stainless steel steam turbine blade, from the low-pressure side of the turbine, is shown in Figure 1.1b. The severely eroded area shows a substantial increase in surface roughness, features similar to spherical indentation marks, and material losses. 

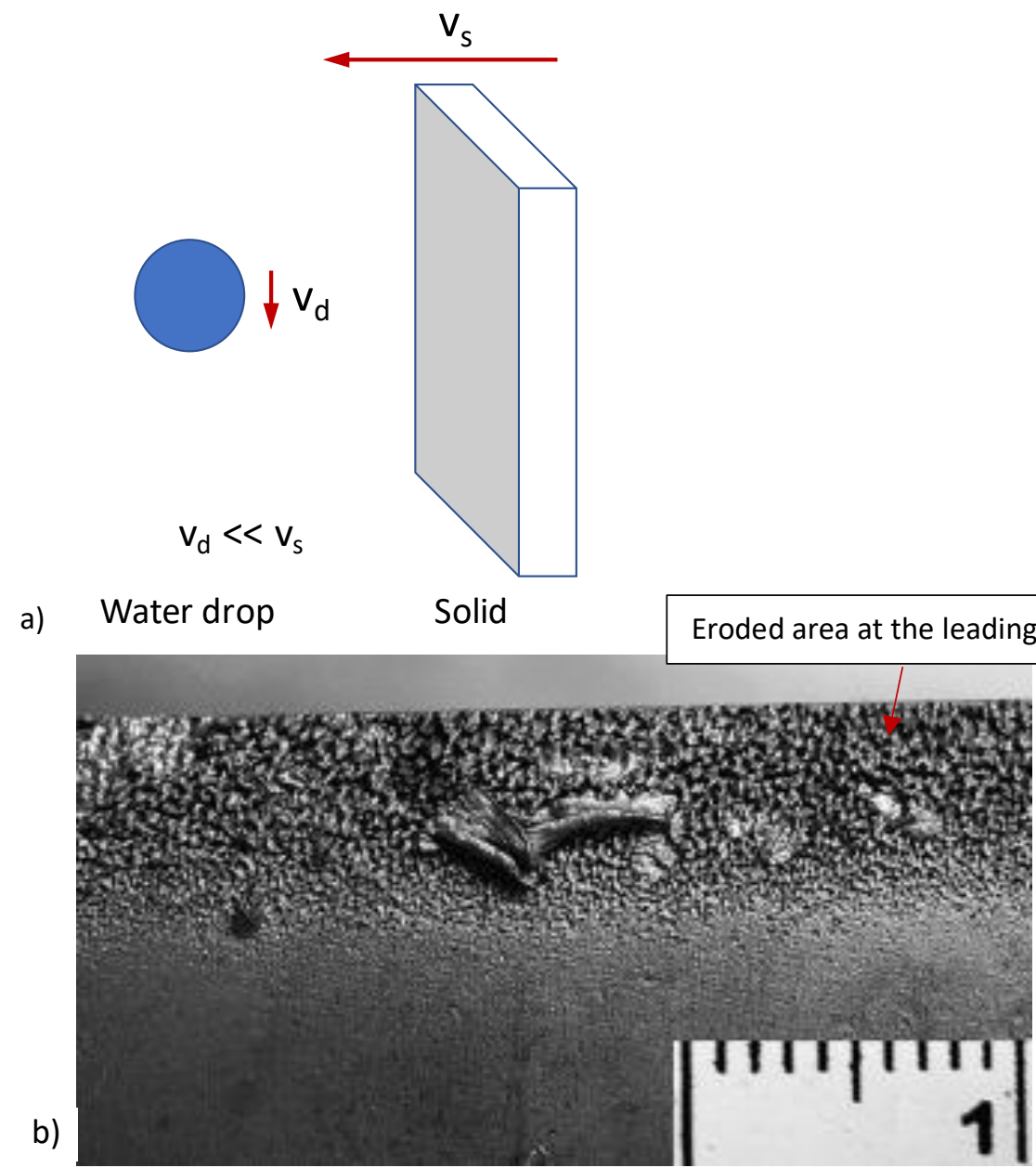

Figure 1.1. a) The impact of slowly moving drops which hit a solid moving at high velocity (v), b) Severe droplet impingement erosion of a stainless steel steam turbine blade at the leading edge, in the low-pressure side of the turbine, showing a substantial increase in roughness, and features of severe erosive wear; adapted from [2] (scalebar: $1 \mathrm{~cm})$.

\subsection{Fatigue}

Fatigue, in general terms, is material degradation as a result of cyclic loading. Figure 1.2 shows an example of cyclic stress and a fatigue life curve as obtained by axial cyclic loading of a smooth cylindrical specimen. The maximum stress of the cyclic loading $\left(S_{\max }\right)$ is shown as a function of the number of cycles to failure $\left(N_{f}\right)$. 

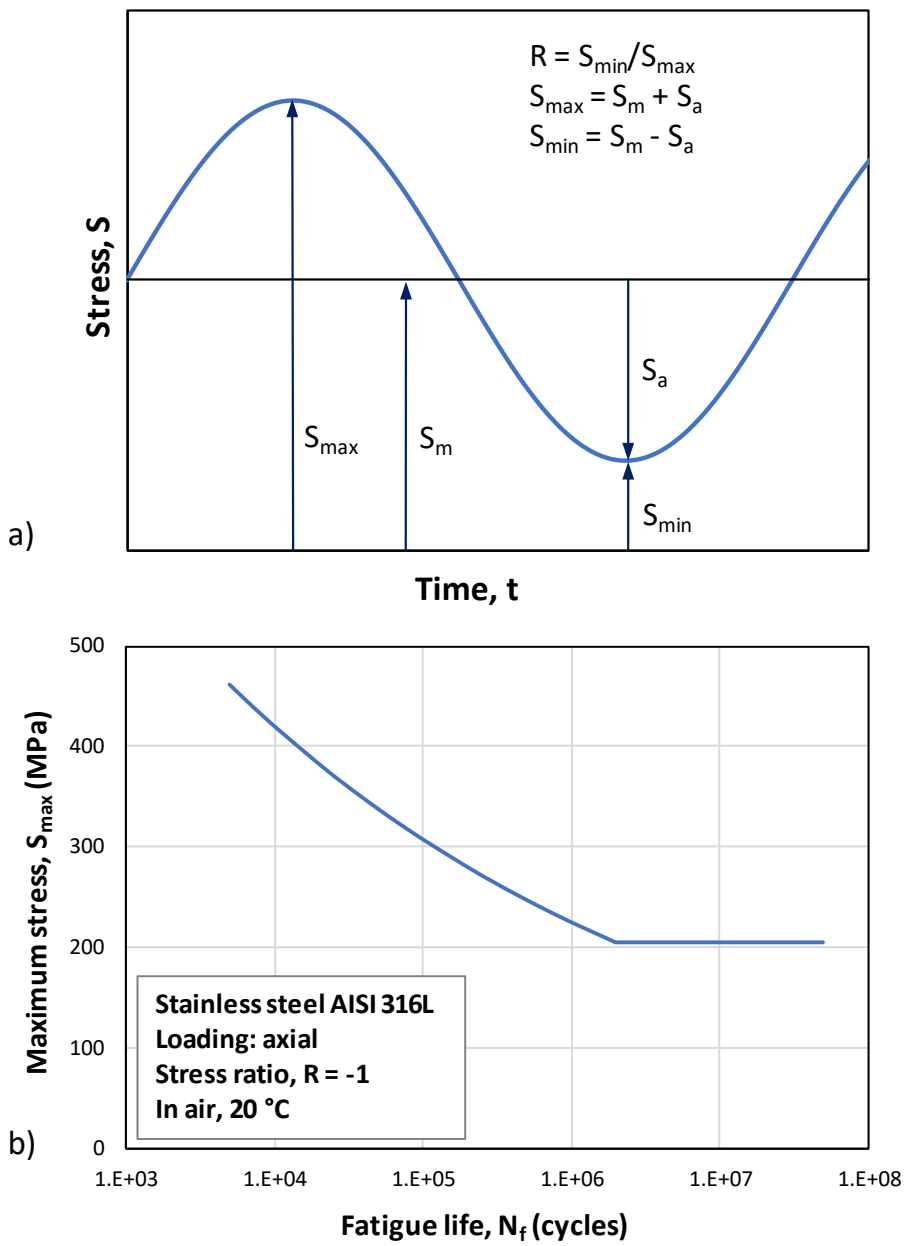

Figure 1.2. a) Cyclic stress and b) fatigue life curve, maximum stress versus number of cycles to failure, [4].

The damage in the fatigue process starts with the accumulation of dislocations on certain critical slip planes in grains at the outer free surface; this accumulation of dislocations extends to more slip planes and forms a package called persistent slip band (PSB) [3]. Due to sliding on these crystallographic slip planes, intrusions and extrusions on the outer surface are formed. On the boundaries of these PSBs, microcracks smaller than the microstructural grain size are formed. These microcracks are schematically depicted in the cross section at the surface in Figure 1.3. The microcracks are formed mainly in shear and are called "stage I" cracks. Due to the cyclic loading, these short stage-I cracks grow, coalesce and bend in a 
direction perpendicular to the maximum principal stress, creating "stage II" cracks. Figure 1.3 shows schematically a cross section at the surface of the fatigue crack initiation and crack growth of a short crack which gradually transforms into a long crack. In the final stage, net section yielding and ductile failure will occur in the remaining area.

Intrusions and extrusions (surface roughening)

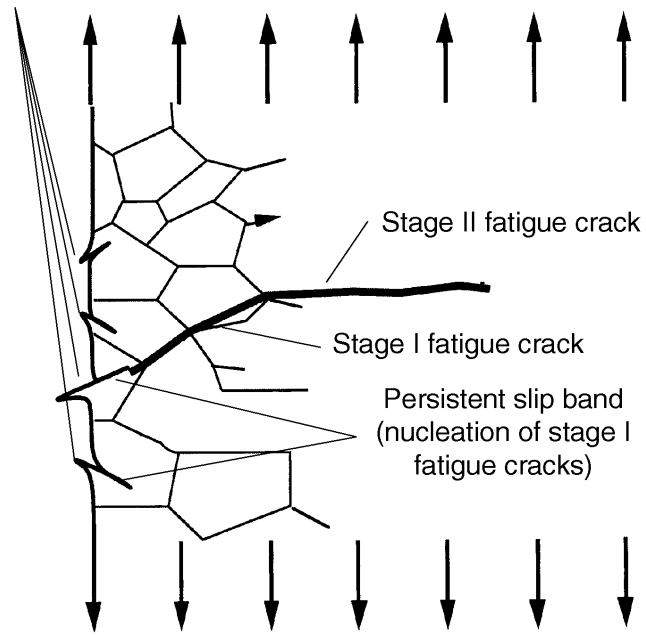

Figure 1.3. Stage I: fatigue crack initiation and short crack growth - Stage II: transition from a short fatigue crack to a long crack; adapted from [3].

The rolling and/or sliding contact of solids or impacting contact of solids and/or liquids results in cyclic surface stressing [5] as well. The repeated alternating loading might result in crack formation and flaking or spalling of material, introducing wear to the surface. This process is usually referred to as surface fatigue.

\subsection{Tribological system}

Droplet impingement erosion of engineering surfaces is a wear phenomenon with complex interactions. A systematic approach to analysing such a phenomenon is needed. Salomon [6], and Czichos [7], [8] introduced the system approach in tribology to analyse friction and wear. This approach is relevant because friction and wear data are not intrinsic material properties of one of the contacting materials, but the result of the whole system of operational conditions, environmental conditions, the physics of the interaction of the materials, and by the material properties of the surfaces of the contacting materials. This is 
demonstrated by a comparison between the test conditions to obtain strength data or to obtain friction and wear data, as shown in Figure 1.4. The tensile test in Figure 1.4a results in strength and ductility properties representing the tested material for the operational conditions used. However, the tribological test in Figure 1.4b results in friction and wear data which represent the whole tribological system of both contacting materials for the operational conditions used.

This characteristic of a tribological system should already be recognised at an early stage in the design process, as it affects the design and engineering of surfaces greatly. Droplet impingement erosion, as a specific case of wear, is also a systems property rather than a materials property. That means that the amount and the manifestation of the erosive wear or erosion is determined by the operational conditions, by the environmental conditions, by the physics of the interaction, by the material properties of the particles and/or droplets and by the material properties of the solid surface. As such, droplet impingement erosion by a substance such as liquified natural gas (LNG) will result in erosion, in contrast to what is found due to wet steam or suchlike.

In this thesis, droplet impingement erosion is studied for engineering surfaces of thermoplastic polymers, elastomers and metals and for droplets of water only.

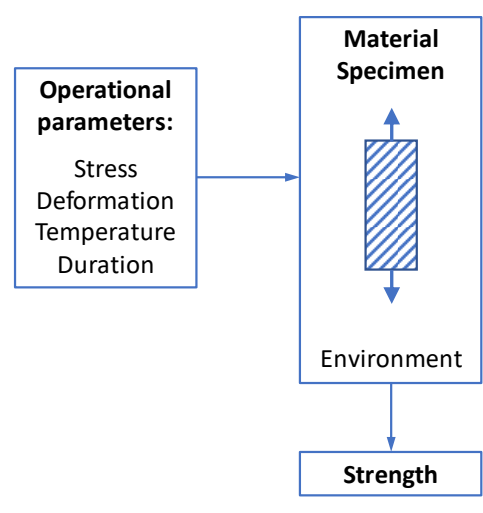

a)

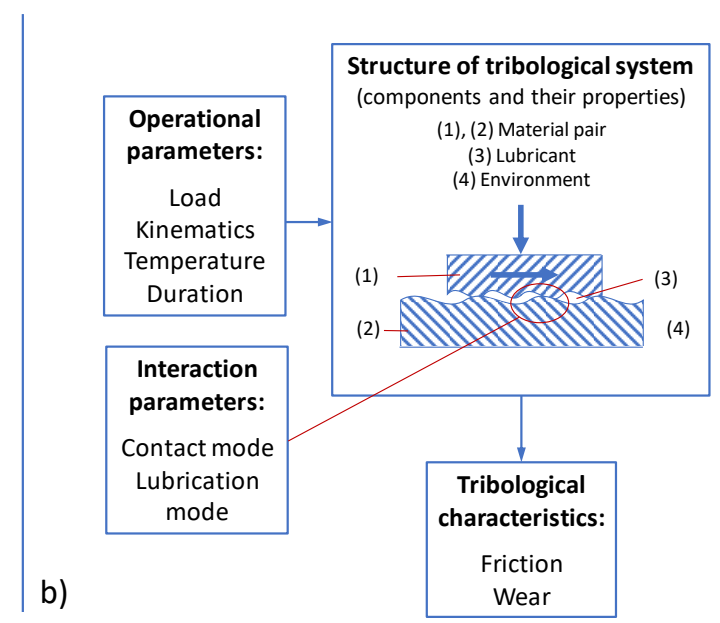

Figure 1.4. Characteristics and parameters of (a) tensile test and (b) friction and wear test [8].

Although the erosion rate or wear rate is governed by the whole tribological system, the wear rate can be influenced substantially by changing the physical and/or mechanical properties of one of the contacting materials in the system. Typically, the wear rate in tribological systems that interact with solid particles is 
decreased by increasing the surface hardness or by changing the mechanical properties of the surface which are strongly related to the hardness [5]. For surfaces that interact with droplets this is typically also the first action, as this follows frequently from experimental work on a laboratory scale [9]. Increasing the understanding of the correlation between the physical and/or mechanical properties of the surfaces and the erosion or wear rate would create more options than changing the hardness only. Formulating guidelines on mechanical properties of surfaces for resistance to droplet erosion is one of the aims of this work.

\subsection{Erosion by water hammer}

In his paper "Erosion by Water-hammer", published in Royal Society Proceedings of 1928 [10], Stanley S. Cook was probably as one of the first researchers to explain the connection between the "water hammer pressure" of an impacting water drop and the observed erosion of rotating steel blades in the end part of steam turbines. Based on conservation of energy, Cook derived a simple equation for the water hammer pressure $\left(p_{w h}\right)$ of a moving water column which is suddenly arrested by a fixed surface, see Figure 1.5. The kinetic energy of a volume element of the moving column with velocity $v$ is fully transferred to potential energy of water pressure $\left(p_{w h}\right)$. This gives:

$$
\frac{1}{2} \rho v^{2}=\frac{p_{w h}^{2}}{2 B}=>p_{w h}=v \rho \sqrt{\frac{B}{\rho}}=>p_{w h}=v \rho c
$$

where

$\rho=$ density of water

$c=$ speed of sound of water

$B=$ bulk modulus of water

Cook uses $\rho=1000 \mathrm{~kg} / \mathrm{m}^{3}$ and $\mathrm{B} \approx 20000 \mathrm{~atm}$, giving a speed of sound in water $c \approx$ $1425 \mathrm{~m} / \mathrm{s}$. Thus, an impact velocity of $120 \mathrm{~m} / \mathrm{s}$ results in a water pressure $p_{w h} \approx 170$ $\mathrm{MPa}$, and for an impact velocity of $300 \mathrm{~m} / \mathrm{s}$ in a water pressure $p_{w h} \approx 430 \mathrm{MPa}$. 

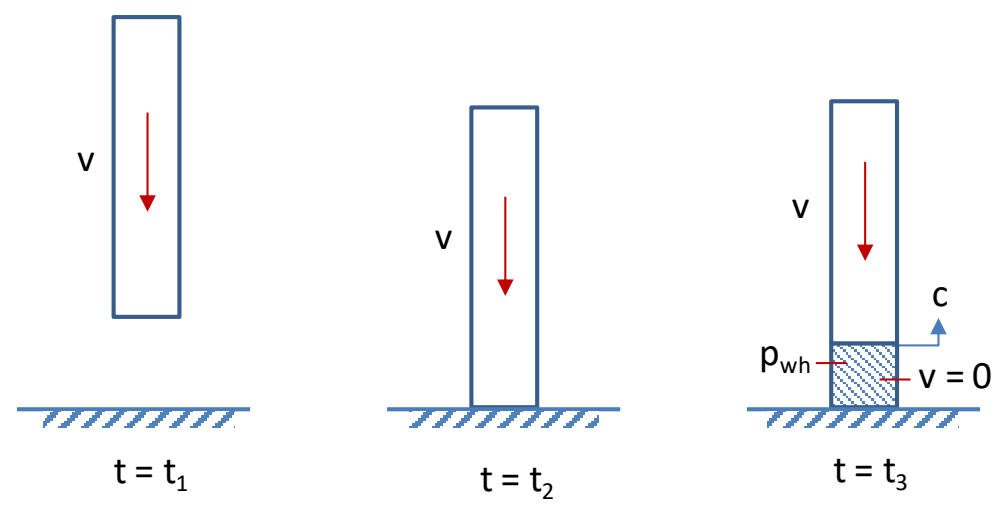

Solid: Elastic modulus $\mathrm{E}=\infty$

Figure 1.5. A moving water column suddenly arrested by a fixed surface.

This water pressure $\left(p_{w h}\right)$, although applied for a short time period, is much greater than the steady pressure due to the momentum of a jet of water at the same velocity. This pressure $p_{j}=\rho v^{2}$ will have the same value as the water hammer pressure only when the velocity $(v)$ is equal to the speed of sound $(c)$.

Citing Cook [10]: "...the erosion of steam turbine blades may be attributed to the water-hammer of drops of water impinging on the surface of the blades in a high vacuum. On the outer portion of the moving blades at the exhaust end the leading edges are found to be thickly honeycombed with minute indentations of conical shape of varying depths and are sometimes completely perforated... It occurs chiefly at peripheral speeds in excess of about $120 \mathrm{~m} / \mathrm{s}$, and is of increasing intensity as the speed is increased. This erosion is attributed to drops of water arising from condensation of the steam by expansion, which drops moving at a lower velocity are overtaken by the rotating blade."

Cook [10] was also probably as one of the first researchers to perform droplet impingement erosion tests with a rotating wheel, see Figure 1.6, showing a part of the test set-up with some eroded specimens. 


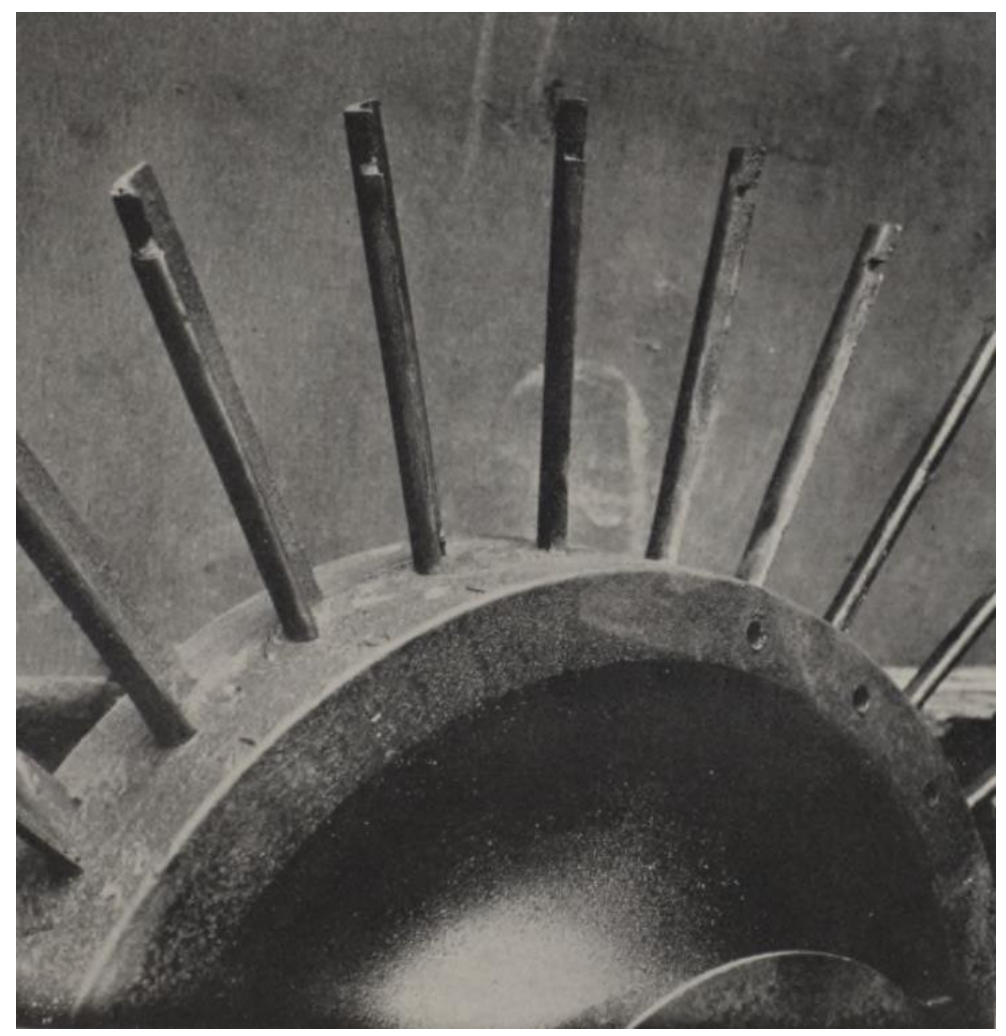

Figure 1.6. The droplet impingement erosion test with a rotating wheel with specimens of different steel grades (yield stress between 245 and $775 \mathrm{MPa}$ ) and Monel, as used by Cook [10] in 1928. Test conditions: a rotational speed of $8800 \mathrm{rpm}$, a rotor diameter of $305 \mathrm{~mm}$, diameter including specimens of $508 \mathrm{~mm}$, tip velocity of $233 \mathrm{~m} / \mathrm{s}$, root velocity of $140 \mathrm{~m} / \mathrm{s}$. At two sides of the rotating wheel a "fine spray of water" was applied. The picture shows eroded specimens after a test duration of 18.5 hours.

It should be noted that the water hammer pressure induced by a suddenly arrested column of water is independent of the length of the column. It follows that drops of water, however minute, will at the first moment of impact produce the same water hammer effect as large volumes of water, the only difference being in the area of attack and the duration [10].

\subsection{Experimental results of droplet impingement erosion tests}

Experimental results of droplet impingement erosion tests, as obtained by whirling arm tests, and standardised by ASTM [11] and DNVGL [12], show three distinct stages: 
1. an incubation period, in which the surface is apparently unaffected (i.e. no material losses)

2. the steady-state erosive wear stage where the surface wears at a relatively high wear-rate

3. the final erosion stage with a strongly reduced wear-rate due to the higher surface roughness which was produced in the second phase.

Figure 1.7 shows graphically the first two stages based on the erosion depth as a function of time.

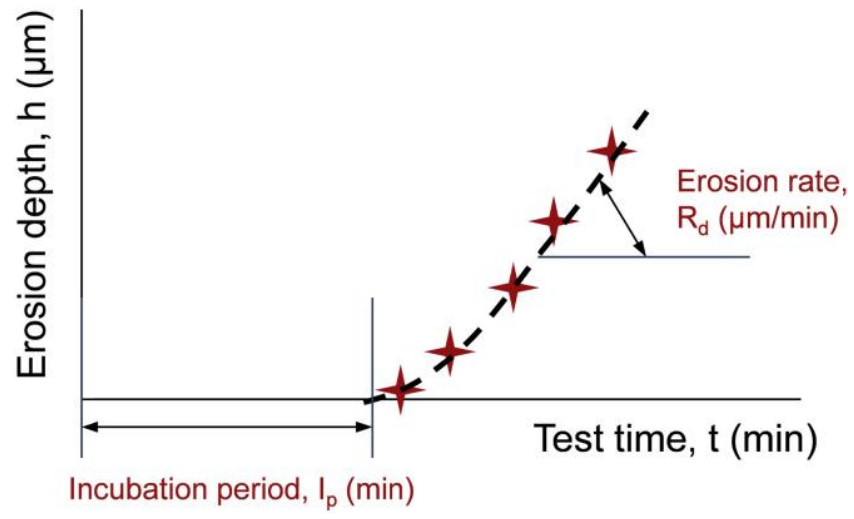

Figure 1.7. Schematic representation of impingement wear showing the incubation period and the stage with a constant erosion rate.

The time from incubation to a certain erosion depth is typically much shorter than the time covered by the incubation period itself. This is especially true for coated systems, in which the erosion depth is limited to the thickness of the coating. Consequently, it is usually assumed that the end of the coating life is reached at the moment a particle is detached from the surface. The incubation period $\left(I_{p}\right)$ is therefore taken as an estimate for the materials surface or coating life in this work. The spanwise locations of the blade at which the end of coating life is reached can be calculated from the velocity profile over the leading edge. Leading-edge erosion typically starts at the tip of the blade, where the droplet impact velocity is at its maximum. The droplet impact velocity reduces towards the centre of rotation and, as such, cumulative damage occurs at a lower stress level.

\subsection{Industrial applications}

\subsubsection{Wet steam injection system}

The Tribology \& Surface Engineering and Heat Transfer \& Fluid Dynamics departments of TNO were involved in an erosion lifetime evaluation study of a 
design for a wet steam injection system, now used in the exploitation of the Schoonebeek oil field in the Netherlands. The developed design has been patented by the client as "Enhanced Crude Oil Recovery Method and System" [13]. Figure 1.8 shows a schematic drawing of the wet steam injection system. The red rectangle in the figure highlights the wet steam injection spool [13].

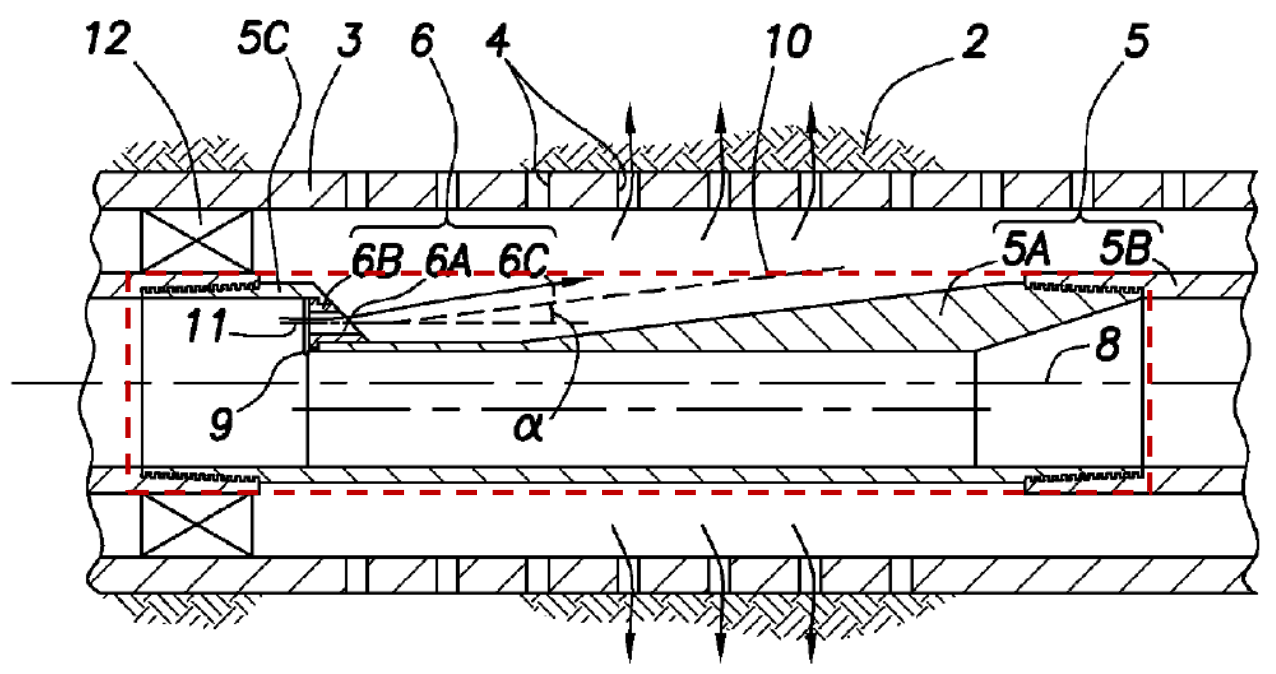

Figure 1.8. Wet steam injection system as used in the Schoonebeek oil field in the Netherlands. The red rectangle highlights the wet steam injection spool [13].

Part 11 of the spool in Figure 1.8 is the nozzle where the high-pressure steam expands. Due to the pressure drop and strong expansion, the wet steam chokes and this results in a critical flow velocity in the nozzle. Steam and waterdrops flow out of this nozzle at an extremely high velocity. Part 5A of the spool is a thick walled section with a high resistance against droplet impact erosion. In Figure 1.8 this section has an angle of $7^{\circ}$ with respect to the longitudinal axis. The stream of waterdrops leaving the nozzle (part 11) has the shape of a cone with on average a small angle $(\alpha)$ with respect to the longitudinal axis. Some of the waterdrops in this cone impinge on the thick walled section (part 5A) at an angle of $7^{\circ}$ but, as can be seen in Figure 1.8, the local angle of impact on this thick section will be small. For the droplet erosion lifetime evaluation study of this wet steam injection system a combined fluid dynamics model with a large amount of drop trajectory calculations, with starting points distributed over the perpendicular cross section of the nozzle (part 11), were performed. The impact velocities and angles of impact were calculated for the part of the drops impacting the thick walled section (part $5 A)$. From this point onwards, only empirical work was available to assess the 
lifetime. As such, these results were combined with the empirical erosion model of Springer [14] or the multi-regression equation of Heymann [9], depending on the materials and conditions evaluated. Based on these erosion lifetime evaluation results, proper materials for the relevant parts have been advised to the client. This shows the need for a more fundamental predictive model for the erosion incubation period and erosion rate based on mechanical and physical properties of the materials.

\subsubsection{Droplet impingement erosion of wind turbine blades}

Wind energy has developed significantly over the last two decades. In 2010, $81 \mathrm{GW}$ of onshore wind and $2.9 \mathrm{GW}$ of offshore wind was brought online in the EU-27 via the installation of, respectively, 70488 onshore turbines and 1132 wind turbines installed at European offshore locations. A further increase to over $250 \mathrm{GW}$ in 2022 is expected, with a compound annual growth rate of about $10 \%$, particularly by growth in offshore capacity [15], [16], [17], [18]. A similar prominent role for offshore wind energy is envisaged by the US Department of Energy, assuming a large reduction in the current cost of wind energy and assuming the availability of the required operational capacity of specialized vessels, purpose-built portside infrastructure, robust undersea electricity transmission lines, and grid interconnections [18], [19]. The latter aspects stress the engineering challenges that are related to the remote character of the offshore locations of interest. Cost reduction is served greatly by reducing on-site maintenance and replacement costs and by increasing the scale of offshore wind turbines, e.g. by developing blade lengths up to $90 \mathrm{~m}$ [17], [18].

Droplet impingement erosion of the leading edges of wind turbine blades occur on wind turbines both offshore and onshore. However, the technical challenges are greater offshore [20]. Examples of the impact by particles and droplets are given in Figure 1.9a-c [21], [22].

Recent studies show high repair costs related to leading edge erosion of wind turbine blades at several offshore wind farms [20], [23]. The relationship between leading edge erosion by droplet impingement on the one hand and drop impact velocity on the other has been established through testing in laboratories using whirling arm erosion testers [24], [25], [26]. These erosion tests simulate the impact by rain drops at high velocities and accelerate the degradation process. 


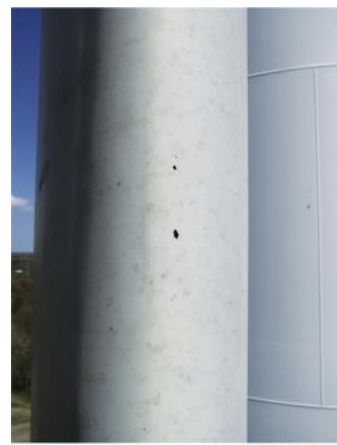

a)

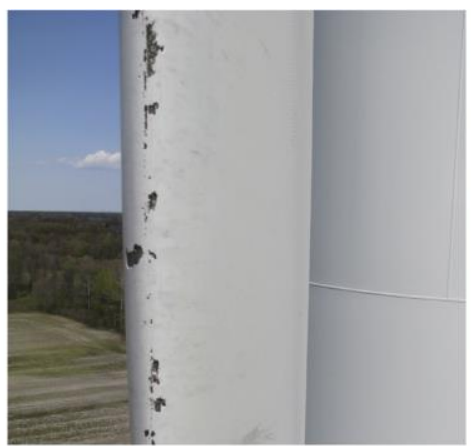

b)

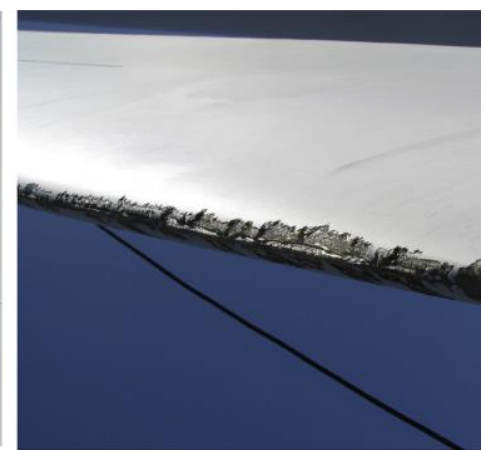

c)

Figure 1.9. Changes to the leading edge surface due to impact with a different degree of severity, adapted from Refs. [21],[22]: a) leading edge erosion at an early stage, b) severely damaged coating and c) leading edge erosion starts to wear the shell material.

An increase in wind turbine size nearly always results in an increase in blade tip velocity and thus an increase in sensitivity for leading edge erosion. Over the last 20 years, the installed maximum wind turbine power has increased from about 2.5 to $9.5 \mathrm{MW}$, see Figure 1.10 [27]. The installed average wind turbine power in 2017 increased in 2018 significantly in nearly all the countries listed in Figure 1.11 [27]. This emphasizes the steady-state growth of turbine power, of this market, and the relevancy of the leading-edge erosion problem. Thus, prediction of lifetime and development of new materials and coatings with a substantially longer lifetime for this application is highly relevant and is a key factor in developing wind energy. New research challenges arise from this: what are the physical and mechanical properties of these wind turbine blade outer surfaces and how should they be optimised to obtain a substantially longer lifetime, a longer erosion incubation period and a lower erosion rate? The first steps to answering the questions require the development of a predictive failure model specifically aimed at determining the incubation period. 


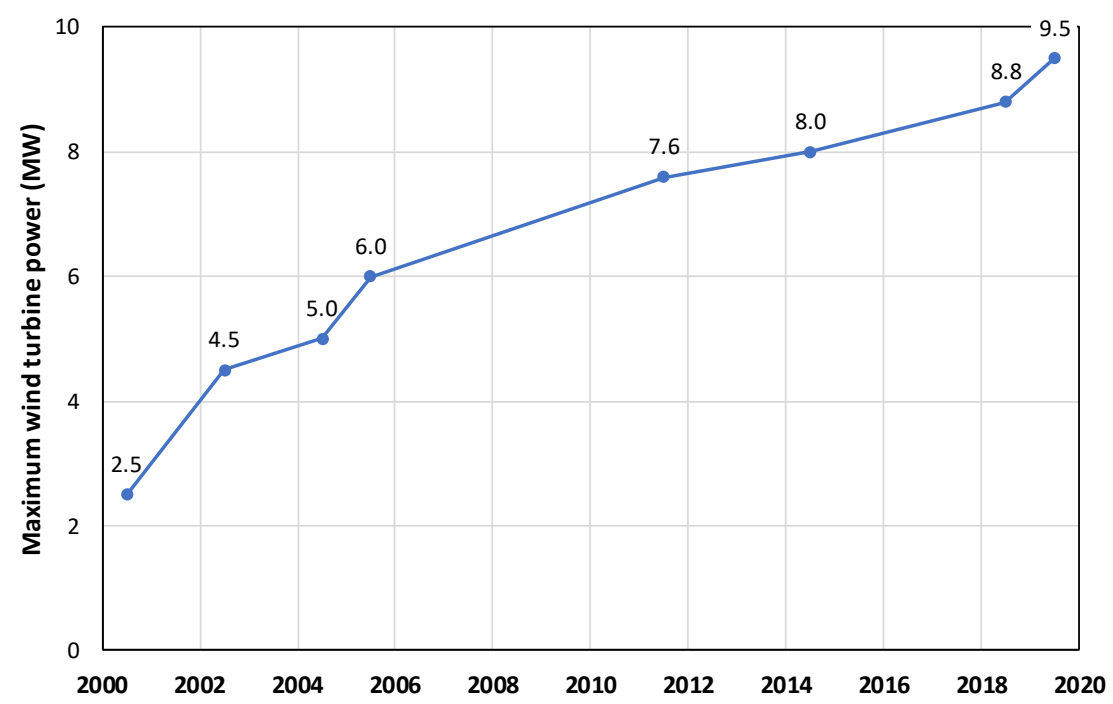

Figure 1.10. The increase in maximum wind turbine power over the last 20 years [27].

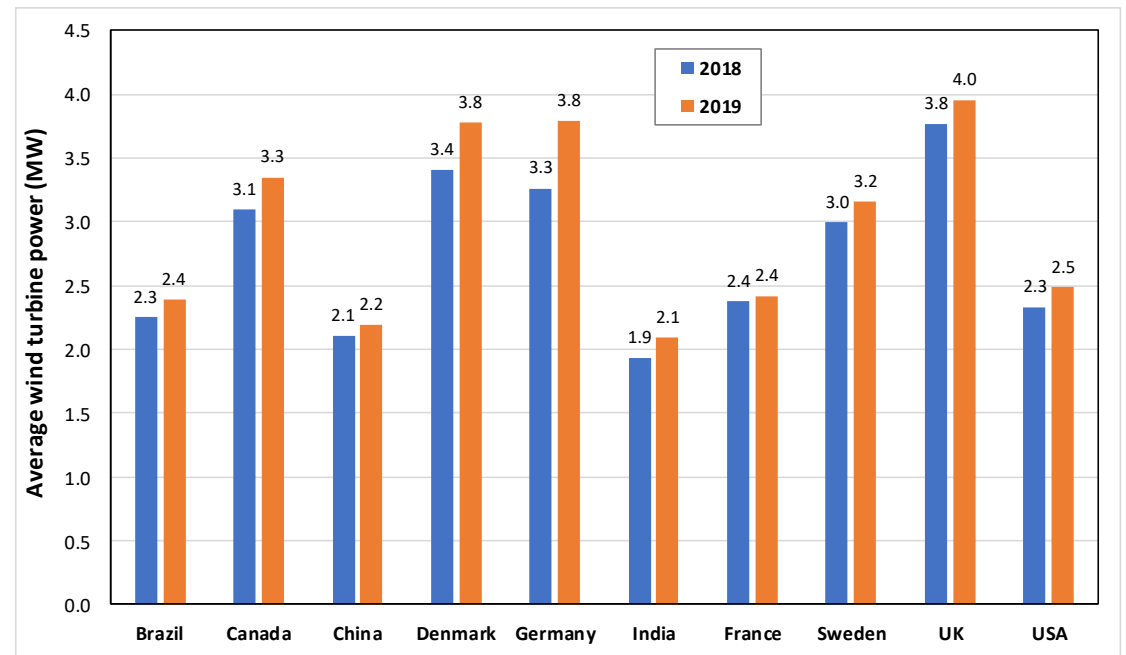

Figure 1.11. The average wind turbine power installed in different countries in 2017 and 2018 [27].

\subsection{Objectives of this research}

For the lifetime assessment of material surfaces damaged by droplet impingement erosion, at this moment droplet impact test facilities are available only to evaluate and rank materials and coatings. Such methods depend heavily on a trial-and-error based strategy and result in qualitative rankings only. Given the great need for a 
predictive model it has been decided to focus on the droplet impingement erosion incubation period for this thesis. By understanding and controlling the incubation period one could extend the time in which the surface is apparently unaffected. This would be highly beneficial in terms of factors such as wind energy efficiency or steam injection stability. The improved understanding of the droplet impingement erosion incubation life allows the required directions for optimising the material properties to be identified.

The aim of this research is therefore to develop a model, based on a fundamental understanding of water drop impact physics and based on surface properties, that is able to predict the drop impact erosion incubation period of metals, thermoplastic material and elastomers.

The systems approach in tribology is adopted as the central method for developing the model. That approach shows that it is necessary to

- understand the interaction mechanisms of water droplet erosion

- understand the relationships that determine the structure of the tribological system

- model and validate the primary damage mechanism(s) for the operational conditions of interest and the relevant scale.

It has been decided to reduce the complexity of the interacting transient processes upon drop impact, by assuming half infinite materials. Thus, more practically, to focus the work on thick materials or relatively thick coatings where the influence of the substrate on stiffness and wave reflections on the interface can be neglected.

\subsection{Outline of the thesis}

This thesis is structured in two main parts: Part I provides an overview of the objectives of this research, a literature review to determine the primary damage mechanism(s), the main outcomes of the research, and conclusions with an outlook, and Part II contains the publications A, B and C and patent proposal D that provide the scientific basis for this thesis. Part I contains five chapters. The current chapter gives an introduction and describes the objective of the research. Chapter 2 presents a literature review of the wear mechanisms, materials and analytical modelling results up to 2015, the year of publication of Paper A. Chapter 3 summarises the main outcomes of the research. Chapter 4 presents a discussion accompanied by a literature review of journal papers published after 2015 and an outlook of the performed research. Part I concludes with Chapter 5, which lists the 
conclusions and recommendations for further research. The three publications and patent proposal are included in Part II of the thesis. 


\section{Chapter 2}

\section{LITERATURE REVIEW}

\subsection{Introduction}

Wind turbine blades for offshore wind energy production are an important area of application for the funding of the research of this thesis. The cross section of blades for large wind turbines is typically air foil-shaped to create lift and following rotation of the blades. As important as the design of the blades is the weight. Currently, an optimum balance between weight, performance of the turbine blades and structural integrity is found by applying polymer composite materials and related manufacturing techniques such as moulding. The surface of the blade is formed by two shells of epoxy or polyester matrix composites, reinforced with glass or other fibres. The blade is stiffened with an intermediate web and by a supporting shell core from balsa wood [29], foam [17] or combinations [29]. Furthermore, a blade root is used for connection to the rotor and a tailored tip is used to connect the two shells at the trailing edge. The amount of lift during operation is controlled by the angle of attack between the chord extending from the leading edge to the trailing edge of the blade, and the relative wind. The amount of drag can be minimised by careful design optimisation. This approach of optimising drag, lift and weight while maintaining structural integrity as a function of the loading conditions was successfully applied for the current onshore European wind turbine locations.

New, offshore or near-shore locations give rise to more demanding environmental conditions, among which the possibility of water droplet laden winds. Such winds can easily compromise the integrity of blade surfaces.

Blades that encounter the impact of sand particles and/or water droplets or mixtures will first show an increase in surface roughness that affects the aerodynamic performance negatively, for example by increased friction drag and by an earlier onset of stall [21]. The information presented by Keegan et al. [21], [30] shows that drag could increase from 6 to $500 \%$ depending on the level of leading edge erosion. Furthermore, it is predicted that an $80 \%$ increase in drag could lead to approximately a $5 \%$ reduction in annual energy production. With greater levels of erosion both the lift reduction and the drag increase are more severe, such as in the case presented by Gaudern [31]. Severely worn surfaces carry the risk of reduced structural integrity, which in turn results in turbine downtime and high maintenance costs. An overview of documented cases of leading edge 
erosion in literature is given by Ref. [21]. Examples of the impact by particles and droplets are given in Figure 1.9a-c [21], [22].

The wear patterns shown in Figure 1.9 are illustrative of droplet impingement erosion of the leading edge. The amount and the manifestation of wear are determined by the operational conditions, the environmental conditions, the physics of the interaction, the material properties of the particles and/or droplets and the material properties of the blade surface, the system approach as mentioned in Section 1.3. The latter aspect is well recognised in industry as there are several commercially available gel coats or elastomeric coatings, including tapes, that can be applied at the finished blade to improve the resistance of the surface to erosion [21], [32], [33]. Research on protective materials and coatings depends heavily on experimental work, although efforts were made to correlate the erosion resistance to the physics of impingement erosion for aircraft wings, windows or radomes that encounter supersonic rain [34][24]. Furthermore, similarities are found in erosion of steam turbine parts [35][36].

The review in this chapter summarises the state of the art in droplet impingement erosion modelling and gives an overview of experimentally validated building blocks of erosion models that can be used to predict the life of the leading edge of coated wind turbine blades. By linking these to the material technology aspects of blade coatings it becomes possible to identify promising directions for resistance to droplet impingement erosion.

\subsection{Modelling the mechanical aspects of droplet impact}

\subsubsection{Analytical modelling}

Clearly, the work of R.M. Blowers [37] on analytically modelling of stresses at the surface after perpendicular impact of a perfect spherical water droplet on a perfect flat surface and the work of J.E. Field on the physics of rain [38] and combined rain and sand erosion [39] are important is this field. Many researchers such as Zhou [40], Kunaporn [41], Lee [36], Kim [42], Adler [43] and Evans [44] have used and expanded this work to calculate or to validate the impact response of a variety of materials.

\subsubsection{Transient stresses due to single droplet impact}

The initial stage of impact between a solid and a water droplet is determined by compression of the liquid, which results to the water hammer pressure. This pressure $p_{w h}$ is given by [38]: 


$$
\begin{aligned}
& p_{w h}=v_{d} \frac{\rho_{w} c_{w}}{\left(\frac{\rho_{w} c_{w}}{\rho_{m} c_{l, m}}+1\right)} \\
& c_{w}=c_{w 0}+k v_{d}
\end{aligned}
$$

$v_{d}=$ drop impact velocity

$\rho_{w}=$ density of water at 1 bar, $1000 \mathrm{~kg} / \mathrm{m}^{3}$

$c_{W}=$ speed of sound in water at the pressure $p_{w h}$

$c_{w 0}=$ speed of sound in water at a pressure of $1 \mathrm{bar}, 1647 \mathrm{~m} / \mathrm{s}$

$k=$ constant for the pressure influence on the speed of sound [23], 1.921

$\rho_{m}=$ density of material

$c_{l, m}=$ longitudinal wave velocity of material.

As a result of the impact, longitudinal and transverse body waves immediately start propagating and from the free surface boundary it follows that that a Rayleigh wave is generated as well. Figure 2.1 gives an overview of the geometrical wave attenuation of the body waves and surface waves as a result of a sudden distortion on the surface [46],[47].

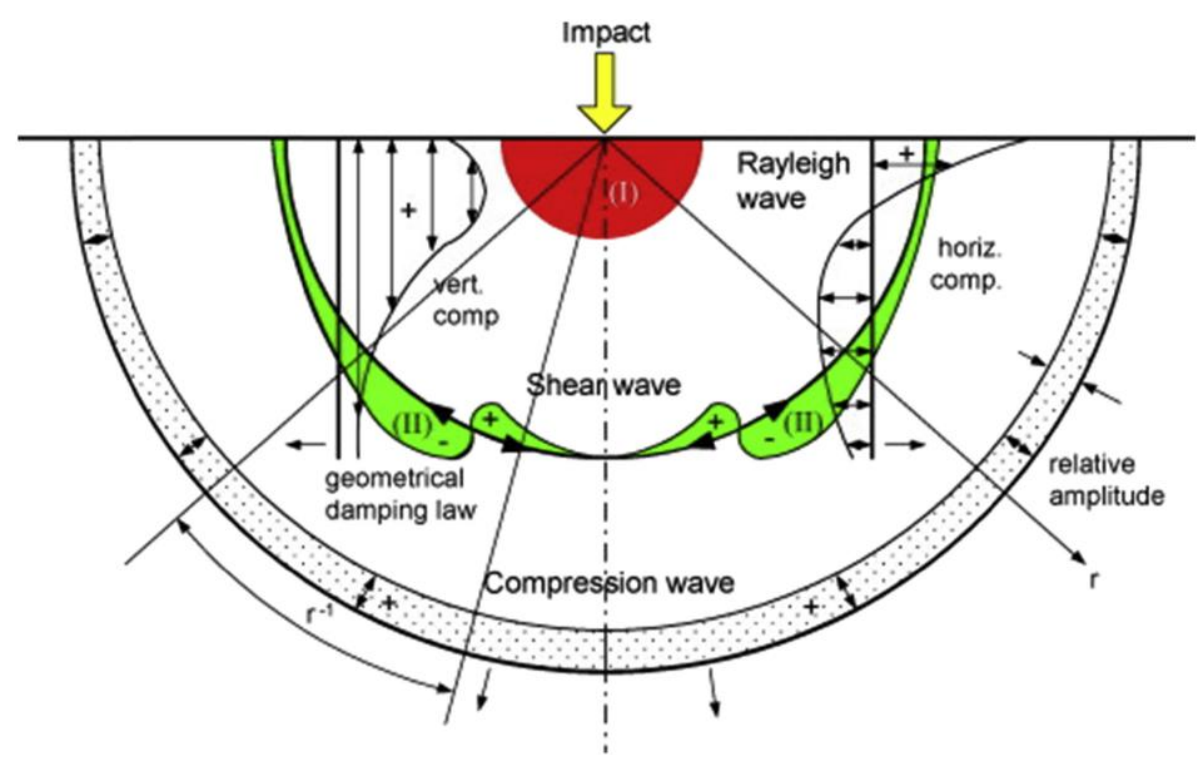

Figure 2.1. The waves and displacements as a result of a harmonic vertical "point source" acting on the surface of a homogeneous, isotropic, linear elastic half space, based on Ref. [46], [47]. 
Damping of the waves is related to the distance $r$ from the impact centre, see for example Ref. [46]. Bulk waves decay with $1 / r$ into the solid and with $1 / r^{2}$ at the surface. This is much stronger than damping of the Rayleigh waves that occurs at $1 / v r$. As such, it can be assumed that the disturbance in the far field is dominated by the Rayleigh waves. The positions of the wave fronts and the resulting stress variations with time are available in an analytical form [37]. This shows that the transient surface stresses are primarily compressive with high tensile stresses in a narrow band immediately behind the Rayleigh wave front. The radial dimensions in which this occurs are quite small, and together with the high wave velocity this gives rise to short stress peaks of typically tens of micro-seconds, see Figure 2.2 for the non-dimensional radial stress $S_{R R}$. (In the graphs presented in the Figures 2.2 to 2.4 the stresses in the cylinder coordinate system $(r, \theta, z)$ are presented as nondimensional stresses relative to the water hammer pressure, $S_{R R}=\sigma_{r r} / p_{w h}$ and $S_{\theta \theta}=$ $\sigma_{\theta \theta} / p_{w h}$, where $\sigma_{r r}$ is the stress in $r$ direction on a plane with the normal in $r$ direction and $\sigma_{\theta \theta}$ is the stress in $\theta$ (tangential) direction on a plane with the normal in $\theta$ direction.)

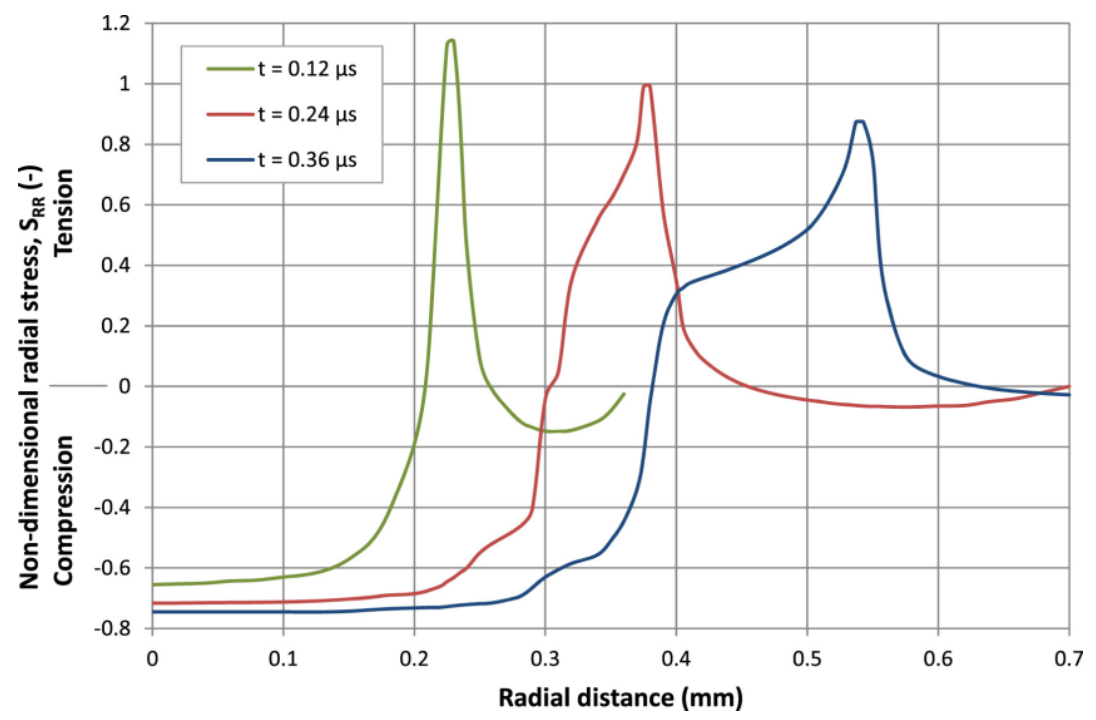

Figure 2.2. The variation of non-dimensional radial stress component due to the Rayleigh surface wave as a function of radial distance in $P M M A$, for a water drop diameter $d_{d}=1.8$ $\mathrm{mm}$ and impact velocity $v_{d}=222 \mathrm{~m} / \mathrm{s}$ at $5 \mu \mathrm{m}$ depth. Adapted from Ref. [28].

Numerical results for thin hard elastic coating are presented by Kim et al. in Ref. [42]. In this reference, reflection at the coating-substrate interface is taken into account as well. Calculations are made with a water droplet diameter $d_{d}=2 \mathrm{~mm}$, a 
droplet impact velocity $v_{d}=453 \mathrm{~m} / \mathrm{s}$ and a $90^{\circ}$ impact angle. Table 2.1 summarises the other input parameters of the calculations made in Ref. [42]. The water hammer pressure is used to normalise the stresses to non-dimensional numbers.

Figure 2.3 shows a snapshot of the non-dimensional stress $S_{R R}$ at time $t=0.05 \mu \mathrm{s}$ after impact. The sharp peak near the surface corresponds to the Rayleigh wave front at $r=224 \mu \mathrm{m}$. The boundary of the loaded area is $r_{p}=v\left(d_{d} V_{d} t\right)=213 \mu \mathrm{m}$. The effect of a coating on the results follows from Figure 2.4, showing the stresses $S_{R R}$ and $\mathrm{S}_{\theta \theta}$ at the surface as a function of the radial distance, in which the symbols " $\mathrm{B}$ ", " $R$ " and "L" refer to the boundary of the loaded area, Rayleigh wave front and longitudinal wave front respectively. This figure it shows that at that time $t=0.05$ $\mu s$ an annular strip with high tensile stresses is formed between the edge of the loaded area and the Rayleigh wave front. This annular strip has a width of about 15 $\mu \mathrm{m}$. The normalised $\mathrm{S}_{\mathrm{RR}}$ tensile stresses in this strip vary from 1.5 to 3.0. The presented results for thin hard elastic coatings are in line with the analytical solution for the uncoated case and show similar behaviour for the coated case. The location and singular behaviour of the Rayleigh wave front are found from the pressure model and are seen to be independent of the coating thickness. The region directly below the contact area is in pure compression. Since the stresses cannot have infinite magnitude in real impact situations, the singularity in the work of Ref. [42] may be due to the abrupt change of pressure model at the impact boundary.

Table 2.1. System and material properties used in Ref. [42].

\begin{tabular}{|l|l|l|c|c|}
\hline Properties & Symbol & Unit & Coating & Substrate \\
\hline Material & & & - & ZnSe \\
Thickness & $\mathrm{h}$ & $(\mu \mathrm{m})$ & 43 & Half space \\
Density & $\rho$ & $\left(\mathrm{kg} / \mathrm{cm}^{3}\right)$ & 6.59 & 5.27 \\
Young's modulus & $\mathrm{E}$ & $(\mathrm{MPa})$ & 171 & 67.4 \\
Poisson's ratio & $\mathrm{V}$ & $(-)$ & 0.3 & 0.3 \\
Longitudinal wave speed & $\mathrm{C}_{1}$ & $(\mathrm{~m} / \mathrm{s})$ & 5910 & 4150 \\
Transverse wave speed & $\mathrm{C}_{2}$ & $(\mathrm{~m} / \mathrm{s})$ & 3160 & 2220 \\
Rayleigh wave speed & $\mathrm{C}_{3}$ & $(\mathrm{~m} / \mathrm{s})$ & 2930 & 2058 \\
Transverse wave speed ratio & $\mathrm{s}_{2}$ & & 0.535 & 0.535 \\
Rayleigh wave speed ratio & $\mathrm{s}_{3}$ & & 0.496 & 0.496 \\
\hline
\end{tabular}




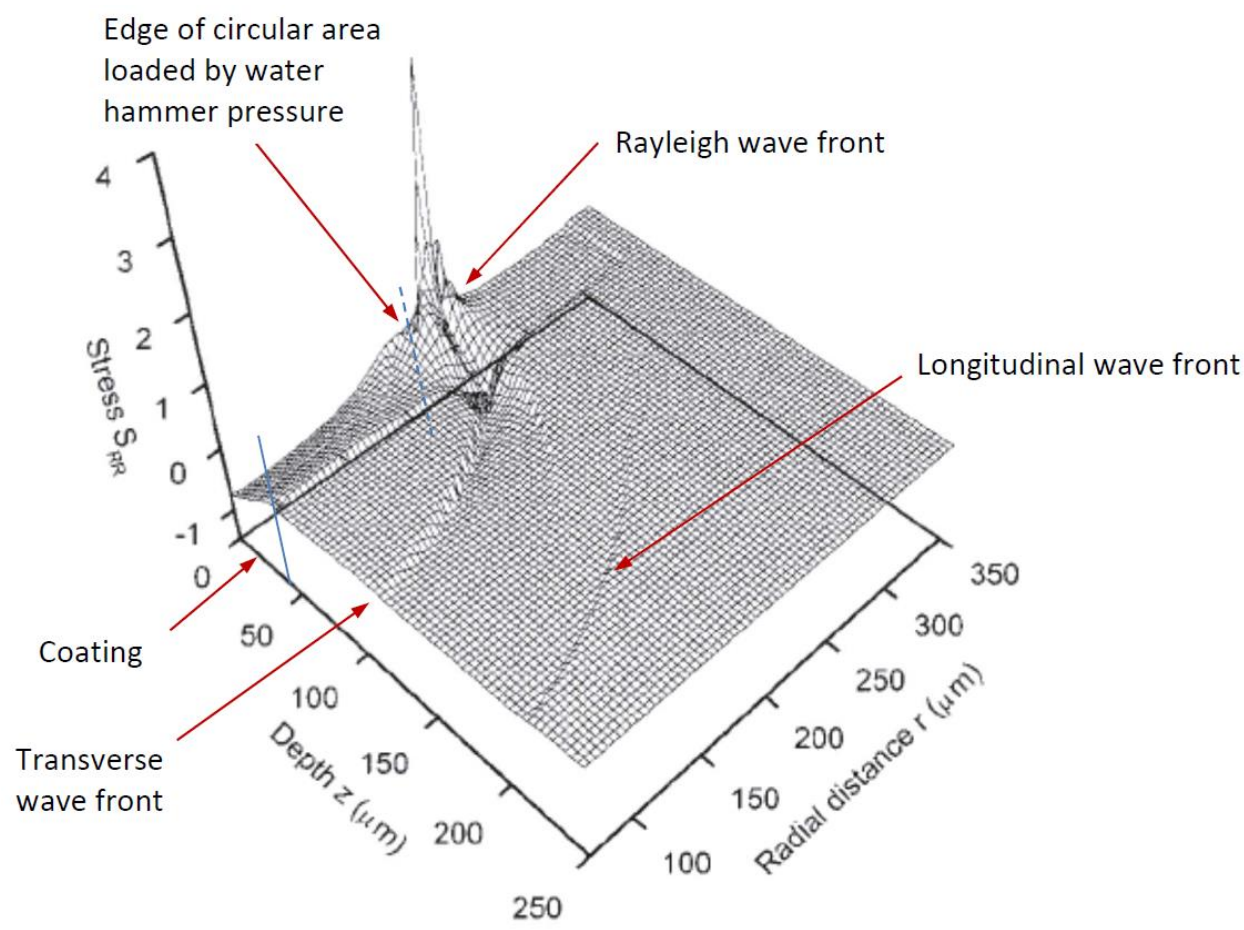

Figure 2.3. Plot of the normalised stress $S_{R R}$ as a function of radial distance $(r)$ and depth ( $z$ ) at $t=0.05 \mu \mathrm{s}$. Adapted from Ref. [42]. 


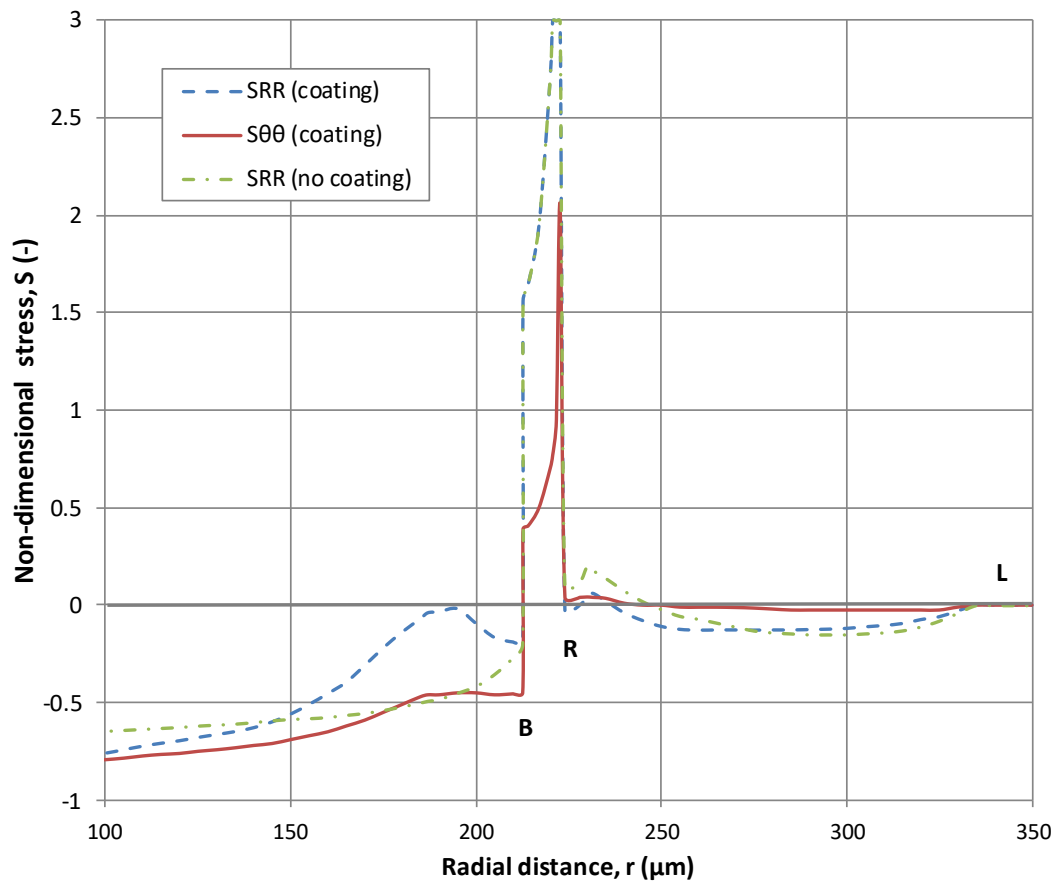

Figure 2.4. Variation of the non-dimensional stresses $S_{R R}$ and $S_{\theta \theta}$ as functions of the radial distance $(r)$ at the surface for $t=0.05 \mu \mathrm{s}$. Solid line with marks corresponds to $S_{R R}$ when there is no coating and the substrate is filled with the same material as coating. Adapted from Ref. [42].

Numerical results with thick compliant coatings are presented in the work of Adler and Mihora [48], [49], [50] based on finite element analysis of a water droplet impacting a structured target material. A major difference with thin hard elastic coatings is that deep craters develop in impacted polyurethane coatings, which alters the evolving water drop shape substantially. Furthermore, both the water drop and the polyurethane layer undergo large strains and displacements simultaneously. Calculations presented in Refs. [48], [49], [50] clearly show that impact by a single water droplet at relatively high impact velocity cannot initiate failure for a range of polyurethane coatings, either by increasing the water droplet diameter or by changing of the contact angle. This can be explained from the calculated elongations (strains) in the FE model. The calculated tensile strains now reach $80 \%$ in some cases. However, tensile failures are not predicted since even the weakest polyurethane material exhibited $210 \%$ strain to failure at dynamic loading conditions. The results further indicate that the time to reach the maximum tensile strains now reaches $4-8 \mu \mathrm{s}$, which is much longer than for hard materials. Even with 
these relatively long time frames, strain rates exceeding $2.5 \times 10^{5} \mathrm{~s}^{-1}$ were calculated. The transverse and Rayleigh stress waves in polyurethanes travel at much lower velocities than in metals and ceramics.

For very hard materials the peak transient stresses occur early in the water drop deformation cycle, before significant lateral outflow occurs when the drop hits the surface. By contrast, the maximum stresses in the polyurethane layers develop late in the water drop distortion cycle when severe distortions of the drop are present. The angle of attack $\theta$ affects the stress situation as well, by decreasing the impact velocity of the droplet, in the direction normal to the surface, roughly with the sine of this angle $(\sin \theta)[51]$.

\subsection{Wear mechanisms and droplet impact}

\subsubsection{Brittle fracture}

The relevance of these transient stresses due to a single drop impact in relation to surface damage of uncoated materials is demonstrated by Adler [28] and Hackworth [52], based on experimental results with zinc selenide, zinc sulphide and gallium arsenide. Single water drop impacts are generated with $0.7,2.0$ and $2.5 \mathrm{~mm}$ diameter drops and impact velocities of 222 and $341 \mathrm{~m} / \mathrm{s}$. Each single-drop impact produced a ring fracture pattern consisting of a number of circumferential cracks. Ceramics, glasses and some other materials show an elastic - brittle response upon loading, and some especially when high loading rates are applied, as is the case for some polymers or some steel grades at low temperature. An example of damage produced in a brittle material by liquid impact is shown in Figure 2.5 [53]. The damage pattern is typically a series of discrete circumferential fractures around the undamaged central loaded zone. The fractures are caused by the Rayleigh surface wave emanating from the impact area [53]. The extremely low fracture toughness or critical stress intensity factor $\left(K_{c}\right)$ of the material combined with a high drop impact velocity, resulting in a high stress level of the Rayleigh surface wave, are responsible for this type of fracture. 


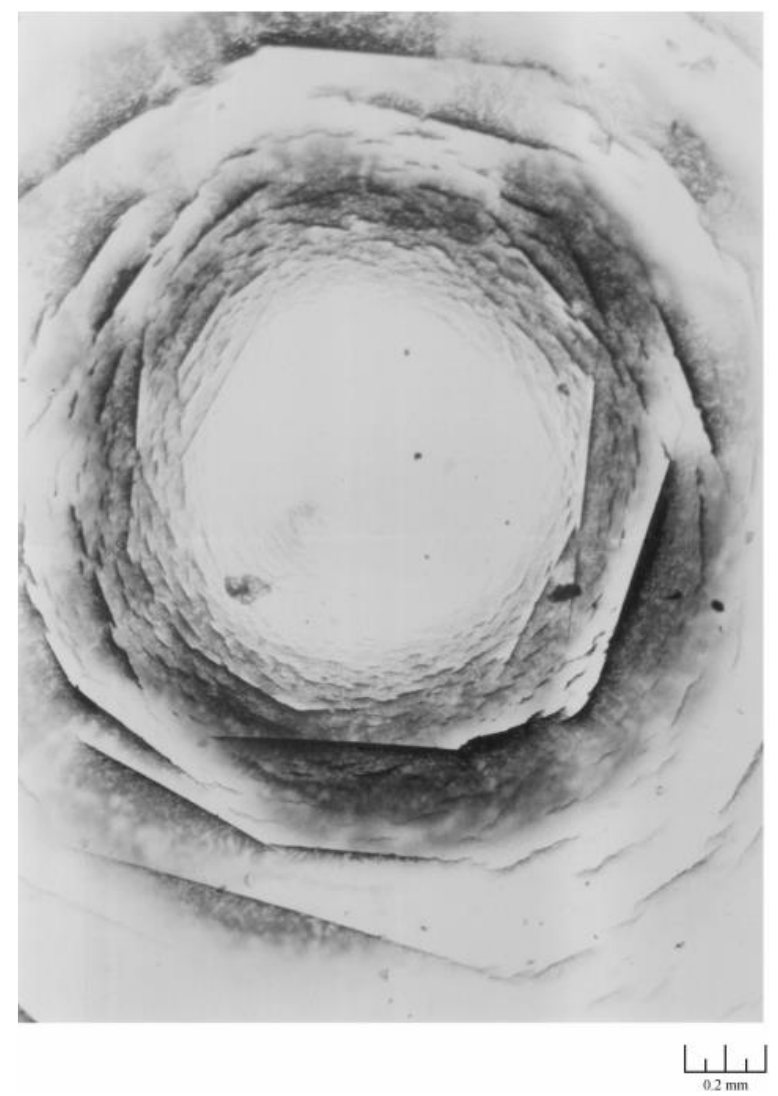

Figure 2.5. An example of damage in an infrared transmitting brittle material resulting from a single liquid impact at $350 \mathrm{~m} / \mathrm{s}$ [53].

Similar results are described [54] for thermosetting polymers, polyester and epoxy resins. At an impact velocity of $550 \mathrm{~m} / \mathrm{s}$ polyester develops brittle fracture in the form of short circumferential cracks, see Figure 2.6 [54]. 


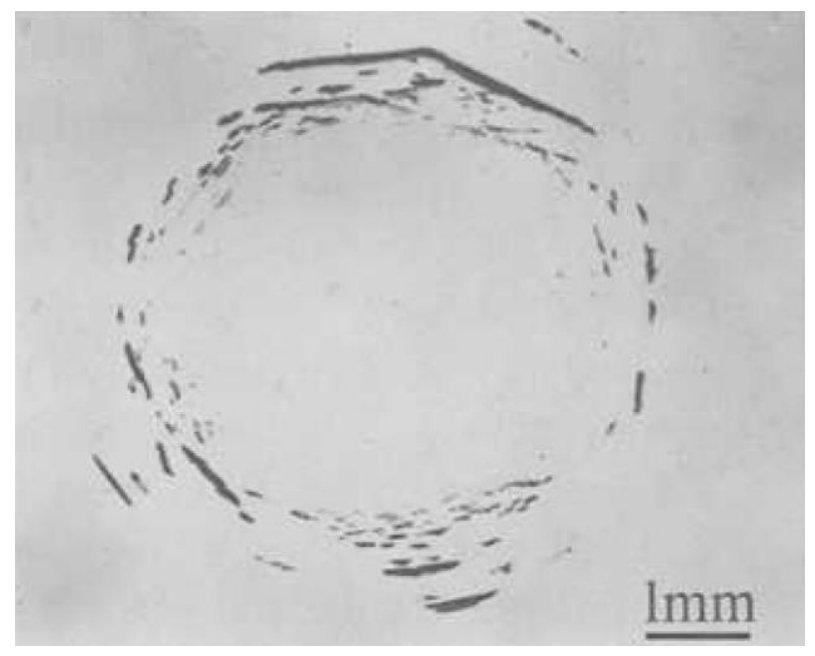

Figure 2.6. Water impact damage on a brittle thermoset (polyester) resulting from a single liquid impact at $550 \mathrm{~m} / \mathrm{s}$. Adapted from Ref. [54].

Analytical model calculations [52] predict radial tensile stresses which greatly exceeded the ultimate strength of the materials for the experimental conditions, see Table 2.2.

Table 2.2. The highest (peak) radial tensile stresses $\left(\sigma_{r r, m a x}\right)$ predicted for two impact velocities and two depths below the impacted surface. The ultimate flexural strengths of ZnSe, ZnS and GaAs are 58, 110 and $140 \mathrm{MPa}$ [52].

\begin{tabular}{|cc|c|c|c|c|}
\hline \multicolumn{2}{|l|}{$\begin{array}{c}\text { Impact velocity, } \mathrm{v}_{\mathrm{d}}(\mathrm{m} / \mathrm{s}): \\
\text { Depth, } \mathrm{z}(\mu \mathrm{m}):\end{array}$} & \multicolumn{2}{|c|}{222} & \multicolumn{2}{|c|}{341} \\
\hline Material type & $\begin{array}{c}\text { Drop size } \\
\mathrm{d}_{\mathrm{d}}(\mathrm{mm})\end{array}$ & \multicolumn{4}{|c|}{ Highest radial tensile stress, } \\
& 0.7 & 188 & 103 & 464 & 240 \\
\hline ZnSe & 2.0 & 369 & 214 & 973 & 524 \\
& 2.5 & 442 & 240 & & 614 \\
\hline ZnS & 0.7 & & 79 & & 207 \\
& 2.0 & 285 & 196 & 757 & 475 \\
& 2.5 & & 230 & & \\
\hline GaAs & 2.0 & 374 & 200 & & 456 \\
\hline
\end{tabular}

The analytical model describes the surface related nature of the damage caused by a single-drop impact. Figure 2.7 for example shows the maximum value of the radial tensile stress as a function of depth below the surface for a $2.0 \mathrm{~mm}$ drop impacting zinc selenide at $222 \mathrm{~m} / \mathrm{s}$. For each depth, the stress at several radial locations is 
computed and the maximum value selected for this curve. The radial stress exceeds the ultimate bending strength of the material over a depth of about $100 \mu \mathrm{m}$.

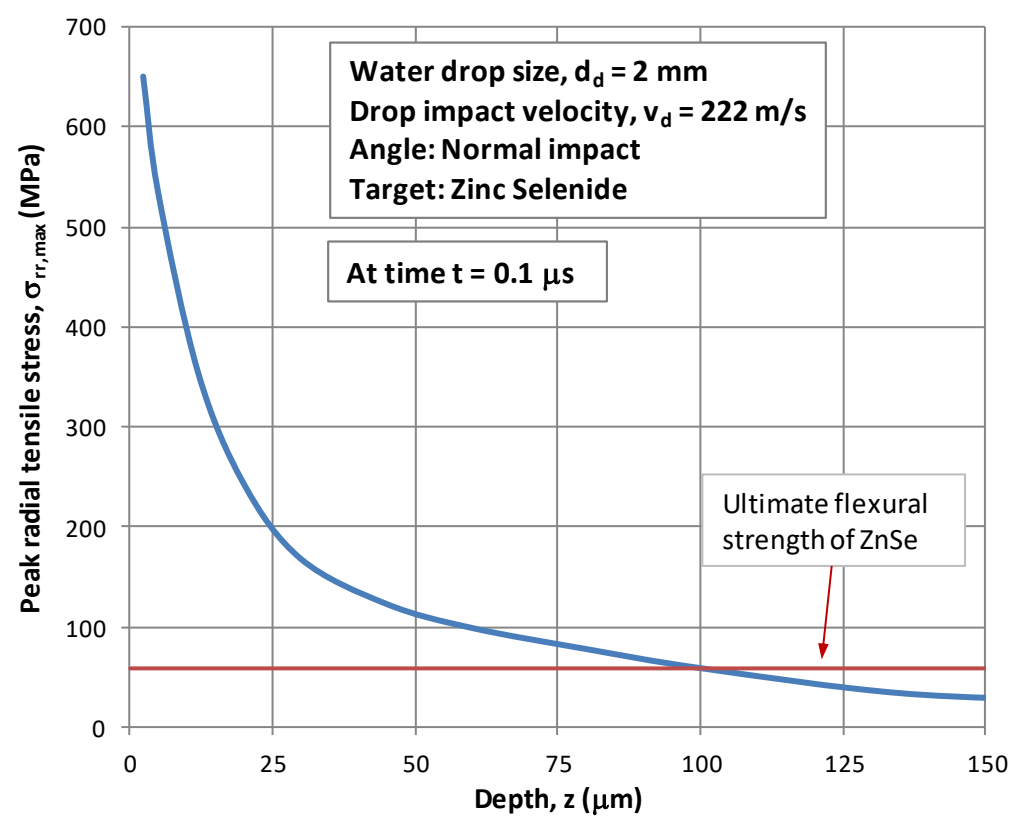

Figure 2.7. Variation of peak radial stress, at time $t=0.1 \mu \mathrm{s}$, with depth for a $2.0 \mathrm{~mm}$ water drop impacting Zinc Selenide at $v_{d}=222 \mathrm{~m} / \mathrm{s}$. Adapted from Ref. [52].

Experimental results [52] show that the radial location and the approximated magnitude of the peak stress change with the size of the water droplet and with the impact velocity. For this class of relatively brittle materials and operational conditions, damage within the material originates from overloading or surface fatigue at a low number of stress cycles. In most cases the impact of one droplet is enough to cause brittle failure on a local scale.

\subsubsection{Fracture threshold drop impact velocity}

The initial damage in this regime is found to occur as short circumferential surface cracks (Figure 2.5). These cracks are attributed to the activation of small preexisting cracks by the relatively large tangential tensile stresses associated with the Rayleigh wave. Evans et al. [44], [45] addressed this problem by examining the variables that influence both the dynamic elastic stresses and the crack propagation characteristics under stress wave loading.

An analytic solution for the dynamic elastic stresses that develop in response to the pressure has been obtained by approximating the pressure distribution with a 
uniform pressure by using Blower's model [37] and the calculation results of Adler [28].

Evans et al. [44], [45] have defined the fracture threshold velocity $\left(v_{d, t h, K}\right)$ based on the critical fracture toughness $\left(K<K_{c}\right)$. Using the simple relation for the water hammer pressure $\left(p_{w h}=v_{d} \rho_{l} c_{l}\right)$, the derived fracture threshold velocity $\left(v_{d, t h, K}\right)$ is given by:

$$
v_{d, t h, K}=1.41\left(\frac{K_{c}}{\rho_{l} c_{l}}\right)^{\frac{2}{3}}\left(\frac{c_{R}}{d_{d}}\right)^{\frac{1}{3}}
$$

$K_{C}=$ fracture toughness

$c_{R}=$ Rayleigh wave velocity

$d_{d}=$ drop diameter

$v_{d}=$ drop impact velocity

$\rho_{l}=$ density of water

$c_{l}=$ wave velocity in water

The small pre-existing cracks in the materials surface should be smaller than a critical crack size $\left(a_{c}\right)$ to prevent brittle fracture. This critical crack size is given by:

$$
a_{c}=\frac{0.63}{\pi}\left(\frac{K_{c}}{\sigma_{0}}\right)^{2}
$$

$\sigma_{0}=$ peak stress

\subsubsection{Surface fatigue and experimental results}

Surface fatigue or fatigue wear is characterised by the removal of particles detached by fatigue arising from cyclic stress variations [1], see also Section 1.3. The relation between (surface) fatigue properties of a material or coating and the incubation lifetime for liquid impingement erosion is first constructed by Springer [14], based on a large database that includes whirling arm tests. There are three distinct stages:

1. an incubation period, in which the surface is apparently unaffected

2. the steady-state erosive wear stage where the surface wears at a relatively high wear-rate

3. the final erosion stage with a strongly reduced wear rate due to the higher surface roughness, which was produced in the second phase. 
Figure 1.7 shows in graphical form the first two stages based on the erosion depth as a function of time.

The time from incubation to a certain erosion depth is typically much shorter than the time covered by the incubation period itself. This is especially true for coated systems, in which the erosion depth is limited to the thickness of the coating. Consequently, it is usually assumed that the end of the coating life is reached at the moment a particle is detached from the surface. In this work, the incubation period is therefore taken as an estimate for the coating life. The span-wise locations of the blade, at which the end of coating life is reached, can now be calculated from the velocity profile over the leading edge. Leading edge erosion typically starts at the tip of the blade, where the droplet impact velocity is at its maximum. The droplet impact velocity reduces towards the centre of rotation and, as such, cumulative damage occurs at a lower stress level.

The slope of the erosion versus time curve, the second stage is an important characteristic of materials if low cycle fatigue is dominant, e.g. in the case of extreme stress levels. Figure 2.8 shows the cumulative weight loss of eight steel types, with varying hardness levels between 103 and $327 \mathrm{HV}$, as extracted from Ref. [73].

Experimental results for uncoated $12 \% \mathrm{Cr}$-steel and Stellite 6B and for $12 \% \mathrm{Cr}$-steel and Stellite $6 \mathrm{~B}$ coated with a $1.2 \mu \mathrm{m}$ thin layer of TiN are presented by Lee et al. [36], [55]. See Figure 2.9 for a summary of the experimental results [36]. The first 100 droplet impacts on TiN coated samples did not reveal any wear due to cracks. Plastic deformation of the substrate material near the interface of the coating occurred in these experiments, however, giving rise to a certain deformation depth. Damage occurs with uncoated $12 \% \mathrm{Cr}$ steel, yet Figure 2.9 shows that it takes several impacts to initiate removal of material. This is commonly referred to as incubation time. Both observations point towards surface fatigue - removal of wear particles detached by fatigue crack growth arising from cyclic stress variations [1] as the wear mechanism. Damage is initiated after a small number of stress cycles for $12 \% \mathrm{Cr}$ steel and a larger number of cycles for TiN coated material. The beneficial effect of the TiN coating could be predicted qualitatively based on a modified Blowers model [37], incorporating reflection of stress waves at the coating-substrate interface [36]. 


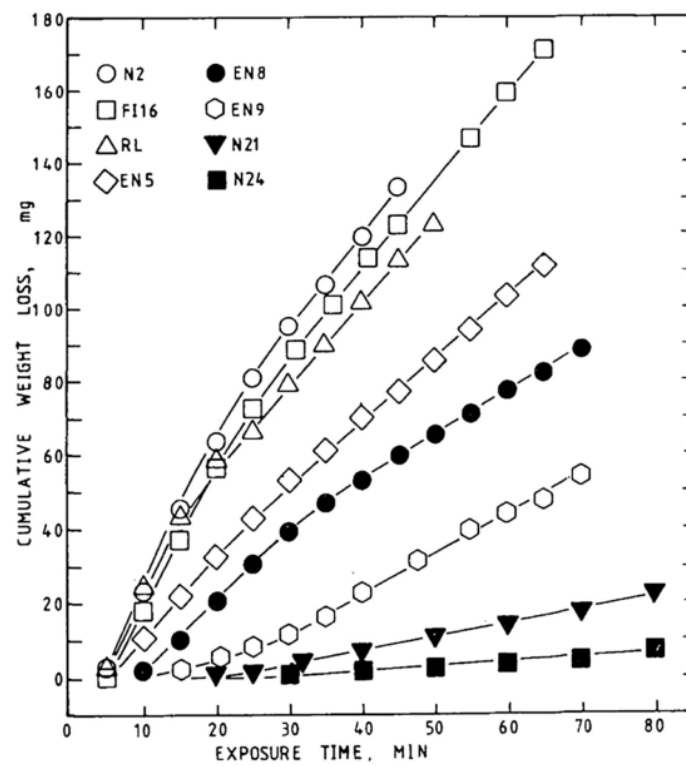

Steel properties

\begin{tabular}{|c|c|c|}
\hline $\begin{array}{c}\text { Steel } \\
\text { type }\end{array}$ & $\begin{array}{c}\text { Carbon } \\
\text { content } \\
\text { (wt\%) }\end{array}$ & $\begin{array}{c}\text { Hardness } \\
\text { Vickers } \\
\text { (HV) }\end{array}$ \\
\hline N2 & 0.03 & 103 \\
RL & 0.08 & 114 \\
FI16 & 0.11 & 132 \\
En5 & 0.31 & 169 \\
En8 & 0.41 & 181 \\
En9 & 0.53 & 215 \\
N21 & 0.73 & 270 \\
N24 & 1.33 & 327 \\
\hline
\end{tabular}

Figure 2.8. Cumulative mass loss of 8 steels with varying hardness levels due to liquid impingement erosion. (Exposure time scale in minutes.) Droplet impact velocity, $v=200 \mathrm{~m} / \mathrm{s}$ (perpendicular to the specimen surface), specimen eroding area: $\emptyset 12 \mathrm{~mm}$ [73].

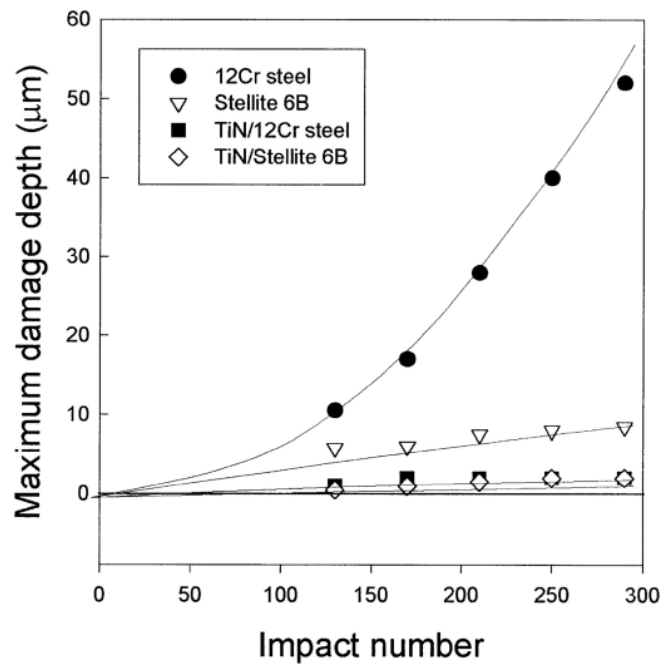

Figure 2.9. Maximum damage depth with an increasing number of impacts for $12 \mathrm{Cr}$ steel, Stellite $6 B$, TiN-coated $12 \mathrm{Cr}$ steel, and TiN-coated Stellite $6 B$ at an impact velocity of $350 \pm$ $20 \mathrm{~m} / \mathrm{s}$, [36].

The magnitude of the stress cycle at the coating-substrate interface decreases with increasing coating thickness. The results of Ref. [36] suggest that by lowering the 
maximum stress below the fatigue limit of the blade materials it is possible to extend the lifetime of the blade with respect to impact wear.

The presented numerical results for the polyurethane coated surfaces [48],[49] showed that the predicted stresses and strains remain well below the values that cause failure. Instead of brittle fracture or tearing it is hypothesised by Ref. [48] that repeated large strains may lead to fatigue initiation as the nucleating mechanism for erosion damage. This is in line with high cycle surface fatigue as the origin of the damage.

\subsubsection{Impact of water droplets \& surface fatigue}

The fatigue life of a surface can be estimated based on the linear cumulative damage rule of Palmgren-Miner [56], [57]. This damage rule is widely used and standardised for fatigue lifetime calculations of roller bearings [58], but also for welded steel constructions for bridges and vessels [59], [60].

The basic equation in Palmgren-Miner rule is given by Eq. (2.4):

$$
D=\sum_{i=1}^{k} \frac{n_{i}}{N_{f, i}}
$$

in which $D$ is the accumulated amount of damage, $N_{f, i}$ is the amount of cycles to failure at stress level $i$ and $n_{i}$ the amount of cycles that occurred at stress level i. A frequently used expression to describe fatigue life curves is [66]:

$$
S_{\text {max }}=S_{f} N_{f}^{-1 / m}
$$

which $S_{\max }$ the maximum fatigue stress and $N_{f}$ the number of cycles to failure. The material parameters $m$ and $S_{f}$ are commonly used for fatigue studies. The fatigue properties of the surface for a stress level $i$ and for the specific conditions of drop impact can be expressed as:

$$
S_{\text {max }, i}=h_{t o t} S_{f} N_{f, i}^{-1 / m}
$$

which $S_{\text {max }, i}$ the maximum fatigue stress at stress level i for the actual drop impact conditions, $h_{t o t}$ corrects for the differences between the standardised fatigue test conditions and the actual drop impact conditions. The fatigue limit $S_{D, d}$ for the actual drop impact conditions is given by: 


$$
S_{D, d}=h_{t o t} S_{D}
$$

with $S_{D}$ being the fatigue limit at standardised fatigue test conditions.

\subsubsection{Mixed fracture modes}

Besides cracks due to full brittle fracture, brittle phases in a microstructure, embedded in a tough matrix can also show localised brittle fractures after drop impact at high velocities. This mechanism is described by Adler [61],[62]. He studied the growth of craters in strongly eroded Ti-6Al-4V through progressive sectioning and observed features of localised brittle fractures along the $\alpha-\beta$ interfaces and along slip lines in the $\beta$ phase. For this metal, and for the drop impact velocity used, the erosion process is a mixture of fatigue crack growth and local brittle fracture. This shows that surface fatigue is the failure mechanism, provided that the fracture toughness of all microstructural phases is above a certain threshold value which, however, depends on the drop impact velocity.

This mechanism was also confirmed by O'Carroll et al. [63] for polymers. They studied multiple liquid impact erosion of various polymers, including extruded polycarbonate (PC), polyethylene (PE), PE terephthalate (PET), polypropylene (PP), cast polymethylmethacrylate (PMMA-C) and extruded polymethylmethacrylate (PMMA-E). PMMA and PET showed poor results in comparison with PC, PE and PP. It was noticed that the polymers showing ductile damage mechanisms demonstrate much better erosion resistance than the polymers with brittle mechanisms.

\subsubsection{Conclusion}

The wear modes observed in literature are brittle fracture, surface fatigue and a mixed mode of local brittle fracture and local fatigue crack growth. The mixed mode is described by Adler [61],[62] for a titanium alloy and by O'Carroll et al. [63] for certain polymers. These observations show that surface fatigue is the failure mechanism, provided that the fracture toughness values of all microstructural phases are above a certain threshold value which, however, depends on the drop impact velocity.

\subsection{Synthesis to material selection for droplet impingement resistance}

\subsubsection{Counter measures to surface fatigue}

From Section 2.3 it is concluded that the droplet impingement life is determined mainly by surface fatigue. Based on literature it was possible to derive an equation from which the life can be estimated, i.e. Eq. (15) in paper A mentioned in Part II. 
Although some terms in this equation need additional research to be of similarly high value as currently in, for example, ISO 281 [58], it does give a clear direction for material selection to protect surfaces from droplet impingement erosion: surfaces need to be optimised with respect to fatigue life.

The fatigue life of surfaces can be expressed by a Wöhler curve, similar to the fatigue life of bulk materials, see Figure 2.10. From this figure it is clear that lower stress levels are associated with greater fatigue life for a given material. This wear mechanism can be neglected at stress levels below the fatigue limit of the material. General counter measures to minimise the risk of surface fatigue wear are:

1. Reduction of the pressure, e.g. by applying surfaces with a low modulus of elasticity

2. Enlarging the safe area by:

a. applying surfaces with adjustable compressive stresses

b. applying surfaces with adjustable hardness

c. preventing defects and impurities at and near the surface.

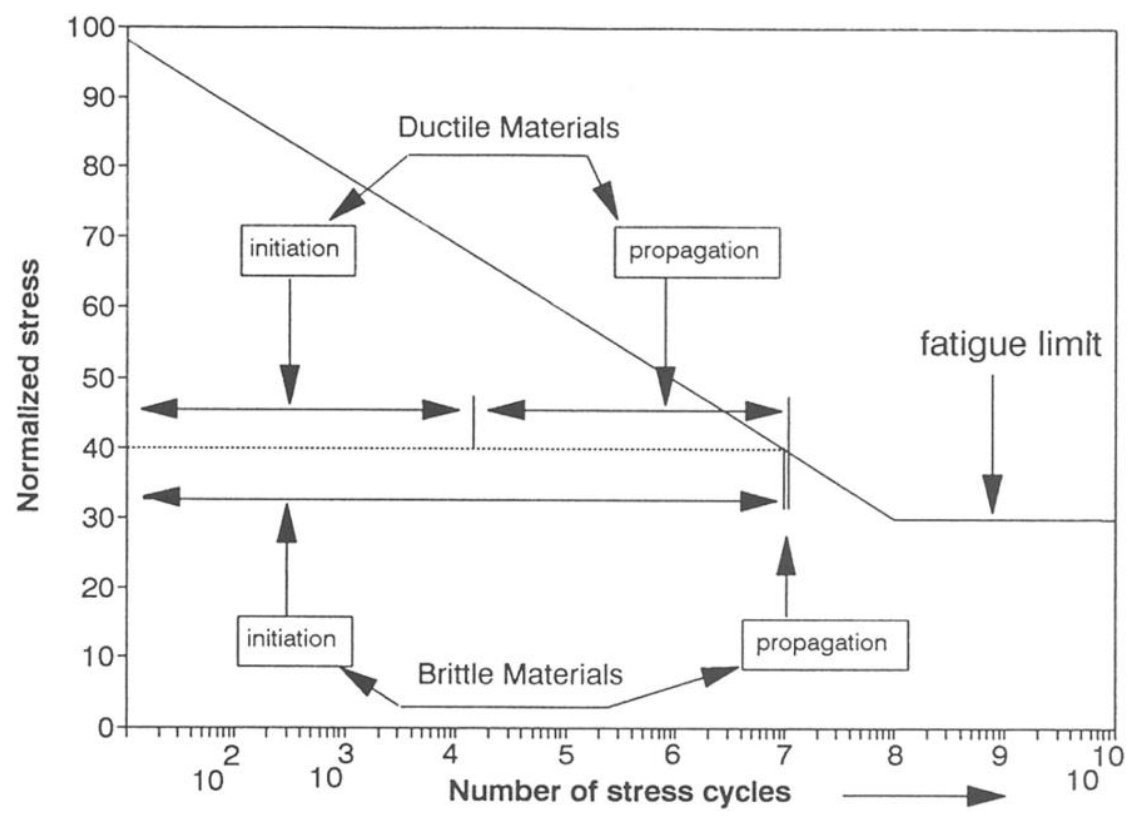

Figure 2.10. Wöhler curve for surface fatigue (rolling contact fatigue) of roller bearings. Extracted from Ref. [74].

These general rules to reduce fatigue wear are based either on reducing the stress, preferably to below the fatigue limit, or on material selection that causes a shift of 
the Wöhler curve to a higher number of stress cycles or to a high stress level. Both strategies are discussed in the following sections.

\subsubsection{Reducing the stresses caused by Rayleigh waves}

The maximum stress at the surface due to Rayleigh waves is determined by the water hammer pressure $\left(p_{w h}\right)$ which in turn depends on the acoustic properties of the liquid $\left(\rho_{w} c_{w}\right)$ and the dynamic impedance of the surface material $\left(Z_{m}=\rho_{m} c_{l, m}\right)$, see also Eq. (2.1). An overview of material properties and dynamic impedances, largely based on the information presented by Refs. [9], [14], [64], [65], is given in Table 2.3. The table gives an overview of the density, Young's modulus, speed of sound, dynamic impedance and the combined dynamic impedance $\left(Z_{r}\right)$ which is based on Eq. (2.1a), but using a constant value for the speed of sound in water ( $c_{w}$ $=1480 \mathrm{~m} / \mathrm{s}$ ). For this case the combined dynamic impedance $\left(Z_{r}\right)$ is equal to the relative impact pressure $\left(p_{w h} / v_{d}\right)$, and thus $\left(Z_{r}=p_{w h} / v_{d}\right)$.

Table 2.3. Material properties, dynamic impedances and combined dynamic impedance with water for materials and classes of materials.

\begin{tabular}{|c|c|c|c|c|c|}
\hline & $\begin{array}{c}\text { Density } \\
\rho \\
\left(\mathrm{kg} / \mathrm{m}^{3}\right)\end{array}$ & $\begin{array}{l}\text { Young's } \\
\text { modulus } \\
\mathrm{E} \text { (MPa) }\end{array}$ & $\begin{array}{l}\text { Speed of } \\
\text { sound } \\
\mathrm{c}_{1}(\mathrm{~m} / \mathrm{s})\end{array}$ & $\begin{array}{c}\text { Dynamic } \\
\text { impedance } \\
\mathrm{Z} \text { (MPa s/m) }\end{array}$ & $\begin{array}{c}\text { Combined } \\
\text { with water } \\
\mathrm{Z}_{\mathrm{r}}(\mathrm{MPa} \mathrm{s} / \mathrm{m})\end{array}$ \\
\hline Water & 1000 & & 1480 & 1.48 & \\
\hline \multicolumn{6}{|l|}{ Metals } \\
\hline Magnesium & 1800 & 45000 & 5000 & 9.0 & 1.44 \\
\hline Aluminium (alloys) & 2700 & 70000 & 5092 & 13.7 & 1.53 \\
\hline Titanium (alloys) & 4430 & 115000 & 5095 & 22.6 & 1.60 \\
\hline Steel & 7850 & 205000 & 5110 & 40.1 & 1.65 \\
\hline Copper (alloys) & 8000 & 130000 & 4031 & 32.2 & 1.63 \\
\hline Nickel & 8890 & 204000 & 4790 & 42.6 & 1.65 \\
\hline Nickel alloys & 8200 & 218000 & 5156 & 42.3 & 1.65 \\
\hline Cobalt (CoCr-alloys) & 8590 & 225000 & 5118 & 44.0 & 1.66 \\
\hline Cobalt (Stellite 6B) & 8390 & 215000 & 5062 & 42.5 & 1.65 \\
\hline Tin & 7300 & 41200 & 2376 & 17.3 & 1.56 \\
\hline Zinc & 7140 & 88300 & 3517 & 25.1 & 1.61 \\
\hline $\operatorname{Zinc}\left(\mathrm{Zn}-\mathrm{Al}_{4}\right)$ & 6600 & 130000 & 4438 & 29.3 & 1.62 \\
\hline Lead & 11300 & 17700 & 1252 & 14.1 & 1.53 \\
\hline \multicolumn{6}{|l|}{ Ceramics } \\
\hline $\mathrm{Al}_{2} \mathrm{O}_{3}$ & 3800 & 360000 & 9733 & 37.0 & 1.64 \\
\hline $\mathrm{SiC}$ & 3000 & 400000 & 11547 & 34.6 & 1.64 \\
\hline $\mathrm{Si}_{3} \mathrm{~N}_{4}$ & 3200 & 280000 & 9354 & 29.9 & 1.63 \\
\hline $\mathrm{ZrO}_{2}$ & 6000 & 200000 & 5774 & 34.6 & 1.64 \\
\hline Diamond & 3500 & 440000 & 11212 & 39.2 & 1.65 \\
\hline Normal glass & 2500 & 69000 & 5254 & 13.1 & 1.52 \\
\hline Polycrystalline glass & 2600 & 120000 & 6794 & 17.7 & 1.57 \\
\hline \multicolumn{6}{|l|}{ Fibres } \\
\hline E-glass fibre & 2540 & 70000 & 5250 & 13.3 & 1.52 \\
\hline
\end{tabular}




\begin{tabular}{|c|c|c|c|c|c|c|}
\hline \multicolumn{2}{|l|}{ S-glass fibre } & 2490 & 85000 & 5843 & 14.5 & 1.54 \\
\hline \multicolumn{2}{|l|}{ HM-aramid fibre } & 1450 & 130000 & 9469 & 13.7 & 1.53 \\
\hline \multicolumn{2}{|l|}{ SM-carbon-fibre } & 1800 & 230000 & 11304 & 20.3 & 1.59 \\
\hline \multicolumn{2}{|l|}{ HM-carbon-fibre } & 1850 & 390000 & 14519 & 26.9 & 1.62 \\
\hline \multicolumn{7}{|l|}{ Thermosets } \\
\hline \multicolumn{2}{|l|}{ UP-resin (low E) } & 1150 & 2400 & 1445 & 1.7 & 0.85 \\
\hline \multicolumn{2}{|l|}{ UP-resin (high E) } & 1250 & 4600 & 1918 & 2.4 & 1.00 \\
\hline \multicolumn{2}{|l|}{ EP-resin (low curing) } & 1175 & 3500 & 1726 & 2.0 & 0.93 \\
\hline \multicolumn{2}{|l|}{ EP-resin (high curing) } & 1250 & 3500 & 1673 & 2.1 & 0.94 \\
\hline \multicolumn{2}{|c|}{ UD fibre/epoxy; $90^{\circ} ; v_{f}=60 \%$} & & $\mathrm{E}_{\mathrm{T}}$ & & & \\
\hline \multicolumn{2}{|c|}{ E-glass/epoxy } & 2000 & 10000 & 2236 & 4.5 & 1.24 \\
\hline \multicolumn{2}{|l|}{ HM-aramid/epoxy } & 1350 & 5500 & 2018 & 2.7 & 1.05 \\
\hline \multicolumn{2}{|l|}{ SM-carbon/epoxy } & 1550 & 9000 & 2410 & 3.7 & 1.18 \\
\hline \multicolumn{7}{|l|}{ Thermoplastics } \\
\hline \multicolumn{2}{|l|}{ LDPE } & 920 & 400 & 659 & 0.61 & 0.45 \\
\hline \multicolumn{2}{|l|}{ UHMWPE } & 945 & 800 & 920 & 0.87 & 0.58 \\
\hline \multicolumn{2}{|l|}{ PTFE } & 2180 & 490 & 474 & 1.03 & 0.65 \\
\hline \multicolumn{2}{|l|}{ PA6.6 } & 1140 & 1800 & 1257 & 1.43 & 0.78 \\
\hline \multicolumn{2}{|l|}{ PPO } & 1080 & 2550 & 1537 & 1.66 & 0.84 \\
\hline \multicolumn{2}{|l|}{ PC } & 1200 & 2400 & 1414 & 1.70 & 0.85 \\
\hline \multicolumn{2}{|l|}{ PMMA } & 1185 & 3000 & 1591 & 1.89 & 0.90 \\
\hline \multicolumn{2}{|l|}{ PES } & 1370 & 2700 & 1404 & 1.92 & 0.91 \\
\hline \multicolumn{2}{|l|}{ POM-C } & 1410 & 3000 & 1459 & 2.06 & 0.94 \\
\hline \multicolumn{2}{|l|}{ POM-H } & 1430 & 3300 & 1519 & 2.17 & 0.96 \\
\hline \multicolumn{2}{|l|}{$\mathrm{PI}$} & 1430 & 3100 & 1472 & 2.11 & 0.95 \\
\hline \multicolumn{2}{|l|}{ PETP } & 1390 & 3400 & 1564 & 2.17 & 0.96 \\
\hline PEEK & & 1320 & 4200 & 1784 & 2.35 & 0.99 \\
\hline PPS & & 1430 & 4400 & 1754 & 2.51 & 1.02 \\
\hline ABS \& rubber composite & & 1020 & 1380 & 1163 & 1.19 & 0.70 \\
\hline Elastomers \& rubbers & & & & & & \\
\hline Natural rubber & NR & 920 & 25 & 165 & 0.15 & 0.14 \\
\hline Styrene-butadiene rubber & SBR & 910 & 300 & 574 & 0.52 & 0.40 \\
\hline Nitrile rubber & NBR & 1000 & & & & \\
\hline Neoprene (chloroprene) & & 1240 & 40 & 180 & 0.22 & 0.20 \\
\hline Polyurethane (low) & PUR & 1150 & 10 & 93 & 0.11 & 0.10 \\
\hline Polyurethane & PUR & 1150 & 75 & 255 & 0.29 & 0.25 \\
\hline Polyurethane (high) & PUR & 1150 & 300 & 511 & 0.59 & 0.44 \\
\hline Thermoplastic rubber & SBS & 950 & & & & \\
\hline Silicone rubber & & 1100 & & & & \\
\hline
\end{tabular}

The relative impact pressure $\left(p_{w h} / v_{d}\right)$ can be used to identify to what extent certain material classes reduce the water hammer pressure and corresponding maximum stress due to the Rayleigh wave, see Figure 2.11. A substantially lower impact pressure due to droplet impact is expected for low and very low stiffness materials such as certain thermoplastics, elastomers and rubbers. As can be observed, metals such as stainless steel result in a relative water hammer pressure, $p_{w h} / v_{d}=1.65$, and the elastomers natural rubber (NR) and soft and medium polyurethane (PUR) in a relative water hammer pressure, $p_{w h} / v_{d} \approx 0.15$. Consequently, for these elastomers the water hammer pressure and corresponding 
maximum stresses due to the Rayleigh wave are about $10 \%$ of the pressure and stress developed by stainless steel.

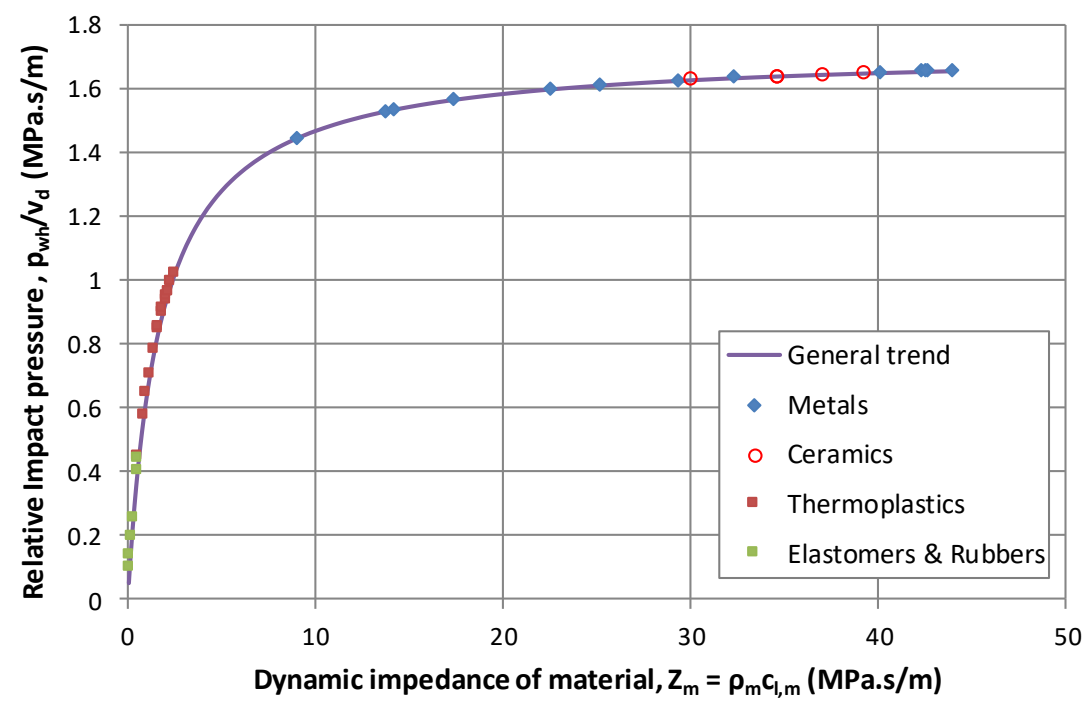

Figure 2.11. The relative impact pressure $\left(p_{w h} / v_{d}\right)$ for some classes of materials: metals, ceramics, thermoplastics and elastomers \& rubbers. Data taken from Table 2.3.

The application of surface layers or coatings introduces a specific situation, namely the possibility that some of the body waves that are generated by liquid impingement reflect from the coating-substrate interface. This can be solved by applying coatings of sufficient thickness. The threshold thickness of the specimen for which the results of wave reflections within the specimen become negligible are constructed by Springer [14]. Assuming two time characteristics, one related to the liquid $\left(t_{L}\right)$ and one related to the surface layer material $\left(t_{S}\right)$ :

$$
\begin{aligned}
& t_{L}=\frac{2 d_{d}}{c_{L}} \\
& t_{S}=\frac{h_{S}}{c_{S}}
\end{aligned}
$$

$d_{d}=$ droplet diameter

$h_{S}=$ thickness of the specimen

$c_{L}=$ speed of sound in the liquid 
$c_{S}=$ speed of sound in the solid

Negligible wave reflections in the specimen hence occur when $t_{S}>t_{L}$ resulting in:

$$
h_{S}>2 d_{d}\left(\frac{c_{S}}{c_{L}}\right)
$$

This $h_{S}$ is the threshold specimen thickness for which the results of bulk wave reflections within the specimen are negligible.

\subsubsection{Shift in Wöhler curve}

\subsubsection{The fatigue life of coatings based on polymeric materials}

The fatigue life of a surface will not equal the bulk fatigue life of the same material, yet it is most likely gives a first approximation. Equation (2.5), to describe the fatigue life curve, is also frequently used for polymers [66]. As an example, Figure 2.12 [68] shows the fatigue $\mathrm{S}-\mathrm{N}$ curves of the polypropylene, talc-filled polypropylene and polypropylene nano-composite. In this figure, the vertical axis or the $\mathrm{S}$-axis represents the maximum cyclic stress and the horizontal axis or the $\mathrm{N}$ axis represents the number of cycles to failure. The corresponding constants given by Eq. (2.5) are summarised in Table 2.4, using for these polymers a fatigue limit $\left(S_{D}\right)$ at $10^{7}$ cycles to failure [76], [83]. From these results it is clear that fillers need to be selected carefully as they can both delay and/or promote the initiation of fatigue. 


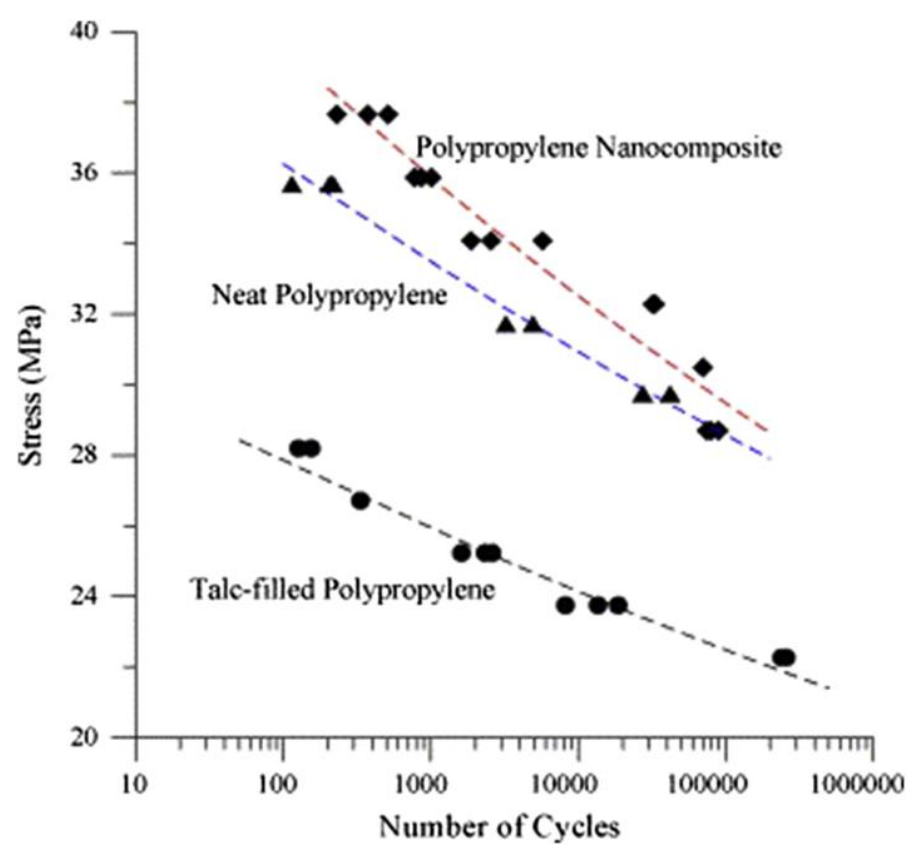

Figure 2.12. Fatigue curves $\left(S_{\max } v s N_{f}\right.$ ) of neat polypropylene (PP) and two PP composites: talc-filled polypropylene and polypropylene nano-composite. Tests at room temperature, stress ratio $R=0.1$, and a cyclic frequency of $1 \mathrm{~Hz}$. Adapted from Ref. [68].

Table 2.4. Fit constants for the lifetime equation and estimated fatigue limit of fatigue test results in Figure 2.12. Adapted from Ref. [68].

\begin{tabular}{|lccc|}
\hline Polypropylene type & $\begin{array}{c}\mathrm{S}_{\mathrm{f}} \\
(\mathrm{MPa})\end{array}$ & $\begin{array}{c}\mathrm{m} \\
(-)\end{array}$ & $\begin{array}{c}\mathrm{S}_{\mathrm{D}}\left(10^{7}\right) \\
(\mathrm{MPa})\end{array}$ \\
\hline Neat polypropylene & 42.5 & 29.9 & 24.8 \\
40 wt.\% talc-filled polypropylene & 31.5 & 33.8 & 19.6 \\
Polypropylene nano-composite & 48.1 & 23.5 & 24.2 \\
\hline
\end{tabular}

The stage of steady state erosion is also influenced by fillers and fibre reinforcements. Yet, the response of polymeric materials is found to be different for relatively ductile thermoplastics such as PP, PE, PA, PPO and relatively brittle thermosets such as UP (unsaturated polyester) and EP (epoxy). The addition of fillers and fibres to thermoplastics is often detrimental because they result in local stress risers and decrease fatigue life, also the relatively brittle fibres tend to break out at repeated impingement, enhancing mass loss in the steady state erosion regime. The relatively brittle thermosetting polymers benefit from reinforcement 
because the fibres reduce massive brittle fracture and chunking of the brittle resin [69].

\subsubsection{Experimental results with coatings}

The liquid impact erosion of elastomeric coatings has been studied extensively [25], [70], [71], [72] especially directed towards the development of polyurethane and fluorocarbon coatings for protection of aircraft radomes and composite surfaces. The first polyurethane coatings have been developed and compared with the performance of neoprene coatings [25]. Fluorocarbon coatings to resist impingement wear have been developed for higher temperature applications [71]. These developments have been empirically validated by large test schemes using the whirling arm rain erosion simulation apparatus tests [72]. Neoprene coatings erode under liquid impact by a gradual roughening of the surface and eventually adhesion loss. The polyurethane coating fails by isolated holes typically the size of fractions of a millimetre. The fluorocarbon coatings erode by a chunking of pieces from its surface and gradual wearing away until the substrate is exposed. Other brittle polymeric coatings such as epoxies, silicones, polyesters, acrylics and nonelastomeric polyurethanes fail by brittle rupture and/or spall of the coating very rapidly upon impact [72]. Whirling arm rain erosion tests with polyurethane (PUR) coatings and colour fillers, at a glass fibre reinforced epoxy substrate as presented in Ref. [26], can be arranged as in Figure 2.13. This figure shows the liquid drop impact lifetime ( $\mathrm{N}$, number of drop impacts) as a function of rotational speed ( $\approx$ drop impact velocity) for three PUR coatings. The lifetime of unprotected glass fibre reinforced epoxy laminate is also shown. These results confirm that optimisation needs to be conducted carefully, balancing positive and negative effects of fillers on coating life. 


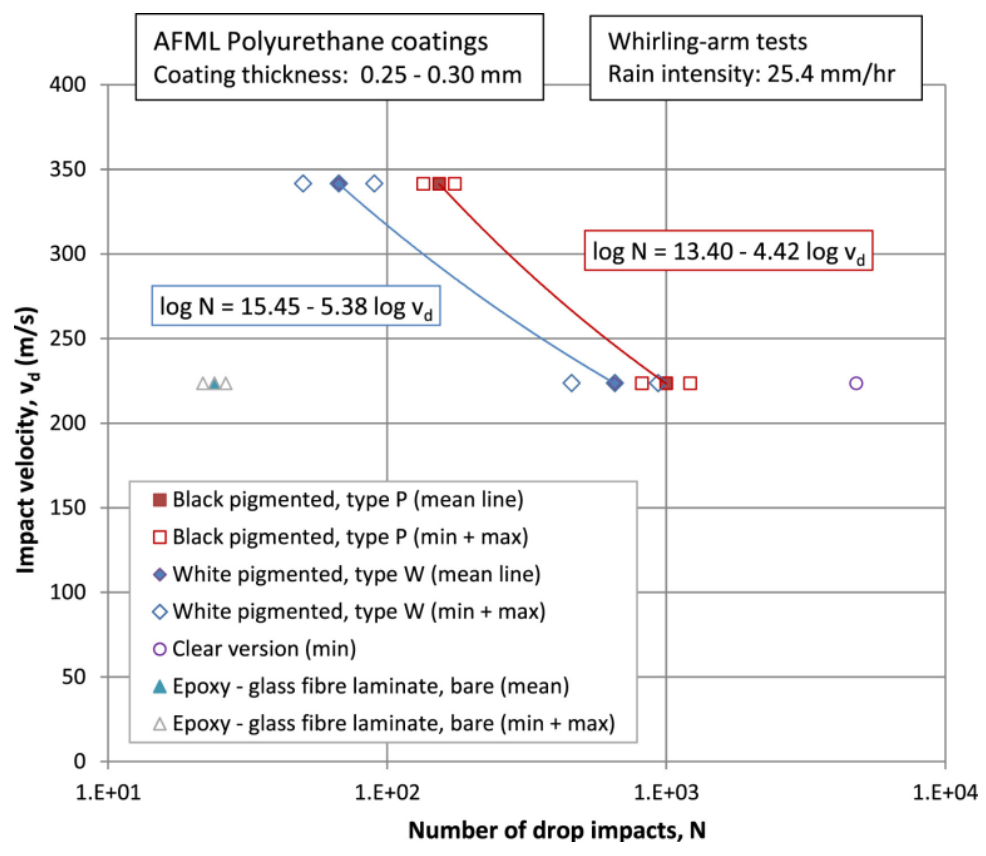

Figure 2.13. Liquid drop impact lifetime ( $N$, number of drop impacts) as a function of rotational speed ( $\approx$ drop impact velocity) for PUR coatings with three types of colour fillers and a thickness of $0.25-0.30 \mathrm{~mm}$. Incubation time equation: $\log N=-n \log v_{d}+\log C$. Adapted from Ref. [26].

\subsection{Conclusions}

From the reviewed work it is concluded that:

1. Transient surface stresses due to the impact of one water droplet can be described analytically. Longitudinal and transverse body waves immediately start propagating due to the impact and it follows from the free surface boundary that that a Rayleigh wave is generated as well. The disturbance in the far field is dominated by the Rayleigh waves.

2. The positions of the wave fronts and the resulting stress variations indicate primarily compressive surface stresses, with a narrow band of high tensile stresses, immediately behind the Rayleigh wave front. The radial dimensions in which this occurs is quite small, and together with the high wave velocity this gives rise to short stress peaks of typically tenths of microseconds.

- $\quad$ For brittle materials, this band of tensile stresses initiate failure due to the impact of a few droplets, assuming relatively high impact velocity. 
- For thick compliant coatings, however, single water droplet cannot initiate failure, either by increasing the water droplet diameter or by changing of the impact angle. The calculated tensile strains now reach values within the maximum strain to failure at dynamic loading conditions. Repeated large strains may lead to failure.

- Surface fatigue, as nucleating wear mechanism for erosion damage, can explain failure for brittle and for ductile materials as well. The relation between fatigue properties of materials and material damage in a droplet erosion test set-up is demonstrated in literature, e.g. by G.S. Springer [14].

3. Brittle fractures and local fractures in brittle phases result in a relatively low erosion incubation period in comparison with surface fatigue as dominant wear mechanism.

4. Surface fatigue can be considered as the wear mechanism provided that the fracture toughness of all microstructural phases is above a certain threshold value which, however, depends on the drop impact velocity and the drop size.

General countermeasures to surface fatigue are expected to minimise the risk of damage due to droplet impingement.

1. This might be realised by:

- Reduction of the water pressure, e.g. by applying surfaces with a low modulus of elasticity

- Enlarging the safe area by:

a) applying surfaces with adjustable compressive stresses

b) applying surfaces with adjustable hardness

c) preventing defects and impurities at and near the surface.

2. Fillers such as clay, carbon, glass fibres can both be beneficial by creating compressive stresses or high hardness but also detrimental as they can initiate failure at the interface of the filler and the matrix material.

3. The relative impact pressure $\left(p_{w h} / v_{d}\right)$ can be used to identify to which extent certain material classes reduce the water hammer pressure and corresponding maximum stress due to the Rayleigh wave. 


\section{Chapter 3}

\section{RESULTS}

\subsection{Model for the incubation period}

The model for the incubation period that resulted from the research is described in detail in Papers A, B and C included in this thesis. This fatigue based model has been applied to a range of thermoplastic polymers and especially two PBT types with different production routes, for details see Paper B. Furthermore, the model is able to include the so called "shot peening effect" in the fatigue behaviour of metals.

In the developed predictive model, surface fatigue is considered the controlling wear mechanism provided that the fracture toughness $\left(K_{c}\right)$ of all microstructural phases are above a certain threshold value. This, however, depends on the drop impact velocity and the drop size.

The model will be summarised in the next sections showing the role of transient stresses that result from the Rayleigh wave and showing the interrelation of the physical and mechanical properties of thermoplastic, elastomeric and metallic surfaces with the droplet impingement erosion incubation period.

\subsubsection{Rayleigh surface wave}

Drop impact on a material's surface results in three types of stress waves: the longitudinal or compression wave, the transverse or shear wave and the Rayleigh surface wave (see Figure 2.3). The latter gives rise to the highest cyclic stresses $(S)$ and is considered to cause surface fatigue. This fatigue results in the removal of particles detached by short fatigue crack growth. The maximum stress of this cycle due to the Rayleigh surface wave is given by:

$$
S_{\max }=\frac{A}{r^{0.5}}
$$

in which $A$ depends on the water hammer pressure $\left(p_{w h}\right)$ according to Eq. (2.1a), and $r$ is the radial coordinate.

By assuming that the stress cycle starts at $r=r_{0}$ (radius at which the Rayleigh surface wave starts, see also Eq. 4 in Paper C) and is attenuated, at $r=r_{1}$ at a maximum stress level $S_{\max }=S_{\max , 1}$, which is made equal to the fatigue limit after which no further fatigue damage occurs, the stress cycle at each location due to the Rayleigh wave is known. The value $A$ in Eq. (3.1) is determined for $d_{d}=1.8 \mathrm{~mm}$, and reads: 


$$
A=0.60 p_{w h} \quad\left(d_{d}=1.8 \mathrm{~mm}\right)
$$

and the stress ratio of the stress cycle due to the Rayleigh wave reads $R=-0.5$ (see Papers A and B).

\subsubsection{Fatigue life model that includes strain hardening and shot peening}

Applying a general expression for fatigue life for a stress level $i$ to the case of drop impact results in an equation as given in Eq. (2.6), in which $h_{\text {tot }}$ makes a correction for the differences between the fatigue test conditions and the actual conditions. The constants $m$ and $S_{f}$ are the commonly used material parameters in fatigue tests. The fatigue limit $S_{D, d}$ for the actual erosion conditions is defined by Eq. (2.7). In this approach, the number of fatigue cycles to failure in a fatigue test $\left(N_{f}\right)$ equals the number of fatigue cycles of the incubation period $\left(N_{i}\right)$.

For materials - and especially metals - showing strain hardening, the effects of additional surface hardening and the related residual compressive stress state at the surface due to the "water drop peening effect" has been included, as it will affect the fatigue life. The well-known Morrow's equation with mean stress correction can be used for this purpose. In the present case the modified version as derived by Landgraf et al. [84] is used:

$$
\frac{S_{a}}{\left(\frac{H}{H_{0}} S_{f, 0}-S_{m}-\sigma_{R}\right)}=\left(2 N_{f}\right)^{-(1 / m)}
$$

where:

$S_{a}=$ stress amplitude

$S_{m}=$ mean stress

$H / H_{0}=$ ratio of increased surface hardness to initial surface hardness

$\sigma_{R}=$ residual stress at the metal surface

$N_{f}=$ fatigue life (number of cycles to failure)

$S_{f, 0}=$ fatigue strength coefficient of metal with initial hardness $H_{0}$, mean stress

$S_{m}=0$ (or $R=-1$ ), and residual stress $\sigma_{R}=0$

$R=$ stress ratio, ratio of minimum stress and maximum stress.

The fatigue strength coefficient $\left(S_{f}\right)$ in Eq. (2.6) needs to be determined for a stress ratio of $R=-0.5$, given by the Rayleigh wave amplitudes (see Paper A). Using Eq. (3.3) and assuming that the fatigue curves are available for a stress ratio $R=-1$ (the 
definition used for $\left.S_{f, 0}\right)$, the following expression for fatigue strength coefficient $S_{f}$ in Eq. (2.6) was derived:

$$
S_{f}=\left(1+\frac{1+R}{1-R}\right)\left(\frac{H}{H_{0}} \cdot \frac{S_{f, 0}}{2^{-\left(\frac{1}{m}\right)}}-\sigma_{R}\right) 2^{-\left(\frac{1}{m}\right)}
$$

This equation now includes the possibly beneficial effect of surface hardening and residual stress. It is assumed in this work that this beneficial effect occurs relative to the water hammer pressure $\left(p_{w h}\right)$ according to Eq. (2.1a) and the maximum loaded surface area with a contact radius $\left(r_{w h}\right)$, see also Eq. 5 in Paper C. By using a threshold water hammer pressure $\left(p_{w h, t h}\right)$ above which surface hardness and residual compressive stresses increase, it was possible to construct the following model.

- if $p_{w h}>p_{w h, t h}$ :

$\frac{H}{H_{0}}=1+a\left(p_{w h}-p_{w h, t h}\right)$

$\sigma_{R}=b\left(p_{w h}-p_{w h, t h}\right)$

- if $p_{w h} \leq p_{w h, t h}$ :

$\frac{H}{H_{0}}=1.0$

$\sigma_{R}=0$

$p_{w h, t h}=$ threshold water hammer pressure, $a, b=$ material dependent constants; see Table 3.1.

Supported by publications for shot peening, cavitation peening, and water drop peening the constants $\left(a, b, p_{w h, t h}\right)$ in Eq. (3.5a) to (3.5d) were defined for the increase in surface hardness and residual compressive stress as a function of the water hammer pressure $\left(p_{w h}\right)$, see Paper $\mathrm{C}$. These estimated trends are shown in Figure 3.1. The numerical values are given in Table 3.1. 
The threshold water hammer pressures $\left(p_{w h, t h}\right)$ in Table 3.1, using Eq. (2.1a) and (2.1b) for the water hammer pressure $\left(p_{w h}\right)$, give threshold impact velocities of $v_{d}$ $=112 \mathrm{~m} / \mathrm{s}$ and $92 \mathrm{~m} / \mathrm{s}$ for stainless steel AISI 316 and AI-6061-T6 respectively.

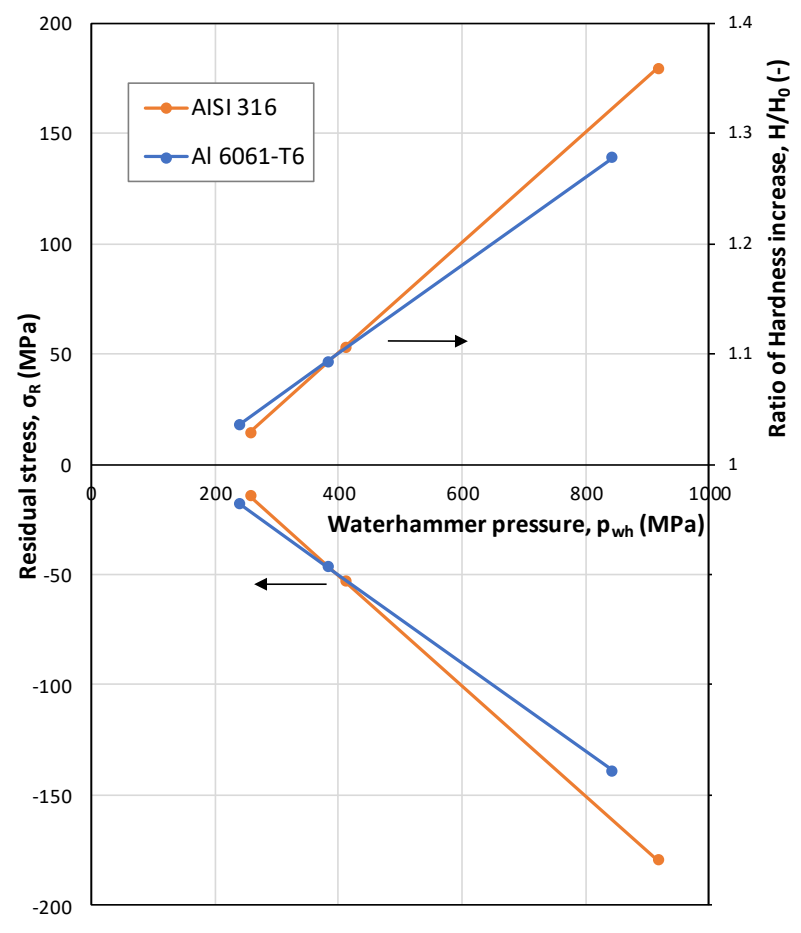

Figure 3.1. Ratio of increased surface hardness to initial surface hardness and residual compressive stress due to waterdrop peening for stainless steel AISI 316 and aluminium 6061-T6 (estimated trends).

Table 3.1. Constants for the surface hardness ratios and residual stresses in Eq. (3.5a to d).

\begin{tabular}{|c|cc|}
\hline & $\begin{array}{c}\text { Stainless steel } \\
\text { AISI 316 }\end{array}$ & $\begin{array}{c}\text { Aluminium } \\
6061-\mathrm{T} 6\end{array}$ \\
\hline$a(1 / \mathrm{MPa})$ & 0.0005 & 0.0003 \\
$b(1 / \mathrm{MPa})$ & -0.25 & -0.15 \\
$p_{w h, t h}(\mathrm{MPa})$ & 200 & 150 \\
\hline
\end{tabular}

\subsubsection{Droplet erosion incubation period}

In this work, a random uniform distribution of droplet impact at the specimen surface is assumed. As such, for a point located at the origin, only drop impacts 
within the area with a certain radius will result in a stress cycle that generates damage associated with surface fatigue.

The total number of drop impacts on the area per hour is related to the spatial distribution of drops, characterised by the volume concentration of water $\left(C_{v}\right)$ and the specimen velocity in this spatial distribution of drops $\left(v_{d}\right)$. The drop impact density or rate of impact is now given by $C_{v} v_{d}\left(\mathrm{~m} / \mathrm{s}\right.$ or $\mathrm{m}^{3}$ water drops $/ \mathrm{s} . \mathrm{m}^{2}$ specimen area). Thus, the total amount of drops during the incubation period $\left(I_{p}\right)$, as given by the surface coverage, is $3600 C_{v} v_{d} I_{p} \mathrm{~m}^{3}$ water $\mathrm{drops} / \mathrm{m}^{2}$ specimen area. In this derivation the volume concentration of water $\left(C_{v}\right)$ is defined as: $C_{v}=I_{r} / v_{g}$, in which $I_{r}$ is the rain intensity and $v_{g}$ the gravitational drop velocity, which is a function of drop size [24]. For typical rain conditions, rain intensity $I_{r}=25.4 \mathrm{~mm} / \mathrm{h}$, drop size $d_{d}=1.8 \mathrm{~mm}$, and gravitational drop velocity $v_{g}=6.2 \mathrm{~m} / \mathrm{s}$ [24], the volume concentration of water in air $C_{v}=1.1 \times 10^{-6}$.

The Palmgren-Miner rule in Eq. (2.4) can be used to account for the cumulative fatigue damage at different stress levels. The droplet erosion incubation period is now defined as:

$$
I_{p}=\frac{D_{f}}{D_{h}}
$$

$I_{p}=$ Droplet erosion incubation period $(\mathrm{h})$,

$D_{f}=$ Cumulative fatigue damage at failure,

$D_{h}=$ Cumulative fatigue damage per hour $(1 / \mathrm{h})$.

According to the general Palmgren-Miner approach, $D_{f}=1$. Using this approach, a fatigue-based model for the droplet impingement erosion incubation period of metallic surfaces can be formulated. An expression for the incubation period can be derived (see also Papers B and C):

$$
\begin{aligned}
& I_{p}=\frac{d_{d}^{3}}{24 \Phi_{v}} \frac{(m-4)\left(h_{t o t} S_{f}\right)^{m}}{A^{4}} \frac{1}{\left[S_{\max (r 0)}{ }^{(m-4)}-\left(h_{t o t} S_{D}\right)^{(m-4)}\right]} \\
& \Phi_{v}=3.6 \times 10^{6} C_{v} v_{d}
\end{aligned}
$$

where

$\Phi_{v}=$ volume of impacting water drops per unit area $(\mathrm{mm} / \mathrm{h})$, with $S_{\max (r 0)}$ according to Eq. (3.1) and using $r_{0}$ according to Eq. 4 in Paper C. 
Furthermore $S_{\max (r 0)}>h_{t o t} S_{D}$ and for the complementary condition $S_{\max (r 0)} \leq$ $h_{\text {tot }} S_{D}$, resulting in $I_{p} \rightarrow \infty$. Thus the condition $S_{\max (r 0)}=h_{t o t} S_{D}$ gives the threshold drop impact velocity for fatigue $\left(v_{d, t h}\right)$. For drop impact conditions $\left(v_{d}, d_{d}\right)$ resulting in $S_{\max (r 0)} \leq h_{t o t} S_{D}$, the fatigue damage will not accumulate and turn into fatigue failure, so the life of the material surface will be infinite.

A flow diagram of the model is given in Figure 3.2.

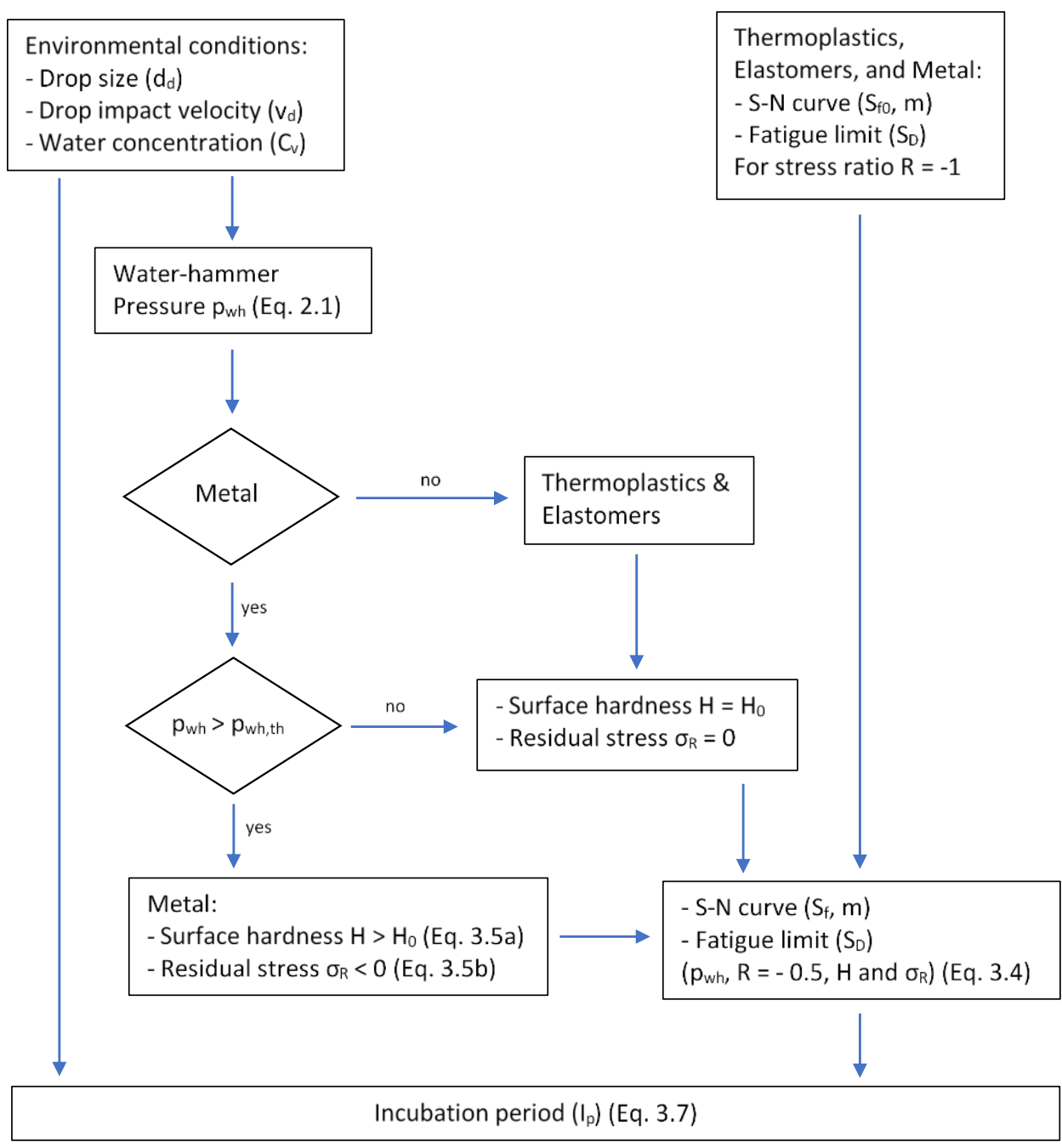

Figure 3.2. Flow diagram to estimate the impingement erosion incubation period for thermoplastics, elastomers and metals, based on the S-N curve measured under standard fatigue test conditions. 


\subsection{Validation of the model}

\subsubsection{Predicted incubation period}

The predictive model was first applied to the thermoplastic material PBT and compared with drop impact erosion results of injection moulded and compression moulded PBT. For that purpose, droplet impingement measurements were conducted based on a set-up that has been derived from Duraiselvam et al. [86] and Oka et al. [87]. It is based on a nozzle system spraying water drops on a stationary specimen surface. Figure 3.3 shows schematically the droplet impingement test set-up. Figure $3.4 \mathrm{a} / \mathrm{b}$ show details of the nozzle system and specimen location in the test set-up.

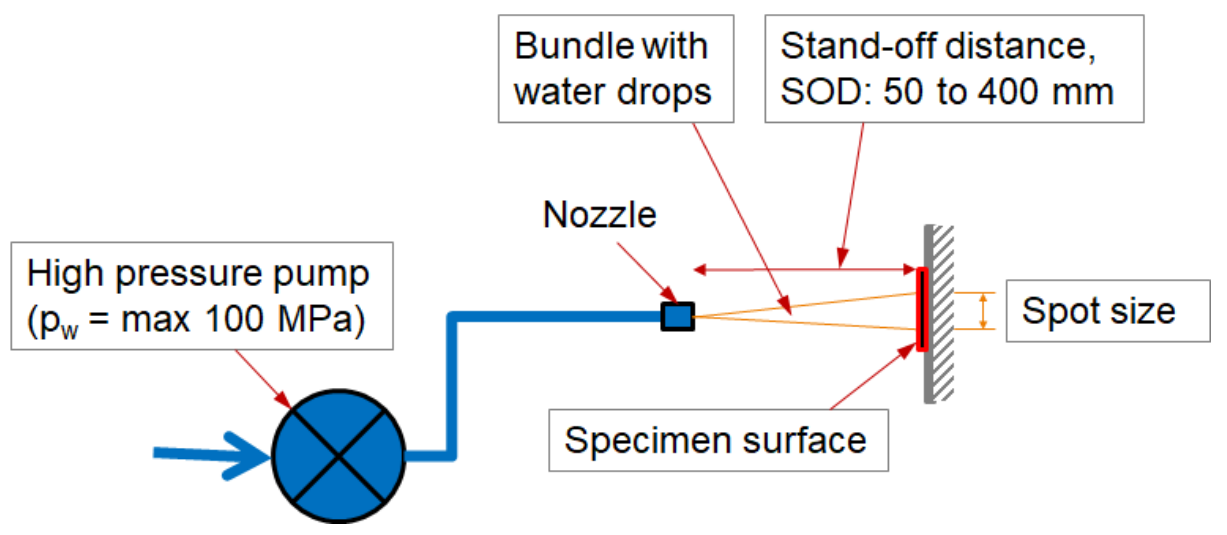

Figure 3.3. Schematic overview of the TNO droplet impingement test set-up.

The water jet is delivered through a nozzle. The high pressure pump generates water pressures that can be operated between 5 and $100 \mathrm{MPa}$ to feed the nozzle system. The round jet nozzle, with an exit orifice diameter $d_{n}$ of $0.45 \mathrm{~mm}$, creates a round spray pattern of small droplets and is able to maintain a high droplet velocity over a certain distance. The water nozzle exit velocity is estimated based on Eq. (3.9) [88]:

$$
V_{e}=C_{N} \sqrt{\frac{2 p_{w}}{\rho_{w}}}
$$

in which $V_{e}$ is the water velocity at nozzle exit, $C_{N}$ the nozzle discharge coefficient $\left(C_{N}=0.963\right.$ for a round jet nozzle [88]), $p_{w}$ the water pressure and $\rho_{w}$ the water density. The water droplet impact velocity $\left(v_{d}\right)$ on the specimen surface is assumed 
to be equal in this work to the water nozzle exit velocity $\left(V_{e}\right)$. The latter because momentum estimates based on force measurements in the support of the specimen holder, see Figure 3.4a, showed only a small deviation from the result of Eq. (3.9).
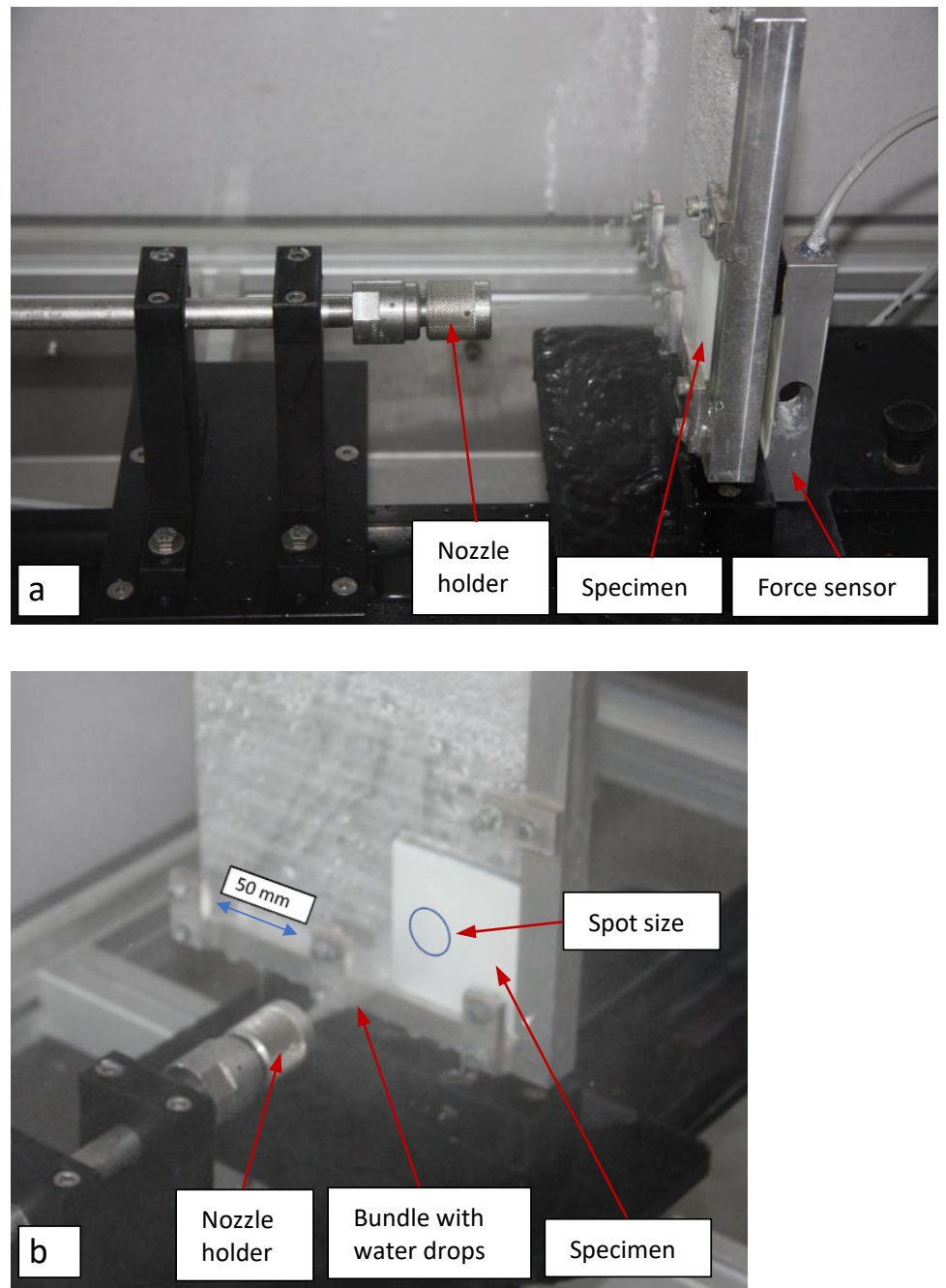

Figure 3.4a/b. Images of the droplet impingement chamber interior of the TNO test set-up.

For the current work an operating pressure $p_{w}=8 \mathrm{MPa}$ was selected, which resulted in an estimated mean droplet velocity of $120 \mathrm{~m} / \mathrm{s}$, equivalent to a typical wind turbine blade tip velocity. Furthermore, the selected angle of impact was $90^{\circ}$ 
and the nozzle-to-specimen distance $150 \mathrm{~mm}$. The spot size on the specimen surface with a high density of drops has an estimated diameter $d_{s} \approx 25 \mathrm{~mm}$, see also Figure 3.4b. The PBT specimen thickness was $3.7 \mathrm{~mm}$.

The test was conducted until surface damage or a substantial increase in surface roughness in the spot size was observed. The maximum test duration was set at 480 minutes. The spraying was stopped and the spot size visually inspected after every 10 minutes of spraying during the first 30 minutes of testing, and then every 30 minutes. The mean of the exposure times - "no surface damage observed" and "first surface damage observed" - was taken as the incubation period $\left(I_{p}\right)$ of the test.

Details of the measurements and the precise description of the version of the model that was used for the prediction of the droplet impingement incubation period can be found in Paper B. The results are summarised in Figure 3.5.

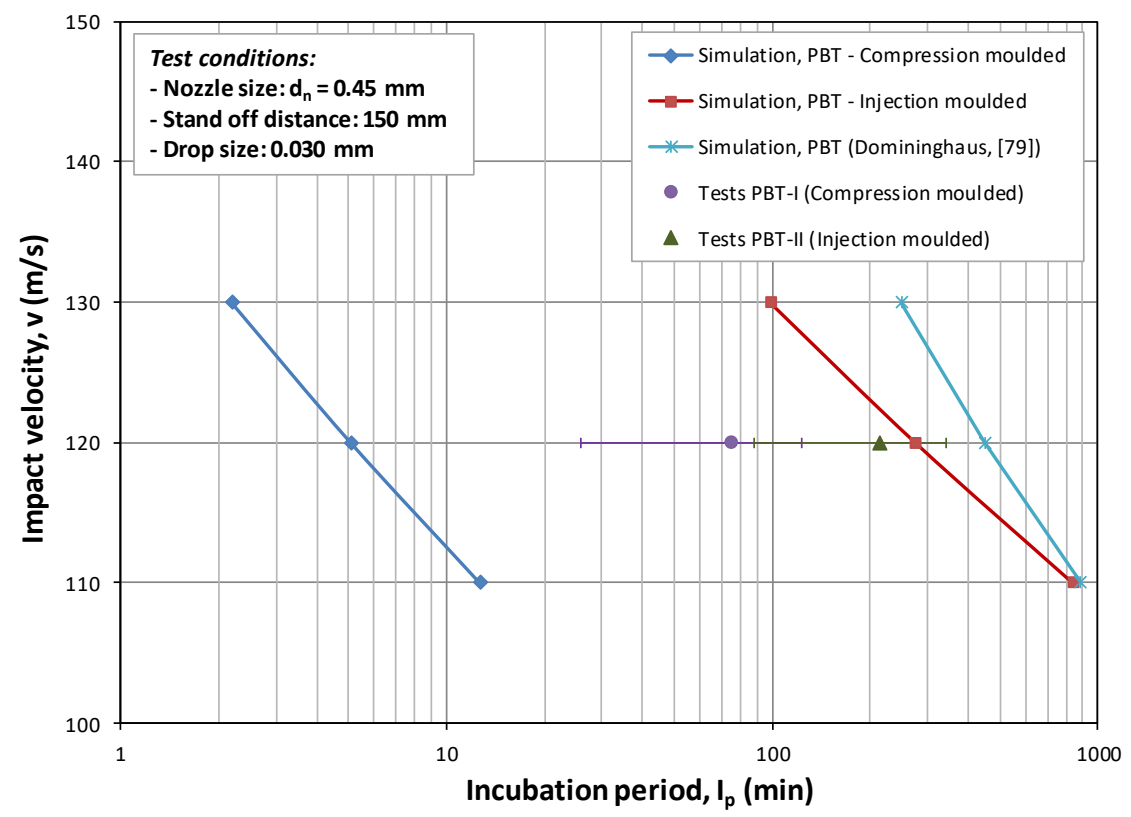

Figure 3.5. Predicted incubation periods as a function of droplet impact velocity for a droplet size of $0.030 \mathrm{~mm}$ * (test conditions) The mean incubation life from the tests of both PBT types and the $95 \%$ confidence ranges of the mean $(m \pm 1.98 \mathrm{~s} / \mathrm{Vn})$ are shown. Predictions for a PBT grade from [83] are shown for comparison. *value from [89].

Although a good similarity between test results and model calculations for the injection moulded PBT (PBT-II) was found (deviation of $29 \%$ ), the absolute value of 
the incubation period predicted by the model calculations for compression moulded PBT (PBT-I), see Figure 3.5, differed by a factor of 15. This deviation probably resulted from the lower confidence level of the $\mathrm{S}-\mathrm{N}$ curve (only three valid test results at a high number of cycles) for compression moulded PBT (PBT-I) than for the injection moulded PBT (PBT-II).

To accurately validate the model a set of droplet erosion test results and dedicated fatigue-life curves of the same produced material charges is desired. Within the framework of this research a reliable set of droplet erosion test results for metals was found and adopted from literature. During the 1970s, under supervision of the American Society for Testing Materials (ASTM), an interlaboratory test program using liquid impact erosion test facilities was organised. In six different laboratories in four different countries tests were performed with rotating disc or whirling arm test facilities using water drops [85]. The metals supplied to the laboratories were: aluminium $1100-0$ and 6061-T6, nickel 270, stainless steel AISI 316, and a Co-Cr alloy "Stellite 6B". The chemical compositions, treatments, supplied form, and mechanical properties of these metals were reported. Based on these properties fatigue-life curves for stainless steel AISI 316, and aluminium 6061-T6 were gathered from at least five different literature sources for each metal.

Applying the flow diagram presented in Figure 3.2 resulted in the predicted incubation period curves for the literature sources, see Table B-1 in Paper C; for stainless steel AISI 316 shown in Figure 3.6 and for aluminium 6061-T6 see Figure 4 in Paper C.

The mean predicted values are depicted by a blue line in these figures. These predicted results are shown in comparison with the incubation periods and confidence limits according to the multi-regression equation [85] (see Eq. A-1 in Paper C) as depicted by the red lines.

The figures show that these predicted incubation periods are nearly all within the 2.5 and $97.5 \%$ confidence limits of the multi-regression equation for the given metal. 


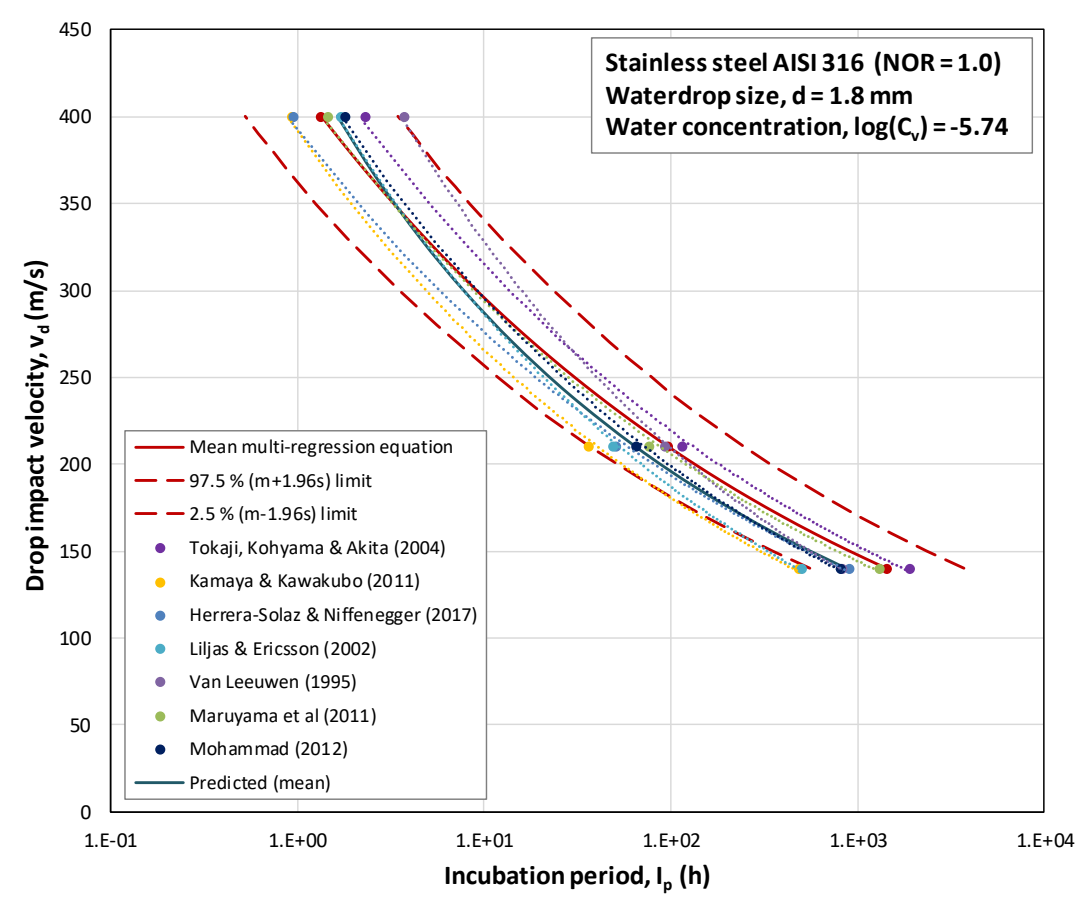

Figure 3.6. The predicted incubation periods for AISI 316 using literature data (see Table B1 in Paper C), and summarised by a mean line (blue line), compared with the incubation periods and confidence limits for AISI $316(N O R=1.0)$ using the multi regression (see Eq. A1 in Paper C) (red line).

The presented model predictions for stainless steel AISI 316 and aluminium 6061T6, using S-N fatigue curves from different literature sources, and including the defined additional surface hardening and a residual compressive stress state at the surface due to the water drop peening effect, showed for the droplet impact velocity range of 140 to $400 \mathrm{~m} / \mathrm{s}$ excellent agreement with the multi-regression equation as determined from an ASTM interlaboratory test program. Nearly all incubation period predictions were within the $95 \%$ confidence limits of the aforementioned multi-regression equation.

Thus, using these metals for which incubation periods and static mechanical properties were given in ASTM interlaboratory test program, and using different literature sources for the fatigue properties, an accurate model validation has been performed. 


\subsubsection{Model prediction of the incubation resistance number ${ }^{1}$}

The same interlaboratory liquid impact erosion test program introduced in Section 3.2.1 and Paper $C$, uses a valuable tool for assessing the liquid impact erosion response of surfaces: "Incubation resistance number" $(N O R)$. The NOR is defined and determined for each metal that is used in this interlaboratory ASTM program, in this program NOR was assumed to be independent of drop impact velocity [85]. Using the developed predictive model, the dependence of the NOR of a material on its physical properties and fatigue properties can be quantified. The NOR of a material is given as the resistance value relative to stainless steel AISI 316 , thus for a certain metal NOR is defined as [85]:

$$
N O R=\frac{I_{p, m}}{I_{p, \text { Ref }}}
$$

Index $R e f$ refers to stainless steel AISI 316, and index $m$ to the considered material.

The developed model for the incubation period can now be used to predict the NOR. Validation follows from comparing the NOR that is predicted by the developed model with the laboratory based experimental results of [85]. Substituting the equations for the incubation period (see Eq. 9, 10, and 13 in Paper C) and some rearranging gives:

$$
N O R=\frac{\left(m_{m}-4\right)\left(S_{f, m}\right)^{m_{m}}}{\left(m_{R e f}-4\right)\left(S_{f, R e f}\right)^{m_{R e f}}}\left(\frac{p_{w h, R e f}}{p_{w h, m}}\right)^{4} \frac{\left[S_{\max (r 0), R e f}\left(m_{R e f}-4\right)-S_{D, R e f}{ }^{\left(m_{R e f}-4\right)}\right]}{\left[S_{\max (r 0), m}{ }^{\left(m_{m}-4\right)}-S_{D, m}{ }^{\left(m_{m}-4\right)}\right]}
$$

In this equation $p_{w h}=$ the water hammer pressure according to Eq. (2.1), and $S_{\max (r 0)}=$ the maximum stress at $r_{0}$ (see Eq. 6, and 9 in Paper C). The water hammer pressure $\left(p_{w h}\right)$ and the maximum stress at $r_{0}\left(S_{\max (r 0)}\right)$ are both functions of the drop impact velocity $\left(v_{d}\right)$.

For aluminium 6061-T6, this equation predicts a $N O R=0.048,0.042$ and 0.031 for 140,210 and $400 \mathrm{~m} / \mathrm{s}$ respectively, as a function of drop impact velocity but independent of the drop size, as depicted in Figure 3.7. These values are based on the mean predicted incubation periods, using a log-normal distribution, as shown in Figures 6 and 7 in Paper C for AISI 316 and Al-6061-T6. The multi-regression

\footnotetext{
${ }^{1}$ Number of Eq. and figures mentioned in this Section 3.2.2 refer to Paper C in Part II of this thesis.
} 
analysis by Heymann in the interlaboratory program [85] gives for aluminium 6061T6 (see Table 1 in Paper C) a mean NOR $=0.037$ (standard deviation $\approx 0.25$ on logarithmic scale). As a result of the differences between the slope of the S-N curves for stainless steel AISI 316 and aluminium 6061-T6, the predicted NOR for aluminium 6061-T6 showed an impact velocity dependence.

The predicted incubation resistance numbers for aluminium 6061-T6 were in excellent agreement with the value determined in the multi-regression analysis based on the ASTM interlaboratory test program.

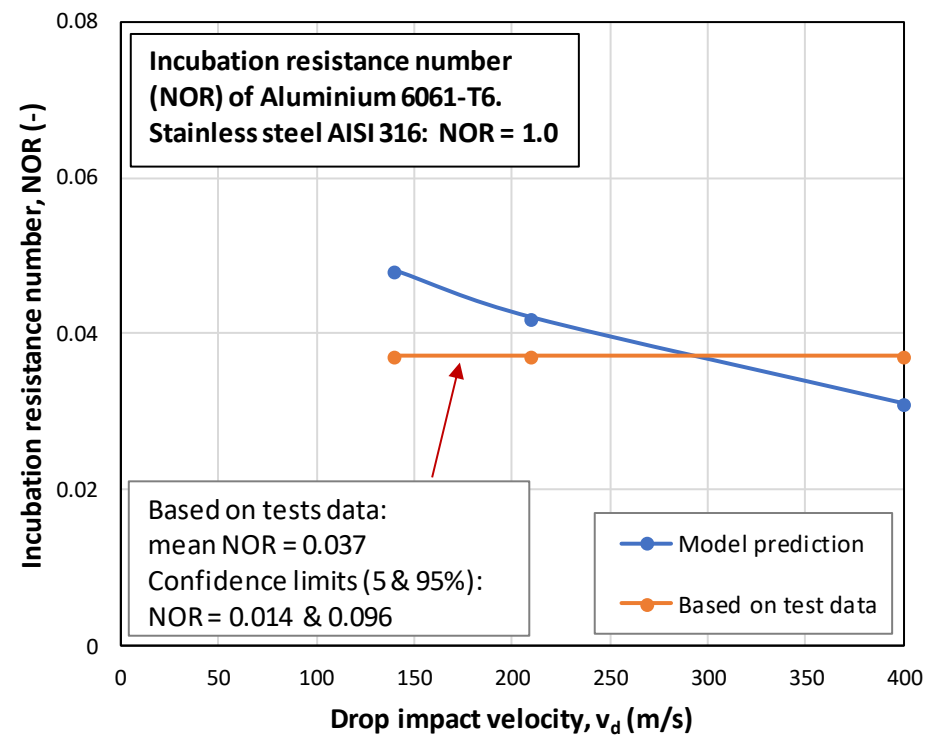

Figure 3.7. The predicted incubation resistance numbers (NOR) for aluminium 6061-T6, and the mean value with its confidence limits determined in the multi-regression analysis of the ASTM interlaboratory test program [85].

\subsection{Guidelines for optimised material properties}

As the presented model also gives the interrelation of the physical and mechanical properties, it becomes possible to define guidelines for a longer droplet impingement erosion incubation life based on optimised physical and mechanical properties. Selected properties of the materials used in the presented analytical model are summarised in Table 3.2. The required direction of the property ( $\uparrow$ : increase, and $\downarrow$ : decrease) for an optimal long droplet impingement erosion incubation life is indicated. From Table 3.2. it follows that a higher fatigue strength 
affects the incubation period positively. Using the corresponding equations shows that for instance an increase in the fatigue strength coefficient $\left(S_{f, 0}\right)$ of AISI 316 with $10 \%$, using $m=7.8$ (average value for AISI 316 in Paper $C$ ), results in an increase in the incubation period $\left(I_{p}\right)$ by a factor of 2.1.

Another clear example of the influence of the fatigue properties on the model predictions of the droplet impingement erosion incubation period, based on fatigue properties from literature [83], is shown in Figure 4 in Paper B. These results show clear distinctions between different types of thermoplastics. The longest incubation period is predicted for PBT and the second best is PA 6 .

The physical and mechanical properties of materials are interrelated, so it is important to perform the optimisation of the material properties, for the properties given in Table 3.2, in an iterative, step by step process. As the physical and mechanical properties of materials are interrelated, and the influence of all these material properties on the droplet impingement erosion incubation period is complex, an evaluation of each optimisation step using the developed predictive model is necessary to determine its net effect on incubation period.

Table 3.2. Material properties used in the presented analytical model, and required direction ( $\uparrow:$ increase, and $\downarrow$ : decrease) for enhanced droplet impingement erosion incubation life.

\begin{tabular}{|c|c|c|}
\hline Metal property & Defined in ${ }^{3)}$ & $\begin{array}{l}\text { For long droplet } \\
\text { impingement erosion } \\
\text { incubation life }\end{array}$ \\
\hline \multicolumn{3}{|l|}{ Physical properties: ${ }^{1)}$} \\
\hline Young's modulus $(E)$ & Eq. 1a, Eq. 4 & $\downarrow$ \\
\hline Density $\left(\rho_{m}\right)$ & Eq. 1a, Eq. 4 & $\downarrow$ \\
\hline Poisson constant $(v)$ & Eq. 1a, Eq. 4 & $\downarrow$ \\
\hline \multicolumn{3}{|l|}{ Fatigue properties: ${ }^{2)}$} \\
\hline Fatigue strength coefficient $\left(S_{f, 0}\right)$ & Eq. 8a, Eq. 10 & $\uparrow$ \\
\hline Reciprocal of fatigue exponent $(m)$ & Eq. $8 \mathrm{a}$ & $\uparrow$ \\
\hline \multicolumn{3}{|l|}{ Strain hardening \& Residual stress: } \\
\hline Strain hardening $(a)$ & Eq. 11a & $\uparrow$ \\
\hline Residual compressive stress $(b)$ & Eq. $11 b$ & $\downarrow$ \\
\hline Threshold water hammer pressures $\left(p_{w h, t h}\right)$ & Eq. $11 \mathrm{a}$ to $\mathrm{d}$ & $\downarrow$ \\
\hline
\end{tabular}




\subsection{Sensing damage of protective coatings}

The developed predictive analytical model for the droplet impingement erosion incubation period is used as evaluation algorithm in a monitoring system with sensors in the leading edge coating of wind turbine blades.

This invention comprised a fibre Bragg grating (FBG) monitoring system in a wind turbine blade with the sensors positioned between the outer surface of the composite structure and the protective coating to detect intensity and number of rain drop impacts combined with the predictive model ${ }^{2}$ for the incubation period evaluation.

With this invention, an FBG system was integrated in or below the leading edge protective coating of the wind turbine blade. This FBG system measures the stresses of the impact waves. Using FBG, quasi-distributed sensing with multiple sensors in a single optical fibre can be realised to reduce costs and improve system integration.

In this invention, the amplitude of the wave upon droplet impact can be related to the energy of such a droplet by using proper FBG interrogation technology. Hence, this invention makes it possible to track 1) the number, and 2) the energy of the impacts on the protective coating of a wind turbine blade.

Based on statistical considerations, only a few FBGs are required to monitor large structures such as a wind turbine blade, since the droplet distribution of a certain rain shower leads to an average impact distribution over the blade surface and as a function of time. Combining these results with the predictive model ${ }^{2}$, which is part of this invention, the measured droplet impact data is used to 3) predict cumulative erosion behaviour of the protective coating with certain physical and mechanical properties.

A short patent proposal, "Sensing damage of protective coatings", from the inventors, Lun Kai Cheng, Jonathan van den Ham, Henk Slot \& Rob Jansen (TNO, Delft), is included in Part II of this thesis.

\subsection{Conclusions}

1. The test set-up based on a water jet / nozzle system can be used for ranking surfaces with respect to droplet impingement resistance. The mean incubation period determined by testing with this test set-up cannot be used directly for life predictions in real wind turbine blade situations.

\footnotetext{
${ }^{2}$ Slot et al., Leading edge erosion of coated wind turbine blades: Review of coating life models, Renewable Energy 80, 2015, 837-848 (Paper A in Part II of this thesis).
} 
2. The physical and metallurgical mechanisms resulting in the degradation process of the metal surface during the incubation period $\left(I_{p}\right)$ were identified, these consisted of 1) surface plastic deformation and formation of dents, 2) surface hardening and residual compressive stress as a result of these surface plastic deformations, 3) fatigue crack initiation, 4) fatigue crack growth.

3. The model predictions for stainless steel AISI 316 and aluminium 6061-T6, using $\mathrm{S}-\mathrm{N}$ fatigue curves from different literature sources and including the defined additional surface hardening and a residual compressive stress state at the surface due to the water drop peening effect, showed for the droplet impact velocity range of 140 to $400 \mathrm{~m} / \mathrm{s}$ excellent agreement with the multi-regression equation as determined from an ASTM interlaboratory test program. Nearly all incubation period predictions were within the $95 \%$ confidence limits of the aforementioned multi-regression equation.

For the thermoplastic material PBT a good similarity between test results and model predictions for the injection moulded PBT was found (deviation of $29 \%$ ). However, the absolute value of the incubation period predicted by the model for the compression moulded PBT differed by a factor of 15 .

4. The predicted incubation resistance numbers $(N O R)$ for aluminium 6061-T6 were in excellent agreement with the value determined in the multi-regression analysis based on the ASTM interlaboratory test program. The predicted NOR values showed an impact velocity dependence.

5. The selected dynamic impedances and fatigue properties of the metals, thermoplastics and elastomers used in the presented analytical model were identified with respect to developing guidelines for enhanced droplet impingement erosion incubation life.

6. The developed predictive model for the droplet impingement erosion incubation period can be used as evaluation algorithm in a monitoring system with sensors in the surface of the drop impact loaded location. 


\section{Chapter 4}

\section{GENERAL DISCUSSION \& OUTLOOK}

\subsection{Droplet impingement erosion \& fatigue modelling aspects}

\subsubsection{Surface fatigue mechanism}

The presented predictive model for the incubation period of droplet impingement erosion depends greatly on the assumption that surface fatigue is the dominant wear mechanism. This assumption is consistent with the work by Springer [14] as discussed in Section 2 of this thesis, yet it is also confirmed by other recent work. In 2019, a droplet impingement erosion model specifically for polyurethane coatings was presented by Mishnaevsky \& Sütterlin [90]. The model is based on the weakest-link theory and a distribution of material strength due to a distribution of internal cracks, defects or voids, for the rain erosion life of polyurethane coatings. They observed that erosion of coatings in the field often occurred at manufacturing defects in the coating, see for example Figure 4.1. The model is based on the assumption that surface damage of the coatings is triggered by these local defects.

a) As manufactured
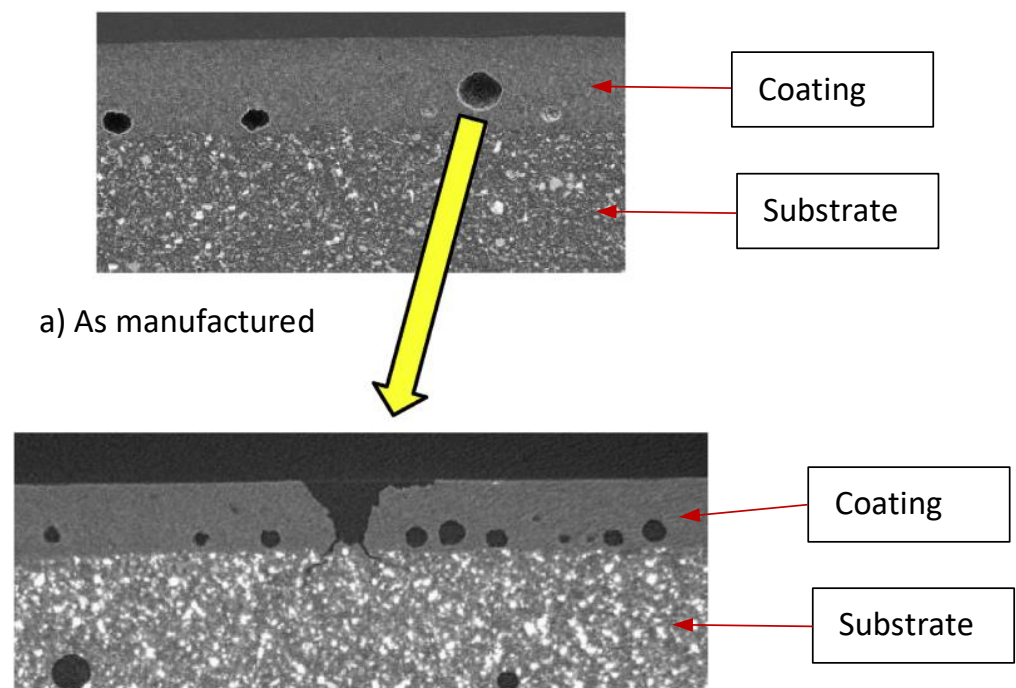

b) After use showing coating erosion

Figure 4.1. Micrographs of coatings showing bubble defects [90].

In 2020, Doagou-Rad \& Mishnaevsky, [92], [93] performed a computational analysis based on a transient fluid - solid coupled finite element analysis of rain droplet - 
coating interaction and coupled with a fatigue based surface degradation analysis. For this surface degradation of the coating under random water drop impacts, a multiaxial critical plane fatigue model was applied to predict fatigue crack initiation. Critical plane models are based on the approach that fatigue damage accumulates on a specific plane in the material, designated as the "critical plane". The damage parameter is a linear combination of shear stress and normal stress, acting on the critical plane. Clearly, such research underpins the selected strategy in this thesis as well as the fact that it is well known that surface fatigue can be initiated by local defects. Verma et al. [91] used a coupled fluid - structure interaction computational model to investigate rain drop impacts on wind turbine blades protected by a gelcoat. The analysis for a drop size of $2.7 \mathrm{~mm}$ and an impact velocity of $108 \mathrm{~m} / \mathrm{s}$ shows a local maximum surface stress of $150 \mathrm{MPa}$ present in a ring shaped zone at the outer boundary of the contact area with a plastic strain of $2.1 \%$. Repetitive rain droplet impacts on the same location were considered. The number of impacts required for onset of erosion damages $\left(N_{o}\right)$ was calculated assuming fatigue by ratcheting (accumulation of plastic deformation until the plastic failure strain has been reached). The onset of erosion $N_{o}$ was found to increase at impact velocities of 88 to $148 \mathrm{~m} / \mathrm{s}$, with an impact velocity exponent $n=3.7$ - value substantially lower than found in the ASTM interlaboratory test program by Heymann [9] with an exponent $(n)$ of 5.6. This difference might well be due to the adopted wear mechanism, fatigue by ratcheting [91] and high cycle surface fatigue, as explained in Chapter 2 of this thesis. Amirzadeh et al [95],[96] present a computational framework for rain erosion prediction of the gelcoat on a wind turbine blade. In this situation fatigue essentially starts from the surface. A multiaxial state of stress is identified, in which case direct application of the S-N curve is not possible. In this study, the absolute maximum principal stress was used to handle the multiaxial state of stress in the fatigue damage calculations.

\subsubsection{Viscoelastic properties}

In some recent publications [92], [93], [94], [97], [98], viscoelastic properties of coating materials such as polyurethane (PUR) have been incorporated in the predictive models. Doagou-Rad \& Mishnaevsky [92], [93] used viscoelastic properties of the studied polymeric coating, measured in dynamic mechanical (DMA) experiments in their transient fluid - solid coupled FE model. They also used a hyperelastic model, based on uniaxial tensile test results, in order to capture the variation of coating stiffness with strain, see Figures $4.2 \mathrm{a} / \mathrm{b}$. 

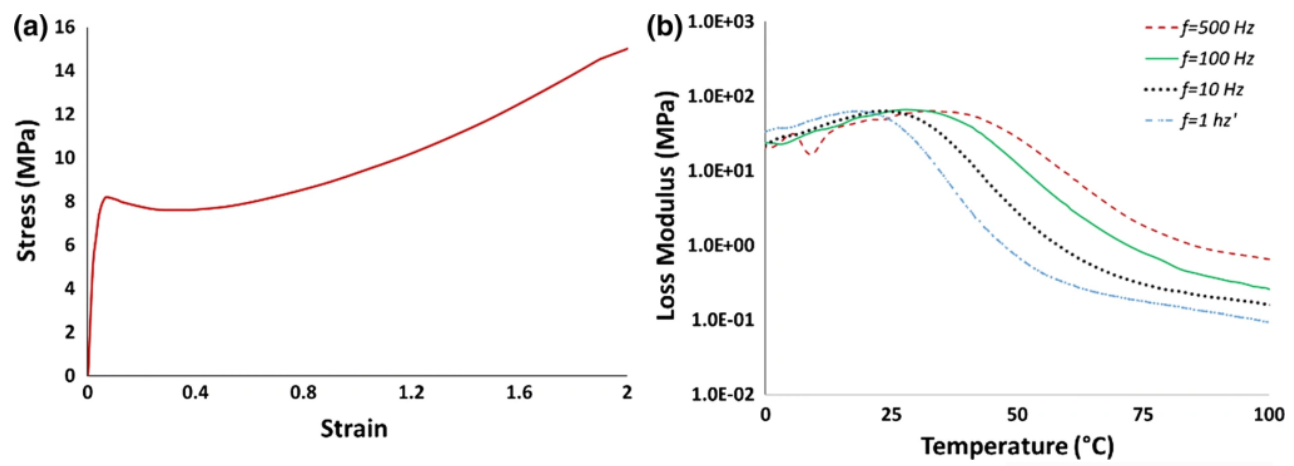

Figures 4.2a/b. Mechanical properties of a polymeric coating material: a) uniaxial stress strain curve, and b) shear loss moduli versus frequency curves, [92].

Ibrahim \& Medraj [98] pointed out the ability of polymeric materials, and especially elastomers, to recover after deformation. This is because materials that can quickly recover viscoelastically, usually exhibit high erosion resistance [86]. Consequently, the recommendation is that more research should be carried out to understand the effect of damping and a material's ability to recover on erosion incubation life. Mishnaevsky [97] mentions in his overview of methods for optimising anti-erosion protective coatings of wind turbine blades, enhancing the viscoelastic damping and wave attenuation properties for polymers, and especially elastomers, to increase erosion life significantly. Both longitudinal and shear wave absorption increase with frequency, and wave propagation in lossy materials decays with distance. The ratio of the loss modulus to the storage modulus $(\tan \delta)$ characterises the degree to which a viscoelastic material dissipates energy. PUR, most widely used for antierosion coating, consists of hard and soft segments. The content and properties of soft segments are assumed to influence the damping properties. Increasing the soft segment content from $27 \%$ to $48 \%$ results in an increase in tan $\delta$ from about 0.05 to 1.5 [99]. These studies indicate that viscoelastic damping and wave attenuation in polymers can reduce the transient mechanical stresses due to drop impact. Incorporating measured viscoelastic and hyper-elastic properties in the analytical and numerical (FEM) erosion models will probably enhance the accuracy of the prediction, especially for elastomeric coatings.

\subsubsection{Fatigue damage in contact area}

Some aspects of fatigue are not considered in detail in the current version of the model. The fatigue damage due to the compressive loading by the water hammer pressure in the contact area of the impinged water drop is ignored in the developed predictive model. This can be understood from the following analysis. First consider an extended Goodman diagram, including fatigue with a large part of the stress 
cycle in compression (negative mean stresses), for aluminium 2024-T4 as shown in Figure 4.3 [100], [101]. Extended Goodman diagrams are particularly scarce, therefore this one for aluminium 2024-T4 is used here. This extended Goodman diagram shows the stress amplitude $\left(\mathrm{S}_{\mathrm{a}}\right)$ as a function of mean stress $\left(\mathrm{S}_{\mathrm{m}}\right)$ for a constant life $\mathrm{N}$ (cycles). For $\mathrm{N}=10^{7}$ cycles, the fatigue limit $\left(\mathrm{S}_{\mathrm{D}}\right)$ (as maximum stress) can be derived from this figure as a function of mean stress $\left(\mathrm{S}_{\mathrm{m}}\right)$.

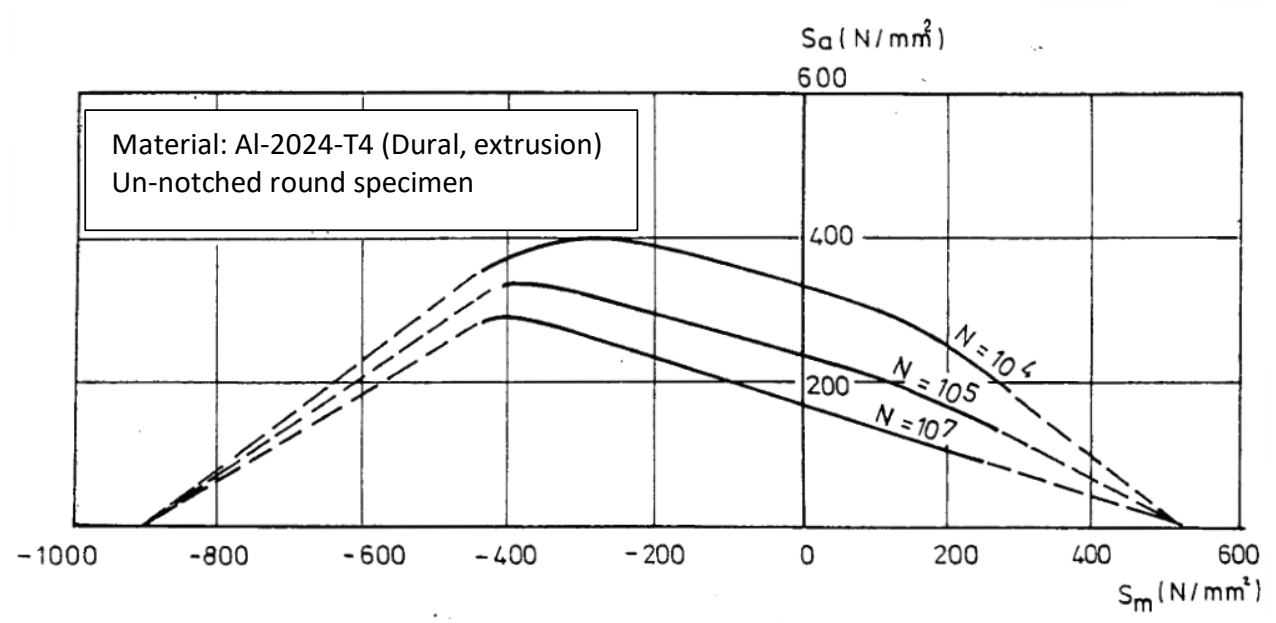

Figure 4.3. Extended Goodman diagram with negative mean stresses, for aluminium 2024T4 [100], [101].

For a stress ratio $R=-0.5$, as used in the predictive model for the stress cycle due to the Rayleigh wave, the fatigue limit (as maximum stress) $S_{D, R=-0.5}=S_{\max }=S_{m}+$ $S_{a}=153+51=204 \mathrm{MPa}$. For a stress ratio $\mathrm{R}=\infty$ (compression), as present in the contact area with the water hammer pressure, the fatigue limit (now as minimum stress), $S_{D, R=\infty}=S_{\min }=S_{m}+S_{a}=-251-251=-501 \mathrm{MPa}$. Thus, a ratio of absolute values of fatigue limits $\left|S_{D, R=\infty}\right| /\left|S_{D, R=-0.5}\right|=501 / 204=2.46$. This ratio clearly shows that the area outside the contact area, loaded mainly by tensile stresses due to the Rayleigh wave, is much more fatigue sensitive than the contact area itself, which is loaded by the compressive stresses directly resulting from the water hammer pressure.

Although a full S-N curve for this compressive fatigue loading is not available and an exact fatigue damage accumulation calculation cannot be performed, the above consideration shows that fatigue damage accumulation due to compressive loading by the water hammer pressure in the contact area is probably lower than the fatigue damage accumulation due to the Rayleigh wave outside the contact area. 
In addition to considering the fatigue limit, the sizes or ratio of the loaded areas by the water hammer pressure $\left(p_{w h}\right)$ and loaded by the Rayleigh wave is of interest. Figure 9 in Paper $\mathrm{A}$ in Part II of this thesis shows the maximum radius $\left(r_{0}\right)$ of the area loaded by the water hammer pressure and the radius $\left(r_{1}\right)$ of the area loaded by the expanded Rayleigh wave until the stress is equal to the fatigue limit $\left(\mathrm{S}_{\mathrm{D}, \mathrm{R}=-0.5}\right)$. Fatigue damage accumulates in both areas, However, the addition of damage due to the compressive stresses in the area loaded by the water hammer pressure is also very small as a result of the area ratio, as shown by the following example. For a water drop with a diameter of $1.8 \mathrm{~mm}$ impacting an AISI 316 stainless steel surface with a velocity of $140 \mathrm{~m} / \mathrm{s}$, the $r_{0}=0.045 \mathrm{~mm}$ and radius $r_{1}=$ $0.292 \mathrm{~mm}$, thus a ratio in exposed areas of $r_{0}^{2} / r_{1}^{2}=0.023$ (based on predictions shown in Paper C).

Both facts - the consideration of the fatigue limits and the consideration of the loaded areas - show that ignoring the fatigue damage as a result of the loaded area by the water hammer pressure $\left(p_{w h}\right)$ is justified for the current accuracy of the prediction. Future research could, however, benefit from including this effect.

\subsubsection{Similarity with cavitation erosion}

Other researchers [9], [10], [103], [105] suggested and observed during many years great similarities between surface damage due to droplet impact and impact by collapsing cavities in a fluid, indicating the importance of fatigue as damage mechanism. The latter is often designated as "cavitation erosion". Cavitation erosion is defined as "wear of a solid body moving relative to a liquid in a region of collapsing vapour bubbles which cause local high impact pressures or temperatures" [1]. When a liquid is subjected to sufficiently high tensile stresses, vapour-filled voids or cavities are formed at weak regions within the liquid and usually grow under tensile conditions. In practice, all liquids contain gaseous, liquid and solid impurities, which act as nucleation sites for the cavities. When the liquid that contains cavities is subsequently subjected to compressive stresses, in other words to higher hydrostatic pressures, these cavities will collapse. This collapse is directly responsible for the erosion process [102].

The mechanism by which cavitation causes erosion is described briefly below. When a cavity collapses within the body of the liquid, away from any solid boundary, it does so symmetrically and emits a shock wave into the surrounding liquid. On the other hand, those cavities that are either in contact with or very close to a solid surface will collapse asymmetrically, forming a microjet of liquid directed toward the solid, as shown in Figure 4.4, [102],[104]. The shock wave from spherical 
collapse and the jet impact from asymmetrical collapse have previously been regarded as the most likely causes of erosion.
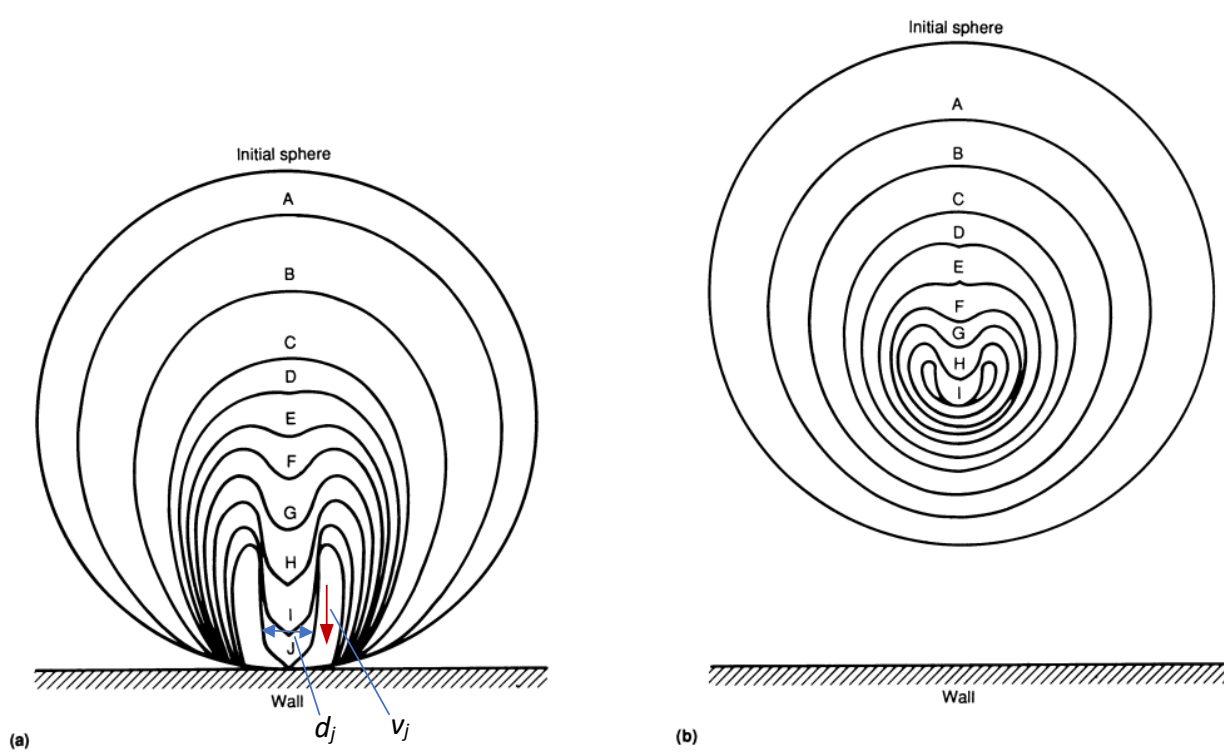

Figure 4.4. The asymmetrical collapse of a cavity, (a) in contact with a solid surface, (b) adjacent to solid surface [104]. Adapted from [102]. The diameter $\left(d_{j}\right)$ and velocity $\left(v_{j}\right)$ of the impacting jet are indicated.

Ahmed et al. [105] performed scanning electron microscopy (SEM) observation of the cavitation-fracture modes in stainless steel AISI 304 during the incubation period. They investigated the behaviour of fracture modes on a smooth surface, as well as the small roughness effect in the development and propagation of cracks and particle fall-off in the second stage of the incubation period. They concluded that the failure mode is fatigue and ductile fracture and also that slight roughness plays an important role in the development and/or propagation of the cracks and also in microscopic removals, which shorten the incubation period. Będkowski et al. [106] investigated the relation between cavitation erosion resistance of three steel grades and their uniaxial fatigue properties under variable amplitude loading. From the analysis it appears that there is a correlation between the fatigue strength of the material under random loading and its cavitation erosion resistance.

\subsection{Experimental validation}

It is important to have experimental erosion facilities on a laboratory scale, not only to validate erosion models but also because it is difficult to perform controlled 
experiments at the scale of turbine blades. In a recent review paper, Bartolomé \& Teuwen [107] point out that the quality of experimental erosion facilities should be improved so as to enable a confident prediction of erosion life and damage. Principally the two kinds of experimental facilities to study rain erosion are: 1) jet erosion test facilities and 2) whirling arm test facilities. The authors argue that experimental results obtained from the two erosion test facilities cannot be correlated easily [107]; the relative erosion resistance between the same materials can be quite different, depending on the used test facility. Reasons mentioned are:

1) how the water drops impact on the sample

2) size and shape distributions of water drops

3) presence of a water film on the sample surface.

These observations are consistent with the conclusion in Section 3.5 in this thesis that the mean incubation period determined by testing with a water jet / nozzle erosion test set-up cannot be used directly for life predictions in real wind turbine blade situations.

This is especially true in determining the incubation period for polymeric surfaces. In fatigue testing the number of cycles to failure of polymers, especially thermoplastics, can be strongly dependent on the frequency of loading. Due to the internal damping or friction a strong temperature rise can be observed during cyclic loading at a relatively high test frequency. This temperature rise of the specimen often results in failure at a relatively low number of cycles. This mode of failure is usually referred to as thermal fatigue and is clearly demonstrated for polyoxymethylene (POM) in Figure 4.5 [76]. In this figure all test results labelled with a " $T$ " have been influenced by an increase in specimen temperature.

From these test results it can be concluded that below a particular test frequency, which depends on the applied maximum stress level, and test temperature, a fatigue life curve ( $S-N$ curve) independent of the frequency of loading can be observed. The blue curve in Figure 4.5 at a frequency of $0.167 \mathrm{~Hz}$ indicated this result. This $S-N$ curve, as can be represented by the equations (2.6) and (2.7), should be used in the predictive model presented in this thesis. 


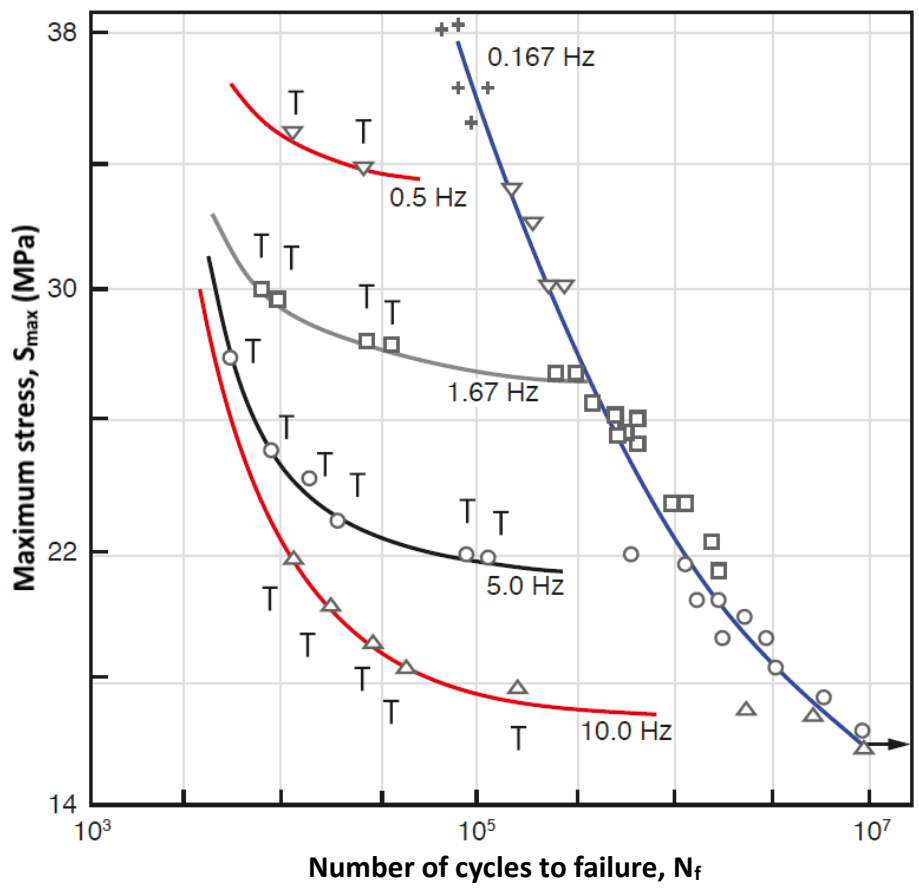

Figure 4.5. Fatigue and thermal failures in POM tested at various frequencies [76]. Stress ratio, $R=S_{\min } / S_{\max }=-1$.

Recently, Hoksbergen et al [108] used a pulsating jet erosion tester to study the droplet impact erosion behaviour of ABS. An impact velocity of $160 \mathrm{~m} / \mathrm{s}$ and an impact frequency of about $200 \mathrm{~Hz}$ were used. The droplet erosion mechanisms during the incubation period were investigated. The authors observed a pitting behaviour at the surface after only a few impacts.

Although laboratory liquid impact erosion test facilities such as whirling arm tests and nozzle devices ejecting water have provided a lot of information on factors influencing erosion resistance, there still is much scatter in droplet impact erosion results. Conditions that have been shown to influence these test results are drop size, drop shape distributions, drop intensity variations and the presence of a water film [107], [108]. The latter indicates the need for standardisation.

\subsection{Standardisation}

The predictive model developed and presented in this thesis can be used as a base for a standardised methodology for predicting turbine blade coating life loaded by 
drop impingement. The life of the leading edge of an individual turbine blade can be defined as:

Droplet impingement life $=$ the number of droplet impacts which the surface encounters before the first evidence of fatigue develops in the material of the surface.

This definition is constructed with the definition of roller bearing life given in ISO 281 standard [74], [58] in mind. Roller bearing fatigue cracks start at a certain depth beneath the surface although initiation at the surface is also possible. The initiation and growth of cracks will not be the same for each individual component surface. As such, it is common to include the concept of reliability in life calculations. Reliability in the context of coating life for a group of apparently identical surfaces operating at the same conditions is defined as the percentage of the group that is expected to attain or exceed a specified life. Typically, the life is estimated based on the basic rating life or $L_{10}$ :

$L_{10}=$ predicted value of life based on a basic dynamic load rating associated with $90 \%$ reliability [58].

The $L_{10}$ can be used only in the case of standardised blades manufactured with commonly used high quality material, of good manufacturing quality, and operating at conventional operating conditions that can be translated to basic dynamic load ratings. This method of standardisation can probably be applied by a blade manufacturer that uses a certain production route with only very small variations for all sizes of blades.

For roller bearings, this is currently common practise due to a combined research effort of roller bearing companies, universities, knowledge centres and standardisation committees. In all these cases, surface fatigue determines the bearing life, even though it is initiated differently. With standardised test methods and with standardised bearing materials it is possible to define the $L_{10}$ for welldefined loading environments.

With standardised surfaces used in conventional applications, $L_{10}$ coating life calculations based on the basic rating life are adequate for representing fatigue life experience based on the actual operating conditions. The rating life modified for $90 \%$ or other reliability or exceptional conditions is referred to in ISO 281 [58] as modified rating life $L_{n, m}$. The relation between the basic rating life $L_{10}$ and the modified rating life $L_{n, m}$ is then given by: 


$$
L_{n, m}=h_{1} h_{S T} L_{10}
$$

with $h_{1}$ the modification factor for reliability and $h_{S T}$ the standardised life modification factor.

The task of determining the value of the modification factors for the fatigue conditions for wind turbine blades is probably the most important task, yet also the most challenging task due to the large number of variables involved. The effects of frequency, waveform, and load level and type must be assessed to determine if material's temperature will increase, leading to thermal fatigue, or if mechanical failure will occur with little or no temperature increase. Other conditions that should be considered or matched from the laboratory specimen to the component include environmental effects (e.g. temperature), stress state, stress concentrations and stress ratio. The relative importance of modification factors could be assessed from current literature. A list is given in Table 4.1. The effect of UV is not mentioned in this list as it will completely change the fatigue properties of the coating and as such requires a new $L_{10}$ value. The effect could, however, be extremely large [49].

Table 4.1. Correction factors $h_{i}$ for the lifetime equations of polymers for different factors of influence.

\begin{tabular}{|l|l|l|l|}
\hline No. & $\begin{array}{l}\text { Correction } \\
\text { factor }\end{array}$ & Factor of influence & Ref. \\
\hline 1 & $h_{1}$ & Failure probability, 50\% (mean) or 5\% ... & \\
2 & $h_{2}$ & Load-controlled or displacement-controlled & {$[66]$} \\
3 & $h_{3}$ & Specimen type, stress gradient & \\
4 & $h_{4}$ & Stress ratio, R & {$[66],[68],[75],[76],[77],[78],[79]$} \\
5 & $h_{5}$ & Frequency, $f$ & {$[66],[67],[68],[75],[76],[77],[78],[79]$} \\
6 & $h_{6}$ & Waveform (sine, triangle, square) & {$[67],[78]$} \\
7 & $h_{7}$ & Temperature & {$[66],[67],[68],[75],[76],[77],[78],[79]$} \\
8 & $h_{8}$ & Environmental effects (humidity, moisture, ...) & \\
9 & $h_{9}$ & Stress state (plain stress, plain strain, ...) & {$[80],[81],[82]$} \\
10 & $h_{10}$ & Surface conditions, roughness & {$[39],[109]$} \\
11 & $h_{11}$ & Effect of sand and dust & \\
\hline
\end{tabular}

The combined effect of sand and rain erosion is likely to affect life extremely, yet it has only rarely been the subject of research, an exception being the work of G.H. Jilbert and J.E. Field [39]. This work focuses on brittle materials and shows that sand erosion rates can be increased by pre-impact of liquid drops. The combined effect of rain and sand for the zinc sulphide window material was further investigated by 
Kelly et al. [109] in different exposure scenarios. For thick compliant coatings, no work on sand-rain erosion was found in open literature.

\subsection{Conclusions and recommendations}

1. In recent literature:

a. Fatigue by ratcheting is used to evaluate repetitive droplet impacts on the same location of a gelcoat. Using this mechanism, the gelcoat lifetime shows a velocity exponent $n \approx 3.7$, a value substantially lower than found in the ASTM interlaboratory test program with an exponent $(n)$ of 5.6. This difference might well be due to the adopted wear mechanism. For the results of the interlaboratory test program high cycle surface fatigue was adopted as mechanism in this thesis.

b. A fatigue based surface degradation analysis of a coating under random water drop impacts is performed using a multiaxial critical plane fatigue model to predict fatigue crack initiation.

2. As viscoelastic damping and wave attenuation in polymers can substantially reduce the transient mechanical stresses due to drop impact, incorporating measured viscoelastic properties and measured hyper-elastic properties in the analytical and numerical (FEM) erosion models is expected to enhance the accuracy of the prediction, especially for elastomeric coatings.

3. To avoid a significant temperature rise of viscoelastic materials such as thermoplastics and elastomers during droplet impingement erosion testing and fatigue testing, the frequency of loading should be below a certain value, depending on the applied maximum stress level and the test temperature.

4. Although laboratory liquid impact erosion test facilities, including whirling arm tests and nozzle devices, have provided much information on factors influencing erosion resistance, there still is a lot of scatter in droplet impact erosion results. Conditions that have been shown to influence these test results are drop size drop shape distributions, drop intensity variations and the presence of a water film.

5. A promising future model application could be modelling the incubation period in cavitation erosion, as the loading type and wear mechanisms by collapsing cavities and by droplet impingement are similar. 
6. Surface fatigue data relies heavily on standardised calculation procedures and standardised testing protocols. For roller bearings this has been successfully realised by a combined research effort of companies, universities, knowledge centres and standardisation committees, in the form of standard ISO 281. A similar approach is needed for surfaces loaded by droplet impingement. 


\section{Chapter 5}

\section{CONCLUSIONS \& RECOMMENDATIONS}

\subsection{Conclusions}

1. The research described in this thesis has yielded an enhanced understanding of the relevant wear mechanisms, such as 1) cracking by brittle fracture, 2) surface fatigue and 3) a mixture of fatigue crack growth and local brittle fracture during droplet impact erosion. Brittle fractures and local fractures in brittle phases result in a relatively low erosion incubation period in comparison with surface fatigue as dominant wear mechanism. Surface fatigue can be considered as the wear mechanism provided that the fracture toughness of all microstructural phases is above a certain threshold value, depending on the drop impact velocity and the drop size.

2. A strongly enhanced understanding of the relationship between the physical and mechanical properties and the drop impact erosion incubation period of metals, thermoplastics and elastomers has been obtained. The physical and metallurgical mechanisms resulting in the degradation process of the metal surface during the incubation period were identified. These consisted of 1) surface plastic deformation and formation of dents, 2) surface hardening and residual compressive stress as a result of these surface plastic deformations, 3) fatigue crack initiation and 4) fatigue crack growth.

3. Using S-N fatigue curves from different literature sources, and including the defined additional surface hardening and a residual compressive stress state at the surface due to the water drop peening effect, the model predictions for stainless steel AISI 316 and aluminium 6061-T6 showed for the droplet impact velocity range of 140 to $400 \mathrm{~m} / \mathrm{s}$ excellent agreement with the multi-regression equation as determined from an ASTM interlaboratory test program. Nearly all incubation period predictions were within the $95 \%$ confidence limits of the aforementioned multi-regression equation.

4. The selected dynamic impedances and fatigue properties of the metals, thermoplastics and elastomers used in the presented analytical model were identified with respect to developing guidelines for enhanced droplet impingement erosion incubation life. 
5. The relative impact pressure $\left(p_{w h} / v_{d}\right)$ can be used to identify the extent to which certain material classes reduce the water hammer pressure and corresponding maximum stress due to the Rayleigh wave.

6. The test set-up based on a water jet / nozzle system can be used for ranking surfaces with respect to droplet impingement resistance. The mean incubation period determined by testing with this test set-up cannot be used directly for life predictions in real wind turbine blade situations.

7. The knowledge and predictive model developed in this research and presented in this thesis can be used as a tool to study combinations of material properties for an optimised drop impact incubation period.

8. The developed predictive model for the droplet impingement erosion incubation period can be used as evaluation algorithm in a monitoring system with sensors in the surface of the drop impact loaded location.

\subsection{Recommendations}

1. As viscoelastic damping and wave attenuation in polymers can substantially reduce the transient mechanical stresses due to drop impact, incorporating measured viscoelastic properties and measured hyper-elastic properties in the analytical and numerical (FEM) erosion models is expected to enhance the accuracy of the prediction, especially for elastomeric coatings.

2. A promising future model application could be modelling the incubation period in cavitation erosion, as the loading type and wear mechanisms by collapsing cavities and by droplet impingement are similar.

3. Surface fatigue data relies heavily on standardised calculation procedures and standardised testing protocols. For roller bearings this has been successfully realised by a combined research effort of companies, universities, knowledge centres and standardisation committees, in the form of an ISO standard (ISO 281). A similar approach is recommended for surfaces loaded by droplet impingement. 


\section{References}

[1] De Gee A.W.J., Rowe G.W., Glossary of terms and definitions in the field of friction, wear and lubrication (tribology), International Research Group on Wear of Engineering Materials, Organisation for Economic Cooperation and Development (IRG-OECD), Paris, 1969.

[2] Azevedo C.R.F., Sinátora A., Erosion-fatigue of steam turbine blades, Engineering Failure Analysis 16/7, 2009, 2290-2303.

[3] Lawrence F.V., Dimitrakis S.D., Munse W.H., Factors Influencing Weldment Fatigue, In: ASM Handbook 19, Fatigue and Fracture, 1996.

[4] Mohammad K.A., Ali A., Sahari B.B., Abdullah S., Fatigue behavior of Austenitic Type 316L Stainless Steel, IOP Conf. Series: Materials Science and Engineering 36 (012012), 2012, 1-9.

[5] Zum Gahr K.-H., Microstructure and Wear of Materials, Tribology series 10, Elsevier, 1987.

[6] Salomon G., Application of systems thinking to tribology, ASLE Trans 17(4), 1974, 295-299.

[7] Czichos H., Tribology - A system approach to the science and technology of friction, lubrication, and wear, 1978, Elsevier, Amsterdam.

[8] Czichos H., Systematic Diagnosis of Friction and Wear Test Data, In: ASM Handbook 18, Friction, Lubrication, and Wear Technology, 1998.

[9] Heymann F.J., Liquid impingement erosion, In: Friction, lubrication and wear technology, ASM Handbook, American Society of Metals, 1992, 221-232.

[10] Cook S.S., Erosion by Water-hammer, Royal Society Proceedings A 119, May 1928, 481-488.

[11] ASTM G73-10(2017), Standard Test Method for Liquid Impingement Erosion Using Rotating Apparatus, American Society of Testing Materials, 2017.

[12] DNVGL-RP-0171, Testing of rotor blade erosion protection systems, 2018.

[13] Boer de S.B., Flamma J.W., Lammers G.L., Vandeweijer A.A.H, Werf J.L. van der, Zeemans H.J. (Inventors), Enhanced Crude Oil Recovery Method and System, Patent pub. no.: US 2010/0101791 A1, Pub. date: Apr. 29, 2010.

[14] Springer G.S., Erosion by liquid impact, Scripta Publishing Company, 1976.

[15] Wilkes J., Kjaer C., Gruet R., Pure power - wind energy targets for 2020 and 2030, European Wind Energy Association, July 2011.

[16] European Renewable Energy Council, Mapping renewable energy pathways towards 2020-EU roadmap, Brussel, Belgium, March 2011.

[17] Goch G., Knapp W., Hartig F., Precision engineering for wind energy systems, CIRP Annual Manufacturing Technology 61(2), 2012, 611-634. 
[18] Wind blade using cost-effective advanced composite lightweight design WALID. EU FP7 project grant agreement no. 309985, www.eu-walid.com.

[19] Beaudry-Losique J. et al, A national offshore wind strategy - Creating an offshore wind energy industry in the United States, U.S. Department of Energy, Office of Energy Efficiency and Renewable Energy, Wind \& Water Power Program U.S. and Department of the Interior, Bureau of ocean energy Management, Regulation, and Enforcement, February 7, 2011.

[20] Hasager C., Vejen F., Bech J.I., Skrzypiński W.R., Tilg A.-M., Nielsen M., Assessment of the rain and wind climate with focus on wind turbine blade leading edge erosion rate and expected lifetime in Danish Seas, Renewable Energy 149, 2020, 91-102.

[21] Keegan M.H., Nash D.H., Stack M.M., On erosion issues associated with the leading edge of wind turbine blades, J Phys D Appl Phys 46, 2013, 383001.

[22] Rempel L., Rotor blade leading edge erosion - Real life experiences, Oct 2012, 22-24, www.windsystemsmag.com.

[23] Mishnaevsky L. Jr., Repair of wind turbine blades: review of methods and related computational mechanics problems, Renew. Energy 140, 2019, 828839.

[24] Gohardani O., Impact of erosion testing aspects on current and future flight conditions, Prog Aerosp Sci 47, 2011, 280-303.

[25] Schmitt G.F. Jr., Polyurethane coatings for rain erosion protection, In: Fyall A.A., King R.B. (Eds.), Proc. of the $2^{\text {nd }}$ Meersburg conference on rain erosion and allied phenomena, Royal Aircraft Establishment, Farnborough, England, 1967, 329-357.

[26] Conn A.F., Rudy S.L., The effects of fatigue and dynamic recovery on rain erosion, In: Erosion wear and interfaces with corrosion, ASTM-STP-567, 1974, 239-269.

[27] Zhang S., Wei J., Chen X., Zhao Y., China in global wind power development: Role, status and impact, Renewable and Sustainable Energy Reviews 127, 2020, 109881.

[28] Adler W.F., Liquid drop collisions on deformable media, Journal of Material Science 12, 1977, 1253-1271.

[29] www.Imwindpower.com/Rotor-Blades/Technology/Design/Blade-Concept; 14/10/2013.

[30] Sareen A., Chinmay A., Selig M.S., Effects of leading edge erosion on wind turbine blade performance, Wind Energy 17(10), 2014, 1531-1542.

[31] Gaudern N., A practical study of the aerodynamic impact of wind turbine blade leading edge erosion, J Phys Conf Ser 524, 2014, 012031. 
[32] Giguere P., Selig M.S., Aerodynamic effects of leading edge tape on aerofoils at low Reynolds numbers, Wind Energy 2, 1999, 125-136.

[33] Dalili N., Edrisy A., Carriveau R., A review of surface engineering issues critical to wind turbine performance, Renew Sustain Energy Rev 13, 2009, 428-438.

[34] Grundwuermer M., Nuyken O., Meyer M., Wehr J., Schupp N., Sol-gel derived erosion protection coatings against damage caused by liquid impact, Wear 263, 2007, 318-329.

[35] Wang S.S., Cai L.X., Mao J.R., Zhang J.J., Xu Y.T., Mechanisms of steam turbine blade particle erosion and crucial parameters for minimizing blade erosion, Proc IMechE Part A: J Power Energy 227(5), 2013, 546-556.

[36] Lee M.K., Kim W.W., Rhee C.K., Lee W.J., Liquid impact erosion mechanism and theoretical impact stress analysis in TiN-coated steam turbine blade materials, Metall Mater Trans A 30, 1999, 961.

[37] Blowers R.M., On the response of an elastic solid to droplet impact, IMA J Appl Math 5, 1969, 167-193.

[38] Field J.E., ELSI conference: invited lecture liquid impact: theory, experiment, applications, Wear 233-235, 1999, 1-12.

[39] Jilbert G.H., Field J.E., Synergistic effects of rain and sand erosion, Wear 243, 2000, 6-17.

[40] Zhou Q., Li N., Chen X., Xu T., Hui S., Zhang D., Analysis of water drop erosion on turbine blades based on a nonlinear liquid-solid impact model, Int $J$ Impact Eng 36, 2009, 1156.

[41] Kunaporn S., Ramulu M., Hashish M., Mathematical modeling of ultra-highpressure waterjet peening, J. Eng. Mater Technol 127, 2005, 186.

[42] Kim H.S., Kim J.S., Kang H.J., Kim S.R., Stress wave propagation in a coated elastic half-space due to water drop impact, J. Applied Mechanics 68(2), 2000, 346-348.

[43] Adler W.F., Rain impact retrospective and vision for the future, Wear 233235, 1999, 25-38.

[44] Evans A.G., Ito Y.M., Rosenblatt M., Impact damage thresholds in brittle materials impacted by water drops, J. Appl. Phys. 51, 1980, 2473-2482.

[45] Evans A.G, On impact damage in the elastic response regime, Journal of Applied Physics 49/6, 1978, 3304-3310.

[46] Woods R.D., Screening of surface waves in soils, J.Soil Mech Found Div 94(4), 1968, 951-979.

[47] Haosheng C., Shihan L., Inelastic damages by stress wave on steel surface at the incubation stage of vibration cavitation erosion, Wear 266(1-2), 2009, 69-75. 
[48] Adler W.F., Mihora D.J., Waterdrop impact modeling, Wear 186-187, 1995, 341-351.

[49] Adler W.F., Mihora D.J., Analysis of polyurethane advanced rotor blade erosion protection system, In: Weigel W.D. (Ed.), Advanced rotor blade erosion protection system, Kaman Aerospace Corporation, Bloomfield, CT, July 1996, Appendix E.

[50] Adler W.F., Mihora D.J., Analysis of waterdrop impacts on layered window constructions, In: Klocek P. (Ed.), Window and dome technologies and materials IV - 2286, SPIE (27-28 July 1994).

[51] Hattori S., Kakuichi M., Effect of impact angle on liquid droplet impingement erosion, Wear 298-299, 2013, 1-7.

[52] Hackworth J.V., Kocher L.H., Snell I.C., Response of infrared transmitting materials to high-velocity impact by water drops, In: Adler W.F. (Ed.), Erosion: prevention and useful applications, ASTM STP 664, 1979, 255-278.

[53] Kennedy C.F., Field J.E., Damage threshold velocities for liquid impact, Journal of Materials Science 35, 2000, 5331-5339.

[54] Gorham D.A., Matthewson M.J., Field J.E., Damage Mechanisms in Polymers and Composites Under High-Velocity Liquid Impact, In: Adler W.F. (Ed.), Erosion: prevention and useful applications, ASTM STP 664, 1979, 320-342.

[55] Lee M.K., Kim W.W., Rhee C.K., Lee W.J., An analysis of stress waves in $12 \mathrm{Cr}$ steel, Stellite 6B and TiN by liquid impact loading, Nucl Eng Des 214, 2002, 183.

[56] Palmgren A.Z., Die Lebensdauer von Kugellagern, Z Ver Dtsch Ing 68(339), 1924.

[57] Miner M.A., Cumulative damage in fatigue, J Appl Mech 12, 1945, A139.

[58] ISO 281, Rolling bearings - Dynamic load ratings and rating life, 2007.

[59] NEN-EN 1993-1-9+C2, Eurocode 3: design of steel structures - part 1-9: fatigue (Dutch version of European standard), 2012.

[60] DNV-RP-C203, Fatigue design of offshore steel structures, recommended practice, Det Norske Veritas, August 2005.

[61] Adler W.F., The mechanics of liquid impact, In: Treatise on Materials Science and Technology 16; Preece C.M. (Ed.), Academic Press: Cambridge, MA, USA, 1979.

[62] Adler W., Vyhnal R., Rain erosion of Ti-6Al-4V, In: Proceedings of the 4th International Conference on Rain Erosion and Associated Phenomena, Fyall A.A., King R.B. (Eds.); Germany 1974.

[63] O'Carroll A., Hardiman M., Tobin E.F., Young T.M., Correlation of the rain erosion performance of polymers to mechanical and surface properties measured using nanoindentation, Wear 412-413, 2018, 38-48. 
[64] Schmitt G.F. Jr., Liquid and solid particle impact erosion, In: Peterson M.B., Winer W.O. (Eds.), Wear Control Handbook, 1980, 231-282.

[65] Schmitt G.F. Jr., Erosion behavior of polymeric coatings and composites at subsonic velocities, In: Fyall A.A., King R.B. (Eds.), Proc. third international conference on rain erosion and associated phenomena, Elvetham Hall , Aug. 1970, 107-145.

[66] Mandell J.F., Fatigue behavior of short fiber composite materials, In: Reifsnider K.L. (Ed.), The fatigue behavior of composite materials, Elsevier, 1991 (chapter 7).

[67] Kanter D. de, On the predictability of fatigue failure of glassy polymers, PhD thesis, Eindhoven University of Technology, 2006.

[68] Zhou Y., Rangari V., Mahfuz H., Jeelani S., Mallick P.K., Experimental study on thermal and mechanical behavior of polypropylene, talc/polypropylene and polypropylene/clay nanocomposites, Mater Sci Eng. A 402, 2005, 109-117.

[69] Gorham D.A., Matthewson M.J., Field J.E., Damage mechanisms in polymers and composites under high-velocity liquid impact, In: Adler W.F. (Ed.), Erosion: prevention and useful applications, ASTM-STP-664, 1979, 320-342.

[70] Rieger H., Boche H., Erosion behavior of surface coatings, In: Fyall A.A., King R.B. (Eds.), Proc. of the $4^{\mathrm{e}}$ international conference on rain erosion and associated phenomena, Royal Aircraft Establishment, Farnborough, England, 1974, 637-675.

[71] Schmitt G.F., Elevated temperature resistant, subsonic rain erosion resistant fluoroelastomer radome coatings, Proc. of the $3^{\mathrm{e}}$ international conference on electromagnetic windows, Paris, 1975, 211-232.

[72] Schmitt G.F., Advanced rain erosion resistant coating materials, Science of advanced materials and process engineering series, vol. 18, 1973, 57-75.

[73] Lee G.M.C., The erosion resistance of plain carbon steel under water droplet impact conditions, Wear 141, 1990, 185-201.

[74] Voskamp A., Microstructural changes during rolling contact fatigue, PhDthesis, Delft University of Technology, 1996.

[75] Sauer J.A., Richardson G.C., Fatigue of polymers, Int J Fract 16(6), 1980, 499532.

[76] Osswald T.A., Menges G., Material Science of Polymers for Engineers, 3rd Edition, Hanser Publishers, Munich, 2012.

[77] Trantina G.G., Design with plastics, Materials selection and design, ASM handbook 20, American Society of Metals, 2003, 639-647.

[78] Janssen R.P.M., Govaert L.E., Meijer H.E.H., An analytical method to predict fatigue life of thermoplastics in uniaxial loading: sensitivity to wave type, frequency, and stress amplitude, Macromolecules 41, 2008, 2531-2540. 
[79] Janssen R.P.M., Kanter D. de, Govaert L.E., Meijer H.E.H., Fatigue life predictions for glassy polymers: a constitutive approach, Macromolecules 41, 2008, 2520-2530.

[80] Klimkeit B., Nadot Y., Castagnet S., Nadot-Martin C., Dumas C., Bergamo S., Multiaxial fatigue life assessment for reinforced polymers, Int J Fatigue 33, 2011, 766-780.

[81] Klimkeit B., Nadot Y., Castagnet S., Benoit G., Bergamo S., Dumas C., Damage mechanisms, Multiaxial fatigue of short fibre reinforced thermoplastics, Proc. $17^{\text {th }}$ international conference on composite materials (ICCM17), Edinburgh, 2009.

[82] Launay A., Maitournam M.H., Marco Y., Raoult I., Multiaxial fatigue models for short glass fiber reinforced polyamide - Part I: nonlinear anisotropic constitutive behavior for cyclic response, Int J Fatigue 47, 2013, 382-389.

[83] Domininghaus H., Plastics for Engineers - Materials, Properties, Applications, Hanser Publishers, 1993.

[84] Landgraf R.W., Chernenkoff R.A., Residual Stress Effects on Fatigue of Surface Processed Steels, In: R.L. Champoux, J.A. Kapp, J.H. Underwood (Eds), Analytical and Experimental Methods for Residual Stress Effects in Fatigue, ASTM STP 1004, ASTM International, 1988, 1-12.

[85] Heymann F.J., Conclusions from the ASTM Interlaboratory Test Program with Liquid Impact Erosion Facilities, In: Field JE, eds. Proceedings of the Fifth International Conference on Erosion by Liquid and Solid Impact (ELSI-V), Cambridge: Cavendish Laboratory; 1979: paper 20, 1-10.

[86] Duraiselvam M., Galun R., Siegmann S., Wesling V., Mordike B.L., Liquid impact erosion characteristics of martensitic stainless steel laser clad with $\mathrm{Ni}$ based intermetallic composites and matrix composites, Wear 261, 2006, 1140-1149.

[87] Oka Y.I., Miyata H., Erosion behaviour of ceramic bulk and coating materials caused by water droplet impingement, Wear 267, 2009, 1804-1810.

[88] Salomon Jetting Parts, datasheet nozzle type SJP 8/12/24, 2014.

[89] Fujisawa N., Takano S., Fujisawa K., Yamagata T., Experiments on liquid droplet impingement erosion on a rough surface, Wear 398-399, 2018, 158164.

[90] Mishnaevsky L., Sütterlin J., Micromechanical model of surface erosion of polyurethane coatings on wind turbine blades, Polymer Degradation and Stability 166, 2019, 283-289.

[91] Verma A.S., Castro S.G.P., Jiang Z., Teuwen J.J.E., Numerical investigation of rain droplet impact on offshore wind turbine blades under different rainfall conditions: A parametric study. Composite Structures 241, 2020, 112096. 
[92] Doagou-Rad S., Mishnaevsky L. Jr, Rain erosion of wind turbine blades: computational analysis of parameters controlling the surface degradation, Meccanica 55, 2020, 725-743.

[93] Doagou-Rad S., Mishnaevsky L., Bech J.I., Leading edge erosion of wind turbine blades: Multi-axial critical plane fatigue model of coating degradation under random liquid impacts, Wind Energy 23, 2020, 1752-1766.

[94] Domenech L., Renau J., Šakalyte A., Sánchez F., Top coating anti-erosion performance analysis in wind turbine blades depending on relative acoustic impedance - Part 1: Modelling approach, Coatings 10(7), 2020, 685.

[95] Amirzadeh B., Louhghalam A., Raessi M., Tootkaboni M., A computational framework for the analysis of rain-induced erosion in wind turbine blades Part I: Stochastic rain texture model and drop impact simulations, Journal of Wind Engineering and Industrial Aerodynamics 163, 2017, 33-43.

[96] Amirzadeh B., Louhghalam A., Raessi M., Tootkaboni M., A computational framework for the analysis of rain-induced erosion in wind turbine blades Part II: Drop impact-induced stresses and blade coating fatigue life, Journal of Wind Engineering and Industrial Aerodynamics 163, 2017, 44-54.

[97] Mishnaevsky L., Toolbox for optimizing anti-erosion protective coatings of wind turbine blades: Overview of mechanisms and technical solutions, Wind Energy 22(11), 2019, 1636-1653.

[98] Ibrahim M.E., Medraj M., Water droplet erosion of wind turbine blades: Mechanics, testing, modeling and future perspectives, Materials 13(1), 2020, 157.

[99] Sain T., Yeom B., Waas A.M., Arruda E.M., Effect of soft segment and clay volume fraction on rate dependent damping of polyurethane and polyurethane-clay nanocomposites. Journal of Reinforced Plastics and Composites 33(23), 2014, 2129-2135.

[100] Schijve J., Fatigue of Structures, Post-academic Course, Delft University of Technology, Aerospace Engineering, (in Dutch), 1982.

[101] Wallgren G., Direct Fatigue Tests with Tensile and Compressive Mean Stresses on 24S-T Aluminium Plain Specimens and Specimens Notched by a Drilled Hole, Report Nr. 48, Aeronautic Research Institute of Sweden, 1953.

[102] Hansson C.M., Hansson I.L.H., Cavitation Erosion, In: ASM Handbook 18, Friction, Lubrication, and Wear Technology, ASM International, 1998.

[103] Lord Rayleigh O.M., On the pressure developed in a liquid during the collapse of a spherical cavity, The Philosophical Magazine 34, 1917, 94-98.

[104] Plesset M.S., Chapman R.B., Collapse of an initially spherical vapour cavity in the neighbourhood of a solid boundary, Journal of Fluid Mechanics 47(2), 1971, 283-290. 
[105] Ahmed S.M., Hokkirigawa K., Oba R., Kikuchi K., SEM Observation of the Vibratory Cavitation-Fracture Mode during the Incubation Period and the Small Roughness Effect, JSME international - Serie II 34(3), 1991, 298-303.

[106] Będkowski W., Gasiak G., Lachowicz C., Lichtarowicz A., Łagoda T., Macha E., Relation between cavitation erosion resistance of materials and their fatigue strength under random loading., Wear 230(2), 1999, 201-209.

[107] Bartolomé L., Teuwen J., Prospective challenges in the experimentation of the rain erosion on the leading edge of wind turbine blades, Wind Energy 22(1), 2019, 140-151.

[108] Hoksbergen T.H., Baran I., Akkerman R., Rain droplet erosion behavior of a thermoplastic based leading edge protection system for wind turbine blades, IOP Conf. Series: Materials Science and Engineering 942, 2020, 012023.

[109] Kelly E.S., Ondercin R.J., Detrio J.A., Greason P.R., Environmental testing of long wave infrared (LWIR) windows, Proc. of SPIE, vol. 3060, 1997, 68-75. 
Part II

Papers 


\section{Research papers}

\section{Paper A}

Slot H.M., Gelinck E.R.M., Rentrop C., Van der Heide E., Leading edge erosion of coated wind turbine blades: Review of coating life models, Renewable Energy 80, 2015, 837-848.

\section{Paper B}

Slot H.M., IJzerman R.M., le Feber M., Nord-Varhaug K., Van der Heide E., Rain erosion resistance of injection moulded and compression moulded polybutylene terephthalate PBT, Wear 414-415, 2018, 234-242.

\section{Paper C}

Slot H.M., Matthews D.T.A., Schipper D.J., Van der Heide E., Fatigue-based model for the droplet impingement erosion incubation period of metallic surfaces, Fatigue \& Fracture of Engineering Materials \& Structures 44(1), 2021, 199-211.

\section{Patent proposal D}

Cheng L.K., Ham J. van den, Slot H.M, Jansen R., Sensing damage of protective coatings, Draft-Patent, 2019.

\section{Fatigue related research papers - not included in this thesis}

Slot H.M., Nicoreac M., Maljaars J., Influence of material anisotropy on fatigue crack growth in C-Mn steels of existing structures, Fatigue \& Fracture of Engineering Materials \& Structures 43(11), 2020, 2527-2541.

Maljaars J., Pijpers R.J.M., Slot H.M., Load sequence effects in fatigue crack growth of thick-walled welded C-Mn steel members, International Journal of Fatigue 79, 2015, 10-24.

Kouters M.H.M., Slot H.M., Van Zwieten W., Van der Veer J., The influence of hydrogen on the fatigue life of metallic leaf spring components in a vacuum environment, International Journal of Fatigue 59, 2014, 309-314.

Huis in 't Veld A.J., Slot H.M., Carvalho N.J.M., De Hosson J.Th.M., Surface fatigue resistance of tool steel coated with thin brittle PVD layers, Tribology Series 38, 2000, 139-144. 
Paper A 


\title{
Leading edge erosion of coated wind turbine blades: Review of coating life models
}

\author{
H.M. Slot ${ }^{a}$, E.R.M. Gelinck ${ }^{a}$, C. Rentrop ${ }^{a}$ and E. van der Heide ${ }^{a, b}$ \\ ${ }^{a}$ TNO, De Rondom 1, 5612 AP Eindhoven \\ ${ }^{b}$ University of Twente, Laboratory for Surface Technology and Tribology, Enschede \\ Published in: Renewable Energy 80, 2015, pp. 837-848.
}

\begin{abstract}
Erosion of the leading edge of wind turbine blades by droplet impingement wear, reduces blade aerodynamic efficiency and power output. Eventually, it compromises the integrity of blade surfaces. Elastomeric coatings are currently used for erosion resistance, yet the life of such coatings cannot be predicted accurately. This review paper gives an overview of experimentally validated erosion model blocks that can be used to predict the life of the leading edge of coated wind turbine blades. From the reviewed work it is concluded that surface fatigue, as nucleating wear mechanism for erosion damage, can explain erosive wear and failure of the coatings. An engineering approach to surface fatigue, using the Palmgren-Miner rule for cumulative damage, allows for the construction of a rain erosion incubation period equation. Coating life was described as a function of the rain intensity, the droplet diameter, the fatigue properties of the coating and the severity of the conditions. It is recommended to focus coating development on reduction of the impact pressure, e.g. by developing surfaces with a low modulus of elasticity; or on enlarging the safe area by: developing coatings with adjustable compressive stresses and hardness, or coatings without defects and impurities.
\end{abstract}

\section{Keywords}

Wind energy, Erosion, Droplet impingement, Coatings, Surface fatigue

\section{Introduction}

Wind energy has developed significantly over the last two decades. In 2010, $81 \mathrm{GW}$ of onshore wind and $2.9 \mathrm{GW}$ of off shore wind was brought online in the EU-27 via 
the installation of 70488 onshore turbines and 1132 wind turbines installed at European off shore locations, respectively. A further increase to over $213 \mathrm{GW}$ in 2020 , is expected with a compound annual growth rate of $9.7 \%$, particular by growth in off shore capacity [1-4]. A similar prominent role for off shore wind energy is envisaged by the US Department of Energy, assuming a large reduction in the current cost of wind energy and assuming the availability of the required operational capacity of specialized vessels, purpose-built portside infrastructure, robust undersea electricity transmission lines, and grid interconnections $[4,5]$. The latter aspects stress the engineering challenges that are related to the remote character of the off shore locations of interest. Cost reduction is served greatly by reducing on-site maintenance and replacement costs and by increasing the scale of off shore wind turbines e.g. by developing blade lengths up to $90 \mathrm{~m}[3,4]$.

The cross section of blades for large turbines is typically air foil shaped to create lift and following rotation of the blades. As important as the design of the blades, is the weight. Currently, an optimum between weight, performance of the turbine blades and structural integrity, is found by applying polymer composite materials and related manufacturing techniques such as moulding. The surface of the blade is formed by two shells from epoxy or polyester matrix composites, reinforced with glass or other fibres. The blade is stiffened with an intermediate web and by a supporting shell core from balsa wood [6], foam [3] or combinations [6]. Furthermore, a blade root is used for connection to the rotor and a tailored tip is used to connect the two shells at the trailing edge. The amount of lift during operation is controlled by the angle of attack between the chord extending from the leading edge to the trailing edge of the blade, and the relative wind. The amount of drag can be minimized by careful design optimization. This approach of optimizing drag, lift and weight while maintaining structural integrity as a function of the loading conditions was successfully applied for the current onshore European wind turbine locations. New, off shore or near-shore locations give rise to more demanding environmental conditions, among which the possibility of water droplet laden winds. Such winds can easily compromise the integrity of blade surfaces.

Blades that encounter the impact of sand particles and/or water droplets or mixtures will first show an increase in surface roughness that affects the aerodynamic performance negatively, for example by increased friction drag and by an earlier onset of stall [7]. The information presented by Keegan et al. [7,8] shows that drag could increase from 6 to $500 \%$ depending on the level of leading edge erosion. Furthermore, it is predicted that an $80 \%$ increase in drag could lead to approximately a $5 \%$ reduction in annual energy production. With greater levels of erosion both the lift reduction and the drag increase are more severe, see e.g. 
the case presented by Gaudern [9]. Severely worn surfaces carry the risk of reduced structural integrity which in turn results in turbine downtime and high maintenance costs. An overview of documented cases of leading edge erosion in literature is given by Ref. [7]. Examples of the impact by particles and droplets, are given in Figure $1 \mathrm{a}-\mathrm{c}[7,10]$.

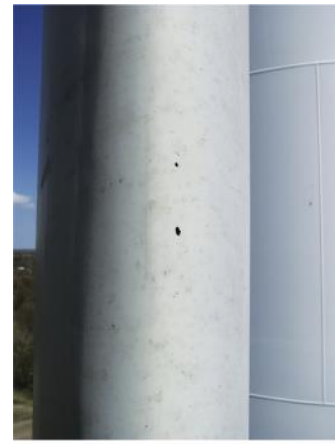

a)

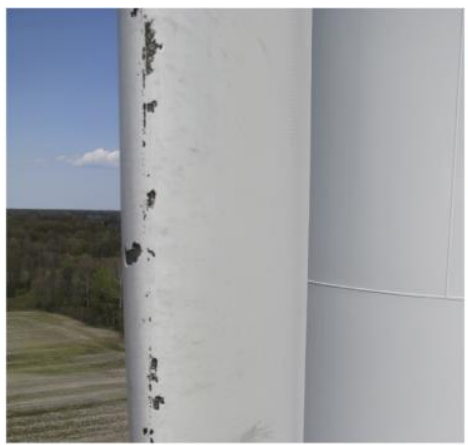

b)

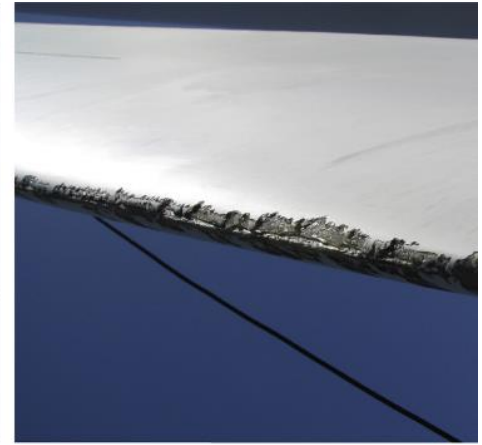

c)

Figure 1. Changes to the leading edge surface due to impact with a different degree of severity, adapted from Refs. [7,10]: a) leading edge erosion at an early stage, b) severely damaged coating and c) leading edge erosion starts to wear the shell material.

The wear patterns shown in Figure 1 are illustrative for leading edge erosion. In the current work the term erosion [11] is used to indicate the loss of material from the solid surface due to relative motion in contact with air which contains solid or fluid particles. The term impingement is added frequently to indicate that the relative motion of the particles or droplets is nearly normal to the solid surface. Impingement wear, as a specific case of wear in general, is a systems property rather than a materials property [12]. That means that the amount and the manifestation of wear is determined by the operational conditions, the environmental conditions, by the physics of the interaction and by the material properties of the particles and/or droplets and by the material properties of the blade surface. The latter aspect is well recognized in industry as there are several commercially available gel-coats, or elastomeric coatings among which tapes, that can be applied at the finished blade to improve the resistance of the surface to erosion $[7,13,14]$. Other technical challenges related wind turbine blade surfaces are reviewed by Ref. [14]. Solutions based on surface engineering are given especially for icing. Research on protective materials and coatings depends heavily on experimental work, although efforts were made to correlate the erosion resistance to the physics of impingement erosion for aircraft wings, windows or 
radomes that encounter supersonic rain $[15,16]$. Furthermore, similarities are found in erosion of steam turbine parts $[17,18]$.

Clearly, the work of R.M. Blowers [19] on analytically modelling of stresses at the surface after impact of a water droplet and the work of J.E. Field on the physics of rain [20] and combined rain and sand erosion [21] are important is this field. Many researchers such as Zhou [22], Kunaporn [23], Lee [18], Kim [24], Adler [25] and Evans [26] have used and expanded this work to calculate or to validate the impact response of a variety of materials. The translation to life modelling of coated surfaces is however only partially touched.

This review paper summarizes the state of the art in droplet impingement erosion modelling and gives an overview of experimentally validated building blocks of erosion models that can be used to predict the life of the leading edge of coated wind turbine blades. By linking these to the material technology aspects of blade coatings it becomes possible to identify promising directions for off shore blade coating technology development. Furthermore, the need for standardization of test methods is addressed in this review.

\section{Modelling the mechanical aspects of droplet impact}

\subsection{Transient stresses due to the impact of a single water droplet}

The initial stage of impact between a solid and a water droplet is determined by compression of the liquid, which results to the 'water-hammer pressure'. For a relatively soft, e.g. coated surface [20] this pressure $p_{w h}$ is given by:

$$
p_{w h}=\frac{v_{d} \rho_{L} c_{L} \rho_{S} c_{S}}{\rho_{L} c_{L}+\rho_{S} c_{S}}
$$

in which $v_{d}$ is the droplet impact velocity and $\rho_{L}, \rho_{S}$ and $c_{L}, c_{S}$ are the densities and the wave velocities of water and the elastic coating, respectively. As a result of the impact, longitudinal and transverse body waves immediately start propagating and from the free surface boundary it follows that that a Rayleigh wave is generated as well. Figure 2 gives an overview of the geometrical wave attenuation of the body waves and surface waves as a result of a sudden distortion on the surface $[27,28]$.

Damping of the waves is related to the distance $r$ from the impact centre, see e.g. Ref. [27]. Bulk waves decay with $1 / r$ into the solid and with $1 / r^{2}$ at the surface. This 
is much stronger than damping of the Raleigh waves that occurs at $1 / \mathrm{vr}$. As such, it can be assumed that the disturbance in the far field is dominated by the Rayleigh waves. The positions of the wave fronts and the resulting stress variations with time are available in an analytical form [19]. It shows that the transient surface stresses are primarily compressive with high tensile stresses in a narrow band immediately behind the Rayleigh wave front. The radial dimensions in which this occurs is quite small, and together with the high wave velocity this gives rise to short stress peaks of typically tenths of micro seconds, see Figure 3 for the non-dimensional radial stress $S_{R R}\left(S_{R R}=\sigma_{R R} / p_{w h}\right)$.

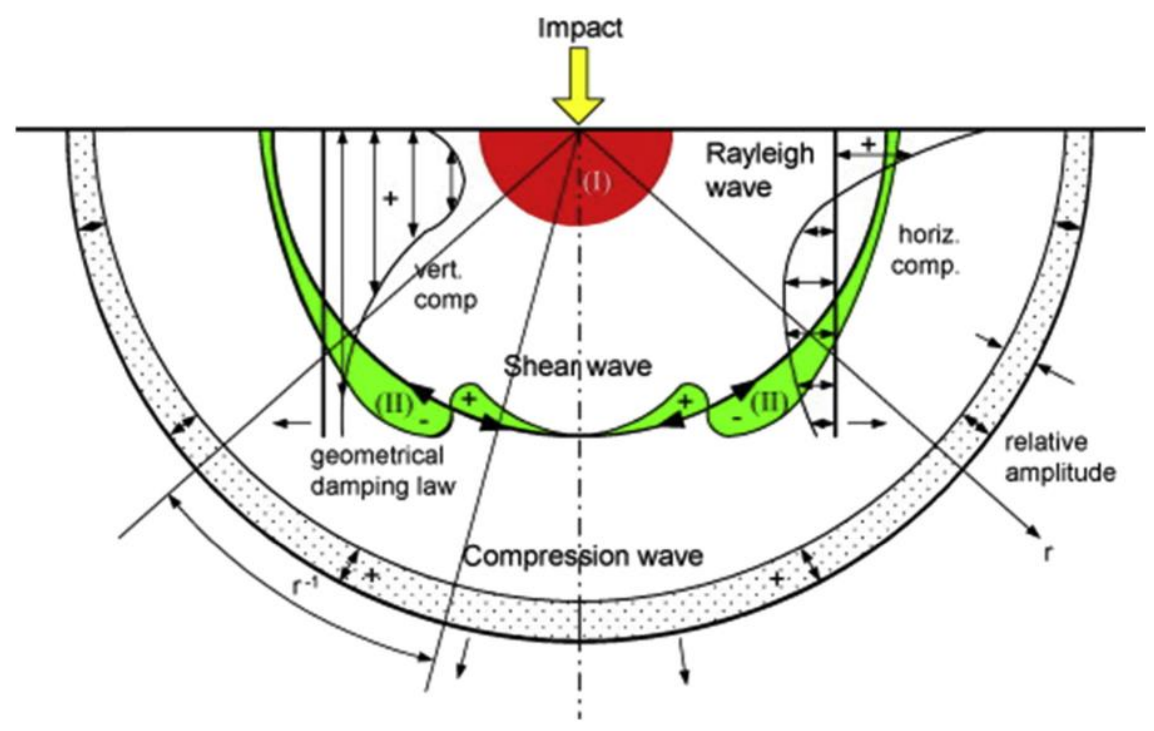

Figure 2. The waves and displacements as a result of a Harmonic vertical "point source" acting on the surface of a homogeneous, isotropic, linear elastic half space, based on Ref. [27]. Adapted from Ref. [28]. 


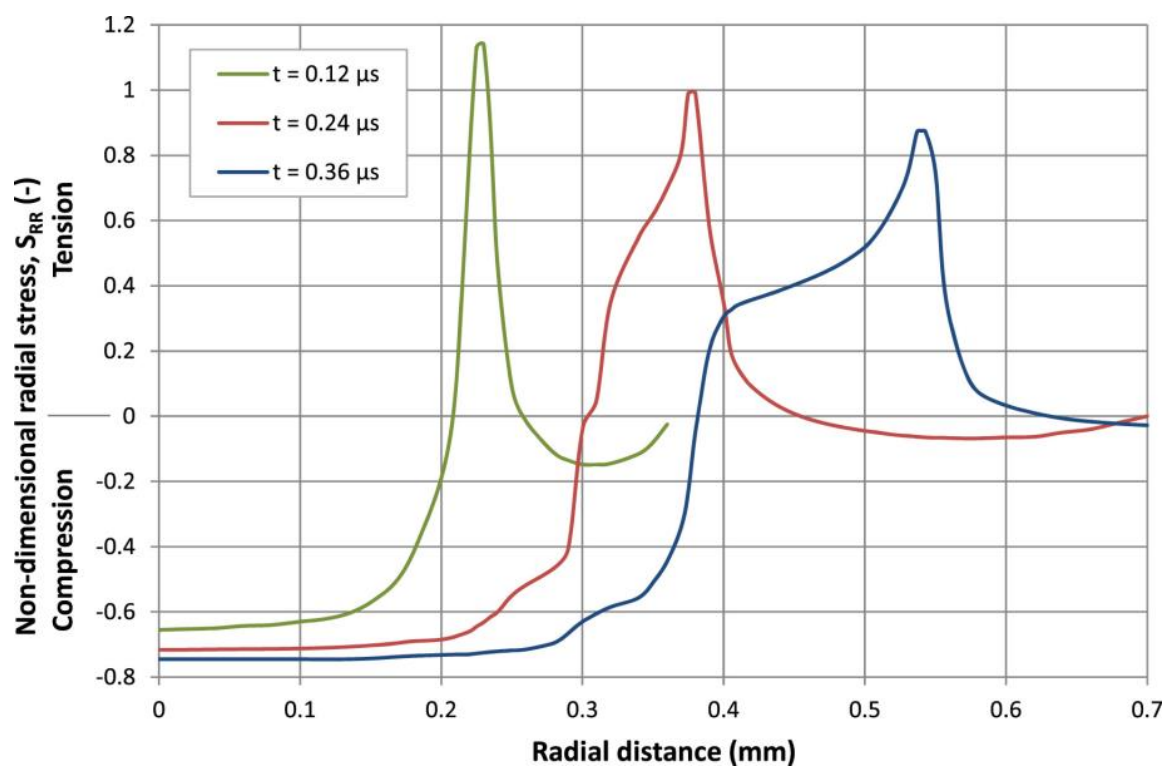

Figure 3. The variation of non-dimensional radial stress component due to the Rayleigh surface wave as a function of radial distance in polymethylmetacrylate PMMA, for a water drop diameter $d_{d}=1.8 \mathrm{~mm}$ and impact velocity $v_{d}=222 \mathrm{~m} / \mathrm{s}$ at $5 \mu \mathrm{m}$ depth. Adapted from Ref. [33].

Numerical results for thin hard elastic coating are presented by Kim et al. in Ref. [24]. In Ref. [24] reflection at the coating-substrate interface is taken into account as well. Calculations are made with a water droplet diameter $d_{d}=2 \mathrm{~mm}$, a droplet impact velocity $v_{d}=453 \mathrm{~m} / \mathrm{s}$ and a $90^{\circ}$ impact angle. Table 1 summarizes the other input parameters of the calculations made in Ref. [24]. The water hammer pressure is used to normalize the stresses to non-dimensional numbers. Figure 4 , adapted from Ref. [24] shows a snapshot of the non-dimensional stress $S_{R R}$ at time $t=0.05$ $\mu$ s after impact. The sharp peak near the surface corresponds to the Rayleigh wave front at $r=224 \mu \mathrm{m}$. The boundary of the loaded area is $r_{p}=v\left(d_{d} v_{d} t\right)=213 \mu \mathrm{m}$. The effect of a coating on the results follows from Figure 5, also adapted from Ref. [24], showing the stresses $S_{R R}$ and $S_{\theta \theta}$ at the surface as a function of the radial distance, in which the symbols " $B$ ", " $R$ ", and " $L$ " refer to the boundary of the loaded area, Rayleigh wave front, and longitudinal wave front, respectively. From this figure it shows that at that time $\mathrm{t}=0.05 \mu \mathrm{s}$ an annular strip with high tensile stresses is formed between the edge of the loaded area and the Rayleigh wave front. This annular strip has a width of about $15 \mu \mathrm{m}$. The normalized $S_{R R}$ tensile stresses in this strip vary from 1.5 to 3.0 [-]. The presented results for thin hard elastic coatings are in-line with the analytical solution for the uncoated case and show similar 
behaviour for the coated case. The location and singular behaviour of the Rayleigh wave front are found from the pressure model and show to be independent of the coating thickness. The region directly below the contact area is in pure compression. Since the stresses cannot have infinite magnitude in real impact situations, the singularity in the work of Ref. [24] may be due to the abrupt change of pressure model at the impact boundary.

Table 1. System and material properties used in Ref. [24].

\begin{tabular}{|l|l|l|c|c|}
\hline Properties & Symbol & unit & Coating & Substrate \\
\hline Material & & & - & ZnSe \\
Thickness & $\mathrm{h}$ & $(\mu \mathrm{m})$ & 43 & Half space \\
Density & $\rho$ & $\left(\mathrm{kg} / \mathrm{cm}^{3}\right)$ & 6.59 & 5.27 \\
Young's modulus & $\mathrm{E}$ & $(\mathrm{MPa})$ & 171 & 67.4 \\
Poisson's ratio & $v$ & $(-)$ & 0.3 & 0.3 \\
Longitudinal wave speed & $\mathrm{c}_{1}$ & $(\mathrm{~m} / \mathrm{s})$ & 5910 & 4150 \\
Transverse wave speed & $\mathrm{c}_{2}$ & $(\mathrm{~m} / \mathrm{s})$ & 3160 & 2220 \\
Rayleigh wave speed & $\mathrm{c}_{3}$ & $(\mathrm{~m} / \mathrm{s})$ & 2930 & 2058 \\
Transverse wave speed ratio & $\mathrm{s}_{2}$ & & 0.535 & 0.535 \\
Rayleigh wave speed ratio & $\mathrm{s}_{3}$ & & 0.496 & 0.496 \\
\hline
\end{tabular}

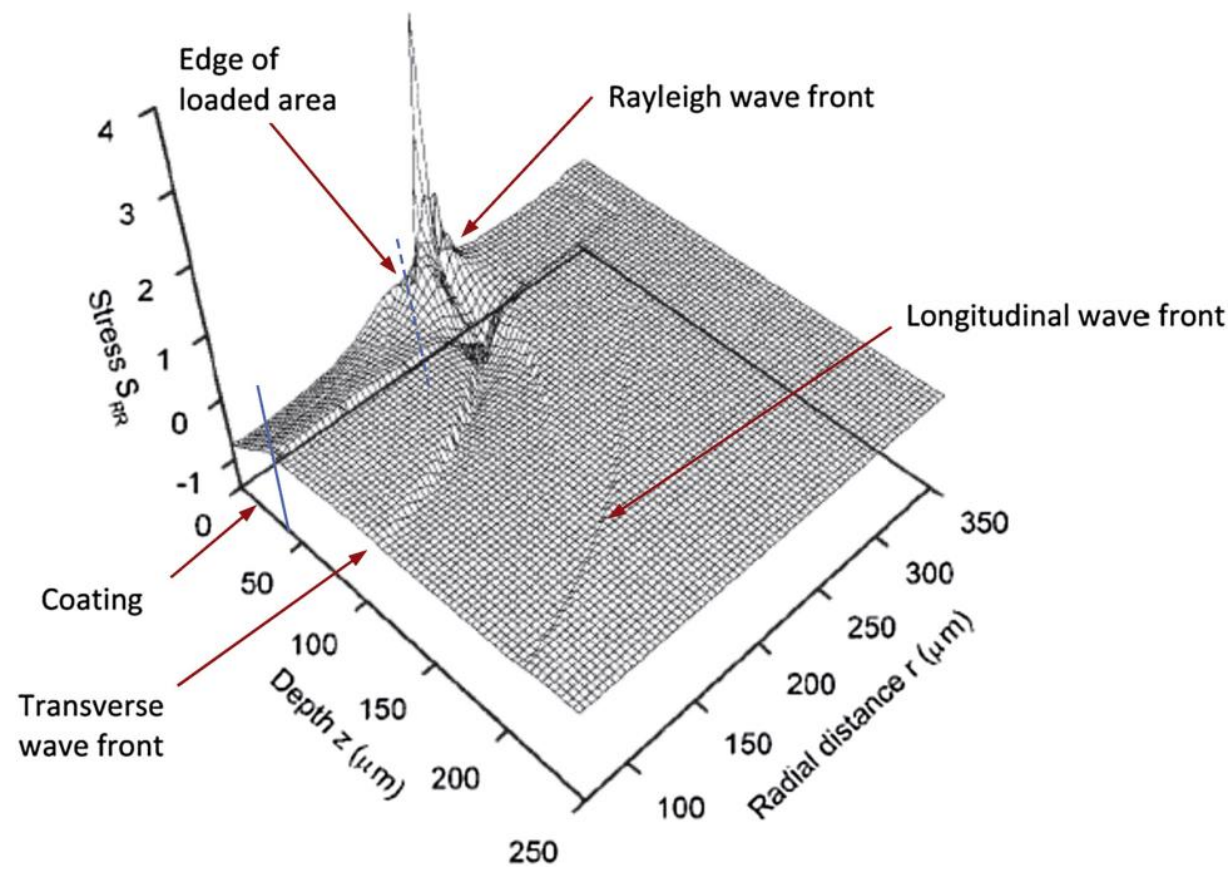

Figure 4. Plot of the normalized stress $S_{R R}$ as a function of radial distance ( $r$ ) and depth (z) at $t=0.05 \mu \mathrm{s}$. Adapted from Ref. [24]. 


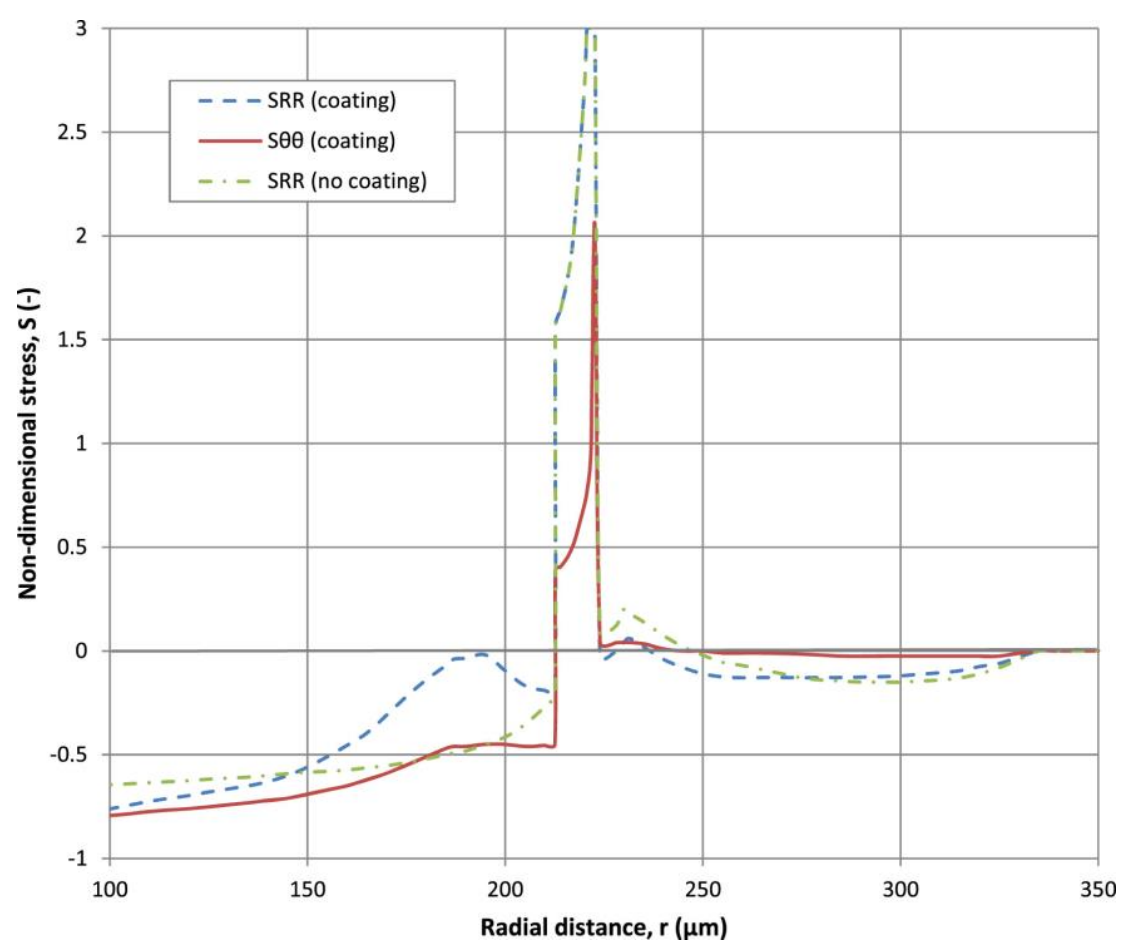

Figure 5. Variation of the non-dimensional stresses $S_{R R}$ and $S_{\theta \theta}$ as functions of the radial distance $(r)$ at the surface for $t=0.05 \mu \mathrm{s}$. Solid line with marks corresponds to $S_{R R}$ when there is no coating and the substrate is filled with the same material as coating. Adapted from Ref. [24].

Numerical results with thick compliant coatings are presented in the work of Adler and Mihora [29-31] based on finite element analysis of a water droplet impacting a structured target material. Major difference with thin hard elastic coatings is that deep craters develop in impacted polyurethane coatings which probably alters the evolving water drop shape, substantially. The same probably holds when the influence of surface roughness is taken into account. Furthermore, both the water drop and the polyurethane layer simultaneously undergo large strains and displacements. Calculations presented in Refs. [29-31] clearly show that impact by a single water droplet at relatively high impact velocity cannot initiate failure for a range of polyurethane coatings, neither by increasing the water droplet diameter nor by changing of the contact angle. This can be explained from the calculated elongations (strains) in the FE model. The calculated tensile strains now reach $80 \%$ in some cases. However, tensile failures are not predicted since even the weakest polyurethane material exhibited $210 \%$ strain to failure at dynamic loading conditions. The results further indicate that the time to reach the maximum tensile 
strains now reaches 4-8 $\mu$ s which is much longer in comparison to hard materials. Even with these relatively long time frames, strain rates exceeding $2.5 \times 10^{5} \mathrm{~s}^{-1}$ were calculated. Compared to metals and ceramics the transverse and Rayleigh stress waves in polyurethanes travel at very low velocities.

For very hard materials the peak transient stresses occur early in the water drop deformation cycle before there is significant lateral outflow as the drop is collapsing onto the surface. By contrast, the maximum stresses in the polyurethane layers develop late in the water drop distortion cycle when severe distortions of the drop are present. The angle of attack $\theta$ affects the stress situation as well, by decreasing the impact velocity of the droplet, in the direction normal to the surface, roughly with $\sin \theta[32]$.

\subsection{Wear mechanism}

The relevance of the analytical results in relation to surface damage of uncoated materials is demonstrated by Adler [33] and Hackworth [34], based on experimental results with zinc selenide, zinc sulphide, and gallium arsenide. Single water drop impacts are generated with 0.7, 2.0, and $2.5 \mathrm{~mm}$ diameter drops and impact velocities of 222 and $341 \mathrm{~m} / \mathrm{s}$. Each single-drop impact produced a ring fracture pattern. Similar results are described [35] for polymeric matrix composites of which a schematic micrograph acquired in the vicinity of a liquid impact site is shown in Figure 6 . The crack length $C_{a}$, inner damage radius $r_{\text {min }}$, and outer damage radius $r_{\max }$ are depicted in the figure. These characteristics can be influenced by the type of material that is used, but also by fillers [35].

Model calculations predict radial tensile stresses which greatly exceeded the ultimate strength of the materials for the experimental conditions, see Table 2. 


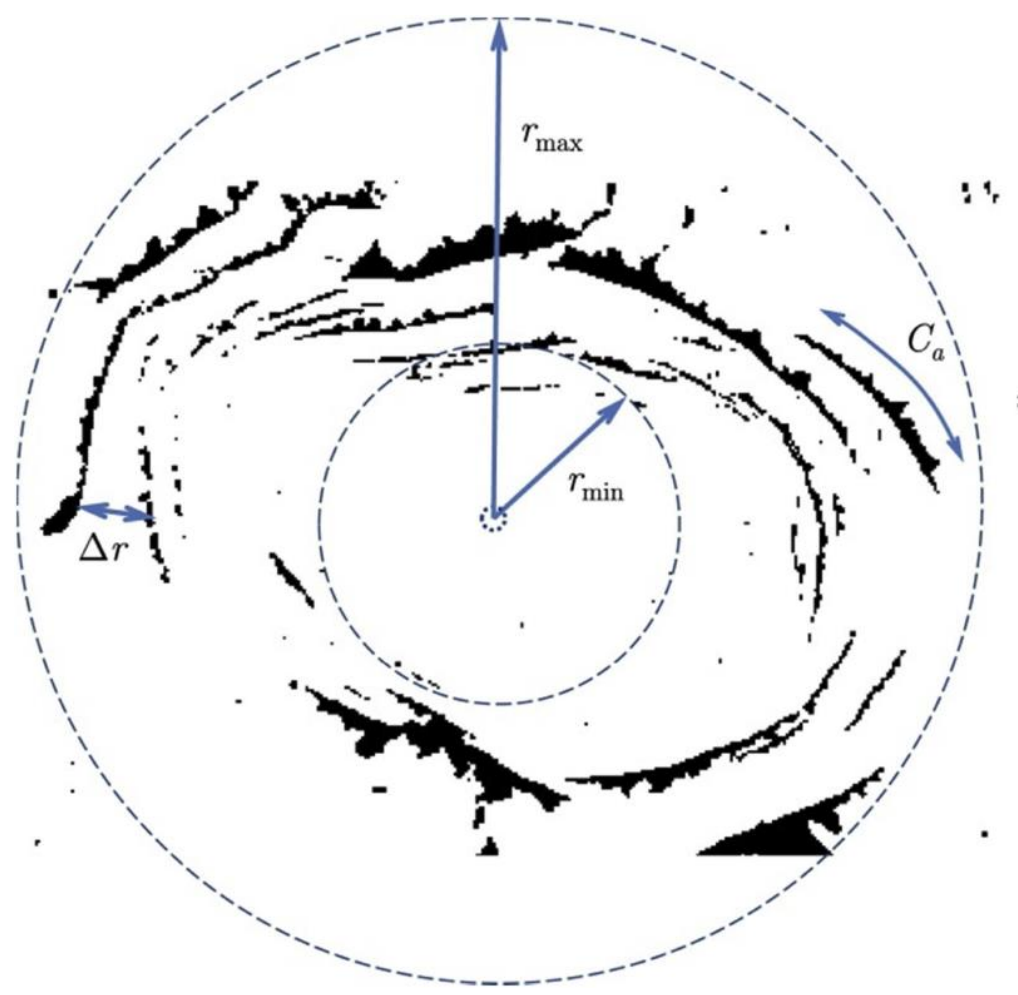

Figure 6. Schematic image of the damage near the impact. The crack length $C_{a}$, inner damage radius $r_{\min }$, and other damage radius $r_{\max }$ are depicted in the figure. Adapted from Ref. [35].

Table 2. The highest (peak) radial tensile stress $\left(\sigma_{r r, \max }\right)$ predicted for each impact case. The ultimate flexural strength of ZnSe, ZnS and GaAs are $58 \mathrm{MPa}, 110 \mathrm{MPa}$ and $140 \mathrm{MPa}$ [34].

\begin{tabular}{|cc|c|c|c|c|}
\hline \multicolumn{2}{|l|}{$\begin{array}{c}\text { Impact velocity, } v_{d}(\mathrm{~m} / \mathrm{s}): \\
\text { Depth. } z(\mu \mathrm{m}):\end{array}$} & \multicolumn{2}{|c|}{222} & \multicolumn{2}{|c|}{341} \\
\hline Material type & $\begin{array}{c}\text { Drop size } \\
\mathrm{d}_{\mathrm{d}}(\mathrm{mm})\end{array}$ & \multicolumn{4}{|c|}{ Highest radial tensile stress, } \\
& 0.7 & 188 & 103 & 464 & 240 \\
\hline ZnSe & 2.0 & 369 & 214 & 973 & 524 \\
& 2.5 & 442 & 240 & & 614 \\
\hline ZnS & 0.7 & & 79 & & 207 \\
& 2.0 & 285 & 196 & 757 & 475 \\
& 2.5 & & 230 & & \\
\hline GaAs & 2.0 & 374 & 200 & & 456 \\
\hline
\end{tabular}


The analytical model describes the surface related nature of the damage caused by a single-drop impact. Figure 7 for example shows the maximum value of the radial tensile stress as a function of depth below the surface for a $2.0 \mathrm{~mm}$ drop impacting zinc selenide at $222 \mathrm{~m} / \mathrm{s}$. For each depth, the stress at several radial locations is computed and the maximum value selected for this curve. The radial stress exceeds the ultimate bending strength of the material over a depth of about $100 \mu \mathrm{m}$. This correlated well with the $140 \mu \mathrm{m}$ depth of the actual cracks measured in the experimental programme given in Ref. [35].

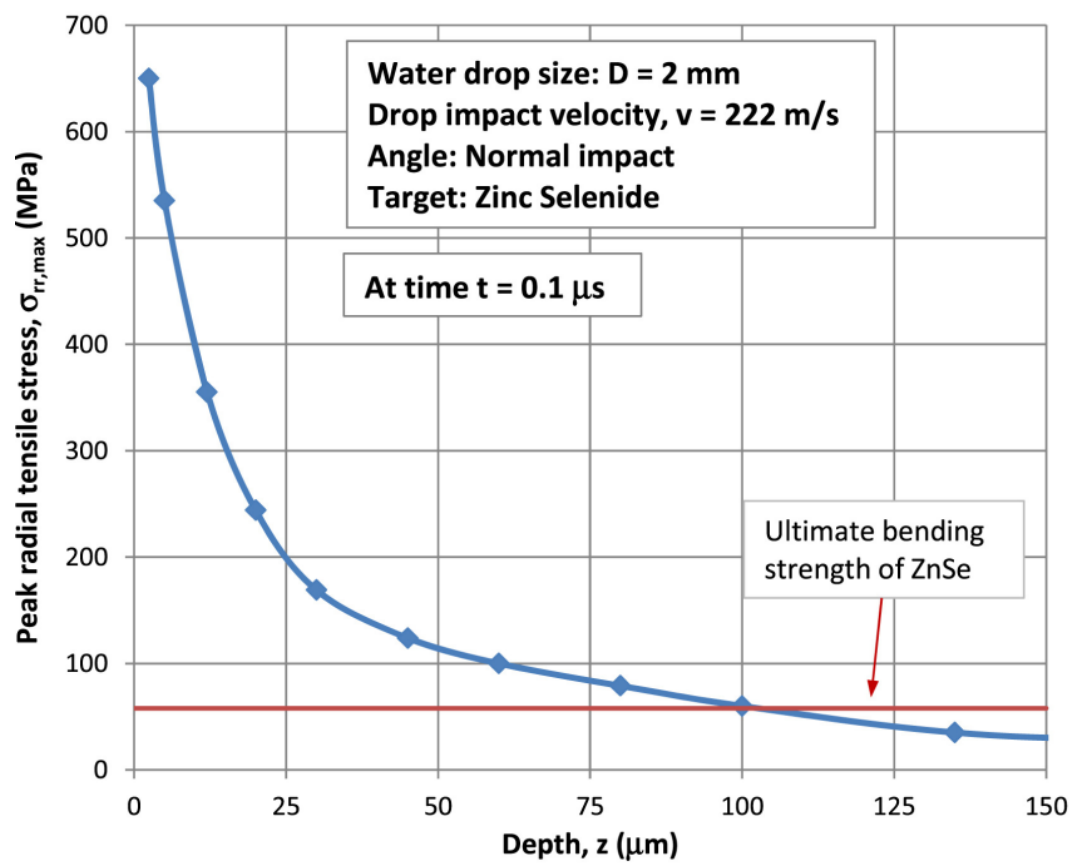

Figure 7. Variation of peak radial stress, at time $t=0.1 \mu \mathrm{s}$, with depth for a $2.0 \mathrm{~mm}$ water drop impacting Zinc Selenide at $v_{d}=222 \mathrm{~m} / \mathrm{s}$.

Experimental results [34] show that the radial location and the approximated magnitude of the peak stress, changes with the size of the water droplet and with the impact velocity. For this class of relatively brittle materials and operational conditions, damage within the material originates from overloading or surface fatigue at a low number of stress cycles. In most cases the impact of one droplet is enough to cause brittle failure at a local scale. 
Experimental results for uncoated $12 \% \mathrm{Cr}$-steel and Stellite 6B, and for coated with a $1.2 \mu \mathrm{m}$ thin layer of TiN are presented by Lee et al. [18,36], see Figure 8 for a summary of the experimental results [18]. The first 100 droplet impacts on TiN coated samples did not reveal any wear due to cracks. Plastic deformation of the substrate material near the interface of the coating however occurred in these experiments, giving rise to a certain deformation depth. For uncoated $12 \% \mathrm{Cr}$ steel damage occurs, yet Figure 8 shows that it takes some impacts to initiate removal of material. This is commonly referred to as incubation time. Both observations point at surface fatigue - removal of wear particles detached by fatigue crack growth arising from cyclic stress variations [11] - as wear mechanism. Damage is initiated after a low number of stress cycles for $12 \% \mathrm{Cr}$ steel and a higher number of cycles for TiN coated material. The beneficial effect of the TiN coating could be predicted qualitatively based on a modified Blowers model, incorporating reflection of stress waves at the coating-substrate interface [18].

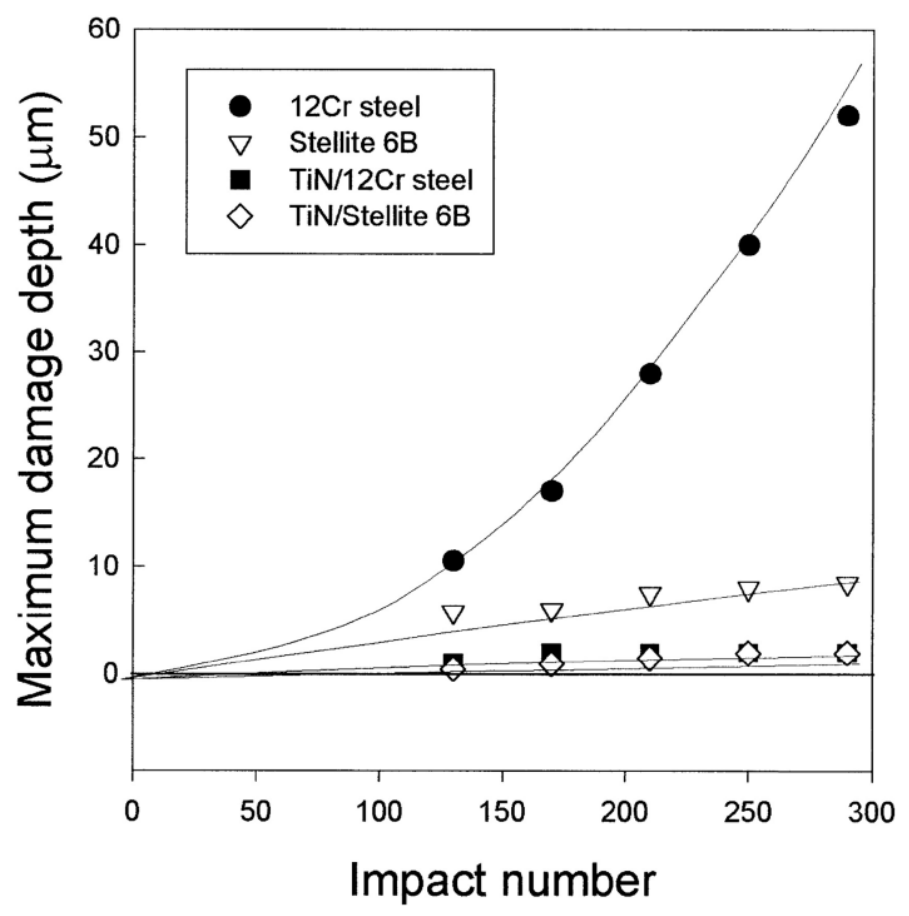

Figure 8. Maximum damage depth with an increasing number of impacts for $12 \mathrm{Cr}$ steel, Stellite $6 B$, TiN-coated $12 \mathrm{Cr}$ steel, and TiN-coated Stellite $6 \mathrm{~B}$ at an impact velocity of $350 \pm$ $20 \mathrm{~m} / \mathrm{s}$. Adapted from Ref. [18]. 
The magnitude of the stress cycle at the coating-substrate interface decreases with increasing coating thickness. The results of Ref. [18] suggest that by lowering the maximum stress below the fatigue endurance strength of the blade materials it is possible to extend the lifetime of the blade with respect to impact wear.

The presented numerical results for the polyurethane coated surfaces $[29,30]$ showed that the predicted stresses and strains remain well below the values that cause failure. Instead of brittle fracture or tearing it is hypothesized by Ref. [29] that repeated large strains may lead to fatigue initiation as the nucleating mechanism for erosion damage. This is in line with high cycle surface fatigue as origin of the damage.

\subsection{An engineering approach to surface fatigue caused by impact of water droplets}

Surface fatigue or fatigue wear is characterized by removal of particles detached by fatigue arising from cyclic stress variations [11]. The maximum of the stress cycle $S_{\max }$ at the surface follows from the Rayleigh surface wave, described in a general form, using cylindrical coordinates, by:

$$
\begin{aligned}
& S_{\text {max }}=\frac{A}{r^{n}} \\
& n=0.5 \\
& A=f\left(v_{d}, d_{d},(\rho . c)_{\text {coating }}\right)
\end{aligned}
$$

The numerator $A$ of Eq. (4) is a function of the impact conditions, i.e. the water drop impact velocity, the water drop diameter and the material acoustic properties of the coating $(\rho . c)_{\text {coating. }}$.

The stress cycle at the surface due to the Rayleigh surface wave starts at a certain distance from the impact centre, in the present work indicated by the index 0 , i.e. at radial coordinate $r=r_{0}$. At radial coordinate $r=r_{1}$ the stress cycle is thought to be attenuated to a local maximum stress level $S_{\max }=S_{\max , 1}$, just below the level at which any significant fatigue damage is expected. Similar to $A, \mathrm{r}_{0}$ also depends on the impact conditions, i.e. the water drop impact velocity, and the water drop diameter. The maximum stress as a function of the distance from the impact centre is depicted in Figure 9 for the case of $A=65 \mathrm{MPaVmm}$. 


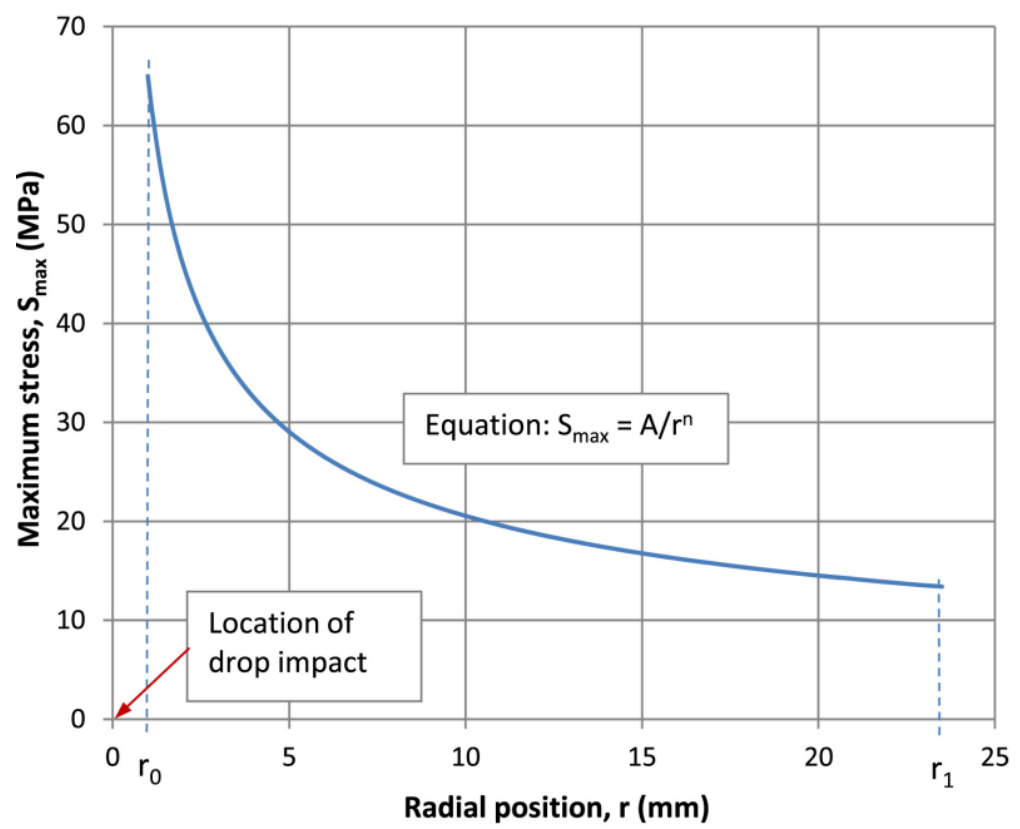

Figure 9. The attenuation of the maximum stress of the fatigue stress cycle as a function of the distance ( $r$ ) to point of drop impact. It is assumed that Rayleigh surface wave starts at $r$ $=r_{0}$ and only causes damage within the area with a radius $r=r_{1}$.

In this work, a random uniform distribution of droplet impact at the blade surface is assumed. As such, for a point located at the origin, only drop impact within the area with a radius $r=r_{1}$ results in a stress cycle that can generate damage related to surface fatigue.

The total number of rain drop impacts on the area per hour, is related to the rain intensity $I_{r}$, i.e. the amount of rain in $\mathrm{mm} /$ hour and the rain drop diameter. This in turn depends heavily on the local meteorological conditions, thus on the off-shore location of the turbine. As such, the radial distribution of drop impacts $n_{S}$ per hour as a function of the local maximum stress $\left(S_{\max , 1}\right)$, can be given only with a term $C_{1}$ :

$$
n_{S}=C_{1}\left(\frac{A}{S_{\max , 1}}\right)^{\frac{1}{n}} \quad C_{1}=f\left(I_{r}, d_{d}\right)
$$


The term $C_{1}$ equals $12 I_{r} / d_{d}{ }^{3}$, for the specific case of a uniform droplet size. The life of the coating can now be estimated based on the linear cumulative damage rule of Palmgren-Miner $[37,38]$. This damage rule is widely used and standardized for fatigue lifetime calculations of roller bearings [39], but also for welded steel constructions for bridges and vessels $[40,41]$.

The basic equation in Palmgren-Miner rule is given by Eq. (6):

$$
D=\sum_{i=1}^{k} \frac{n_{i}}{N_{i}}
$$

In which $\mathrm{D}$ is the accumulated amount of damage, $N_{i}$ is the amount of cycles to failure at stress level $i$ and $n_{i}$ the amount of cycles that have occurred at stress level $i$.

For the case of droplet impingement this equation reads:

$$
D_{h}=\int_{S_{\max (r 1)}}^{S_{\max (r 0)}} \frac{n_{S}}{N} d S_{\max }
$$

with $D_{h}=$ cumulative fatigue damage per hour and $n_{S}$ given by Eq. (5).

The fatigue properties of the coating material for a stress level $i$ and for the specific conditions of rain drop impact can be expressed as:

$$
S_{\max , i}=h_{t o t} S_{f} N_{i}^{-1 / m}
$$

which $h_{\text {tot }}$ corrects for the differences between the standardized fatigue tests conditions and the actual rain impact conditions. The material parameters $m$ and $S_{f}$ are commonly used for fatigue studies.

The fatigue limit $S_{D, i}$ for the actual rain conditions is given by:

$$
S_{D, i}=h_{t o t} S_{D}
$$


with $S_{D}$ being the fatigue limit at standardized fatigue test conditions. In this approach the number of fatigue cycles to failure in a fatigue test $\left(N_{f}\right)$ equals the number of fatigue cycles of the incubation time $\left(N_{i}\right)$

With these equations one can derive an expression for the cumulative fatigue damage per hour:

$$
\begin{aligned}
& D_{h}=\int_{S_{\max (r 1)}}^{S_{\max (r 0)}} \frac{C_{1}\left(\frac{A}{S_{\max }}\right)^{\frac{1}{n}}}{\left(\frac{h_{t o t} S_{f}}{S_{\max }}\right)^{m}} d S_{\max } \\
& D_{h}=C_{1} \frac{(A)^{\frac{1}{n}}}{\left(h_{t o t} S_{f}\right)^{m}} \int_{S_{\max (r 1)}}^{S_{\max (r 0)}} S_{\max }\left(m-\frac{1}{n}\right) d S_{\max }
\end{aligned}
$$

for Rayleigh waves $n$ equals 0.5 , thus

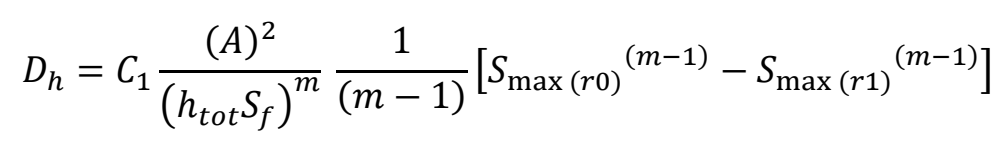

With $S_{\max (r 1)}=S_{D, i}$, and Eq. 9 gives: $\quad S_{\max (r 1)}=h_{t o t} S_{D}$

$$
D_{h}=C_{1} \frac{(A)^{2}}{\left(h_{t o t} S_{f}\right)^{m}} \frac{1}{(m-1)}\left[S_{\max (r 0)}{ }^{(m-1)}-h_{t o t} S_{D}^{(m-1)}\right]
$$

The rain erosion incubation period can now be defined as:

$$
I_{p}=\frac{D_{f}}{D_{h}}
$$

With $I_{p}$ the rain erosion incubation time and $D_{f}$ the cumulative fatigue damage at failure. As $D_{f}$ reads 1 , based on the Palmgren-Miner theory, it is possible to construct a life equation for the leading edge:

$$
I_{p}=\frac{(m-1)\left(h_{t o t} S_{f}\right)^{m}}{C_{1}(A)^{2}} \frac{1}{\left[S_{\max (r 0)^{(m-1)}}-h_{t o t} S_{D}^{(m-1)}\right]}
$$


$I_{p}$ is defined with the assumption that $S_{\max (r 0)}>h_{t o t} S_{D}$. For the complementary condition: $S_{\max (r 0)} \leq h_{t o t} S_{D}$ Eq. (15) reads $I_{p} \rightarrow \infty$. This implies that fatigue damage will not accumulate to surface fatigue failure for droplet impact conditions resulting in a Rayleigh wave with a highest stress $S_{\max (r 0)} \leq h_{t o t} S_{D}$.

\subsection{Surface fatigue and experimental results}

The relation between (surface) fatigue properties of a material or coating and the incubation lifetime for liquid impingement erosion is first constructed by Springer [42], based on a large database of e.g. whirling arm tests. Three stages are distinguished:

1. an incubation period, in which the surface is virtually unaffected;

2. the steady-state erosive wear stage where the surface wears at a relatively high wear-rate;

3. the final erosion stage with a strongly reduced wear-rate due to the higher surface roughness, which was produced in the second phase.

Figure 10 graphically shows the first two stages based on the erosion depth as a function of time.

The time from incubation to a certain erosion depth is typically much shorter than the time covered by the incubation period itself. This is especially true for coated systems, in which the erosion depth is limited to the thickness of the coating. Therefore, it is usually assumed that the end of the coating life is reached, the moment a particle is detached from the surface. The incubation period is therefore taken as an estimate for the coating life in this work. The blade span-wise locations at which the life of the coating are reached, can now be calculated from the velocity profile over the leading edge. Leading edge erosion typically starts at the tip of the blade, as the droplet impact velocity is at its maximum. The droplet impact velocity reduces towards the centre of rotation and as such cumulative damage occurs at a lower stress level.

The slope of the erosion vs. time curve, the second stage is an important characteristic of materials in case low cycle fatigue is dominant, e.g. in case of extreme stress levels. Figure 11 shows the cumulative weight loss of 8 steel types, with varying hardness levels between 103 and $327 \mathrm{HV}$, extracted from Ref. [56]. 


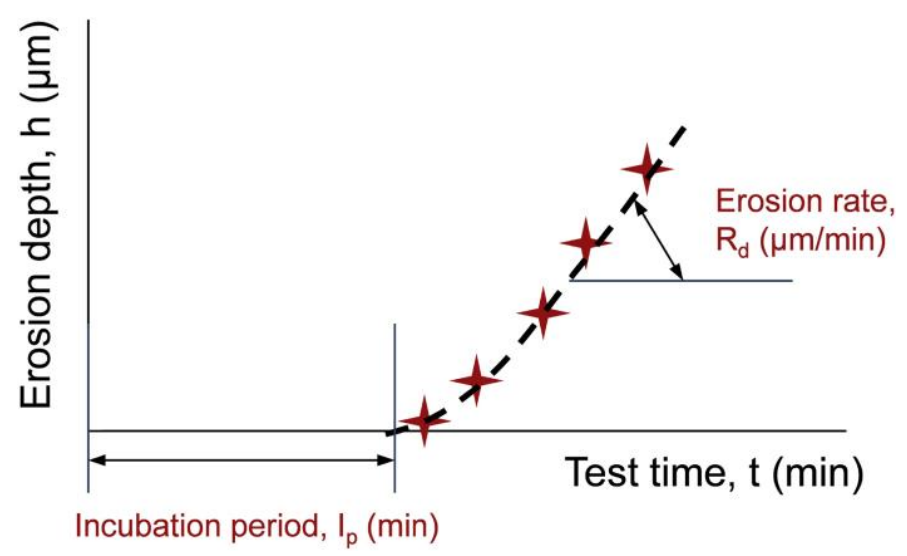

Figure 10. Schematic representation of impingement wear showing the incubation period and the stage with a constant erosion rate.

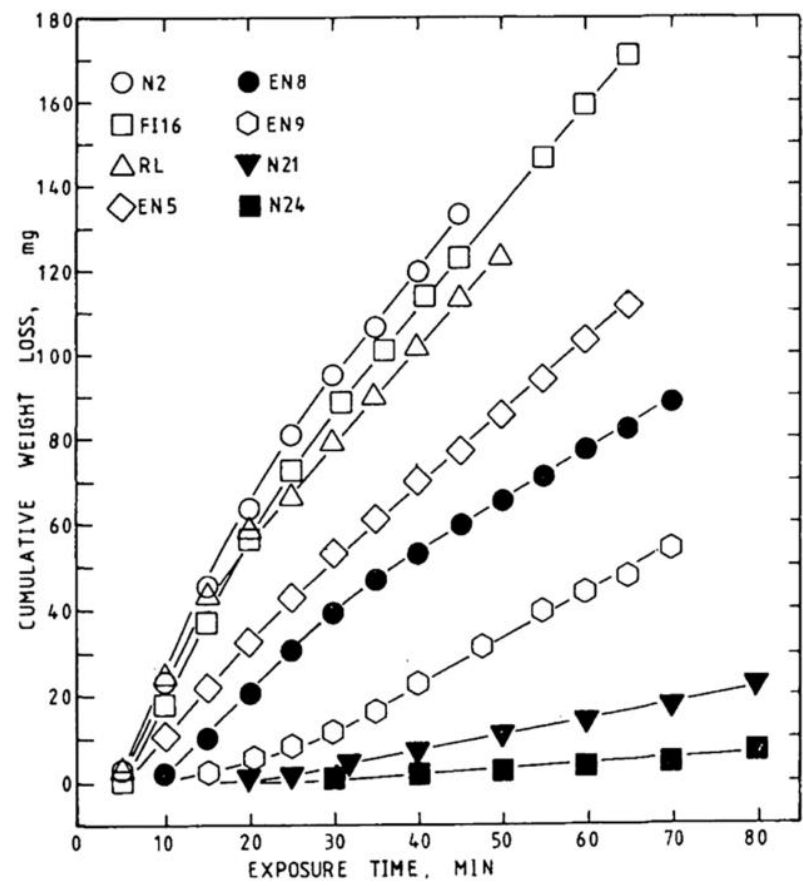

Steel properties

\begin{tabular}{|c|c|c|}
\hline $\begin{array}{c}\text { Steel } \\
\text { type }\end{array}$ & $\begin{array}{c}\text { Carbon } \\
\text { content } \\
\text { (wt\%) }\end{array}$ & $\begin{array}{c}\text { Hardness } \\
\text { Vickers } \\
\text { (HV) }\end{array}$ \\
\hline N2 & 0.03 & 103 \\
RL & 0.08 & 114 \\
F16 & 0.11 & 132 \\
En5 & 0.31 & 169 \\
En8 & 0.41 & 181 \\
En9 & 0.53 & 215 \\
N21 & 0.73 & 270 \\
N24 & 1.33 & 327 \\
\hline
\end{tabular}

Figure 11. Cumulative weight loss of 8 steel types with varying hardness levels due to liquid impingement erosion. (Exposure time scale in minutes.) Droplet impact velocity, $v=200 \mathrm{~m} / \mathrm{s}$ (perpendicular to the specimen surface), specimen eroding area: $\emptyset 12 \mathrm{~mm}$. Source: Ref [56]. 


\section{Coating life and material selection}

\subsection{Counter measures to surface fatigue}

From Section 2 it is concluded that the coating life is determined mainly by surface fatigue. Based on literature it was possible to derive an equation from which the coating life can be estimated, i.e. Eq. (15). Although some terms in this equation need additional research to be of similar high value as currently in ISO 281 [39], it does give a clear direction for material selection to protect turbine blades from leading edge erosion: coatings need to be optimized with respect to fatigue life. The fatigue life of surfaces can be expressed with a Wöhler curve, similar to the fatigue life of bulk materials, see Figure 12. From this figure it is clear that lower stress levels are associated with higher fatigue life for a given material. This wear mechanism can be neglected at stress levels below the fatigue limit of the material. General counter measures to minimize the risk of surface fatigue wear are:

1. Reduction of the pressure, e.g. by applying surfaces with a low modulus of elasticity;

2. Enlarging the safe area by:

a. applying coatings with adjustable compressive stresses

b. applying coatings with adjustable hardness

c. preventing defects and impurities in the layer.

These general rules to reduce fatigue wear are based on either reducing the stress preferably below the fatigue limit, or material selection that causes a shift of the Wöhler curve to a higher number of stress cycles or to a high stress level. Both strategies are discussed below. 


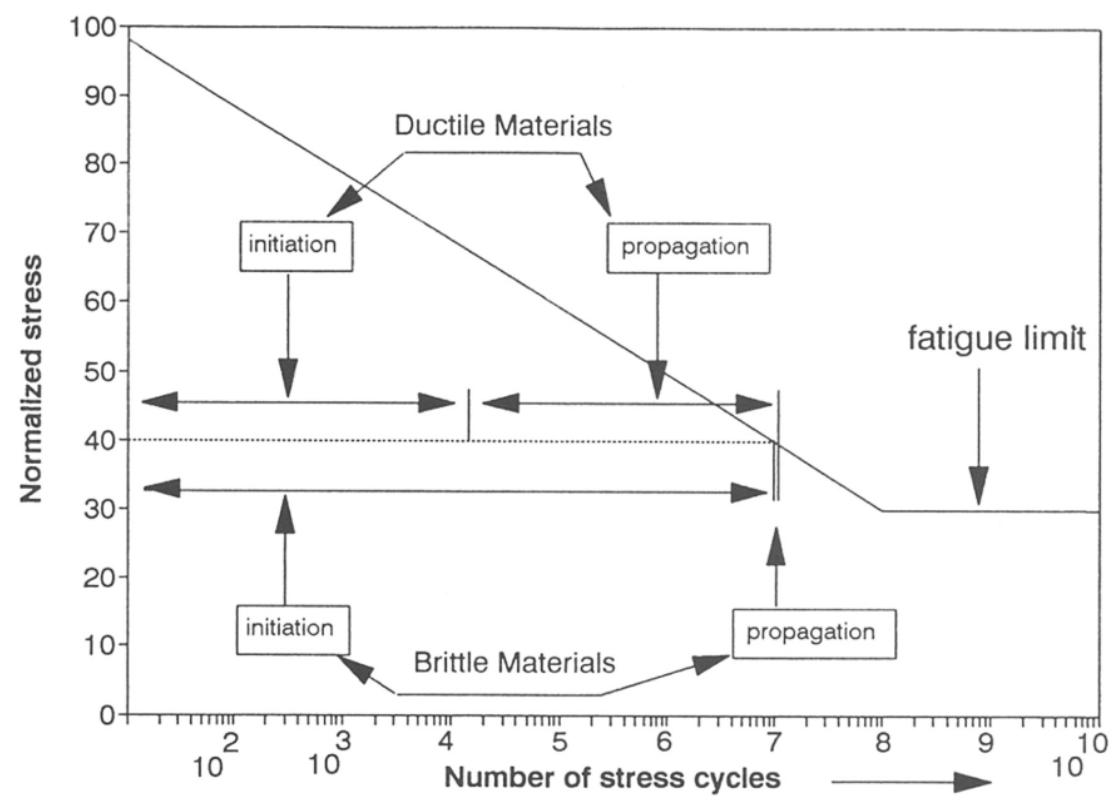

Figure 12. Wöhler curve. Extracted from Ref. [57].

\subsection{Reducing the stresses caused by Rayleigh waves}

The maximum stress at the surface due to Rayleigh waves is determined by the water-hammer pressure $\left(p_{w h}\right)$ which in turn depends on the acoustic properties of the liquid and the acoustic properties of the surface material, see also Eq. (1). An overview of acoustic material properties, largely based on the information presented by Refs. [42-45] is given in Table 3. Table 3 gives an overview of the density, Young's modulus, acoustic velocity, dynamic or acoustic impedance and the combined or reduced dynamic or acoustic impedance $\left(Z_{r}=p_{w h} / v_{d}\right)$.

The relative impact pressure $\left(p_{w h} / v_{d}\right)$ can be used to identify to which extend certain material classes reduce the water-hammer pressure and corresponding maximum stress due to the Rayleigh wave, see Figure 13. A substantial lower impact pressure due to droplet impact is expected for low and very low stiffness materials such as certain polymers and elastomers and rubbers. 
Table 3. Acoustic material properties for materials and classes of materials.

\begin{tabular}{|c|c|c|c|c|c|}
\hline & $\begin{array}{c}\text { Density } \\
\rho\left(\mathrm{kg} / \mathrm{m}^{3}\right)\end{array}$ & $\begin{array}{c}\text { Young's } \\
\text { modulus } \\
\text { E (MPa) }\end{array}$ & $\begin{array}{c}\text { Speed of } \\
\text { sound } \\
c_{1}(\mathrm{~m} / \mathrm{s})\end{array}$ & $\begin{array}{c}\text { Dynamic } \\
\text { impedance } \\
\mathrm{Z}(\mathrm{MPa} \mathrm{s} / \mathrm{m})\end{array}$ & $\begin{array}{c}\mathrm{Z}_{\mathrm{r}} \\
(\mathrm{MPa} \mathrm{s} / \mathrm{m})\end{array}$ \\
\hline Water & 1000 & & 1480 & 1.48 & \\
\hline \multicolumn{6}{|l|}{ Metals } \\
\hline Magnesium & 1800 & 45000 & 5000 & 9.0 & 1.44 \\
\hline Aluminium (alloys) & 2700 & 70000 & 5092 & 13.7 & 1.53 \\
\hline Titanium (alloys) & 4430 & 115000 & 5095 & 22.6 & 1.60 \\
\hline Steel & 7850 & 205000 & 5110 & 40.1 & 1.65 \\
\hline Copper (alloys) & 8000 & 130000 & 4031 & 32.2 & 1.63 \\
\hline Nickel & 8890 & 204000 & 4790 & 42.6 & 1.65 \\
\hline Nickel alloys & 8200 & 218000 & 5156 & 42.3 & 1.65 \\
\hline Cobalt (CoCr-alloys) & 8590 & 225000 & 5118 & 44.0 & 1.66 \\
\hline Cobalt (Stellite 6B) & 8390 & 215000 & 5062 & 42.5 & 1.65 \\
\hline Tin & 7300 & 41200 & 2376 & 17.3 & 1.56 \\
\hline Zinc & 7140 & 88300 & 3517 & 25.1 & 1.61 \\
\hline $\operatorname{Zinc}\left(\mathrm{Zn}-\mathrm{Al}_{4}\right)$ & 6600 & 130000 & 4438 & 29.3 & 1.62 \\
\hline Lead & 11300 & 17700 & 1252 & 14.1 & 1.53 \\
\hline \multicolumn{6}{|l|}{ Fibres } \\
\hline E-glass fibre & 2540 & 70000 & 5250 & 13.3 & 1.52 \\
\hline S-glass fibre & 2490 & 85000 & 5843 & 14.5 & 1.54 \\
\hline HM-aramid fibre & 1450 & 130000 & 9469 & 13.7 & 1.53 \\
\hline SM-carbon-fibre & 1800 & 230000 & 11304 & 20.3 & 1.59 \\
\hline HM-carbon-fibre & 1850 & 390000 & 14519 & 26.9 & 1.62 \\
\hline \multicolumn{6}{|l|}{ Resins } \\
\hline UP-resin (low E) & 1150 & 2400 & 1445 & 1.7 & 0.85 \\
\hline UP-resin (high E) & 1250 & 4600 & 1918 & 2.4 & 1.00 \\
\hline EP-resin (low curing) & 1175 & 3500 & 1726 & 2.0 & 0.93 \\
\hline EP-resin (high curing) & 1250 & 3500 & 1673 & 2.1 & 0.94 \\
\hline UD fibre/epoxy; $v_{f}=60 \%$ & & $\mathrm{E}_{\mathrm{T}}$ & & & \\
\hline E-glass/epoxy & 2000 & 10000 & 2236 & 4.5 & 1.24 \\
\hline HM-aramid/epoxy & 1350 & 5500 & 2018 & 2.7 & 1.05 \\
\hline SM-carbon/epoxy & 1550 & 9000 & 2410 & 3.7 & 1.18 \\
\hline \multicolumn{6}{|l|}{ Polymers } \\
\hline LDPE & 920 & 400 & 659 & 0.61 & 0.45 \\
\hline UHMWPE & 945 & 800 & 920 & 0.87 & 0.58 \\
\hline PTFE & 2180 & 490 & 474 & 1.03 & 0.65 \\
\hline PA6.6 & 1140 & 1800 & 1257 & 1.43 & 0.78 \\
\hline PPO & 1080 & 2550 & 1537 & 1.66 & 0.84 \\
\hline PC & 1200 & 2400 & 1414 & 1.70 & 0.85 \\
\hline PMMA & 1185 & 3000 & 1591 & 1.89 & 0.90 \\
\hline PES & 1370 & 2700 & 1404 & 1.92 & 0.91 \\
\hline POM-C & 1410 & 3000 & 1459 & 2.06 & 0.94 \\
\hline POM-H & 1430 & 3300 & 1519 & 2.17 & 0.96 \\
\hline $\mathrm{PI}$ & 1430 & 3100 & 1472 & 2.11 & 0.95 \\
\hline PETP & 1390 & 3400 & 1564 & 2.17 & 0.96 \\
\hline PEEK & 1320 & 4200 & 1784 & 2.35 & 0.99 \\
\hline PPS & 1430 & 4400 & 1754 & 2.51 & 1.02 \\
\hline \multicolumn{6}{|l|}{ Ceramics } \\
\hline $\mathrm{Al}_{2} \mathrm{O}_{3}$ & 3800 & 360000 & 9733 & 37.0 & 1.64 \\
\hline $\mathrm{SiC}$ & 3000 & 400000 & 11547 & 34.6 & 1.64 \\
\hline
\end{tabular}




\begin{tabular}{|c|c|c|c|c|c|c|}
\hline $\mathrm{Si}_{3} \mathrm{~N}_{4}$ & & 3200 & 280000 & 9354 & 29.9 & 1.63 \\
\hline $\mathrm{ZrO}_{2}$ & & 6000 & 200000 & 5774 & 34.6 & 1.64 \\
\hline Diamond & & 3500 & 440000 & 11212 & 39.2 & 1.65 \\
\hline Normal glass & & 2500 & 69000 & 5254 & 13.1 & 1.52 \\
\hline Polycrystalline glass & & 2600 & 120000 & 6794 & 17.7 & 1.57 \\
\hline \multicolumn{7}{|l|}{ Elastomers \& rubbers } \\
\hline Natural rubber & NR & 920 & 25 & 165 & 0.15 & 0.14 \\
\hline Styrene-butadiene rubber & SBR & 910 & 300 & 574 & 0.52 & 0.40 \\
\hline Nitrile rubber & NBR & 1000 & & & & \\
\hline Neoprene (chloroprene) & & 1240 & 40 & 180 & 0.22 & 0.20 \\
\hline Polyurethane (low) & PUR & 1150 & 10 & 93 & 0.11 & 0.10 \\
\hline Polyurethane & PUR & 1150 & 75 & 255 & 0.29 & 0.25 \\
\hline Polyurethane (high) & PUR & 1150 & 300 & 511 & 0.59 & 0.44 \\
\hline Thermoplastic rubber & SBS & 950 & & & & \\
\hline Silicone rubber & & 1100 & & & & \\
\hline
\end{tabular}

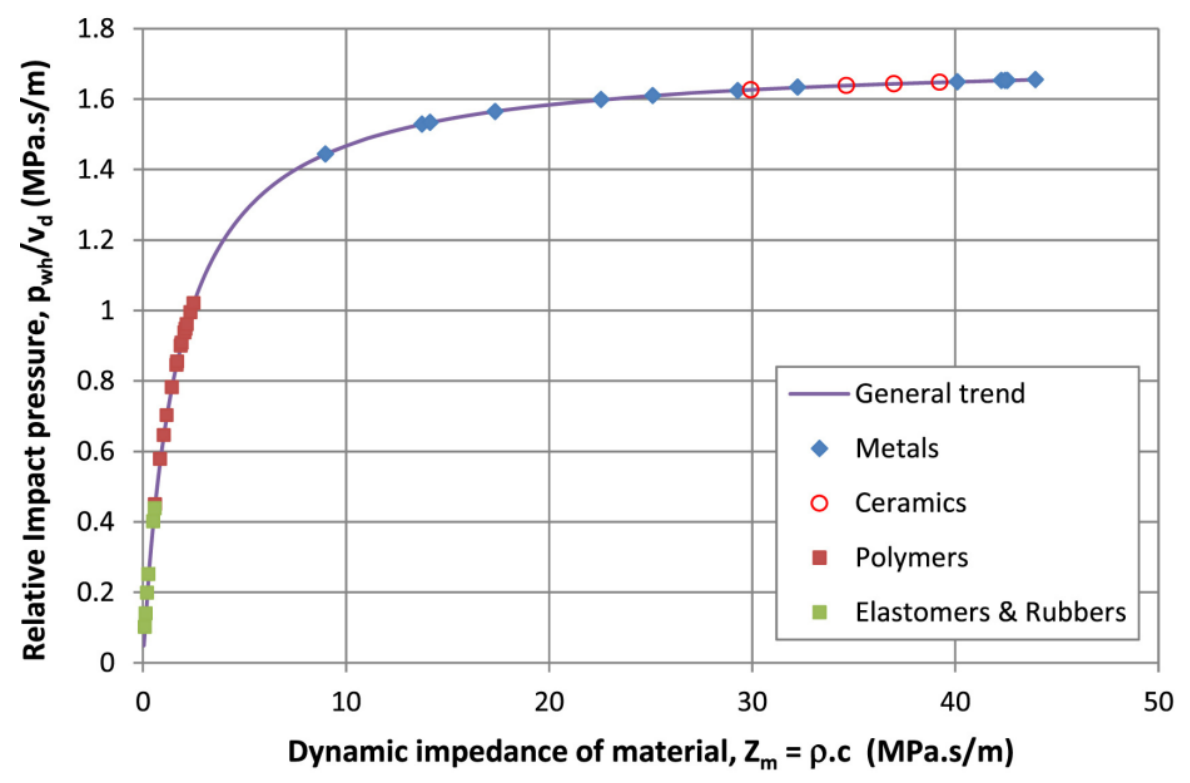

Figure 13. The relative impact pressure $\left(p_{w h} / v_{d}\right)$ for some classes of materials: metals, ceramics, polymers and elastomers \& rubbers. Data taken from Table 3.

The application of surface layers or coatings introduces a specific situation, that is the possibility that part of the body waves that are generated by liquid impingement, reflect from the coating-substrate interface. This can be solved by applying coatings of sufficient thickness. The threshold thickness of the specimen for which the results of wave reflections within the specimen become negligible are 
constructed by Springer [42]. Assume two time characteristics, one related to the liquid and one related to the surface layer material:

$$
\begin{aligned}
& t_{L}=\frac{2 d_{d}}{c_{L}} \\
& t_{S}=\frac{h_{S}}{c_{S}}
\end{aligned}
$$

$d_{d}=$ droplet diameter

$h_{S}=$ thickness of the specimen

$c_{L}=$ speed of sound in the liquid

$c_{S}=$ speed of sound in the solid

Negligible wave reflections in the specimen hence occur when $t_{S}>t_{L}$ resulting in:

$$
h_{S}>2 d_{d}\left(\frac{c_{S}}{c_{L}}\right)
$$

This $h_{S}$ is the threshold specimen thickness for which the results of bulk wave reflections within the specimen are negligible.

\subsection{Shift in Wöhler curve}

\subsubsection{The fatigue life of coatings based on polymeric materials}

The fatigue life of a coating will not equal the bulk fatigue life of the same material, yet it most likely gives a first approximation. A frequently used expression to describe the fatigue life curves of polymers is [46]:

$$
\frac{S_{\max }}{S_{0}}=N_{f}^{-1 / m}
$$


with

$S_{0}=$ is the static strength plotted at one cycle,

$N_{f}=$ is the number of cycles to failure,

$m=$ is a material dependent constant.

The value of $m$ is typically between 4 and $80[46,47]$.

As an example, Figure 14 [48], shows the fatigue S-N curves of the polypropylene, talc-filled polypropylene and polypropylene nano-composite. In this figure, the vertical axis or the S-axis represents the maximum cyclic stress and the horizontal axis or the $\mathrm{N}$-axis represents the number of cycles to failure. The corresponding constants given by Eq. (19) are summarized in Table 4. From these results it is clear that fillers are to be selected carefully as they can both delay and/or promote the initiation of fatigue.

The stage of steady state erosion is also influenced by fillers. Yet, the response of polymeric materials is found to be different for thermoplastics such as PP, PE, PA, PPO and thermosets such as unsaturated polyester and epoxies The addition of reinforcement to thermoplastics is detrimental, because the fibres tend to break out at repeated impingement, enhancing mass loss in the steady state erosion regime. The thermosetting polymers benefit from reinforcement because the fibres reduce massive fracture and chunking of the brittle resin [49]. 


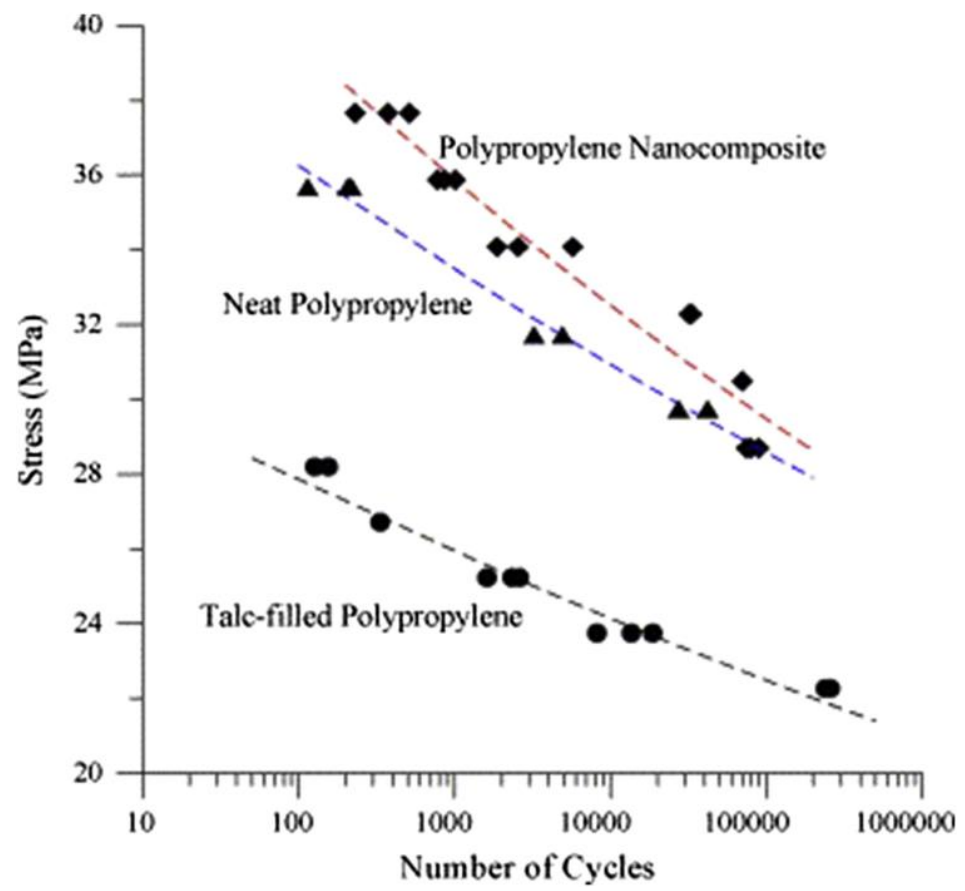

Figure 14. Fatigue curves of neat polypropylene (PP) and two PP composites: talc-filled polypropylene and polypropylene nano-composite. Adapted from Ref. [48].

Table 4. Fit constants for the lifetime equation and estimated fatigue endurance strength [48].

\begin{tabular}{|l|ccc|}
\hline & $\begin{array}{c}\boldsymbol{S}_{\boldsymbol{0}} \\
(\mathbf{M P a})\end{array}$ & $\begin{array}{c}\boldsymbol{m} \\
(-)\end{array}$ & $\begin{array}{c}\boldsymbol{S}_{\boldsymbol{D}}\left(\mathbf{1 0}^{\mathbf{7}}\right) \\
(\mathbf{M P a})\end{array}$ \\
\hline Neat polypropylene & 42.5 & 29.9 & 24.8 \\
40 wt.\% talc-filled polypropylene & 31.5 & 33.8 & 19.6 \\
Polypropylene nano-composite & 48.1 & 23.5 & 24.2 \\
\hline
\end{tabular}

\subsubsection{Experimental results with coatings}

The liquid impact erosion of elastomeric coatings is studied extensively [50-53] especially directed towards the development of polyurethane and fluorocarbon coatings for protection of aircraft radomes and composite surfaces. The first polyurethane coatings are developed and compared to the performance of neoprene coatings [50]. Fluorocarbon coatings to resist impingement wear are developed for higher temperature applications [52]. These developments are 
empirically validated by large test schemes using the whirling arm rain erosion simulation apparatus tests [53]. Neoprene coatings erode under liquid impact by a gradual roughening of the surface and eventually adhesion loss. The polyurethane coating fails by an isolated holes typically the size of a tenths of millimetres. The fluorocarbon coatings erodes by a chunking of pieces from its surface and gradual wearing away until the substrate is exposed. Other brittle polymeric coatings such as epoxies, silicones, polyesters, acrylics, and non-elastomeric polyurethanes fail by brittle rupture and/or spall of the coating very rapidly upon impact [53]. Whirling arm rain erosion tests with polyurethane (PUR) coatings and colour fillers, at a glass fibre reinforced epoxy substrate, presented in Ref. [54], can be arranged as in Figure 15. This figure shows the liquid drop impact lifetime $(\mathrm{N}$, number of drop impacts) as a function of rotational speed ( $\approx$ drop impact velocity) for three PUR coatings. The lifetime of unprotected glass fibre reinforced epoxy laminate is also shown. These results confirm that optimization is to be conducted carefully, balancing positive and negative effects of fillers on coating life.

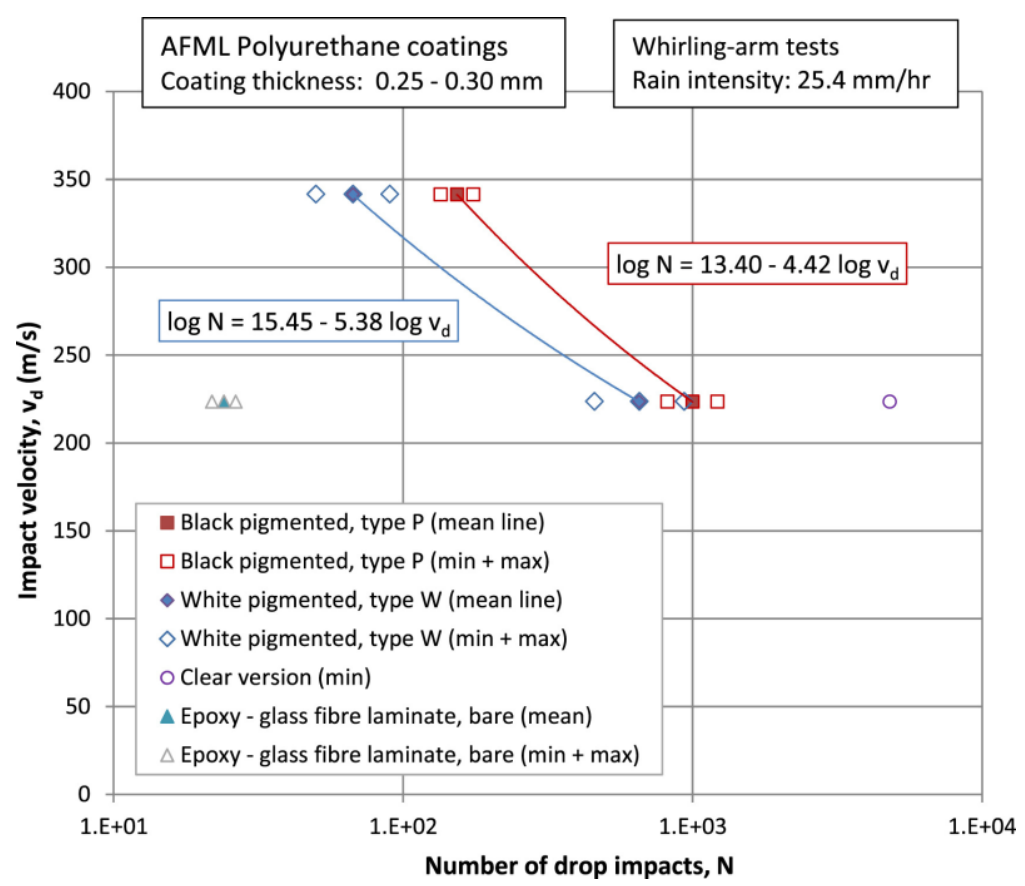

Figure 15. Liquid drop impact lifetime ( $N$, number of drop impacts) as a function of rotational speed ( $\approx$ drop impact velocity) for PUR coatings with 3 types of colour fillers and a thickness of 0.25-0.30 mm. Incubation time equation: $\log N=-a \log v_{d}+\log C$. Adapted from Ref. [54]. 


\section{Other factors that influence the fatigue life}

\subsection{Coating life at standardized conditions}

The life of the leading edge of an individual turbine blade can be defined as:

Coating life $=$ the number of droplet impacts which the leading edge encounters before the first evidence of fatigue develops in the material of the surface.

This definition is constructed with the definition for roller bearing life [39] in mind. Roller bearing fatigue cracks start at a certain depth beneath the surface although initiation at the surface is also possible. The initiation and growth of cracks will not be the same for each individual component surface. As such, it is common to include the concept of reliability in life calculations. Reliability in the context of coatings life for a group of apparently identical surfaces, operating at the same conditions is defined as the percentage of the group that is expected to attain or exceed a specified life. Typically, the life is estimated based on the basic rating life or $L_{10}$ :

\section{$L_{10}=$ predicted value of life based on a basic dynamic load rating associated with $90 \%$ reliability [39]}

The $L_{10}$ can be used only in case of standardized blades manufactured with commonly used high quality material, of good manufacturing quality, and operating at conventional operating conditions that can be translated to basic dynamic load ratings. For roller bearings, this is currently common practise due to a combined research effort of companies, universities, knowledge centres and standardization committees. Surface fatigue, although differently initiated, determines the bearing life. With standardized test methods and with standardized bearing materials and load conditions it proves possible to define the $L_{10}$ for well-defined environments. Unfortunately, this is not the case for turbine blades. Turbine blades are not made from a standardized material, in fact it is clear that variations are introduced by the manufacturing method. A test method in which high cycle fatigue is assessed at a standardized way is missing and this also holds for a description of a well-defined environment.

\subsection{Correction factors}

A possible way to incorporate the effect of exceptional conditions was found by adapting the roller bearing life methodology [39]. With standard coatings used in conventional applications, $L_{10}$ life calculations based on the basic rating life are 
adequate for representing fatigue life experience based on the usual weather conditions. The rating life modified for $90 \%$ or other reliability or exceptional conditions is referred to in ISO 281 as modified rating life $L_{n, m}$. The relation between the basic rating life $L_{10}$ and the modified rating life $L_{n, m}$ is then given by:

$$
L_{n, m}=h_{1} h_{S T} L_{10}
$$

with $h_{1}$ the modification factor for reliability and $h_{S T}$ the standardized life modification factor.

The task of determining the value of the modification factors for the fatigue conditions for wind turbine blades is probably the most important task, yet also the most challenging task due to the large number of variables involved. The effects of frequency, waveform, and load level and type must be assessed to determine if material's temperature will increase, leading to thermal fatigue, or if mechanical failure will occur with little or no temperature increase. Other conditions that should be considered or matched from the laboratory specimen to the component include environmental effects (e.g., temperature), stress state, stress concentrations, and stress ratio. The relative importance of modification factors could be assessed from current literature. A list is given in Table 5. The effect of UV is not mentioned in this list as it will completely change the fatigue properties of the coating and as such require a new $L_{10}$-value. The effect however could be extremely large [30].

Table 5. Correction factors $h_{i}$ for the lifetime equations of polymers for different factors of influence.

\begin{tabular}{|l|l|l|l|}
\hline No. & $\begin{array}{l}\text { Correction } \\
\text { factor }\end{array}$ & Factor of influence & Ref. \\
\hline 1 & $\mathrm{~h}_{1}$ & Failure probability, 50\% (mean) or 5\% ... & \\
2 & $\mathrm{~h}_{2}$ & Load-controlled or displacement-controlled & {$[46]$} \\
3 & $\mathrm{~h}_{3}$ & Specimen type, stress gradient & \\
4 & $\mathrm{~h}_{4}$ & Stress ratio, $\mathrm{R}$ & {$[46],[48],[58],[59],[60],[61],[62]$} \\
5 & $\mathrm{~h}_{5}$ & Frequency, $\mathrm{f}$ & {$[46],[47],[48],[58],[59],[60],[61],[62]$} \\
6 & $\mathrm{~h}_{6}$ & Waveform (sine, triangle, square) & {$[47],[61]$} \\
7 & $\mathrm{~h}_{7}$ & Temperature & {$[46],[47],[58],[59],[60],[61],[62]$} \\
8 & $\mathrm{~h}_{8}$ & Environmental effects (humidity, moister, ...) & \\
9 & $\mathrm{~h}_{9}$ & Stress state (plain stress, plain strain, ...) & {$[63],[64],[65]$} \\
10 & $\mathrm{~h}_{10}$ & Surface conditions, roughness & \\
11 & $\mathrm{~h}_{11}$ & Effect of sand and dust & {$[21],[55]$} \\
\hline
\end{tabular}


The combined effect of sand and rain erosion is likely to affect life extremely, yet it is hardly subject of research, an exception is the work of G.H. Jilbert and J.E. Field [21]. This work focusses on brittle materials and shows that sand erosion rates can be increased by pre-impact of liquid drops. The combined effect of rain and sand for the zinc sulphide window material was further investigated by Kelly et al. [55] in different exposure scenarios. For thick compliant coatings no work on sand-rain erosion was found in open literature, i.e. to the current knowledge of the authors.

\section{Conclusions and recommendations}

This review paper summarizes the state of the art in droplet impingement erosion modelling and gives an overview of experimentally validated building blocks of erosion models that can be used to predict the life of the leading edge of coated wind turbine blades. From the reviewed work it is concluded that:

1. Transient surface stresses due to the impact of one water droplet can be described analytically. Longitudinal and transverse body waves immediately start propagating due to the impact and from the free surface boundary it follows that that a Rayleigh wave is generated as well. The disturbance in the far field is dominated by the Rayleigh waves.

2. The positions of the wave fronts and the resulting stress variations indicate primarily compressive surface stresses, with a narrow band of high tensile stresses, immediately behind the Rayleigh wave front. The radial dimensions in which this occurs is quite small, and together with the high wave velocity this gives rise to short stress peaks of typically tenths of micro seconds.

- For brittle materials, this band of tensile stresses initiate failure already due to the impact of a few droplets, assuming relatively high impact velocity.

- For thick compliant coatings however, single water droplet cannot initiate failure, neither by increasing the water droplet diameter nor by changing of the impact angle. The calculated tensile strains now reach values within the maximum strain to failure at dynamic loading conditions. Repeated large strains may lead to failure.

- Surface fatigue, as nucleating wear mechanism for erosion damage, can explain failure for brittle and for ductile materials as well. The relation between fatigue properties of materials and damage for a specific test setup is demonstrated in literature, e.g. by G.S. Springer.

3. An engineering approach to surface fatigue, using the Palmgren and Miner rule for cumulative damage, allows for the construction of a rain erosion incubation period equation. Coating life was described as a function of the rain intensity, 
the droplet diameter, the fatigue properties of the coating and the severity of the conditions.

As fatigue is the dominant wear mechanism in leading edge erosion, it is clear that general counter measures to fatigue are to be applied in order to minimize the risk of damaged blade surfaces. For that it is recommended to focus coating development on:

1. Reduction of the water pressure, e.g. by applying surfaces with a low modulus of elasticity;

2. Enlarging the safe area by:

a) applying coatings with adjustable compressive stresses

b) applying coatings with adjustable hardness

c) preventing defects and impurities in the layer.

An important implication of the above strategy is the role of fillers in coatings. Fillers such as clay, carbon, glass fibres can both be beneficial by creating compressive stresses or high hardness but also detrimental as they can initiate failure at the interface of the filler and the matrix material.

Surface fatigue data relies heavily on standardized calculation procedures and standardized testing protocols. For roller bearings this is successfully realized by a combined research effort of companies, universities, knowledge centres and standardization committees, in standard ISO 281. A similar approach is needed for coated turbine blade surfaces.

\section{Acknowledgements}

The research leading to these results has received funding from the European Union's Seventh Framework Programme (FP7/2007-2013) under grant agreement no. 309985, www.eu-walid.com.

\section{References}

[1] Wilkes J., Kjaer C., Gruet R., Pure power - wind energy targets for 2020 and 2030, European Wind Energy Association, July 2011.

[2] Mapping renewable energy pathways towards 2020-EU roadmap, European Renewable Energy Council, Brussels, Belgium, March 2011. 
[3] Goch G., Knapp W., Hartig F., Precision engineering for wind energy systems, CIRP Ann Manuf Technol 61(2), 2012, 611-634.

[4] Wind blade using cost-effective advanced composite lightweight design WALID, EU FP7 project grant agreement no. 309985, www.eu-walid.com.

[5] Beaudry-Losique J. et al., A national offshore wind strategy - creating an offshore wind energy industry in the United States, U.S. Department of Energy, Office of Energy Efficiency and Renewable Energy, Wind \& Water Power Program U.S. and Department of the Interior, Bureau of ocean energy Management, Regulation, and Enforcement, February 7, 2011.

[6] www.Imwindpower.com/Rotor-Blades/Technology/Design/Blade-Concept; $14 / 10 / 2013$.

[7] Keegan M.H., Nash D.H., Stack M.M., On erosion issues associated with the leading edge of wind turbine blades, J Phys D Appl Phys 46, 2013, 383001.

[8] Sareen A., Chinmay A., Selig M.S., Effects of leading edge erosion on wind turbine blade performance, Wind Energy 17(10), 2014, 1531-1542.

[9] Gaudern N., A practical study of the aerodynamic impact of wind turbine blade leading edge erosion, J Phys Conf Ser 524, 2014, 012031.

[10] Rempel L., Rotor blade leading edge erosion - real life experiences, Oct 2012, 22-24, www. Windsystemsmag.com.

[11] Gee A.W.J. de, Rowe G.W., Glossary of terms and definitions in the field of friction, wear and lubrication-tribology, Technical report, IRG - OECD, 1969.

[12] Salomon G., Application of systems thinking to tribology, ASLE Trans 17(4), 1974, 295-299.

[13] Giguere P., Selig M.S., Aerodynamic effects of leading edge tape on aerofoils at low Reynolds numbers, Wind Energy 2, 1999, 125-136.

[14] Dalili N., Edrisy A., Carriveau R., A review of surface engineering issues critical to wind turbine performance, Renew Sustain Energy Rev 13, 2009, 428-438.

[15] Grundwuermer M., Nuyken O., Meyer M., Wehr J., Schupp N., Sol-gel derived erosion protection coatings against damage caused by liquid impact, Wear 263, 2007, 318-329.

[16] Gohardani O., Impact of erosion testing aspects on current and future flight conditions, Prog Aerosp Sci 47, 2011, 280-303.

[17] Wang S.S., Cai L.X., Mao J.R., Zhang J.J., Xu Y.T., Mechanisms of steam turbine blade particle erosion and crucial parameters for minimizing blade erosion, Proc IMechE Part A J Power Energy 227(5), 2013, 546-556.

[18] Lee M.K., Kim W.W., Rhee C.K., Lee W.J., Liquid impact erosion mechanism and theoretical impact stress analysis in TiN-coated steam turbine blade materials, Metall Mater Trans A 30, 1999, 961-968. 
[19] Blowers R.M., On the response of an elastic solid to droplet impact, IMA J AppI Math 5, 1969, 167-193.

[20] Field J.E., ELSI conference: invited lecture liquid impact: theory, experiment, applications, Wear 233-235, 1999, 1-12.

[21] Jilbert G.H., Field J.E., Synergistic effects of rain and sand erosion, Wear 243, 2000, 6-17.

[22] Zhou Q., Li N., Chen X., Xu T., Hui S., Zhang D., Analysis of water drop erosion on turbine blades based on a nonlinear liquid-solid impact model, Int J Impact Eng 36, 2009, 1156-1171.

[23] Kunaporn S., Ramulu M., Hashish M., Mathematical modeling of ultra-highpressure waterjet peening, J. Eng Mater Technol 127, 2005, 186-191.

[24] Kim H.S., Kim J.S., Kang H.J., Kim S.R., Stress wave propagation in a coated elastic half-space due to water drop impact, J. Appl Mech 68(2), 2000, 346348.

[25] Adler W.F., Rain impact retrospective and vision for the future, Wear 233-235, 1999, 25-38.

[26] Evans A.G., Ito Y.M., Rosenblatt M., Impact damage thresholds in brittle materials impacted by water drops, J. Appl Phys 51, 1980, 2473.

[27] Woods R.D., Screening of surface waves in soils, J. Soil Mech Found Div 94(4), 1968, 951-979.

[28] Haosheng C., Shihan L., Inelastic damages by stress wave on steel surface at the incubation stage of vibration cavitation erosion, Wear 266, 2009, 69-75.

[29] Adler W.F., Mihora D.J., Waterdrop impact modeling, Wear 186-187, 1995, 341-351.

[30] Adler W.F., Mihora D.J., Analysis of polyurethane advanced rotor blade erosion protection system, In: W.D. Weigel (Ed.), Advanced rotor blade erosion protection system, Kaman Aerospace Corporation, Bloomfield, 1996.

[31] Adler W.F., Mihora D.J., Analysis of waterdrop impacts on layered window constructions, In: Klocek P. (Ed.), Window and dome technologies and materials IV, vol. 2286, SPIE (27-28 July 1994).

[32] Hattori S., Kakuichi M., Effect of impact angle on liquid droplet impingement erosion, Wear 298-299, 2013, 1-7.

[33] Adler W.F., Liquid drop collisions on deformable media, J. Mater Sci 12, 1977, 1253-1271.

[34] Hackworth J.V., Kocher L.H., Snell I.C., Response of infrared transmitting materials to high-velocity impact by water drops, In: Adler W.F. (Ed.), Erosion: prevention and useful applications, ASTM STP 664, 1979, 255-278. 
[35] Gohardania O., Williamson D.M., Hammonda D.W., Multiple liquid impacts on polymeric matrix composites reinforced with carbon nanotubes, Wear 294295, 2012, 336-346.

[36] Lee M.K., Kim W.W., Rhee C.K., Lee W.J., An analysis of stress waves in $12 \mathrm{Cr}$ steel, Stellite 6B and TiN by liquid impact loading, Nucl Eng Des 214, 2002, 183193.

[37] Palmgren A.Z., Die Lebensdauer von Kugellagern, Z. Ver Dtsch Ing 68, 1924.

[38] Miner M.A., Cumulative damage in fatigue, J. Appl Mech 12, 1945, A139.

[39] ISO 281(E) Rolling bearings - dynamic load ratings and rating life, 2007.

[40] NEN-EN 1993-1-9+C2, Eurocode 3: design of steel structures - Part 1-9: fatigue (Dutch version of European standard), 2012.

[41] DNV-RP-C203, Fatigue design of offshore steel structures, recommended practice, Det Norske Veritas, August 2005.

[42] Springer G.S., Erosion by liquid impact, Scripta Publishing Company, 1976.

[43] Schmitt G.F., Liquid and solid particle impact erosion, In: Peterson M.B., Winer W.O. (Eds.), Wear control handbook, 1980, 231-282.

[44] Heymann F.J., Liquid impingement erosion, Friction, lubrication and wear technology, ASM handbook 18, American Society of Metals, 1992, 221-232.

[45] Schmitt G.F., Erosion behavior of polymeric coatings and composites at subsonic velocities, In: Fyall A.A., King R.B. (Eds.), Proc. third inter. conf. on rain erosion and associated phenomena, Elvetham Hall, 1970, 107-145.

[46] Mandell J.F., Fatigue behavior of short fiber composite materials, In: Reifsnider K.L. (Ed.), The fatigue behavior of composite materials, Elsevier, 1991, [chapter 7].

[47] Kanter D. de, On the predictability of fatigue failure of glassy polymers, PhD thesis, Eindhoven University of Technology, 2006.

[48] Zhou Y., Rangari V., Mahfuz H., Jeelani S., Mallick P.K., Experimental study on thermal and mechanical behavior of polypropylene, talc/polypropylene and polypropylene/clay nanocomposites, Mater Sci Eng A 402, 2005, 109-117.

[49] Gorham D.A., Matthewson M.J., Field J.E., Damage mechanisms in polymers and composites under high-velocity liquid impact, In: Adler W.F. (Ed.), Erosion: prevention and useful applications, 1979, ASTM-STP-664, 320-342.

[50] Schmitt G.F., Polyurethane coatings for rain erosion protection, In: Fyall A.A., King R.B. (Eds.), Proc. of the $2^{\mathrm{e}}$ Meersburg conf. on rain erosion and allied phenomena, Royal Aircraft Establishment, Farnborough, 1967, 329-357.

[51] Rieger H., Boche H., Erosion behavior of surface coatings, In: Fyall A.A., King R.B. (Eds.), Proc. of the $4^{\mathrm{e}}$ inter. Conf. on rain erosion and associated phenomena, Royal Aircraft Establishment, Farnborough, 1974, 637-675. 
[52] Schmitt G.F., Elevated temperature resistant, subsonic rain erosion resistant fluoroelastomer radome coatings, Proc. of the third international conference on electromagnetic windows, Paris, 1975, 211-232.

[53] Schmitt G.F., Advanced rain erosion resistant coating materials, Science of advanced materials and process engineering series, vol. 18, 1973, 57-75.

[54] Conn A.F., Rudy S.L., The effects of fatigue and dynamic recovery on rain erosion, In: Erosion wear and interfaces with corrosion, ASTM-STP-567, American Society for Testing and Materials, 1974, 239-269.

[55] Kelly E.S., Ondercin R.J., Detrio J.A., Greason P.R., Environmental testing of long wave infrared (LWIR) windows, Proc. of SPIE, vol. 3060, 1997, 68-75.

[56] Lee G.M.C., The erosion resistance of plain carbon steel under water droplet impact conditions, Wear 141, 1990, 185-201.

[57] Voskamp A., Microstructural changes during rolling contact fatigue, PhDthesis, TU Delft, 1996.

[58] Sauer J.A., Richardson G.C., Fatigue of polymers, Int J Fract 16, 1980, 499-532.

[59] Osswald T.A., Menges G., Materials science of polymers for engineers, Hanser, 1996.

[60] Trantina G.G., Design with plastics, Materials selection and design, ASM handbook 20, ASM International, 2003, 639-647.

[61] Janssen R.P.M., Govaert L.E., Meijer H.E.H., An analytical method to predict fatigue life of thermoplastics in uniaxial loading: Sensitivity to wave type, frequency, and stress amplitude, Macromolecules 41, 2008, 2531-2540.

[62] Janssen R.P.M., Kanter D. de, Govaert L.E., Meijer H.E.H., Fatigue life predictions for glassy polymers: A constitutive approach, Macromolecules 41, 2008, 2520-2530.

[63] Klimkeit B., Nadot Y., Castagnet S., Nadot-Martin C., Dumas C., Bergamo S., Multiaxial fatigue life assessment for reinforced polymers, Int J Fatigue 33, 2011, 766-780.

[64] Klimkeit B., Nadot Y., Castagnet S., Benoit G., Bergamo S., Dumas C., Damage mechanisms, Multiaxial fatigue of short fibre reinforced thermoplastics, Proc. 17th inter. conf. on composite materials, Edinburgh, ICCM17, 2009.

[65] Launay A., Maitournam M.H., Marco Y., Raoult I., Multiaxial fatigue models for short glass fiber reinforced polyamide - Part I: nonlinear anisotropic constitutive behavior for cyclic response, Int J Fatigue 47, 2013, 382-389. 
Paper B 


\title{
Rain erosion resistance of injection moulded and compression moulded polybutylene terephthalate PBT
}

\author{
H.M. Slot ${ }^{a *}$, R.M. IJzerman ${ }^{a}$, M. le Feber ${ }^{a}$, K. Nord-Varhaug ${ }^{b}$ and E. van der Heide ${ }^{c, d, e}$ \\ a TNO, Stieltjesweg 1, 2628 CK Delft, The Netherlands \\ ${ }^{\mathrm{b}}$ Norner AS, Stathelle, Norway \\ ' University of Twente, Laboratory for Surface Technology and Tribology, Enschede, \\ The Netherlands \\ ${ }^{d}$ Delft University of Technology, Railway Engineering, Delft, the Netherlands \\ ${ }^{e}$ Ghent University, Faculty of Engineering and Architecture, Labo Soete, Ghent, \\ Belgium
}

Published in: Wear 414-415, 2018, 234-242.

\begin{abstract}
Offshore wind turbine rotor diameters still increase. Blade tip velocities are up to $110 \mathrm{~m} / \mathrm{s}$, giving rise to more severe raindrop impact conditions and related erosion of the wind turbine blades. In the current work droplet impingement erosion tests were performed for injection moulded and compression moulded polybutylene terephthalate PBT. The measured incubation periods were compared to an extended and improved fatigue based erosion model.

The developed erosion test set-up was based on a high water pressure nozzle system spraying water drops at a stationary PBT surface. Model results with thermoplastic materials simulating heavy rain conditions with a droplet size of 1.8 $\mathrm{mm}$ and an impact velocity of $120 \mathrm{~m} / \mathrm{s}$ are shown. Model results with PBT materials simulating the used test conditions are shown and compared with the measured incubation periods. Although a reasonable similarity between test results and model calculations for the injection moulded PBT was found, the absolute value of the incubation period predicted by the model for compression moulded PBT differed substantially. This probably resulted from the lower confidence level of the $\mathrm{S}-\mathrm{N}$ curve for the compression moulded PBT. The droplet impingement measurements and model predictions both showed a substantially higher incubation period for injection moulded PBT compared to compression moulded PBT.
\end{abstract}




\section{Keywords}

Wind energy, Erosion, Droplet impingement, Polymers, Surface fatigue

\section{Nomenclature}

$A=$ constant in Rayleigh surface wave attenuation (MPaVmm) or elongation at fracture (\%)

$C_{N}=$ nozzle discharge coefficient (-)

$D_{h}=$ cumulative fatigue damage per hour $\left(\mathrm{h}^{-1}\right)$

$D_{f}=$ Cumulative fatigue damage at failure (-)

$E=$ Young's modulus of surface material

$I_{p}=$ Rain erosion incubation period $(\mathrm{h})$

$I_{r}=$ rain intensity $(\mathrm{mm} / \mathrm{h})$

$N_{i}=$ number of fatigue cycles to failure or at level i

$R=$ stress ratio in the fatigue test (-)

$R_{m}=$ tensile strength $(\mathrm{MPa})$

$S_{D}=$ fatigue limit (MPa)

$S_{f}=$ material parameter in fatigue tests (MPa)

$S_{\text {max }, i}=$ maximum fatigue stress at level i $(\mathrm{MPa})$

$V_{e}=$ water velocity at nozzle exit $(\mathrm{m} / \mathrm{s})$

$c_{R}=$ Rayleigh surface wave velocity in a solid $(\mathrm{m} / \mathrm{s})$

$c_{S}=$ longitudinal wave velocity in a solid $(\mathrm{m} / \mathrm{s})$

$d_{d}=$ water drop diameter $(\mathrm{mm})$

$d_{s}=$ diameter of the visible spot size on the specimen surface $(\mathrm{mm})$

$h_{\text {tot }}=$ correction factor for the differences between fatigue test and rain impact conditions (-)

$k_{t}=$ stress concertation factor (-)

$m=$ material parameter in fatigue tests $(-)$

$n=$ exponent for the Rayleigh surface wave attenuation (-)

$n_{A 1}=$ total number of raindrop impacts on the area $A_{1}$ (number of drop impacts/h)

$n_{r}=$ radial distribution of density of drop impacts (impacts $/ \mathrm{mm} . \mathrm{h}$ )

$n_{S}=$ distribution of drop impacts as a function of stress (impacts/MPa.hr)

$p_{w}=$ water pressure $(\mathrm{MPa})$

$p_{w h}=$ water-hammer pressure on the specimen surface (MPa)

$r=$ coordinate in radial direction $(\mathrm{mm})$

$r_{0}=$ radial coordinate where the Rayleigh surface wave starts $(\mathrm{mm})$

$r_{1}=$ radial coordinate where the maximum stress is attenuated $S_{\max (r 1)}(\mathrm{mm})$

$v_{d}=$ water droplet impact velocity on the specimen surface $(\mathrm{m} / \mathrm{s})$

$v=$ Poisson's ratio of surface material (-) 
$\rho=$ density of surface material $\left(\mathrm{kg} / \mathrm{m}^{3}\right)$

$\rho_{w}=$ water density $\left(\mathrm{kg} / \mathrm{m}^{3}\right)$

\section{Introduction}

Today wind energy turbines with a nominal power of 5 to $8 \mathrm{MW}$ [1] dominate the market, with an increasing proportion of larger wind energy turbines up to $9.5 \mathrm{MW}$. The rotor diameter of these multi-MW wind energy turbine systems is typically 165 $\mathrm{m}$ [2]. The combination of large turbine blades with tip velocities up to $120 \mathrm{~m} / \mathrm{s}$ and severe rain conditions gives rise to erosion of the wind turbine blades, especially the leading edge. This reduces blade aerodynamic efficiency, and power output. Protecting the blades of large wind turbines, offshore and onshore, with rain erosion resistant materials is therefore of great economic interest.

Turbine blade manufacturers are searching for alternative blade materials to overcome engineering problems with respect to the weight and manufacturing of future blades of even greater lengths. Blades are currently made of glass fibre in an epoxy matrix, combined with a polyester gelcoat and a polyurethane coating on the outer surface, $[1,3]$. This class of materials, however, limits the application of longer blades because of the resulting total weight. The use of glass fibre reinforced thermoplastics might overcome this because of the expected beneficial weight/performance ratio, [4]. Within the scope of the current work, polybutylene terephthalate (PBT) has been selected as the matrix material. The most economical solution is the use of the matrix thermoplastic also as protective material on the outer surface. The number of papers on liquid impingement erosion of thermoplastic materials is limited and include Polyamide (PA), Low Density Polyethylene (LDPE), Polyethylene (PE), Acetal (POM), Polycarbonate (PC), Polymethylmethacrylate (PMMA), Polysulphone (PS) and Polycarbonate (PC) [5-7]. This study is the first time PBT has been assessed with respect to rain erosion resistance.

Rain impact erosion is studied through extensive screening on whirling arm rain erosion apparatus tests [8-13]. Furthermore, droplet impingement erosion tests are conducted using nozzle systems spraying water droplets on a stationary specimen surface [14-16]. This system is a relatively low-cost experimental research set-up which serves as an alternative to the expensive whirling arm rain erosion apparatus. A similar set-up is selected for this work as well. 
In the rain or liquid impingement erosion process three phases are recognized in time [12-13, 17]:

- Incubation period (in which there is no visible wear),

- Steady-state erosive wear (with a constant wear-rate),

- Final erosion phase (with a reduced wear-rate due to the high surface roughness, which was produced in the second phase).

This work focuses on the incubation period of the rain erosion process.

The main building blocks of a predictive model for the rain erosion incubation period, developed by the authors, has been published elsewhere [18]. This fatigue based model was extended in the current work and applied to thermoplastics to select an optimum candidate, with respect to rain erosion resistance, for a glass fibre reinforced thermoplastic blade material. The predictive model has been applied to thirteen thermoplastics and PBT and compared to rain erosion results of injection moulded and compression moulded PBT.

\section{Experimental}

\subsection{Thermoplastic materials}

The selected material for the samples was PBT. All samples were processed by Norner AS (Stathelle, Norway), based on Ultradur B2550 supplied by BASF. The PBT sheets were processed by two different production methods: compression moulding (PBT-I) and injection moulding (PBT-II).

\subsection{Droplet impingement test set-up}

Droplet impingement measurements were conducted based on a set-up that has been derived from Duraiselvam et al. [14] and Oka et al. [15]. It is based on a nozzle system spraying water drops on a stationary specimen surface. Figure 1 shows schematically the droplet impingement test set-up.

Figures $2 a / b$ show details of the nozzle system and specimen location in the test set-up. 


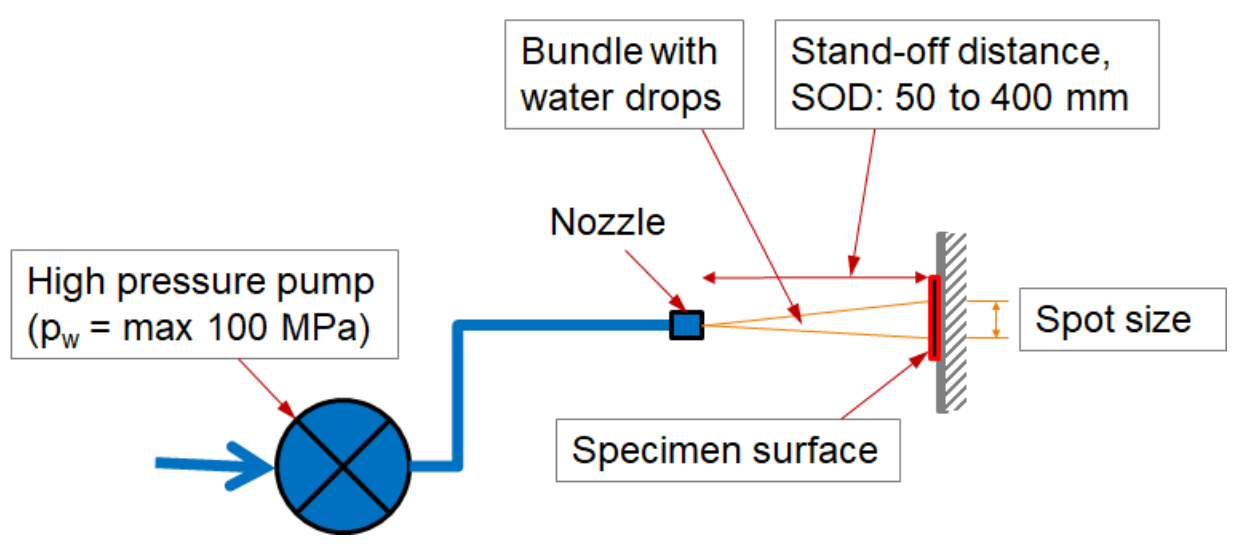

Figure 1. Schematic overview of the TNO droplet impingement test set-up.

The water jet is delivered through a nozzle (type SJP 8/12/24 from Salomon Jetting Parts). The high pressure water pump, driven by compressed air, generates water pressures that can be operated between 5 and $100 \mathrm{MPa}$ to feed the nozzle system. The round jet nozzle, with an exit orifice diameter $d_{n}$ of $0.45 \mathrm{~mm}$, creates a round spray pattern of small droplets, is able to maintain a high droplet velocity over a certain distance. The water nozzle exit velocity is estimated based on Eq. 1:

$$
V_{e}=C_{N} \sqrt{\frac{2 p_{w}}{\rho_{w}}}
$$

in which $V_{e}$ is the water velocity at nozzle exit, $C_{N}$ the nozzle discharge coefficient ( $C_{N}=0.963$ for a round jet nozzle), $p_{w}$ the water pressure and $\rho_{w}$ the water density (estimated at $\left.1025 \mathrm{~kg} / \mathrm{m}^{3}\right)$. The water droplet impact velocity $\left(v_{d}\right)$ on the specimen surface is assumed to be equal in this work to the water nozzle exit velocity $\left(V_{e}\right)$. The latter because momentum estimates based on force measurements in the support of the specimen holder, see Figure $2 \mathrm{a}$, only showed a small deviation compared to the result of Eq. 1. 

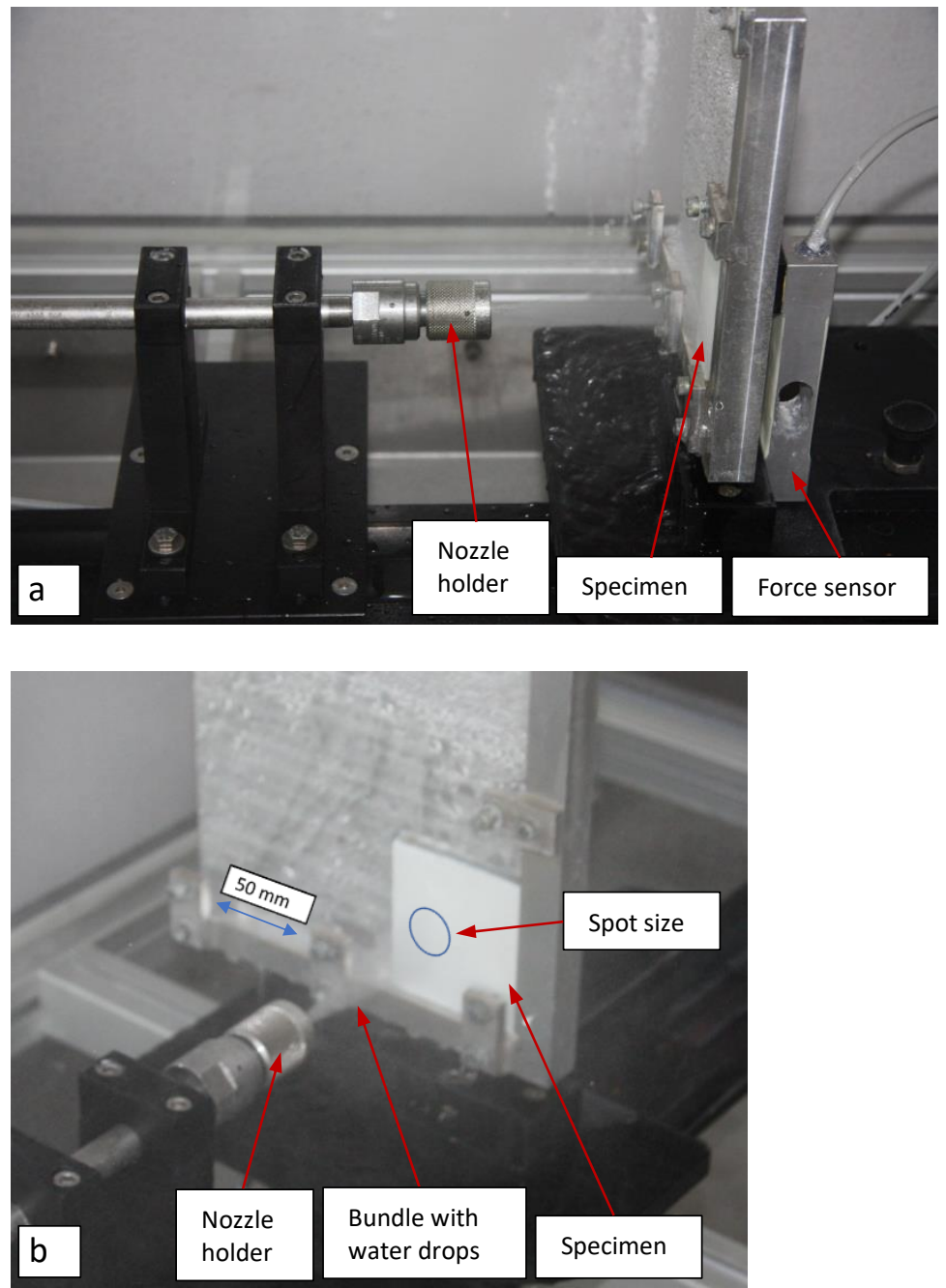

Figures $2 a / b$. Images of the droplet impingement chamber interior of the TNO test set-up.

For the current work an operating pressure $\mathrm{p}_{\mathrm{w}}=8 \mathrm{MPa}$ was selected, which resulted in an estimated mean droplet velocity of $120 \mathrm{~m} / \mathrm{s}$, equivalent to a typical blade tip velocity. The flow rate of sprayed water was verified by measuring the weight of water collected during a certain time of spraying. The selected relative flow rate $\eta_{Q}$ was 0.48 . Furthermore, the selected angle of impact was $90^{\circ}$ and the nozzle-tospecimen distance $150 \mathrm{~mm}$. The spot size on the specimen surface with a high density of drops has an estimated diameter $d_{s} \approx 25 \mathrm{~mm}$, see also Fig $2 b$. Overall PBT specimen size was $50 \times 100 \mathrm{~mm}$, and a thickness of $3.7 \mathrm{~mm}$. 
The test was conducted until surface damage or a substantial increase in surface roughness in the spot size was observed. The maximum test duration was set at 480 minutes. The spraying was stopped and the spot size visually inspected after each 10 minutes of spraying during the first 30 minutes of testing, and after that each 30 minutes. The mean of the exposure times - "no surface damage observed" and "first surface damage observed" - was taken as the incubation period $\left(I_{p}\right)$ of the test.

\subsection{Axial fatigue testing}

The axial fatigue tests were performed on samples with a total length of $75 \mathrm{~mm}$, a width of $45 \mathrm{~mm}$, and thickness of 2 to $3 \mathrm{~mm}$. The samples contained a hole of $\varnothing 10$ $\mathrm{mm}$ at each side of the width, and a net section between the holes of $11 \mathrm{~mm}$, the resulting stress concertation factor was $k_{t}=1.85$. The samples were fatigue tested in a Bose ElectroForce 3300 machine that is force controlled with a stress ratio $R=$ 0.1 , a sinusoidal waveform, a constant amplitude, and a frequency of $2 \mathrm{~Hz}$. The temperature was approximately $23^{\circ} \mathrm{C}$. The fatigue tests were performed by Norner AS (Norway). Each test was cyclic loaded at a specific maximum stress $\left(S_{\max }\right)$ until fracture. The number of cycles at specimen fracture $\left(N_{f}\right)$ was recorded.

\subsection{Tensile testing}

The tensile tests were performed on samples with the same geometry as used for axial fatigue testing. The temperature was approximately $23^{\circ} \mathrm{C}$. Ultimate tensile strength, elongation at fracture and Young's modulus were determined.

\section{Fatigue based model for rain erosion incubation period}

\subsection{Liquid impingement erosion mechanism}

The impact pressures on the surface due to multiple drop impacts give rise to cyclic fatigue stresses (S). The number of drop impacts defines the number of fatigue cycles $(\mathrm{N})$. The fatigue life line (Wohler line or $\mathrm{S}-\mathrm{N}$ line) determines the number of drop impacts necessary for surface fatigue crack initiation and crack growth. As such, a strong relation between the (surface) fatigue properties and the incubation period for liquid impingement erosion is expected, see e.g. Springer's model [17].

The incubation period prediction model previously developed by Slot et al. [18], is based on surface fatigue damage due to multiple drop impact. The raindrop impacts are assumed to be randomly distributed over the blade surface and related to the water-hammer pressure $p_{w h}$. The resulting surface stress waves - the Rayleigh waves - generate fatigue damage and crack initiations on the surface 
which grow, eventually resulting in blade material loss. The moment in time that mass loss starts and the fatigue cracks in the blade surface have formed a network is taken as the end of the incubation period and the start of the erosion rate period.

In this work the previously developed model [18] has been extended with the radius $\left(r_{0}\right)$ at which the Rayleigh surface wave starts (derivation included in Appendix), and for the rain erosion incubation period $\left(I_{p}\right)$ an improved and more efficient derivation is presented.

\subsection{Fatigue life equation}

The fatigue properties of the material for a stress level $i$ and for the specific conditions of raindrop impact can be expressed as:

$$
S_{\max , i}=h_{t o t} S_{f} N_{i}^{-1 / m}
$$

in which $h_{\text {tot }}$ makes corrections for the differences between the fatigue tests conditions and the actual rain impact conditions. The material parameters $m$ and $S_{f}$ are commonly used in fatigue tests. The fatigue limit $S_{D, i}$ for the actual rain conditions is given by:

$$
S_{D, i}=h_{t o t} S_{D}
$$

with $S_{D}$ being the fatigue limit at fatigue test conditions. In this approach the number of fatigue cycles to failure in a fatigue test $\left(\mathrm{N}_{\mathrm{f}}\right)$ equals the number of fatigue cycles of the incubation period $\left(\mathrm{N}_{\mathrm{i}}\right)$.

\subsection{Stress cycle due to Rayleigh wave}

The maximum stress of the stress cycle at the materials surface due to the Rayleigh surface wave can be given, as explained in [18], by:

$$
S_{\max }=\frac{A}{r^{n}}
$$

It is assumed that the stress cycle at the materials surface due to the Rayleigh surface wave starts at a radial coordinate $r=r_{0}$. Secondly, it is assumed that the stress cycle is attenuated at a radial coordinate $r=r_{1}$ to a maximum stress level $S_{\max }=S_{\max , 1}$, which does not result in any further significant fatigue damage. This location $r_{0}$ depends on the impact conditions, thus the water drop impact velocity $v_{d}$, and the water droplet diameter $d_{d}$. The moment of start of the surface Rayleigh 
wave is defined as the time that the velocity of the boundary of the droplet contact area is equal to the Rayleigh wave velocity. In the Appendix the derivation of the radial location $\left(r_{0}\right)$ of this start of the surface Rayleigh wave, and the maximum cyclic stress $\left(S_{\max (r 0)}\right)$ at this location, are given.

\subsection{Fatigue damage model}

Now it is possible, conversely, to determine the stress amplitude history and thus the frequency distribution of maximum stress in a fatigue cycle at a certain location on the surface of the material [18]. First, assume the location at the centre of the circle (origin) as the location for counting the stress history. This means that for the material location at the origin only drop impacts within the area with a radius $r=$ $r_{1}$ result in a stress cycle with a significant amount of fatigue damage.

The total number of raindrop impacts on the area $A_{1}$ is:

$$
n_{A 1}=\frac{I_{r} \times \pi r_{1}^{2}}{\frac{\pi}{6} d_{d}^{3}}
$$

$n_{A 1}=$ total number of raindrop impacts on the area $A_{1}$ (number of drop impacts/h) $I_{r}=$ rain intensity $(\mathrm{mm} / \mathrm{h})$

$d_{d}=$ raindrop diameter $(\mathrm{mm})$.

The raindrop locations of impact are randomly spread over the area. Due to the linear increasing circumference and area with radial coordinate $r$, the number of drop impacts increases also linearly with the distance $(r)$.

The cumulative number of drop impacts $n_{C}\left(r_{1}\right)=n_{A 1}$

$$
\begin{aligned}
& n_{C}=\frac{a}{2} r^{2} \\
& a=\frac{2 n_{A 1}}{r_{1}^{2}}
\end{aligned}
$$

Eq. 4 to 6 give for the radial distribution of density of drop impacts:

$$
n_{r}=\frac{12 I_{r}}{d_{d}^{3}} r
$$


$n_{r}$ is the radial distribution of density of drop impacts (impacts/mm.h), shown in Figure 3 a.

The radial distribution of density of drop impacts $\left(n_{r}\right.$, impact $/ \mathrm{mm}$.h) should be converted into a distribution of drop impacts $\left(n_{S}\right.$,impact/MPa.h) as a function of the local maximum stress $\left(S_{\max }\right)$, see Figure $3 b$. This distribution is now designated as $n_{S}$ :

$$
n_{S}=n_{r} \frac{d r}{d S_{\max }}
$$

Substituting eq. 3 in eq. 8 and using the derivative of Eq. 3 gives:

$$
n_{S}=\frac{12 I_{r}}{d_{d}^{3} n} \frac{A^{\frac{2}{n}}}{S_{\max }^{\frac{2+n}{n}}}
$$

$n_{S}$ is the distribution of drop impacts (impacts/MPa.hr). 

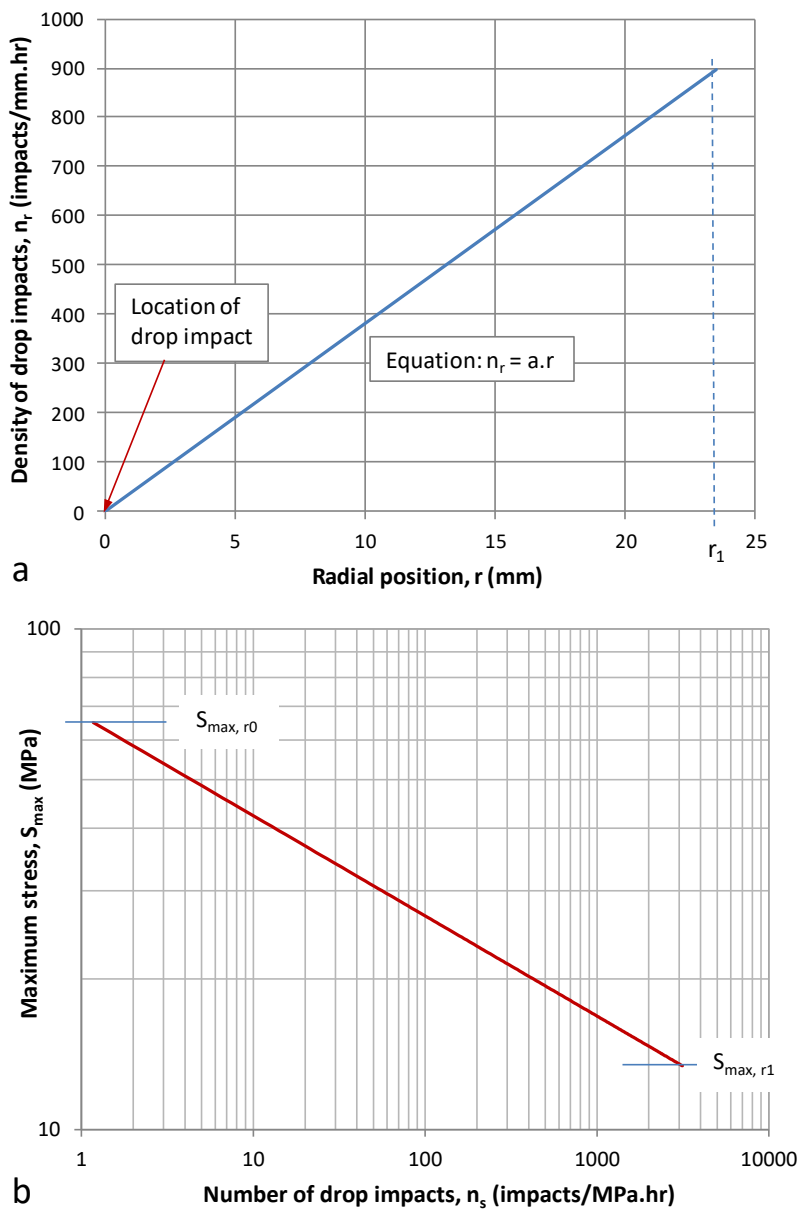

Figures $3 a / b$. Examples of the radial distribution of density of drop impacts $\left(n_{r}\right)$ as a function of the radial position and the distribution of drop impacts $\left(n_{S}\right)$ as a function of maximum stress $\left(S_{\max }\right)$. Table 1 shows the rain properties and radius used in these examples. 
Table 1. Rain properties and radius used in the examples, see Figures $3 a / b$.

\begin{tabular}{|ccl|}
\hline Symbol & Value & Unit \\
\hline $\mathrm{I}_{\mathrm{r}}$ & 25.4 & $\mathrm{~mm} / \mathrm{h}$ \\
$\mathrm{d}_{\mathrm{d}}$ & 2.0 & $\mathrm{~mm}$ \\
$\mathrm{r}_{1}$ & 23.5 & $\mathrm{~mm}$ \\
\hline $\mathrm{n}_{\mathrm{A} 1}$ & 10520 & impact $/ \mathrm{h}$ \\
$\mathrm{a}$ & 38.1 & impacts $/ \mathrm{mm}^{2} . \mathrm{h}$ \\
\hline
\end{tabular}

The linear cumulative damage rule of Palmgren-Miner has been used to calculate the total amount of fatigue damage $[18,21]$. The basic equation for variable amplitude stress loading is:

$$
D=\sum_{i=1}^{k} \frac{n_{i}}{N_{i}}
$$

For $S_{\max }>S_{D, i}$ continuous functions exist for $n_{S}$ and $N$. Using these continuous functions gives for the amount of damage per hour:

$$
D_{h}=\int_{S_{\max (r 1)}}^{S_{\max (r 0)}} \frac{n_{S}}{N} d S_{\max }
$$

$D_{h}=$ cumulative fatigue damage per hour $\left(\mathrm{h}^{-1}\right)$

Substitution of eq. 9 and $2 \mathrm{a} / \mathrm{b}$ in eq. 10 gives:

$$
D_{h}=\frac{12 I_{r}}{d_{d}^{3}} \frac{A^{\frac{2}{n}}}{\left(h_{t o t} S_{f}\right)^{m}} \frac{1}{(m \cdot n-2)}\left[S_{\max (r 0)}\left(m-\frac{2}{n}\right)-S_{\max (r 1)}\left(m-\frac{2}{n}\right)\right]
$$

With eq. $2 \mathrm{~b}$ this gives:

$$
S_{\max (r 1)}=h_{t o t} S_{D}
$$

For the Rayleigh surface waves the geometrical attenuation is: $n=0.5$. Thus: 


$$
D_{h}=\frac{24 I_{r}}{d_{d}^{3}} \frac{A^{4}}{\left(h_{t o t} S_{f}\right)^{m}} \frac{1}{(m-4)}\left[S_{\max (r 0)^{(m-4)}}-\left(h_{t o t} S_{D}\right)^{(m-4)}\right]
$$

This equation represents the extended model, incorporating the effect of the start of the Rayleigh wave at $r=r_{0}$ by using $S_{\max \left(r_{0}\right)}$ from the Appendix.

\subsection{Rain erosion incubation period}

Rain erosion incubation period is now defined as:

$$
I_{p}=\frac{D_{f}}{D_{h}}
$$

$I_{p}=$ Rain erosion incubation period (h)

$D_{f}=$ Cumulative fatigue damage at failure

According to the general Palmgren-Miner approach $[18,21]: D_{f}=1$, which results in an incubation period of:

$$
I_{p}=\frac{d_{d}^{3}}{24 I_{r}} \frac{(m-4)\left(h_{t o t} S_{f}\right)^{m}}{A^{4}} \frac{1}{\left[S_{\max (r 0)}{ }^{(m-4)}-\left(h_{t o t} S_{D}\right)^{(m-4)}\right]}
$$

With the condition for Eq. 16 that: $S_{\max (r 0)}>h_{t o t} S_{D}$.

For the complementary condition $S_{\max (r 0)} \leq h_{t o t} S_{D}$ this results in: $I_{p} \rightarrow \infty$.

Thus the condition $S_{\max (r 0)}=h_{t o t} S_{D}$ gives the threshold rain conditions. For rain conditions $\left(v_{d}, d_{d}\right)$ resulting in a fatigue damage of $S_{\max (r 0)} \leq h_{t o t} S_{D}$ this will not cumulate to fatigue failure and thus the life of the surface material will be infinite.

With Eq. 16 an improved and more efficient derivation is presented for the incubation time compared to the work presented in [18] that still contained a fitting parameter.

\subsection{Impact pressure \& stress wave attenuation}

An overview of the equations for the raindrop impact pressure or "water hammer" pressure can be found in [18]. The attenuation of the maximum stress of the surface wave is given by Eq. 3. The value $A$ in this equation depends on the water hammer 
pressure and the droplet size. Adler [6] shows numerical results for a droplet size $\mathrm{d}_{\mathrm{d}}=1.8 \mathrm{~mm}$ and impact velocity $\mathrm{v}_{\mathrm{d}}=222 \mathrm{~m} / \mathrm{s}$. The results show the attenuation of the radial stress component at a depth of $5 \mu \mathrm{m}$ due to the Rayleigh surface wave. Using these results, and the equations for the water hammer pressure $\left(p_{w h}\right)$, gives for Eq. 3 (see also [18]):

$$
A=0.60 p_{w h} \quad\left(d_{d}=1.8 \mathrm{~mm}\right)
$$

\subsection{Stress ratio for $\mathrm{S}-\mathrm{N}$ curve}

The fatigue life equations have been defined by the Equations $2 a$ and $2 b$. The maximum stress $\left(S_{\max }\right)$ has been given as a function of the number of fatigue cycles. The minimum stress $\left(S_{\min }\right)$ during the fatigue cycles due to the Rayleigh surface wave has not yet been defined. The stress ratio $R=S_{\min } / S_{\max }$ of the stress cycles for the transient surface stress distributions calculated by Adler [6] and shown in [18] is estimated to be $R \approx-0.5$. Fatigue life curves for this stress ratio have been calculated using Haigh's approach, [22].

\section{Model predictions for thermoplastic polymers}

Model predictions have been made for a set of commonly used thermoplastic polymers. The fatigue data (bending, $R=-1$ ) of these polymers have been adopted from [23] and the acoustic properties from $[24,25]$ were used. A rain intensity of $I_{r}$ $=25.4 \mathrm{~mm} / \mathrm{h}$, a droplet size $d_{d}=1.8 \mathrm{~mm}$, and a gravitational raindrop velocity of 10 $\mathrm{m} / \mathrm{s},[8]$, have been used as well. The predictions of the incubation period were made with a drop impact velocity of $120 \mathrm{~m} / \mathrm{s}$. This drop impact velocity is based on a blade tip velocity of a $5 \mathrm{MW}$ offshore wind turbine, [1], which is about $110 \mathrm{~m} / \mathrm{s}$, and the mentioned gravitational raindrop velocity of $10 \mathrm{~m} / \mathrm{s}$, this results in an impact velocity of $120 \mathrm{~m} / \mathrm{s}$ during the upward movement of a turbine blade.

Clear distinctions between the different types of thermoplastic polymers can be seen from Figure 4 . The highest incubation period is predicted for PBT, and second best PA 6, which further underlines the expected feasibility of PBT. 


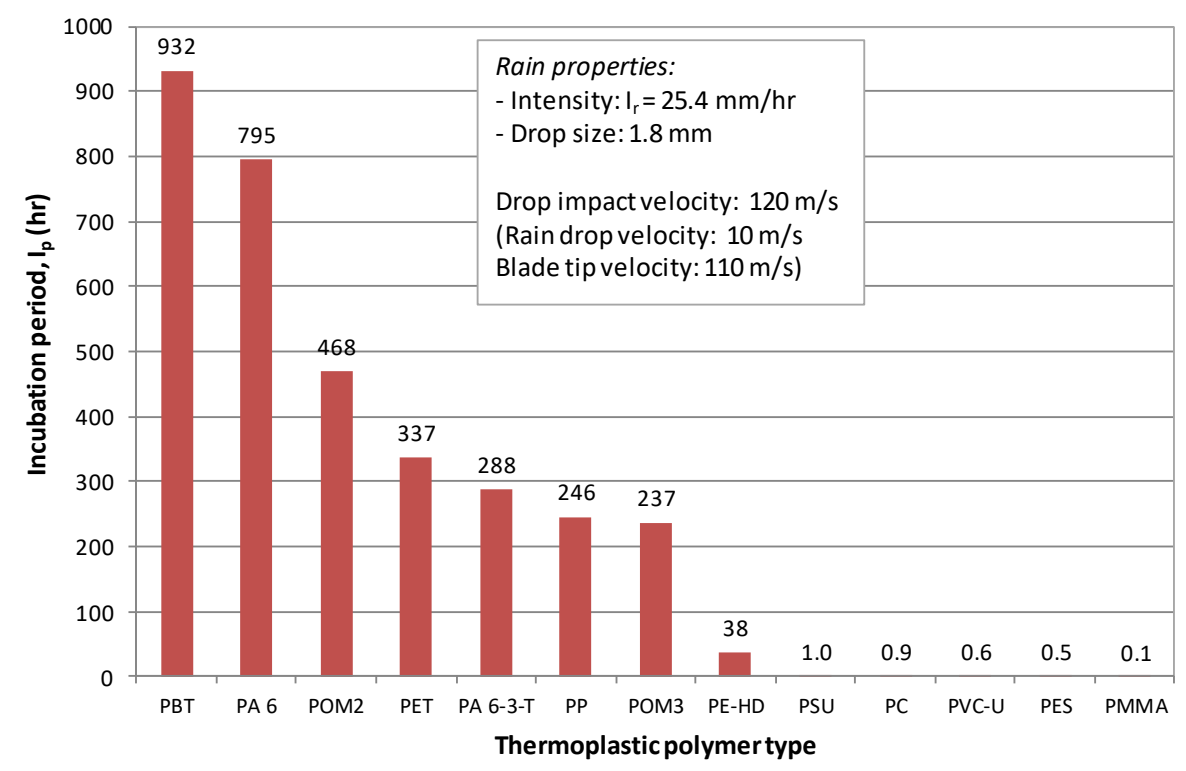

Figure 4. Predictions of the incubation period for selected thermoplastic polymers.

\section{Results}

\subsection{Droplet impingement tests}

The individual test results and an indication of the spot size with observed surface erosion damage after the given testing duration are shown in Table 2. An image of the spot with surface erosion damage of an injection moulded PBT (PBT-II) specimen is shown in Figure 5. 
Table 2. Test results of the droplet impingement tests with PBT.

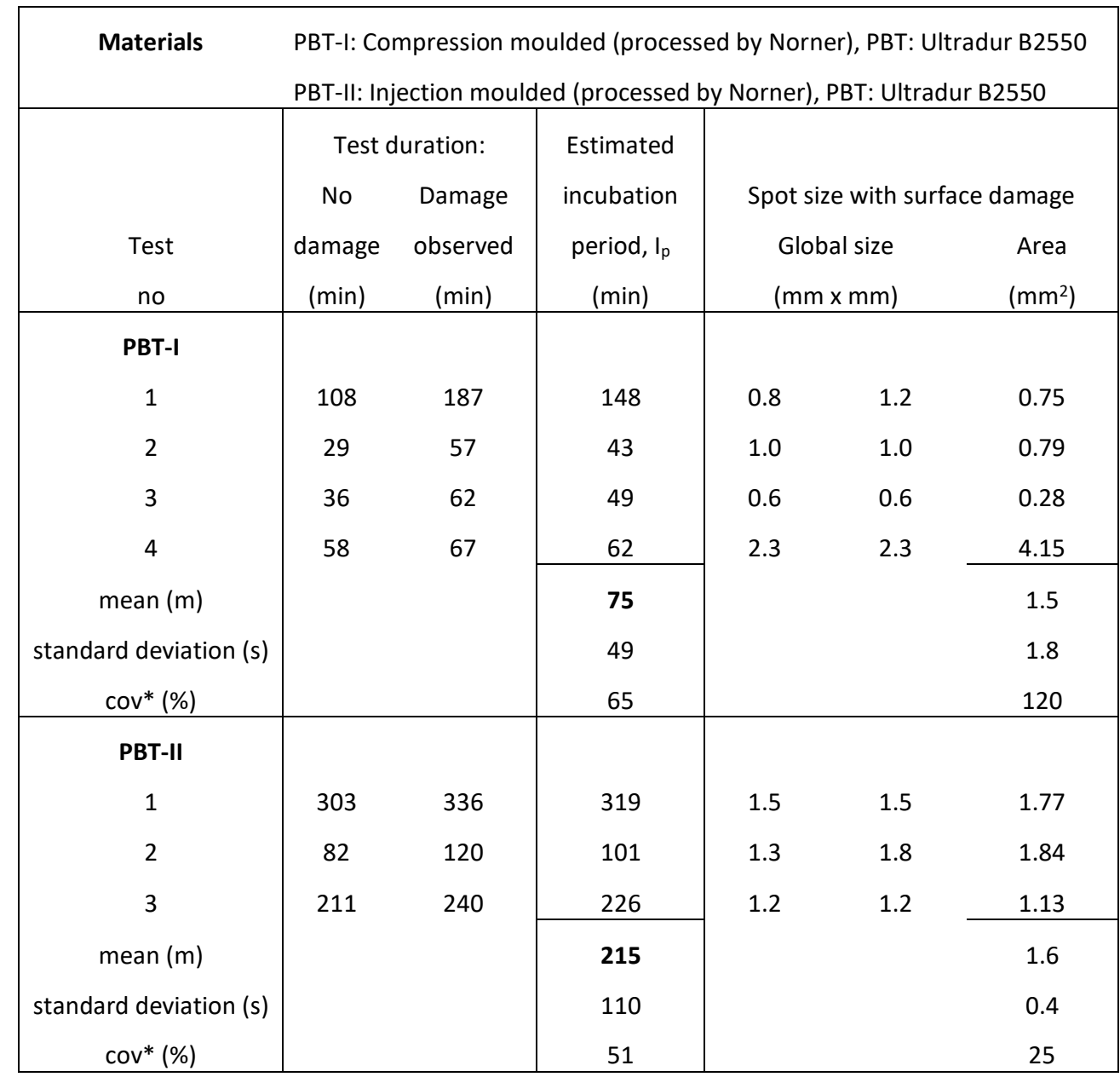

*coefficient of variance, $\operatorname{cov}=100 \times \mathrm{s} / \mathrm{m}$

Both PBT sheet types show a significant difference in mean incubation period. This lifetime is a factor 2.5 to 3 higher for the injection moulded PBT sheet (PBT-II) than the compression moulded version (PBT-I). 


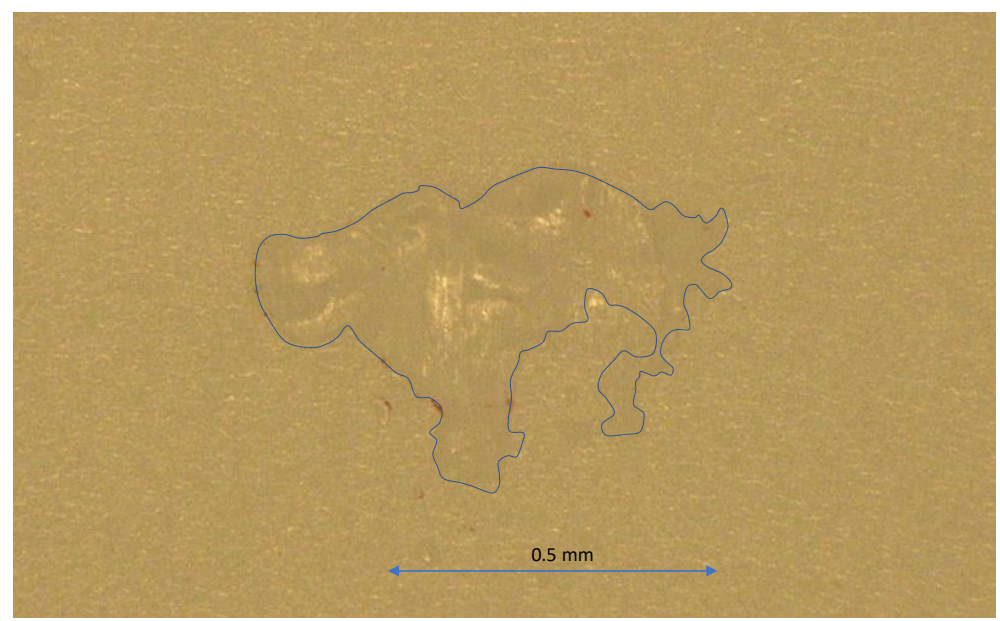

Figure 5. Picture showing the droplet impingement surface erosion of injection moulded PBT after 336 minutes of exposure at an impact velocity of $120 \mathrm{~m} / \mathrm{s}$ (PBT II, test no. 1). Boundary of area with erosion damage marked with a blue line.

\subsection{Axial fatigue tests and tensile tests}

Axial fatigue test results of both PBT types are shown in Figure 6 . The equations of the best fit (least square method), according to Eq. 2a, are shown.

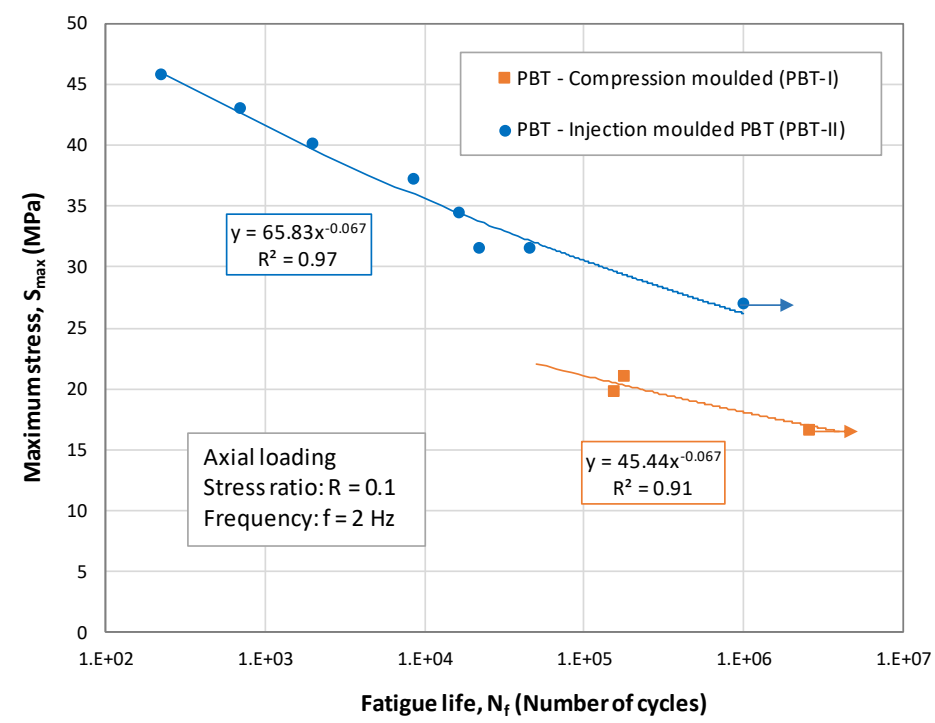

Figure 6. Axial fatigue test results for compression moulded and injection moulded PBT. (The test results with an arrow are run-outs.) 
The ultimate tensile strength, elongation at fracture and Young's modulus measured within the scope of the current work, the calculated acoustic properties and the derived S-N curves of both PBT types based on the experimental work are summarized in Table 3.

The acoustic properties, $\rho c_{S}$, are defined as the product of density and longitudinal wave velocity in the thermoplastic, [18].

Table 3. Ultimate tensile strength, elongation at fracture and Young's modulus, acoustic properties and the S-N curves of both PBT types.

\begin{tabular}{|c|c|c|c|c|c|c|c|c|}
\hline \multirow[t]{2}{*}{$\begin{array}{l}\text { PBT } \\
\text { code }\end{array}$} & \multirow[t]{2}{*}{$\begin{array}{l}\text { Moulding } \\
\text { method }\end{array}$} & Strength & $\begin{array}{l}\text { Tensile test } \\
\text { Elongation }\end{array}$ & $\begin{array}{l}\text { Young's } \\
\text { modulus }\end{array}$ & \multirow{2}{*}{$\begin{array}{c}\text { Acoustic } \\
\text { properties } \\
\quad \rho c_{s,} \\
\text { (MPa.s/m) }\end{array}$} & \multicolumn{3}{|c|}{$\begin{array}{c}\text { Axial fatigue test } \\
\mathrm{S}_{\max }-\mathrm{N} \text { curve }(\mathrm{R}=0.1), \\
\mathrm{Eq} 2 \mathrm{a} / \mathrm{b}\end{array}$} \\
\hline & & $\mathrm{R}_{\mathrm{m}}(\mathrm{MPa})$ & $\mathrm{A}(\%)$ & $\mathrm{E},(\mathrm{MPa})$ & & $\mathrm{S}_{\mathrm{f}}(\mathrm{MPa})$ & $\mathrm{m}$ & $S_{D}\left(10^{7}\right)$ \\
\hline PBT-I & Compression & 23.2 & 0.73 & 3160 & 3.54 & 45.4 & 14.9 & 15.0 \\
\hline PBT-II & Injection & 57.4 & 3.6 & 2545 & 3.18 & 65.8 & 14.9 & 22.4 \\
\hline
\end{tabular}

\subsection{Predictive model calculations}

The droplet impingement conditions shown in Table 4, derived from the experimental conditions, were used as input for the model predictions of the incubation period $\left(I_{p}\right)$. A droplet size of $0.030 \mathrm{~mm}$, based on the droplet size measurements presented by Fujisawa et al., [16], for a comparable erosion test setup, nozzle type and spray regime, [26-28], has been used as an inferred value.

Further, for this small droplet size, it is assumed that the value $A$ in Eq. 17 can be corrected linearly with droplet size. The material properties of Table 3 for both PBT types have been used as input for the equations (A-4), and (16).

The predicted incubation periods for a droplet size of $0.030 \mathrm{~mm}$ are presented as a function of droplet impact velocity, see Figure 7. The mean incubation lives from the tests of both PBT types and the 95\% confidence ranges of the mean $(\mathrm{m} \pm 1.98 \mathrm{~s} / \mathrm{Vn})$ are also indicated. Predictions with these test conditions for the PBT grade given by Domininghaus [23], see Figure 4, are shown for comparison. 
Table 4. Droplet impingement conditions used for the incubation period predictions.

\begin{tabular}{|lccl|}
\hline \multicolumn{4}{l}{ Droplet impingement conditions } \\
\hline Droplet velocity & $\mathrm{v}_{\mathrm{d}}$ & $110,120,130$ & $\mathrm{~m} / \mathrm{s}$ \\
Flow rate & $\mathrm{Q}$ & 0.55 & $\mathrm{I} / \mathrm{min}$ \\
Spot size & $\mathrm{d}_{\mathrm{s}}$ & 25 & $\mathrm{~mm}$ \\
Droplet size & $\mathrm{d}_{\mathrm{d}}$ & $0.030^{*}$ & $\mathrm{~mm}$ \\
\hline For $\mathrm{v}_{\mathrm{d}}=120 \mathrm{~m} / \mathrm{s}$ : & & & \\
Number of droplets & $\mathrm{n}$ & $3.25 \times 10^{8}$ & droplets $/ \mathrm{s}$ \\
Droplet impact density & & 662000 & droplets $/ \mathrm{mm}^{2} . \mathrm{s}$ \\
\hline
\end{tabular}

*inferred value from [16].

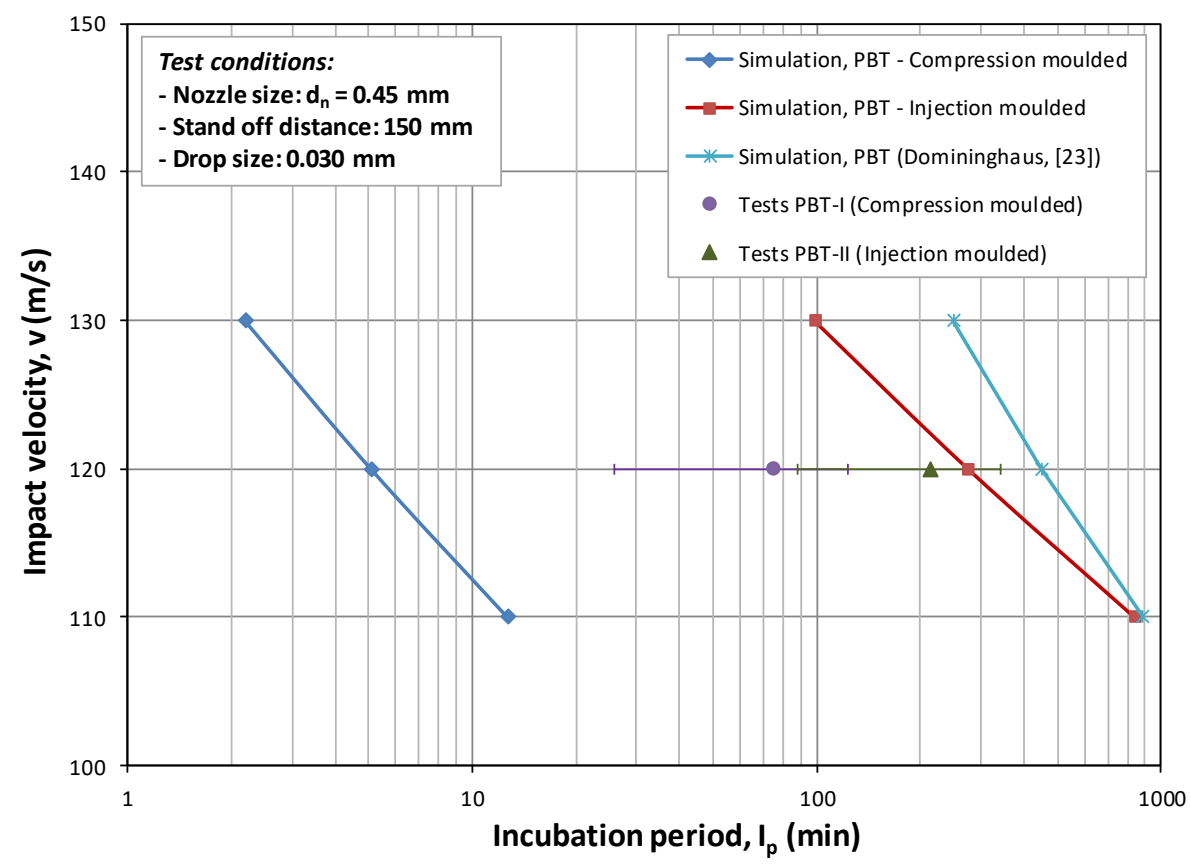

Figure 7. Predicted incubation periods as a function of droplet impact velocity for a droplet size of $0.030 \mathrm{~mm}^{*}$ (test conditions). The mean incubation lives from the tests of both PBT types and the $95 \%$ confidence ranges of the mean $(m \pm 1.98 \mathrm{~s} / \mathrm{Vn})$ are shown. Predictions for PBT grade (see Figure 4), [23] are shown for comparison. *inferred value from [16]. 
The predicted incubation period for the used test conditions, a droplet size of 0.030 $\mathrm{mm}$ and a droplet impact velocity of $120 \mathrm{~m} / \mathrm{s}$, is $I_{p, l}=5.1 \mathrm{~min}$ for compression moulded PBT (PBT-I) and $I_{p, I I}=277$ min for the injection moulded PBT (PBT-II). The prediction for the injection moulded PBT (PBT-II) is, when compared with the test results, quite reasonable: a deviation of only $29 \%$. For the compression moulded PBT (PBT-I) the incubation period is a lot less than predicted, when compared with the test results. The mean incubation period from the tests is a factor 15 higher than predicted. This deviation probably resulted from the lower confidence level (only three valid test results at a high number of cycles) of the S-N curve for compression moulded PBT (PBT-I), see Figure 6, than for the injection moulded PBT (PBT-II).

Predictions for the PBT grade given by Domininghaus [23] result in incubation periods varying between nearly the same to 2 times as high as the injection moulded PBT (PBT-II).

\section{Discussion}

The assessments of the rain erosion resistance of both PBT types by experimental work and model calculations show the same trend and a good similarity between test results and model calculations for the injection moulded PBT (PBT-II).

Comparing the predicted incubation period with measured incubation period for both PBT types revealed that the ranking of injection moulded and compression moulded PBT are the same, i.e. injection moulding resulted in a substantial longer incubation period than compression moulding. This can be understood from the production processes, as compression moulding and injection moulding of the same PBT grade is expected to affect the morphological structure of the polymer. Compression moulding is a process which, due to the slow cooling rate, gives a homogenous structure with more isotropic properties. Injection moulding is a process in which the polymer melt experiences high strains and high cooling rate, and thus a skin layer with high chain orientation is expected to form near the walls. At the core of the sample, the structure is more homogeneous with less chain orientation. These morphological differences lead to different physical and mechanical properties. Due to the slower cooling rate, the crystallinity of the sample which has been compression moulded will be higher that of the sample which has been injection moulded. Higher crystallinity leads to a higher tensile or Young's modulus. This expected effect was indeed measured as a higher Young's modulus for the compression moulded sample $(E=3160 \mathrm{MPa})$ and lower Young's modulus for the injection moulded sample $(E=2545 \mathrm{MPa})$, see Table 3. 
Although a good similarity between test results and model calculations for the injection moulded PBT (PBT-II) was found (deviation of 29\%), the absolute value of the incubation period predicted by the model calculations for compression moulded PBT (PBT-I), see Figure 7, differed more than one decade (factor 15). One can argue that the droplet impingement test based on a water jet / nozzle system should be considered as an accelerated life test. The main reason for the acceleration of the wear mechanism is the high droplet impact density generated by the nozzle equipped test apparatus. The number of drop impacts of the experimental set-up is for a droplet size of $0.030 \mathrm{~mm} 3.25 \times 10^{8} \mathrm{drops} / \mathrm{s}$ on a spot size with a diameter of $25 \mathrm{~mm}$, see Table 4 . This equals a droplet impact density of 662000 drops $/ \mathrm{mm}^{2}$.s.

In the predictive model each drop impact is assumed to be effective and giving rise to a full fatigue stress cycle. A wind turbine blade with a tip velocity of $120 \mathrm{~m} / \mathrm{s}$ [1, 8] in heavy rain with an intensity of $25.4 \mathrm{~mm} / \mathrm{h}$, a drop size of $1.8 \mathrm{~mm}$, and a gravitational raindrop velocity of $10 \mathrm{~m} / \mathrm{s}$ results in an average droplet impact density on the tip of $0.025 \mathrm{drops} / \mathrm{mm}^{2}$.s, thus the model assumption is valid for the practical situation. In the experimental set-up however, for the droplet size of 0.030 $\mathrm{mm}$, the droplet impact density is $10^{7}$ higher than for the practical situation. Therefore, only a part of the droplets is expected to be effective in generating full fatigue stress cycles. In the presented predictive calculations an effective part of $\eta$ $=50 \%$ has been used. Whirling arm test facilities with larger and more realistic test samples $[12,13]$ might produce incubation results that are closer to reality yet full scale tests will ultimately be necessary to validate the model and establish the limitations of the selected experimental method for specific blades and operational conditions. For experimental research and development on materials, the used test set-up and model can be used for ranking surfaces with respect to droplet impingement resistance in a cost effective way.

\section{Conclusions}

The following conclusions are drawn:

- The test set-up based on a water jet / nozzle system can be used for ranking surfaces with respect to droplet impingement resistance.

- The mean incubation period determined by testing with the used test set-up cannot be used directly for life predictions in real wind turbine blade situations.

- Model predictions show clear distinctions between different types of thermoplastic polymers. The highest incubation period is predicted for PBT, and second best PA 6, which further underlines the expected feasibility of PBT. 
- The droplet impingement measurements and model predictions show a substantially higher incubation period for injection moulded PBT compared to compression moulded PBT.

\section{Acknowledgement}

The research leading to these results has received funding from the European Union's Seventh Framework Programme (FP7/2007-2013) under grant agreement no. 309985, www.eu-walid.com [4].

\section{References}

[1] Direct drive wind turbine X115-5MW, www.xemc-darwind.com, 2017.

[2] Dutch Government, www.rvo.nl/subsidies-regelingen/stimulering-duurzameenergieproductie/categorieën/sde-windenergie-op-zee, 2018.

[3] LM Wind Power, www.Imwindpower.com/en/products-and-services/bladetypes/longest-blade-in-the-world, 2018.

[4] EU project WALiD, Wind Blade Using Cost-Effective Advanced Composite Lightweight Design, FP7-NMP-2012-SMALL-6, grant agreement no. 309985, $2013-2017$.

[5] Busch H., Hoff G., Langbein G., Taylor G., Jenkins D.C., Taunton M.A., Fyall A.A., Jones R.F., Harper T.W., Rain Erosion Properties of Materials [and Discussion], Philosophical Transactions of the Royal Society of London. Series A, Mathematical and Physical Sciences 260(1110), 1966, 168-181.

[6] Adler W.F., Liquid drop collisions on deformable media, Journal of Materials Science 12, 1977, 1253-1271.

[7] Schmitt G.F., Material Parameters that Govern the Rain Erosion Behavior of Polymeric Coatings and Composites at Subsonic Velocities, Report AFML-TS71-179, Air Force Materials Laboratory (Ohio), 1979.

[8] Gohardani O., Impact of erosion testing aspects on current and future flight conditions, Progress in Aerospace Sciences 47, 2011, 280-303.

[9] Schmitt G.F., Polyurethane coatings for rain erosion protection, In: Fyall A.A., King R.B. (Eds.), Proceedings of the $2^{\text {nd }}$ Conference on Rain Erosion and Associated Phenomena, Farnborough, England, 1967, 329-357.

[10] Rieger H., Boche H., Erosion Behavior of Surface Coatings, In: Fyall A.A., King R.B. (Eds.), Proceedings of the $4^{\text {th }}$ International Conference on Rain Erosion and Associated Phenomena, Farnborough, England, 1974, 637-675. 
[11] Conn A.F., Rudy S.L., The effects of fatigue and dynamic recovery on rain erosion, In: Thiruvengadam A., Erosion wear and interfaces with corrosion, ASTM-STP-567, American Society for Testing and Materials, 1974, 239-269.

[12] Heymann F.J., Liquid Impingement Erosion, in: Friction, Lubrication and Wear Technology, ASM Handbook 18, 1992, American Society of Metals.

[13] Standard practice for liquid impingement erosion testing, ASTM-G73, 2010, American Society for Testing and Materials, Philadelphia (USA).

[14] Duraiselvam M., Galun R., Siegmann S., Wesling V., Mordike B.L., Liquid impact erosion characteristics of martensitic stainless steel laser clad with $\mathrm{Ni}$-based intermetallic composites and matrix composites, Wear 261, 2006, 1140-1149.

[15] Oka Y.I., Miyata H., Erosion behaviour of ceramic bulk and coating materials caused by water droplet impingement, Wear 267, 2009, 1804-1810.

[16] Fujisawa N., Takano S., Fujisawa K., Yamagata T., Experiments on liquid droplet impingement erosion on a rough surface, Wear 398-399, 2018, 158-164.

[17] Springer G.S., Erosion by liquid impact, Scripta Publishing Company, 1976.

[18] Slot H.M., Gelinck E.R.M., Rentrop C., Heide E. van der, Leading edge erosion of coated wind turbine blades: Review of coating life models, Renewable Energy 80, 2015, 837-848.

[19] Woods R.D., Screening of surface waves in soils, Journal of Soil Mechanics and Foundations Division 94, 1968, 951-979.

[20] Haosheng C., Shihan L., Inelastic damages by stress wave on steel surface at the incubation stage of vibration cavitation erosion, Wear 266, 2009, 69-75.

[21] Miner M.A., Cumulative damage in fatigue, Journal of Applied Mechanics 12, 1945, A159-A164.

[22] Suresh S., Fatigue of Materials, Cambridge University Press, 2001.

[23] Domininghaus H., Plastics for Engineers - Materials, Properties, Applications, Hanser Publishers, 1993.

[24] Krevelen D.W. van, Nijenhuis K. te, Properties of Polymers, Chapter 14: Acoustic properties, $4^{\mathrm{e}}$ edition, Elsevier, 2009.

[25] Sinha M., Buckley D.J., Acoustic properties of Polymers, In: Mark J.E., Physical Properties of Polymers Handbook, $2^{\text {nd }}$ edition, 2007, 1021-1031.

[26] Phinney R., The breakup of a turbulent liquid jet in a gaseous atmosphere, J. Fluid Mech. 60-4, 1973, 689-701.

[27] Birouk M., Lekic N., Liquid jet breakup in quiescent atmosphere: A review, Atomization and Sprays 19-6, 2009, 501-528.

[28] Agrawal K. S., Breakup of liquid jets, International Journal of Emerging Technologies in Computational and Applied Sciences 13-353, 2013, 487-496.

[29] Foti S., Multi-station Methods for Geotechnical Characterization using Surface Waves, PhD Thesis, Chapter 3: Rayleigh Waves, 2000. 
[30] Timoshenko S.P., Goodier J.N., Theory of Elasticity, Chapter 14: The propagation of Waves in Elastic Solid media, McGraw-Hill, $3^{\text {rd }}$ edition, 1987.

\section{Appendix A Radius of start of Rayleigh wave}

The moment of start of the surface Rayleigh wave [29] is defined as the time that the velocity of the boundary of the droplet contact area $\left(v_{a}\right)$ is equal to the Rayleigh wave velocity $\left(c_{R}\right)$. Figure A-1 shows the deformed droplet geometry and the drop part with compressed high water pressure.

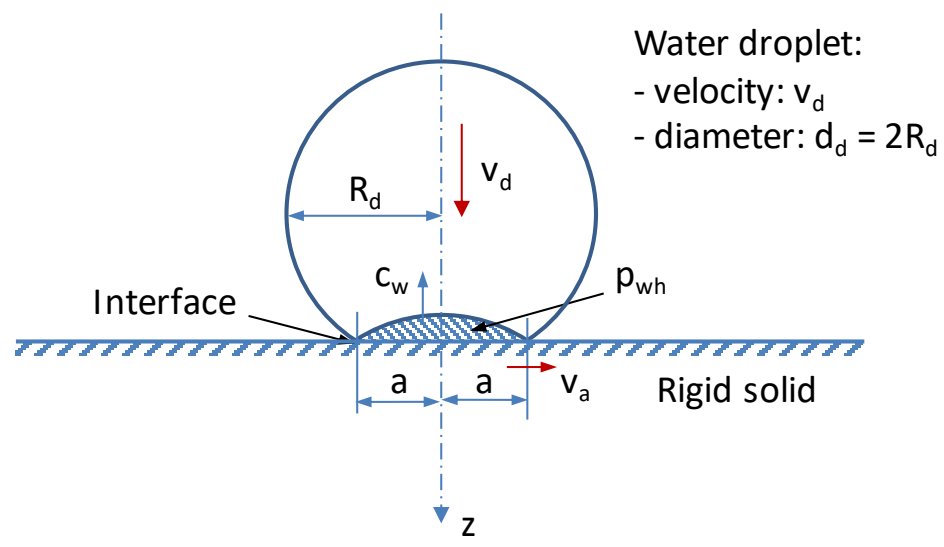

Figure A-1. Deformed droplet geometry and the drop part with high water hammer pressure $\left(p_{w h}\right)$ on the surface of a rigid solid.

Due to the impact and the round shape of the droplet, the initial velocity of the boundary of the contact area with the solid surface is infinitely high. This velocity $v_{a}$ decreases rapidly to respectively the longitudinal wave velocity $\left(c_{L}\right)$, the transverse wave velocity $\left(c_{T}\right)$ and finally the Rayleigh wave velocity $\left(c_{R}\right)$.

The radius of the contact area of the droplet with the solid (rigid) surface, (a), [6], is:

$$
a=\sqrt{\left(2 R_{d} v_{d} t-\left(v_{d} t\right)^{2}\right)}
$$

The velocity of this contact area boundary on the solid surface $\left(v_{a}\right)$ is: 


$$
v_{a}=\frac{d a}{d t}=\frac{\left(R_{d} v_{d}-v_{d}^{2} t\right)}{\sqrt{\left(2 R_{d} v_{d} t-\left(v_{d} t\right)^{2}\right)}}
$$

The impact gives rise to the Rayleigh wave, which is confined to the surface of the specimen and is responsible for $\sim 2 / 3$ of the collision energy. The Rayleigh surface wave (or R-wave) velocity in a solid is given by $[29,30]$ :

$$
c_{R}=\left\{\frac{E}{2 \rho(1+v)}\right\}^{1 / 2}\left\{\frac{(0.87+1.12 v)}{(1+v)}\right\}
$$

where

$v=$ Poisson's ratio of surface material,

$\rho=$ density of surface material

$E=$ Young's modulus of surface material.

Using equation A-1 and A-2, with $R_{d}=d_{d} / 2$, the value $r_{0}$, the radial location of start of the surface Rayleigh wave $\left(v_{a}=c_{R}\right)$ is:

$$
r_{0}=\frac{d_{d} c_{R}}{2 v_{d}}\left\{\sqrt{1+2\left(\frac{v_{d}}{c_{R}}\right)^{2}}-1\right\}
$$

Equations 3 and A-4 are now used for $S_{\max (r 0)}$ in equation 16. 


\section{Paper C}




\title{
Fatigue-based model for the droplet impingement erosion incubation period of metallic surfaces
}

\author{
H.M. Slot ${ }^{a *}$, D.T.A. Matthews ${ }^{b}$, D.J. Schipper ${ }^{b}$ and E. van der Heide ${ }^{b, c}$ \\ a TNO, Structural Reliability dept., Stieltjesweg 1, 2628 CK Delft, the Netherlands \\ ${ }^{b}$ University of Twente, Laboratory for Surface Technology and Tribology, Enschede \\ c Ghent University, Faculty of Engineering and Architecture, Kortrijk, Belgium \\ Published in:
}

Fatigue \& Fracture of Engineering Materials \& Structures 44, 2021, 199-211.

\begin{abstract}
Droplet impingement of metallic surfaces at high impact velocities results, after some time, in erosion of the surface due to fatigue. By extending our previously published analytical model to enable the use of experimental fatigue data ( $\mathrm{S}-\mathrm{N}$ curves), here, for the first time, a wide range of experimental liquid droplet erosion incubation period test states for both ferrous (stainless steel AISI 316) and nonferrous (aluminium 6061-T6) engineering metals have been investigated. To achieve this, the developed model includes additional surface hardening and a residual compressive stress state at the surface due to a water drop peening effect. As such, the interrelation of the physical and mechanical properties that follows from the model has been used to identify how changes in selected metal properties might enhance droplet impingement erosion incubation life.

Model predictions for both metals, using fatigue data from S-N curves from different literature sources, showed for the droplet impact velocity range of 140 to $400 \mathrm{~m} / \mathrm{s}$ an excellent agreement with results from a multi-regression equation as determined from an ASTM interlaboratory test program.
\end{abstract}

\section{Keywords}

Surface Fatigue, Peening, Surface Hardening, Drop Impact, Predictive Model

\section{Nomenclature}

$A=$ constant in Rayleigh surface wave attenuation $(\mathrm{Pa} V \mathrm{~m})$ or elongation at fracture (\%) $a=$ material parameter of strain hardening $(1 / \mathrm{Pa})$, or radius of contact area $(\mathrm{m})$ 
$b=$ material parameter for the residual stress $(1 / \mathrm{Pa})$

$C_{v}=$ volume concentration of water in air (-)

$c_{l, m}=$ longitudinal wave velocity of metal $(\mathrm{m} / \mathrm{s})$

$c_{R}=$ Rayleigh surface wave velocity in a metal $(\mathrm{m} / \mathrm{s})$

$c_{t}=$ transverse wave velocity of metal $(\mathrm{m} / \mathrm{s})$

$c_{w}=$ speed of sound in water at the pressure $p_{w h}(\mathrm{~m} / \mathrm{s})$

$c_{w 0}=$ speed of sound in water at a pressure of $1 \mathrm{bar}(\mathrm{m} / \mathrm{s})$

$D_{h}=$ cumulative fatigue damage per hour $(1 / \mathrm{h})$

$D_{f}=$ cumulative fatigue damage at failure (-)

$d_{d}=$ water drop diameter $(\mathrm{m})$

$E=$ Young's modulus $(\mathrm{Pa})$

$f=$ fatigue cycle frequency $(\mathrm{Hz})$

$H=$ surface hardness after peening at a certain impact velocity ( $\mathrm{Pa})$

$H_{0}=$ material hardness when stress free and without strain hardening $(\mathrm{Pa})$

$h_{\text {tot }}=$ correction factor for the differences between fatigue test and rain impact conditions (-)

$I_{p}=$ droplet impingement erosion incubation period (h)

$k=$ constant for the pressure influence on the speed of sound in water (-)

$m=$ material parameter in fatigue tests $(-)$

$N_{f}=$ fatigue life (number of cycles to failure)

$N_{i}=$ number of fatigue cycles of the incubation period or at level $i(-)$

$N_{0}=$ number of specific impacts for incubation (-)

$N O R=$ incubation resistance number $(-)$

$n=$ number of tests, or exponent for the Rayleigh wave attenuation (-)

$n_{i}=$ number of cycles due to multiple drop impact at stress level $i(-)$

$p_{w h}=$ water-hammer pressure $(\mathrm{Pa})$

$p_{w h, t h}=$ threshold water-hammer pressure $(\mathrm{Pa})$

$R=$ stress ratio in the fatigue test (-)

$R_{d}=$ maximum erosion rate $(\mathrm{m} / \mathrm{s})$

$R_{e}=$ rationalized erosion rate (-)

$R_{m}=$ tensile strength of metal $(\mathrm{Pa})$

$R_{p 0.2}=$ yield strength of metal $(\mathrm{Pa})$

$r=$ radial coordinate $(\mathrm{m})$

$r_{0}=$ radius of contact area when Rayleigh wave starts $(\mathrm{m})$

$r_{w h}=$ radius of maximum contact area with the water-hammer pressure $(\mathrm{m})$

$S_{a}=$ stress amplitude $(\mathrm{Pa})$

$S_{D}=$ fatigue limit $(\mathrm{Pa})$

$S_{f}=$ material parameter in fatigue tests $(\mathrm{Pa})$ 
$S_{f 0}=$ fatigue strength coefficient for stress free metal and without strain

hardening $(\mathrm{Pa})$

$S_{m}=$ mean stress $(\mathrm{Pa})$

$S_{\text {max }}=$ maximum stress in a fatigue cycle $(\mathrm{Pa})$

$S_{\max (r 0)}=$ maximum stress due to Rayleigh wave at location $r_{0}(\mathrm{~Pa})$

$s=$ standard deviation (-)

$v_{d}=$ water droplet impact velocity on the specimen surface $(\mathrm{m} / \mathrm{s})$

$v_{a}=$ radial velocity of contact area boundary $(\mathrm{m} / \mathrm{s})$

$t=$ time $(\mathrm{s})$

$Z=$ reduction of area (\%)

$\Phi_{v}=$ volume of impacting water drops per unit area $(\mathrm{m} / \mathrm{s})$

$v=$ Poisson's ratio $(-)$

$\rho_{m}=$ density of metal $\left(\mathrm{kg} / \mathrm{m}^{3}\right)$

$\rho_{w}=$ density of water $\left(\mathrm{kg} / \mathrm{m}^{3}\right)$

$\sigma_{R}=$ residual (compressive) stress at the surface after peening at a certain impact velocity $(\mathrm{Pa})$

$V_{\text {water }} / A_{e}=$ volume of waterdrops impinged per unit exposed area $(\mathrm{m})$

$A_{d} / V_{d}=$ projected area of a waterdrop divided by the volume of a waterdrop $(1 / \mathrm{m})$

\section{Introduction}

Current research on droplet impingement erosion of metallic surfaces is typically related to the lower pressure stages in steam turbines where the blades suffer from erosion due to the high water content of the steam [1-3]. Another industrial application suffering from droplet impingement erosion is Liquified Natural Gas (LNG) transport. Large LNG droplets in a partly evaporated gas are a source of droplet impact erosion of the metallic surfaces of the transfer systems [4]. The blades of large wind turbines also experience droplet impingement erosion, due to impact of rain. The leading edges of wind turbine blades are often protected with polyurethane coatings $[5,6]$, yet their lifetime is still relatively short. The application of both integrated and flexible strip-like metallic erosions shields to protect the leading edge is therefore becoming a realistic option, thus illustrating the potential interest in controlling impingement erosion for metallic surfaces and enabling higher tip speeds [7].

Droplet impingement of surfaces results, after some time, in erosion of the surface [8-10,12-14]. Recently, work on the modelling of drop impact-induced stresses and related wear, is presented by Slot et al. $[15,16]$, Amirzadeh et al. $[17,18]$, and 
Castorrini et al. [19], for relatively low impact velocities $(<150 \mathrm{~m} / \mathrm{s})$, for Young's moduli that are representative for polymers and elastomers ( $<5 \mathrm{GPa}$ ) and, more importantly for fully elastic deformation during impact. The physical and metallurgical mechanisms which determine the droplet impingement erosion incubation period $\left(I_{p}\right)$, for metallic surfaces however, are presently not fully understood [1-3,5]. As a result, empirical approaches are used for the assessment of droplet impingement erosion sensitive situations involving metallic surfaces $[1,4,10,11]$.

The objective of this paper is to identify and understand the physical and metallurgical mechanisms that determine the droplet impingement erosion incubation period for metallic materials. A previously developed fatigue-based model by the authors $[15,16]$ for droplet impingement erosion of polymeric surfaces is further developed for use of metallic surfaces, given the similarities in general aspects of the erosion process. The extension of the model takes into account fatigue curves of metallic materials, the effect of additional surface hardening and the effect of a residual compressive stress state at the surface due to the "water drop peening effect". The resulting fatigue-based model for the incubation period is tested against the multi-regression fit equation of Heymann [11] - the current state-of-the-art in estimating the incubation period determined from an ASTM interlaboratory test program. The developed model is used for metallic surfaces in general and includes data taken from literature for stainless steel AISI 316 and aluminium 6061-T6. By quantifying the interrelation of the physical degradation mechanisms and the mechanical properties of the metals guidelines can be given for metallic surfaces with respect to droplet impingement erosion life.

\section{Reference interlaboratory test program for liquid impact erosion}

During the 70's of the last century, under supervision of the Technical Committee on Erosion and Wear of the American Society for Testing Materials (ASTM), an interlaboratory test program using liquid impact erosion test facilities was organized. In six different laboratories in four different countries tests were performed with rotating disc or whirling arm test facilities using water drops. In a rotating disc facility, the specimens are attached to this rotating disc and their circular path intersects one or more water sprays. In a whirling arm facility, the specimens are attached to the rotating arms and they continuedly rotate in a simulated rainfall with a certain intensity. In these tests multiple drop impacts occur and their impact velocity is assumed equal to the peripheral velocity of the 
specimen. The tests are performed at drop impact velocities of 140, 210, and 400 $\mathrm{m} / \mathrm{s}$, the drop sizes ranges from 1.2 to $2.0 \mathrm{~mm}$.

In these whirling arm tests $[10,11]$ the mean volume concentration of water in air $C_{v}=1.8 \times 10^{-6}$ (mean $\log \left(C_{v}\right)=-5.74$, standard deviation $\mathrm{s}=0.44$ ). By way of comparison: for typical rain conditions, rain intensity $I_{r}=25.4 \mathrm{~mm} / \mathrm{h}$, drop size $d_{d}=$ $1.8 \mathrm{~mm}$, and gravitational drop velocity $\mathrm{v}_{\mathrm{g}}=6.2 \mathrm{~m} / \mathrm{s}$ [6], the volume concentration of water in air $C_{v}=1.1 \times 10^{-6}\left(\log \left(C_{v}\right)=-5.94\right)$.

The metals supplied to the laboratories are: Aluminium 1100-0 and 6061-T6, Nickel 270, Stainless Steel AISI 316, and Stellite 6B. The first four metals provided most of the test data; only a few were performed with Stellite 6B.

Based on this extensive test program by ASTM, Heymann $[10,11]$ derived a multiple linear regression fit equation for the incubation life, and in this equation each metal tested is characterised by its normalized "incubation resistance number" (NOR). For this normalization the incubation period of AISI 316 (hardness of $170 \mathrm{HV}$ ) was used. This multiple linear regression fit equation for the incubation period using water drops, and the "incubation resistance number" $(N O R)$ of the tested metals and the properties of the tested metals are summarized in Appendix A.

\section{Modelling}

\subsection{Stress cycle due to drop impact}

The main building blocks of the existing model that is described in detail in $[15,16]$ are the water-hammer pressure, which originates from compression of the liquid on impact of the surface, see Figure 1 and the resulting stress cycle from the Rayleigh wave. The water-hammer pressure $p_{w h}$ is given by [15,23]:

$$
\begin{aligned}
& p_{w h}=v_{d} \frac{\rho_{w} c_{w}}{\left(\frac{\rho_{w} c_{w}}{\rho_{m} c_{l, m}}+1\right)} \\
& c_{w}=c_{w 0}+k v_{d}
\end{aligned}
$$

$v_{d}=$ drop impact velocity,

$\rho_{w}=$ density of water at $1 \mathrm{bar}, 1000 \mathrm{~kg} / \mathrm{m}^{3}$,

$c_{w}=$ speed of sound in water at the pressure $p_{w h}$,

$c_{w 0}=$ speed of sound in water at a pressure of 1 bar, $1647 \mathrm{~m} / \mathrm{s}$,

$k=$ constant for the pressure influence on the speed of sound [23], 1.921, 
$\rho_{m}=$ density of metal,

$c_{l, m}=$ longitudinal wave velocity of metal.

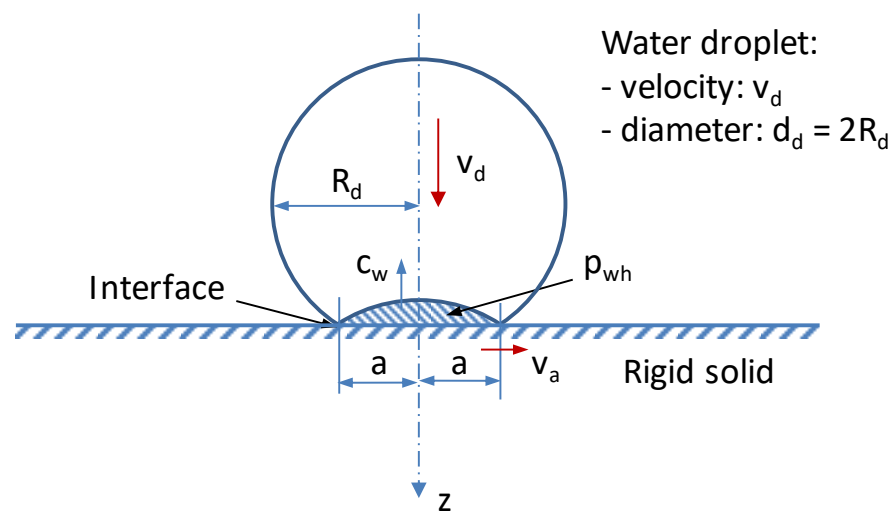

Figure 1. Contact geometry showing the part with high water hammer pressure $\left(p_{w h}\right)[16]$.

Due to the impact and the assumed round shape of the droplet, the initial velocity of the boundary of the contact area with the solid surface is infinitely high. This velocity $v_{a}$ decreases rapidly to, respectively, the longitudinal wave velocity $\left(c_{l, m}\right)$, the transverse wave velocity $\left(c_{t}\right)$, the Rayleigh wave velocity $\left(c_{R}\right)$, and finally to the speed of sound in water for this compressed state $\left(c_{w}\right.$, see Eq. 1$)$. When $v_{a}<c_{w}$ the compressed water volume loses its high pressure $\left(p_{w h}\right)$.

The radius of the contact area $(a)$ of the droplet with the rigid surface as a function of time $(t)[24]$ is described by:

$$
a=\sqrt{\left(2 R_{d} v_{d} t-\left(v_{d} t\right)^{2}\right)}
$$

The radial velocity of this contact area boundary $\left(v_{a}\right)$ is defined by:

$$
v_{a}=\frac{d a}{d t}=\frac{\left(R_{d} v_{d}-v_{d}^{2} t\right)}{\sqrt{\left(2 R_{d} v_{d} t-\left(v_{d} t\right)^{2}\right)}}
$$

With

$R_{d}=d_{d} / 2$ 
At the time when the surface Rayleigh wave starts, $v_{a}$ equals $c_{R}$ and the radius of the contact area $\left(r_{0}\right)$ is given by:

$$
r_{0}=\frac{d_{d} c_{R}}{2 v_{d}}\left\{\sqrt{1+2\left(\frac{v_{d}}{c_{R}}\right)^{2}}-1\right\}
$$

As stated, the compressed water volume loses its high pressure when the velocity of its contact area boundary decreases to the speed of sound in water for this compressed state, $c_{w}$. The maximum contact area for which the water-hammer pressure acts follows from the condition: $v_{a}=c_{w}$. Replacing $c_{R}$ by $c_{w}$ in Eq. 4 and using Eq. $1 \mathrm{~b}$ gives the related contact radius $\left(r_{w h}\right)$ :

$$
r_{w h}=\frac{d_{d}\left(c_{w 0}+k v_{d}\right)}{2 v_{d}}\left\{\sqrt{1+2\left(\frac{v_{d}}{c_{w 0}+k v_{d}}\right)^{2}}-1\right\}
$$

In this work, it is chosen to select one droplet diameter for all model predictions, while the impact velocity is varied. A droplet diameter $d_{d}=1.8 \mathrm{~mm}$ serves as representative value, within the presented range by Heymann [11] of 1.2 to 2.0 $\mathrm{mm}$. The drop impact velocities are taken equal to 140,210 and $400 \mathrm{~m} / \mathrm{s}$, similar to the experimental work that is used by Heymann [11].

For this droplet diameter, the impact velocities result for AISI 316 in contact radii $\left(r_{0}\right)$ of respectively $0.04,0.07$ and $0.13 \mathrm{~mm}$, and radii $\left(r_{w h}\right)$ of respectively $0.07,0.09$ and $0.15 \mathrm{~mm}$.

Drop impact on the metal surface results in three types of stress waves: the longitudinal or compression wave, the transverse or shear wave and the Rayleigh surface wave [15]. The latter gives rise to the highest cyclic stresses $(S)$. These stress cycles are well known to cause fatigue, in this case surface fatigue. This surface fatigue or fatigue wear results in the removal of particles detached by short fatigue crack growth. The maximum stress of this cycle due to the Rayleigh surface wave can be given by [15]:

$$
S_{\max }=\frac{A}{r^{n}}
$$

In which $A$ depends on the water-hammer pressure $\left(p_{w h}\right), n$ is a constant and $r$ is the radial coordinate. By assuming that the stress cycle starts at $r=r_{0}$ (see Eq. 4) 
and is attenuated at $r=r_{1}$ at a maximum stress level $S_{\max }=S_{\max , 1}$, which is equal to the fatigue limit after which no further fatigue damage occurs, the stress cycle is known. The value $A$ in Eq. 6 is determined by Slot et al. $[15,16]$ for $d_{d}=1.8$ $\mathrm{mm}$ and $n=0.5$, and reads:

$$
A=0.60 p_{w h} \quad\left(d_{d}=1.8 \mathrm{~mm}\right)
$$

\subsection{Fatigue life model for metallic surfaces that includes strain hardening and shot peening}

Applying a general expression for fatigue life for a stress level $i$ to the case of drop impact results in Eq. 8a, introducing $h_{t o t}$ that corrects for the differences between the fatigue test conditions and the actual conditions. The constants $m$ and $S_{f}$ are commonly used material parameters in fatigue tests:

$$
S_{\max , i}=h_{t o t} S_{f} N_{i}^{-1 / m}
$$

The fatigue limit $S_{D, i}$ for the actual erosion conditions is given by:

$$
S_{D, i}=h_{t o t} S_{D}
$$

In this approach, the number of fatigue cycles to failure in a fatigue test $\left(N_{f}\right)$ equals the number of fatigue cycles of the incubation period $\left(N_{i}\right)$.

For metals showing strain hardening, the effects of additional surface hardening and the related residual compressive stress state at the surface due to the "water drop peening effect" should be included as it will affect the fatigue life. The wellknown Morrow's equation with mean stress correction [25] can be used for this purpose. In the present case the modified version as derived by Landgraf et al. [26] is used:

$$
\frac{S_{a}}{\left(\frac{H}{H_{0}} S_{f, 0}-S_{m}-\sigma_{R}\right)}=\left(2 N_{f}\right)^{-(1 / m)}
$$

With:

$S_{a}=$ stress amplitude,

$S_{m}=$ mean stress,

$H / H_{0}=$ ratio of increased surface hardness to initial surface hardness,

$\sigma_{R}=$ residual stress at the metal surface 
$N_{f}=$ fatigue life (number of cycles to failure)

$S_{f, 0}=$ fatigue strength coefficient of metal with initial hardness $H_{0}$, mean stress

$S_{m}=0$ (or $R=-1$ ), and residual stress $\sigma_{R}=0$,

$R=$ stress ratio, ratio of minimum stress and maximum stress.

The fatigue strength coefficient $\left(S_{f}\right)$ in Eq. $8 \mathrm{a}$ is to be determined for a stress ratio of $R=-0.5$, given by the Rayleigh wave amplitudes [15]. Using Eq. 9 and assuming that the fatigue curves are available for a stress ratio $R=-1$ (the definition used for $S_{f, 0}$ ), the following expression for fatigue strength coefficient $S_{f}$ in Eq. 8a (with $R=$ $-0.5)$ was derived:

$$
S_{f}=\left(1+\frac{1+R}{1-R}\right)\left(\frac{H}{H_{0}} \cdot \frac{S_{f, 0}}{2^{-\left(\frac{1}{m}\right)}}-\sigma_{R}\right) 2^{-\left(\frac{1}{m}\right)}
$$

Eq. 10 now includes the (possible beneficial) effect of surface hardening and residual stress. It is assumed in this work that this beneficial effect occurs relative to the 'water -hammer pressure' $\left(p_{w h}\right)$, see Eq. 1a, and the maximum loaded surface area with a contact radius $\left(r_{w h}\right)$, see Eq. 5 . By using a threshold waterhammer pressure $\left(p_{w h, t h}\right)$, above which surface hardness and residual compressive stresses increase, it was possible to construct the following model.

- if $p_{w h}>p_{w h, t h}$ :

$\frac{H}{H_{0}}=1+a\left(p_{w h}-p_{w h, t h}\right)$

$\sigma_{R}=b\left(p_{w h}-p_{w h, t h}\right)$

- if $p_{w h} \leq p_{w h, t h}$ :

$\frac{H}{H_{0}}=1.0$

$\sigma_{R}=0$

$p_{w h, t h}=$ threshold water-hammer pressure, $a, b=$ material dependent constants, see Table 1 . 
Surface hardness increase, and surface residual stresses as a function of treatment duration for water jet peening, cavitation peening, shot peening and laser peening of stainless steel have been measured by Soyama [27]. The effect of the treatments on (increased) fatigue life in decreasing order was: shot peening (highest effect), cavitation peening, laser peening, and water jet peening (lowest effect). These numerical values for surface hardness, and surface residual stress of Soyama [27] have been used to derive the material dependent constants for stainless steel AISI 316.

An experimental study of waterjet peening process parameters on aluminium alloy 6061-T6 was conducted by Muruganandhan et al. [28]. The resulting surface hardness has been measured as a function of duration and drop impact velocity. An experimental study of high-pressure waterjet peened aluminium alloy 7075-T6 and its effect on fatigue life was conducted by Ramulu et al. [29].

Supported by publications for shot peening and cavitation peening [30-33], the constants $\left(a, b, p_{w h, t h}\right)$ in Eq. 11a to $11 \mathrm{~d}$, for the increase in surface hardness and residual compressive stress as a function of the 'water -hammer pressure' $\left(p_{w h}\right)$ were defined. These estimated trends are shown in Figure 2. The numerical values are given in Table 1.

Table 1. Constants for the surface hardness ratios and residual stresses in Eq. 11a to 11d.

\begin{tabular}{|c|cc|}
\hline Constant & $\begin{array}{c}\text { Stainless steel } \\
\text { AISI 316 }\end{array}$ & $\begin{array}{c}\text { Aluminium } \\
6061-\mathrm{T} 6\end{array}$ \\
\hline$a(1 / \mathrm{MPa})$ & 0.0005 & 0.0003 \\
$b(1 / \mathrm{MPa})$ & -0.25 & -0.15 \\
$p_{w h, t h}(\mathrm{MPa})$ & 200 & 150 \\
\hline
\end{tabular}




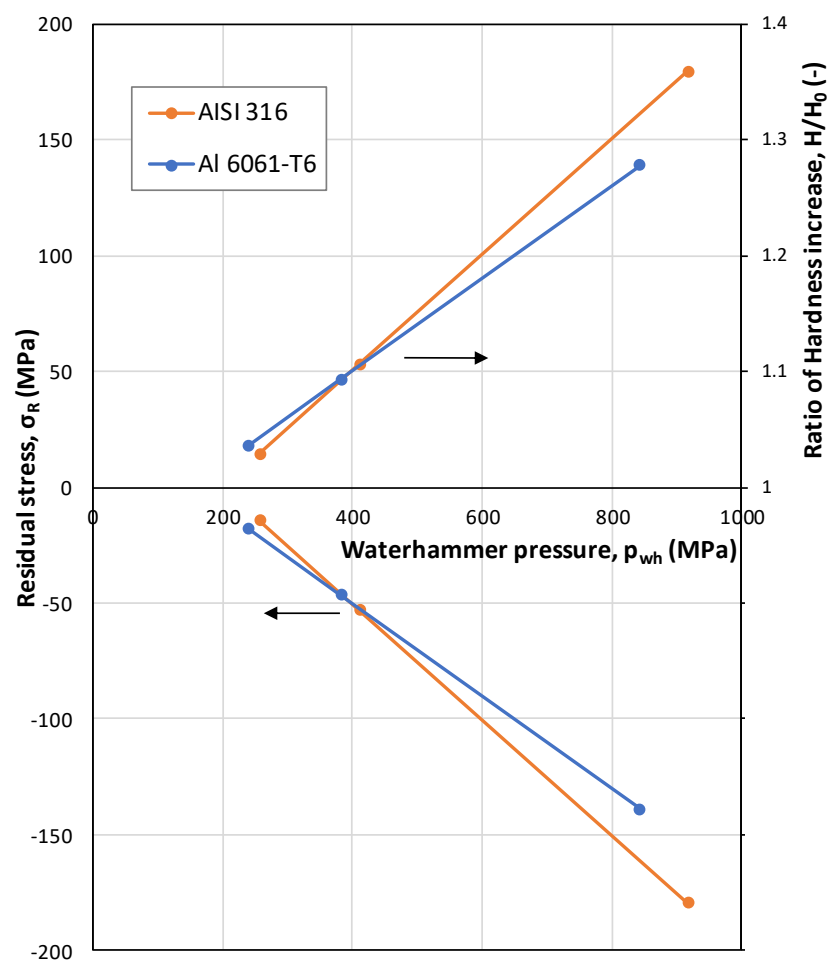

Figure 2. Ratio of increased surface hardness to initial surface hardness and residual compressive stress due to waterdrop peening for stainless steel AISI 316 and aluminium 6061-T6 (estimated trends).

The threshold water-hammer pressures $\left(p_{w h, t h}\right)$ in Table 1, using Eq. $1 \mathrm{a}$ and $1 \mathrm{~b}$, give for stainless steel AISI 316 and Al-6061-T6, respectively threshold impact velocities of $v_{d}=112 \mathrm{~m} / \mathrm{s}$ and $92 \mathrm{~m} / \mathrm{s}$.

For shot peening with hard solid particles, the permanent indentations in the surface can be sharp and angular and result in a substantial increase in surface roughness. For water drop peening the permanent indentations (dents) are smoother and result only in a small roughness increase. Soyama [27] shows for shot peened stainless steel an increase in maximum height of roughness, $R_{z}$, from 1.3 to $7.5 \mu \mathrm{m}$ and for water jet peened stainless steel an increase in roughness $R_{z}$ from 1.3 to $3.0 \mu \mathrm{m}$. In this work the change in roughness due to water drop peening, and its relatively small effect on fatigue life, was neglected. 


\subsection{Droplet erosion incubation period}

In this work, a random uniform distribution of droplet impact at the specimen surface is assumed. As such, for a point located at the origin, only drop impacts within the area with a certain radius will result in a stress cycle that generates damage related to surface fatigue.

The total number of rain drop impacts on the area per hour, is related to the spatial distribution of drops, characterised by the volume concentration of water $\left(C_{v}\right)$ and the specimen velocity in this spatial distribution of drops $\left(v_{d}\right)$. The drop impact density or rate of impact is now given by: $C_{v} v_{d}\left(\mathrm{~m} / \mathrm{s}\right.$ or $\mathrm{m}^{3}$ water drops $/ \mathrm{s} . \mathrm{m}^{2}$ specimen area). Thus, the total amount of drops during the incubation period $\left(I_{p}\right)$, as given by the surface coverage, is $3600 C_{v} v_{d} I_{p} \mathrm{~m}^{3}$ water $\mathrm{drops} / \mathrm{m}^{2}$ specimen area.

Similar to the work described in detail elsewhere [16] one can use the PalmgrenMiner rule to account for the cumulative fatigue damage at different stress levels. The basic form of this equation for variable amplitude stress loading is:

$$
D=\sum_{i=1}^{k} \frac{n_{i}}{N_{i}}
$$

In which $n_{i}=$ number of cycles due to multiple drop impact at stress level $i$.

The droplet erosion incubation period is now defined as:

$$
I_{p}=\frac{D_{f}}{D_{h}}
$$

$I_{p}=$ Droplet erosion incubation period (h)

$D_{f}=$ Cumulative fatigue damage at failure

$D_{h}=$ Cumulative fatigue damage per hour $(1 / \mathrm{h})$

According to the general Palmgren-Miner approach $[15,16]: D_{f}=1$. Using this approach, a fatigue-based model for the droplet impingement erosion incubation period of metallic surfaces can be formulated. An expression for the incubation period can be derived [16]: 


$$
\begin{aligned}
& I_{p}=\frac{d_{d}^{3}}{24 \Phi_{v}} \frac{(m-4)\left(h_{t o t} S_{f}\right)^{m}}{A^{4}} \frac{1}{\left[S_{\max (r 0)}{ }^{(m-4)}-\left(h_{t o t} S_{D}\right)^{(m-4)}\right]} \\
& \Phi_{v}=3.6 \times 10^{6} C_{v} v_{d}
\end{aligned}
$$

In which:

$\Phi_{v}=$ volume of impacting water drops per unit area $(\mathrm{mm} / \mathrm{h})$

With $S_{\max (r 0)}$ according to Eq. 6 and using $r_{0}$ according to Eq. 4.

Furthermore $S_{\max (r 0)}>h_{t o t} S_{D}$ and for the complementary condition $S_{\max (r 0)} \leq$ $h_{t o t} S_{D}$ this results in: $I_{p} \rightarrow \infty$. Thus the condition $S_{\max (r 0)}=h_{t o t} S_{D}$ gives the threshold drop impact velocity $\left(v_{d, t h}\right)$. For drop impact conditions $\left(v_{d}, d_{d}\right)$ resulting in $S_{\max (r 0)} \leq h_{\text {tot }} S_{D}$, the fatigue damage will not accumulate to fatigue failure and thus the life of the metal surface will be infinite.

\section{Results for stainless steel AISI 316 and aluminium 6061-T6}

The droplet impingement incubation period was predicted for stainless steel AISI 316 and aluminium 6061-T6 using the presented analytical model and the fatigue life curves from literature in Table B-1, and including the additional surface hardening and residual compressive stress at the surface due to the "water drop peening effect" with the data summarised in Table 1 . For $h_{t o t}$, a value of 1 was taken, this assuming that there are no corrections necessary for the differences between the fatigue test conditions and the actual droplet impingement erosion test conditions. The predicted incubation period curves for the literature sources in Table B-1 are shown in the Figures 3 and 4 . The mean predicted values are depicted by blue lines in these figures. These predicted results are shown in comparison to the incubation periods and confidence limits according to the multi-regression equation of Heymann [11] Eq. A-1 as given in Appendix A (red lines).

The Figures show that these predicted incubation periods are nearly all within the 2.5 and $97.5 \%$ confidence limits of the multi-regression equation for the given metal. These limits of the multi-regression equation are partly a result of experimental uncertainty and partly due to differences between used test set-ups [11]. 


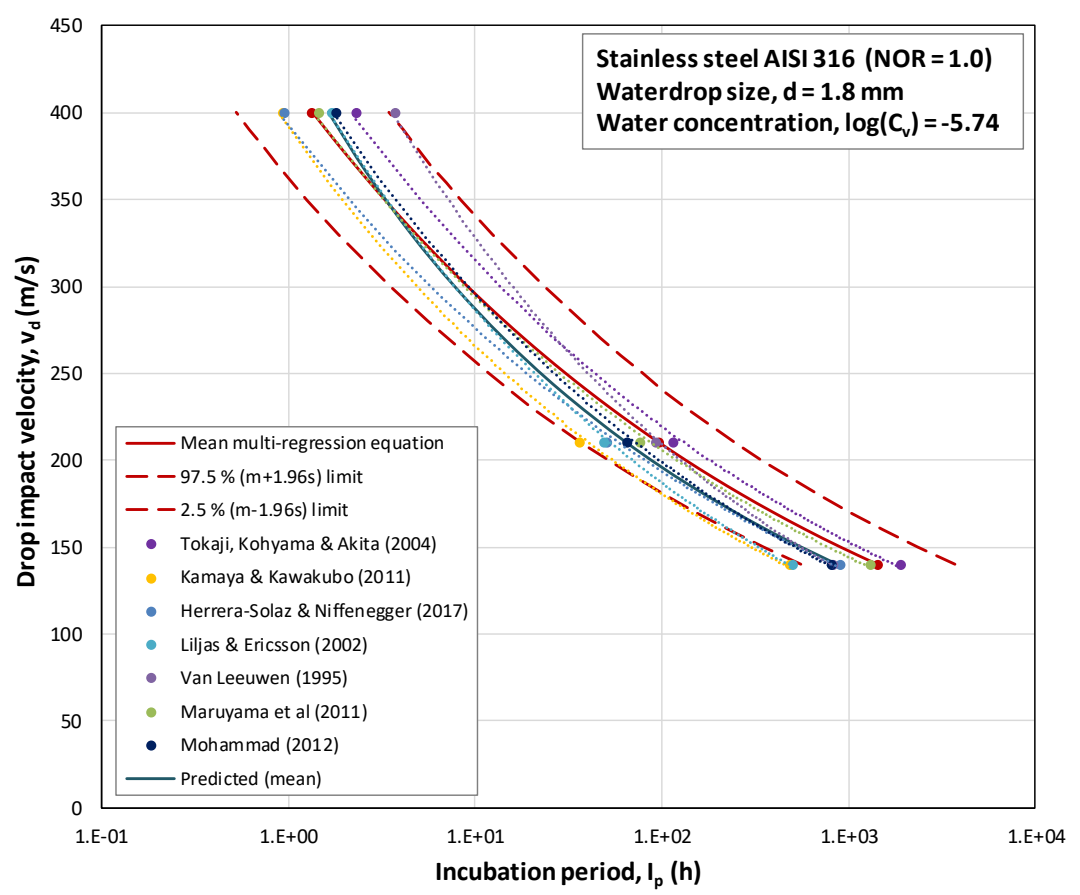

Figure 3. The predicted incubation periods for AISI 316 using data given in Table B-1, and summarized by a mean line (blue line), compared to the incubation periods and confidence limits for AISI $316(N O R=1.0)$ using the multi regression Eq. A-1 (red line).

\section{Discussion}

The model predictions for stainless steel AISI 316 and aluminium 6061-T6 showed an excellent agreement with the multi-regression equation of Heymann [11] that is determined from an ASTM interlaboratory test program. Nearly all incubation period predictions were within the $95 \%$ confidence limits of the mentioned multiregression equation. 


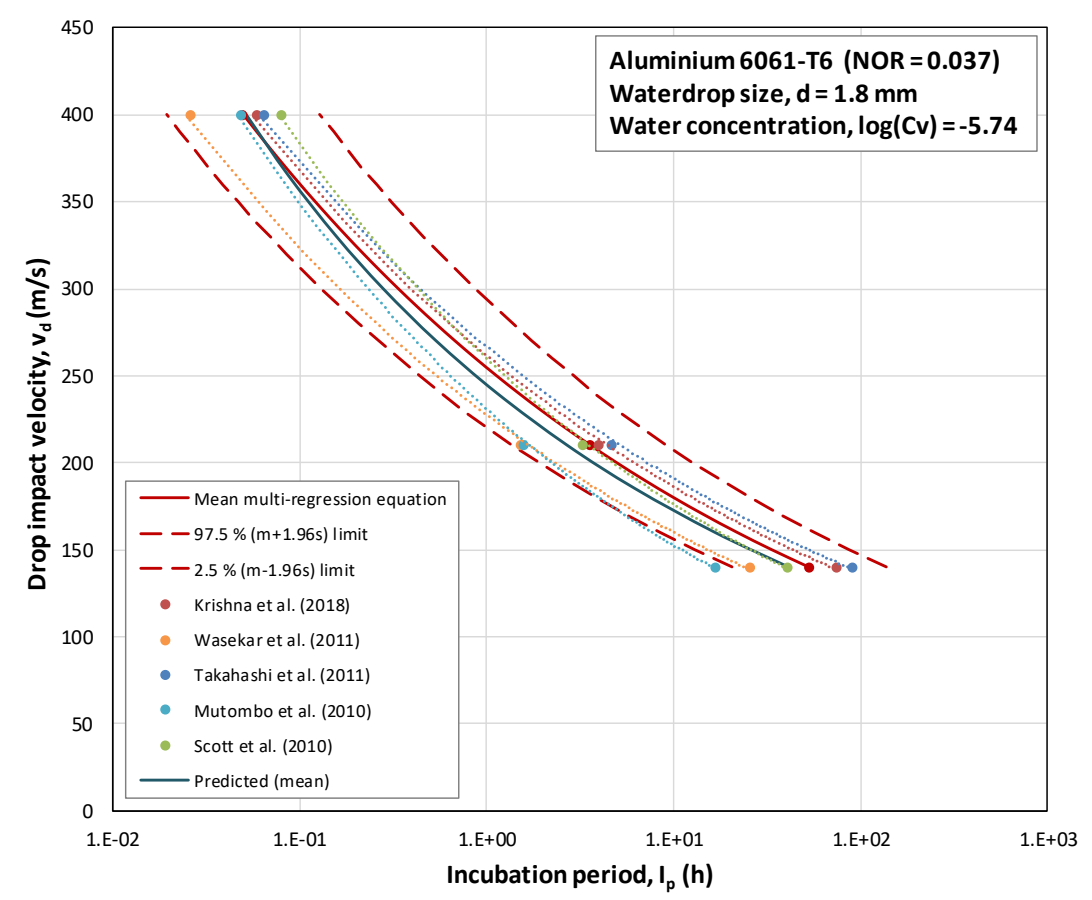

Figure 4. The predicted incubation periods for Al-6061-T6 using data given in Table B-1, and summarized by a mean line (blue line), compared to the incubation periods and confidence limits for Al-6061-T6 (NOR = 0.037) using the multi-regression Eq. A-1 (red line).

An essential aspect of the current model is the fatigue-based approach in which now the surface hardening and residual compressive stress effects caused by the impact of the droplets are taken into account as well. The value for the threshold water-hammer pressure $\left(p_{w h, t h}\right)$, which is used in the Eq. $11 \mathrm{a}$ and $11 \mathrm{~b}$, is based on the extensive research by Thiruvengadam et al. [47-49]. They performed water jet impact erosion tests with metals in a high-speed rotating disk facility. Observation of the specimens to determine when denting or erosion occurred was implemented in the test sequence. Depending on the impact velocity, the specimens were microscopically inspected at intervals ranging from every few minutes to every hour. The number of impacts taken for the initiation of permanent plastic indentations on the surface was recorded at different test velocities. Results for stainless steel AISI 316 (cold drawn), and aluminium 1100-O, as a function of the impact velocity are shown in Figures $5 a$ and $b$. The number of impacts necessary for observing a small permanent plastic dent is a clear function of the impact velocity. 
This number of impacts varies for stainless steel AISI 316 (cold drawn), in the velocity range $70-100 \mathrm{~m} / \mathrm{s}$, between 2 to $5 \%$ of the incubation period. For aluminium $1100-0$, this number of impacts varies, in the velocity range $40-60 \mathrm{~m} / \mathrm{s}$, also between 2 to $5 \%$ of the incubation period.
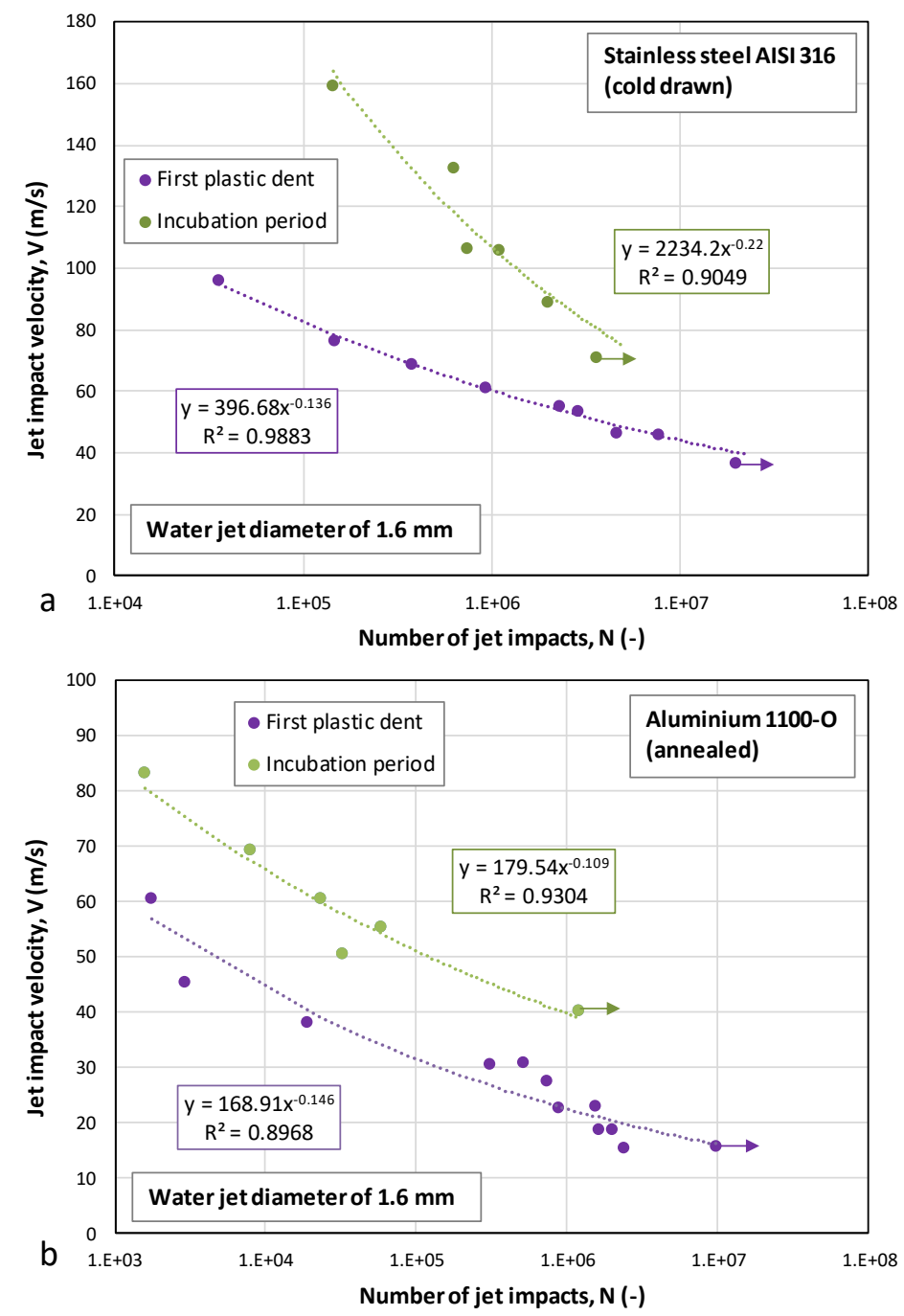

Figures 5. Results of water jet impact erosion tests for a) Stainless steel AISI 316 (cold drawn), and b) Aluminium 1100-O using a high speed rotating disk facility [47-49]. The number of impacts when the first small indent by plastic deformation was observed (purple dots), and the Incubation period (green dots) are shown as a function of impact velocity. 
Thus, it is concluded that permanent plastic indentations in the surface of these metals are present during $95-98 \%$ of the incubation period $\left(I_{p}\right)$. In this period, a form of liquid impact peening of the metal surface gives rise to an additional surface hardening and a residual compressive stress state at the surface.

It is assumed in this work that this beneficial effect occurs relative to the 'water hammer pressure' $\left(p_{w h}\right)$, see Eq. $1 \mathrm{a}$, and the maximum loaded surface area with a contact radius $\left(r_{w h}\right)$, see Eq. 5 , are the parameters which govern the beneficial effects of residual compressive stress and increase in surface hardness, at a certain impact velocity.

The incorporated effect of surface hardening and residual compressive stress for AISI 316 and aluminium 6061-T6 on fatigue strength can be substantiated based on evidence from literature. Soyama [27] compares the improvements made to the fatigue strength of stainless steel AISI $316 \mathrm{~L}$ by cavitation peening, water jet peening, shot peening and laser peening. For each peening method, the optimum coverage was examined by measuring the fatigue life at constant bending stress. The fatigue strength of the non-peened specimen was $280 \mathrm{MPa}$. For the treated samples, the increase was: $25 \%$ for cavitation peening, $16 \%$ for shot peening, $9 \%$ for laser peening and $6 \%$ for water jet peening. Cho [50] performed FEM simulations of the repeated waterdrop impact, drop size of $0.2 \mathrm{~mm}$, on 6061-T6 aluminium. In this computational study, residual effects of repeated waterdrop impact onto an aluminium surface were investigated. The results show that above a critical impact velocity $(74 \mathrm{~m} / \mathrm{s})$, a residual compressive stress zone is built up under the impact surface as a result of local plastic deformation. The depth of the plastic deformation increases with the impact velocity and number of impacts. At an impact speed of $500 \mathrm{~m} / \mathrm{s}$, after 4 impacts, the maximum residual compressive stress is $-345 \mathrm{Mpa}\left(-1.06 \mathrm{R}_{\mathrm{p} 0.2}\right)$ and is obtained at $0.07 \mathrm{~mm}$ under the surface, and the depth of the compressive stress zone is $0.2 \mathrm{~mm}$. Rajesh [51,52] performed multi-droplet impact FE-modelling to predict the residual stresses due to water jet peening for three grades of aluminium. For this modelling approach, a transient elastoplastic finite element analysis is used by considering the impingement of a set of droplets in succession to one another over a certain time period. The pressure is released following this sequence. For aluminium 6063-T6 $\left(R_{\mathrm{p} 0.2}=110 \mathrm{Mpa}\right)$, for drop impact speeds between 532 and $604 \mathrm{~m} / \mathrm{s}$, and applying 1 to 4 "layers" of water drops this was found to result in compressive stresses between $-0.36 R_{p 0.2}$ and $0.61 R_{p 0.2}$ at the impacted surface. These results [27-29,50-52] clearly confirm that for appropriate water drop impact conditions, residual compressive stresses and an increase in surface hardness due to strain hardening occur. 
In the current work, an analytical model for the prediction of the droplet impingement erosion incubation period of metal surfaces is presented. The model is based on the S-N curve of the metal, on the effects of additional surface hardening and residual compressive stress at the surface due to a "water drop peening effect", such as demonstrated for the case of AI 6061-T6 and AISI 316. Application of the model to other metals requires the steps as shown in the flow diagram in Figure 6.

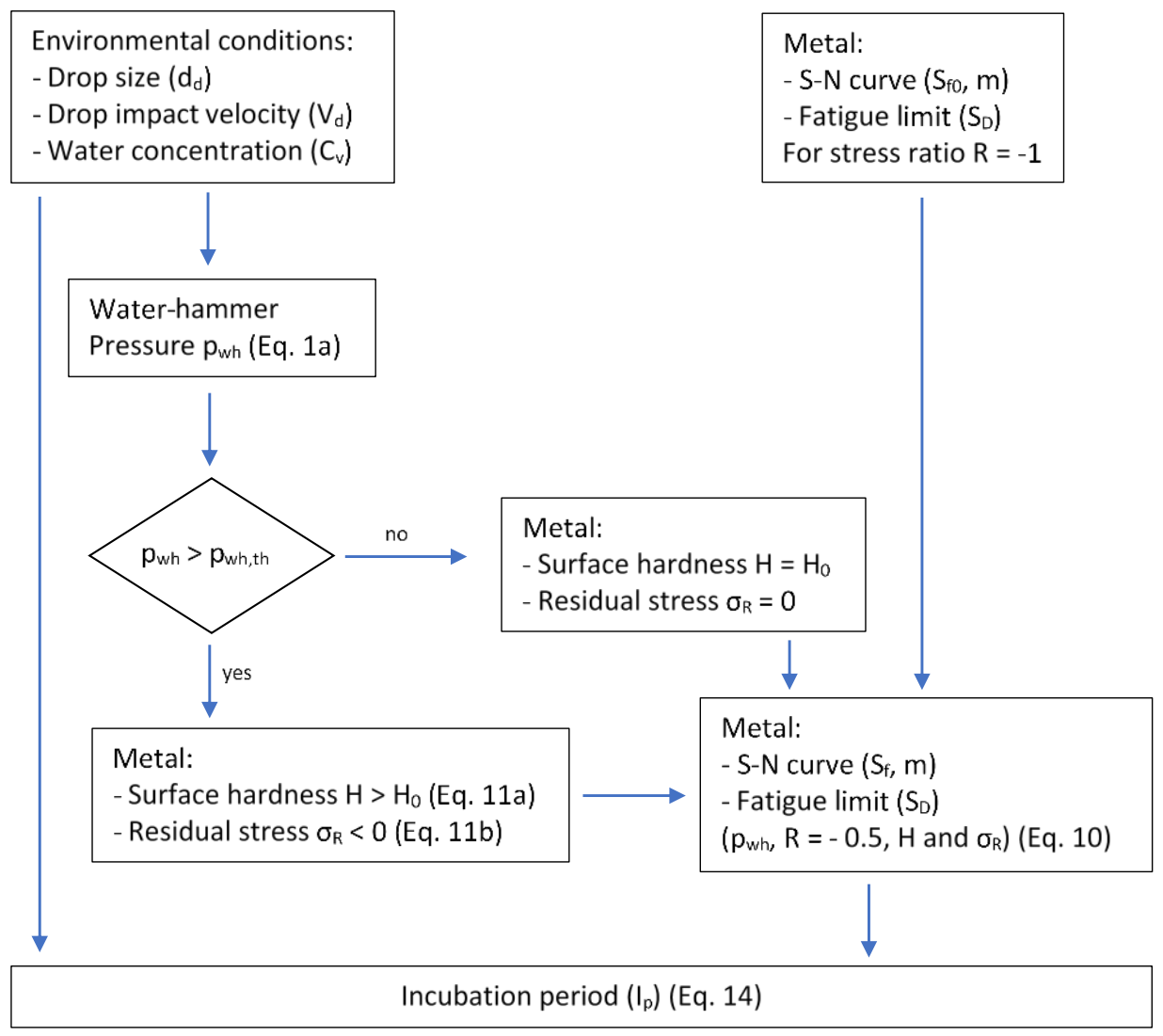

Figure 6. Flow diagram to estimate the impingement erosion incubation period for metals based on the fatigue properties measured at certain fatigue test conditions.

The presented analytical model gives the interrelation of the physical and mechanical properties of the metallic surfaces that determines the droplet impingement erosion incubation period. As such, it becomes possible to define 
guidelines for a longer droplet impingement erosion incubation life based on optimised physical and mechanical properties. Selected properties of the metals used in the presented analytical model are summarised in Table 2 . The required direction of the property ( $\uparrow:$ increase, and $\downarrow$ : decrease) for an optimal long droplet impingement erosion incubation life is indicated. From Table 2 it follows that a higher fatigue strength affects the incubation period positively. Using the corresponding equations shows that for instance an increase in the fatigue strength coefficient $\left(S_{f, 0}\right)$ of AISI 316 with $10 \%$, and using $m=7.8$, the average value for AISI 316 in Table B-1, results, with Eqs. 10 and 14, in an increase in the incubation period $\left(I_{p}\right)$ with a factor of 2.1 .

Table 2. Metal properties used in the presented analytical model, and required direction ( $\uparrow$ : increase, and $\downarrow$ : decrease) for enhanced droplet impingement erosion incubation life.

\begin{tabular}{|l|l|l|}
\hline Metal property & Defined in & $\begin{array}{l}\text { For long droplet impingement } \\
\text { erosion incubation life }\end{array}$ \\
\hline Physical properties: ${ }^{1)}$ & & \\
Young's modulus $(E)$ & Eq. 1a, Eq. 4 & $\downarrow$ \\
Density $\left(\rho_{m}\right)$ & Eq. 1a, Eq. 4 & $\downarrow$ \\
Poisson constant $(v)$ & Eq. 1a, Eq. 4 & $\downarrow$ \\
Fatigue properties: ${ }^{2)}$ & Eq. 8a, Eq. 10 & $\uparrow$ \\
Fatigue strength coefficient $\left(S_{f, 0}\right)$ & Eq. 8a & $\uparrow$ \\
Reciprocal of fatigue exponent $(m)$ & & \\
Strain hardening \& Residual stress: & Eq. 11a & $\uparrow$ \\
Strain hardening $(a)$ & Eq. 11b & $\downarrow$ \\
Residual compressive stress $(b)$ & Eq. 11a to d & $\downarrow$ \\
Threshold water-hammer pressures $\left(p_{w h, t h}\right)$ & \\
\hline
\end{tabular}

1) The longitudinal wave velocity $\left(c_{l, m}\right)$, and Rayleigh wave velocity $\left(\mathrm{C}_{\mathrm{R}}\right)$ are functions of $E, \rho_{m}$, and $v$. 2) The fatigue limit $\left(S_{D}\right)$ is in this paper defined at 2 million cycles, and thus a function of $S_{f, 0}$, and $m$.

\section{Conclusions}

The following conclusions are drawn:

1. A fatigue based analytical model for the prediction of the droplet impingement erosion incubation period of metal surfaces loaded by impacting water drops published by authors (Slot et al. ${ }^{16}$ ), was tested against a wide range of liquid droplet erosion incubation period tests. The model was extended for the use of $\mathrm{S}-\mathrm{N}$ curves for non-ferrous and ferrous metals - namely aluminium and stainless 
steel respectively, by including the effects of additional surface hardening and residual compressive stress at the surface due to a water drop peening effect.

2. The model predictions for stainless steel AISI 316 and aluminium 6061-T6, using $\mathrm{S}-\mathrm{N}$ fatigue curves from different literature sources, and including the defined additional surface hardening and a residual compressive stress state at the surface due to "water drop peening effect", showed for the droplet impact velocity range of 140 to $400 \mathrm{~m} / \mathrm{s}$ an excellent agreement with the multiregression equation as determined from an ASTM interlaboratory test program. Nearly all incubation period predictions were within the $95 \%$ confidence limits of the mentioned multi-regression equation.

3. The physical and metallurgical mechanisms resulting in the degradation process of the metal surface during the incubation period $\left(I_{p}\right)$ were identified, these consisted of: 1) surface plastic deformation and, formation of dents, 2) surface hardening and residual compressive stress as a result of these surface plastic deformations, 3) fatigue crack initiation, 4) short fatigue crack growth.

4. Selected properties of metals used in the presented analytical model were identified with respect to the direction it should be adjusted to provide guidelines for enhanced droplet impingement erosion incubation life.

\section{References}

[1] Ahmad M., Schatz M., Casey M.V., An empirical approach to predict droplet impact erosion in low-pressure stages of steam turbines, Wear 402-403, 2018, 57-63.

[2] Kirols H.S., Kevorkov D., Uihlein A., Medraj M., Water droplet erosion of stainless steel steam turbine blades, Materials Research Express 4, 2017, 1-12.

[3] Ilieva G.I., Erosion failure mechanisms in turbine stage with twisted rotor blade, Engineering Failure Analysis 70, 2016, 90-104.

[4] DNVGL, LNG - $\mathrm{N}_{2}$ Stripper inlet pipe - Velocity limitation. Report No.: 20160290, 2016.

[5] Bartolomé L., Teuwen J., Prospective challenges in the experimentation of the rain erosion on the leading edge of wind turbine blades, Wind Energy 22, 2019, 140-151.

[6] Gohardani O., Impact of erosion testing aspects on current and future flight conditions, Progress in Aerospace Sciences 47, 2011, 280-303. 
[7] Herring R., Dyer K., Martin F., Ward C., The increasing importance of leading edge erosion and a review of existing protection solutions, Renewable and Sustainable Energy Reviews 115 (109382), 2019, 1-13.

[8] Thiruvengadam A., Heymann F.J. (Eds.), Characterization and Determination of Erosion Resistance, ASTM STP 474, ASTM International, 1970.

[9] Thiruvengadam A. (Ed.), Erosion, Wear, and Interfaces with Corrosion, ASTM STP 567, ASTM International, 1974.

[10] Heymann F.J., Toward Quantitative Prediction of Liquid Impact Erosion, In: Thiruvengadam A., Heymann F.J. (Eds), Characterization and Determination of Erosion Resistance, ASTM STP 474, ASTM International, 1970, 212-248.

[11] Heymann F.J., Conclusions from the ASTM Interlaboratory Test Program with Liquid Impact Erosion Facilities, In: Field J.E. (Ed.), Proceedings of the Fifth International Conference on Erosion by Liquid and Solid Impact (ELSI-V), Cavendish Laboratory, Cambridge, 1979, paper 20, 1-10.

[12] Schmitt G.F., Liquid and Solid Particle Impact Erosion, In: Peterson M.B., Winer W.O. (Eds), Wear Control Handbook, American Society of Mechanical Engineers, 1980.

[13] Heymann F.J., Liquid Impingement Erosion, In: ASM Handbook, Friction, Wear and Lubrication, vol. 18, ASM International, 1998.

[14] ASTM-G73, Standard Practice for Liquid Impingement Erosion Testing, American Society for Testing and Materials, 2010.

[15] Slot H.M., Gelinck E.R.M., Rentrop C., Heide E. van der, Leading edge erosion of coated wind turbine blades: Review of coating life models, Renewable Energy 80, 2015, 837-848.

[16] Slot H.M., IJzerman R.M., Feber M. le, Heide E. van der, Rain erosion resistance of injection moulded and compression moulded polybutylene terephthalate PBT, Wear 414-415, 2018, 234-242.

[17] Amirzadeh B., Louhghalam A., Raessi M., Tootkaboni M., A computational framework for the analysis of rain-induced erosion in wind turbine blades, Part I: Stochastic rain texture model and drop impact simulations, Journal of Wind Engineering \& Industrial Aerodynamics 163, 2017, 33-43.

[18] Amirzadeh B., Louhghalam A., Raessi M., Tootkaboni M., A computational framework for the analysis of rain-induced erosion in wind turbine blades, Part II: Drop impact-induced stresses and blade coating fatigue life, Journal of Wind Engineering \& Industrial Aerodynamics 163, 2017, 44-54.

[19] Castorrini A., Corsini A., Rispoli F., Venturini P., Takizawa K., Tezduyar T.E., Computational analysis of wind-turbine blade rain erosion, Computers and Fluids 141, 2016, 175-183. 
[20] Solomon N., Solomon I., Deformation induced martensite in AISI 316 stainless steel, Revista de Metalurgia 46, 2010, 121-128.

[21] Deloro Stellite Inc., Wrought Wear-Resistant Alloys Stellite ${ }^{\circledR} 6 B$ \& Stellite ${ }^{\circledR} 6 \mathrm{~K}$ Plate, Sheet and Bar, Brochure, www.stellite.com, 2008.

[22] Polmear I., StJohn D., Nie J.-F., Qian M., Light Alloys: Metallurgy of the Light Metals, Butterworth-Heinemann, Oxford, 2017.

[23] Heymann F.J., On the Shock Wave Velocity and Impact Pressure in High-Speed Liquid-Solid Impact, J. Basic Eng. 90, 1968, 400-402.

[24] Adler W.F., Liquid drop collisions on deformable media, Journal of Materials Science 12, 1977, 1253-1271.

[25] Morrow J., Fatigue Design Handbook - Advances in Engineering, SAE-AE-4, Society of Automotive Engineers, Warrendale (PA), 1968, 21-29.

[26] Landgraf R.W., Chernenkoff R.A., Residual Stress Effects on Fatigue of Surface Processed Steels, In: Champoux R.L., Kapp J.A., Underwood J.H. (Eds), Analytical and Experimental Methods for Residual Stress Effects in Fatigue, ASTM STP 1004, ASTM International, 1988, 1-12.

[27] Soyama H., Comparison between the improvements made to the fatigue strength of stainless steel by cavitation peening, water jet peening, shot peening and laser peening, Journal of Materials Processing Technology 269, 2019, 65-78.

[28] Muruganandhan R., Mugilvalavan M., Thirumavalavan K., Yuvaraj N., Investigation of water jet peening process parameters on Al6061-T6, Surface Engineering 34, 2018, 330-340.

[29] Ramulu M., Kunaporn S., Jenkins M., Hashish M., Hopkins J., Fatigue Performance of High-Pressure Waterjet-Peened Aluminum Alloy, Journal of Pressure Vessel (ASME) 124, 2002, 118-123.

[30] Masaki K., Ochi Y., Matsumura T., Initiation and propagation behaviour of fatigue cracks in hard-shot peened Type $316 \mathrm{~L}$ steel in high cycle fatigue, Fatigue \& Fracture of Engineering Mater Struct. 27, 2004, 1137-1145.

[31] Gariépy A., Miao H.Y., Lévesque M., Simulation of the shot peening process with variable shot diameters and impacting velocities, Advances in Engineering Software 114, 2017, 121-133.

[32] Hirai N., Tosha K., Rouhaud E., Finite element analysis of shot peening - on the form of a single dent. In: Proc 9th conf shot peening (ICSP9) 2005: 82-87.

[33] Mylonas G.I., Labeas G., Numerical modelling of shot peening process and corresponding products: residual stress, surface roughness and cold work prediction, Surface and Coatings Technology 205, 2011, 4480-4494. 
[34] Tokaji K., Kohyama K., Akita M., Fatigue behaviour and fracture mechanism of a 316 stainless steel hardened by carburizing. International Journal of Fatigue 26, 2004, 543-551.

[35] Kamaya M., Kawakubo M., Fatigue life prediction of stainless steel under variable loading. Journal of the Society of Materials Science (Japan) 60, 2011, 871-878.

[36] Herrera-Solaz V., Niffenegger M., Application of hysteresis energy criterion in a microstructure-based model for fatigue crack initiation and evolution in austenitic stainless steel, International Journal of Fatigue 100, 2017, 84-93.

[37] Maruyama N., Mori D., Hiromoto S., Kanazawa K., Nakamura M., Fatigue strength of 316L-type stainless steel in simulated body fluids, Corrosion Science 53, 2011, 2222-2227.

[38] Leeuwen J.F.C. van, Het vermoeiingsgedrag van Roestvast staal, MSc thesis, TU Delft, 1995.

[39] Liljas M., Ericsson C., Fatigue behaviour of stainless steel welds, ACOM 1/2, Avesta-Polarit, Sweden, 2002.

[40] Mohammad K.A., Ali A., Sahari B.B., Abdullah S., Fatigue behavior of Austenitic Type 316L Stainless Steel, IOP Conf. Series: Materials Science and Engineering 36 (012012), 2012, 1-9.

[41] Rama Krishna L., Madhavi Y., Sahithi T., Wasekar N.P., Chavan N.M., Srinivasa Rao D., Influence of prior shot peening variables on the fatigue life of micro arc oxidation coated 6061-T6 Al alloy, International Journal of Fatigue 106, 2018, 165-174.

[42] Wasekar N.P., Jyothirmayi A., Sundararajan G., Influence of prior corrosion on the high cycle fatigue behavior of microarc oxidation coated 6061-T6 Aluminum alloy, International Journal of Fatigue 33, 2011, 1268-1276.

[43] Takahashi Y., Shikama T., Yoshihara S., Aiura T., Noguchi H., Study on dominant mechanism of high-cycle fatigue life in 6061-T6 aluminum alloy through microanalyses of microstructurally small cracks, Acta Materialia 60, 2012, 2554-2567.

[44] Scott-Emuakpor O., George T., Cross C., Herman Shen M.-H., Hysteresis-loop representation for strain energy calculation and fatigue assessment, Journal of Strain Analysis for Engineering Design 45, 2010, 275-282.

[45] Mutombo K., Toit M. du, Corrosion fatigue behaviour of aluminium alloy 6061T651 welded using fully automatic gas metal arc welding and ER5183 filler alloy, International Journal of Fatigue 33, 2011, 1539-1547.

[46] ASM Handbook, Properties and Selection: Irons, Steels, and High-Performance Alloys, Vol. 1, ASM International, 1998. 
[47] Thiruvengadam A., Rudy S.L., Experimental and Analytical Investigations on Multiple Liquid Impact Erosion, Report of Hydronautics Inc.: NASA-CR-1288, 1969.

[48] Thiruvengadam A., Rudy S.L., Gunasekaran M., Experimental and Analytical Investigations on Multiple Liquid Impact Erosion, Report of Hydronautics Inc.: NASA-CR-1638, 1970.

[49] Thiruvengadam A., Rudy S.L., Gunasekaran M., Experimental and Analytical Investigations on Liquid Impact Erosion, In: Characterization and Determination of Erosion Resistance, ASTM STP 474, ASTM International, 1970, 249-280.

[50] Cho J.R., Simulation of the repeated waterdrop impact onto the Al6061-T6, Journal of Mechanical Science and Technology 29, 2015, 3679-3683.

[51] Rajesh N., Veeraraghavan S., Ramesh Babu N., A novel approach for modelling of water jet peening. International Journal of Machine Tools \& Manufacture 44, 2004, 855-863.

[52] Rajesh N., Ramesh Babu N., Multi-droplet Impact Model for Prediction of Residual Stresses in Water Jet Peening of Materials, Materials and Manufacturing Processes 21, 2006, 399-409.

\section{Appendix A - Additional details on the reference interlaboratory test program for liquid impact erosion}

\section{A.1 ASTM - Multiple linear regression fit equations}

Based on an extensive international test program with rotating disc or whirling arm test facilities using water drops, Heymann $[10,11]$ derived a multiple linear regression fit equation for the incubation life. He presented the following equation for the incubation period as a function of impingement conditions of waterdrops and metal surface grade:

$$
\begin{aligned}
& \log N_{0}=-5.64 \log v_{d}-3.12 \log d_{d}+\log N O R+18.94 \\
& (s=0.21, n=31)
\end{aligned}
$$

With

$N_{0}=$ "number of specific impacts" for incubation (-),

$v_{d}=$ impact velocity normal to the target surface $(\mathrm{m} / \mathrm{s})$,

$d_{d}=$ waterdrop diameter $(\mathrm{mm})$. 
$N O R=$ "incubation resistance number" as defined by Heymann $[10,11]$. This is a normalized resistance value for a certain metal surface grade with respect to stainless steel AISI $316(N O R=1)$ with a hardness of 170 Vickers.

Eq. A-1 is a multi-regression fit equation for tests performed at drop impact velocities of 140,210 , and $400 \mathrm{~m} / \mathrm{s}$, and a drop size range from 1.2 to $2.0 \mathrm{~mm}$.

For stainless steel AISI $316(N O R=1)$ and a drop size of $1.8 \mathrm{~mm}$, this multiregression fit equation (Eq. A-1) results to the number of specific impacts for incubation as a function of water drop impact velocity as shown in Figure A-1. The 2.5 and $97.5 \%$ confidence limits of the log-normal distribution are given. The used nominal drop impact velocities in the interlaboratory test program are also shown.

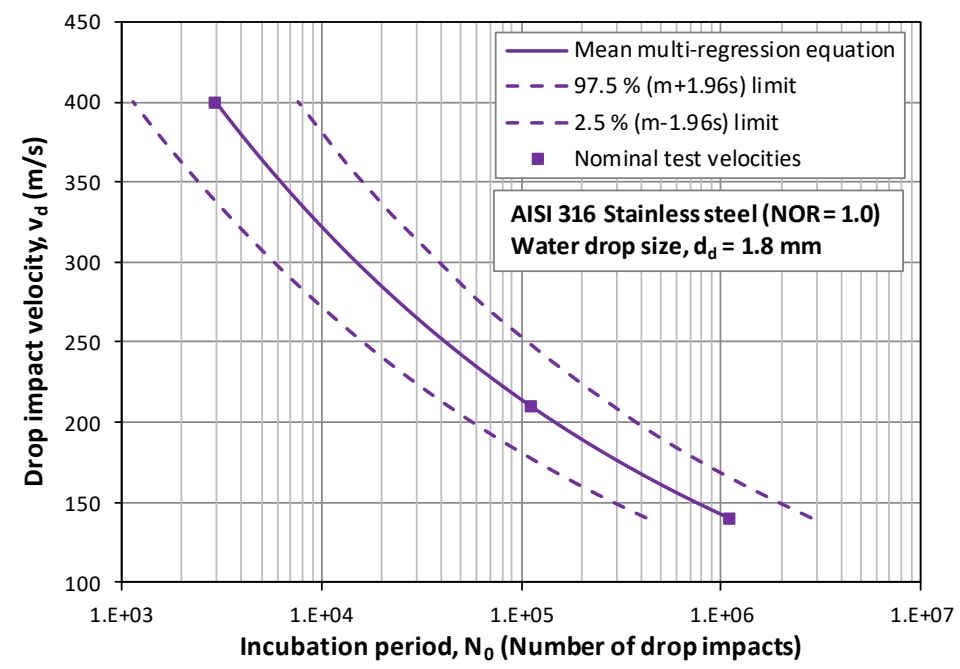

Figure A-1. The multi-regression fit equation (Eq. A-1) [11] for the incubation period as a function of water drop impact velocity for AISI 316 stainless steel. The 2.5 and $97.5 \%$ confidence limits and nominal drop impact velocities used in the interlaboratory test program are indicated.

The number of specific impacts for incubation can be transformed to incubation period in hours by using the definition for "number of specific impacts" is given by $[10,11]$ :

$$
N_{0}=\left(\frac{V_{\text {water }}}{A_{e}}\right) \times\left(\frac{A_{d}}{V_{d}}\right)=3600 C_{v} v_{d} I_{p} \times \frac{3000}{2 d_{d}}=5.4 \times 10^{6} \frac{C_{v} v_{d} I_{p}}{d_{d}}
$$


$V_{\text {water }} / A_{e}=$ volume of waterdrops impinged per unit exposed area

$A_{d} / V_{d}=$ projected area of a waterdrop divided by the volume of a waterdrop

$C_{v}=$ volume concentration of water in air (-)

$I_{p}=$ incubation period $(\mathrm{h})$

The normalized "incubation resistance numbers" (NOR) are determined for each of the metals tested, the numbers are shown in Table A-1. All relevant differences in metal properties compared to AISI 316 (hardness of $170 \mathrm{HV}$ ) are accumulated in the NOR value of the metal.

Table A-1. Incubation resistance numbers of the metals used in the interlaboratory test program [11].

\begin{tabular}{|l|c|}
\hline Metals & $\begin{array}{c}\text { Incubation resistance } \\
\text { number }(N O R)\end{array}$ \\
\hline Stellite 6B & 5.2 \\
Stainless steel AISI 316 & 1.0 \\
Nickel 270 & 0.224 \\
Aluminium 6061-T6 & 0.037 \\
Aluminium 1100-O & 0.0051 \\
\hline
\end{tabular}

\section{A.2 Properties of metals in ASTM test program}

The mechanical properties of the metals used in the ASTM Interlaboratory test program [11] are summarized in Table A-2. For all metals, with the exception of Stellite $6 \mathrm{~B}$, specimens manufactured from sheet and rod have been used in the erosion tests. For stainless steel AISI 316 hardness values ranging from 153 to 205 HV (Hardness Vickers) have been used. The measured incubation periods of AISI 316 have been corrected with a special procedure [10] to a hardness of $170 \mathrm{HV}$.

Austenitic stainless steel AISI 316 contains (in wt\%) $17 \mathrm{Cr}-10 \mathrm{Ni}-2 \mathrm{Mo}-0.02-0.04 \mathrm{C}$ with a thermodynamically stable austenite structure [20]. Stellite $6 \mathrm{~B}^{\circledR}$ is a Co-alloy containing (in wt\%) $28 \mathrm{Cr}, 4.5 \mathrm{~W}$, and $1.1 \mathrm{C}$, and normally supplied as mill-annealed sheet [21]. Aluminium 6061-T6 is an Al-Mg-Si alloy which has been heat treated for precipitation hardening. Aluminium $1100-0$ is an unalloyed annealed soft aluminium [22]. 
Table A-2. Mechanical properties of the metals used for the ASTM Interlaboratory liquid erosion test program [11].

\begin{tabular}{|l|l|c|c|c|c|}
\hline Material & Form & $\begin{array}{c}\text { Hardness } \\
(\mathrm{HV})\end{array}$ & $\begin{array}{c}\text { Tensile strength, } \\
\mathrm{R}_{\mathrm{m}}(\mathrm{MPa})\end{array}$ & $\begin{array}{c}\text { Elongation, } \\
\mathrm{A}(\%)\end{array}$ & $\begin{array}{c}\text { Reduction of } \\
\text { area, } \mathrm{Z}(\%)\end{array}$ \\
\hline Stellite 6B & Sheet & 360 & 1040 & 9.7 & 9.4 \\
\hline AISI 316 & Sheet & 205 & 600 & 49 & 56 \\
& Rod & 153 & 550 & 63 & 77 \\
\hline Nickel 270 (99.98\%) & Sheet & 78 & 350 & 50 & 57 \\
& Rod & 75 & 350 & 62 & 89 \\
\hline Aluminium 6061-T6 & Sheet & 94 & 310 & 12 & 27 \\
& Rod & 116 & 330 & 20 & 35 \\
\hline Aluminium 1100-O & Sheet & 24 & 90 & 39 & 49 \\
& Rod & 29 & 90 & 46 & 83 \\
\hline
\end{tabular}

\section{Appendix B - Fatigue properties of AISI 316 and AI-6061-T6}

Fatigue properties of stainless steel AISI 316(L) and aluminium 6061-T6 as used in the ASTM Interlaboratory test program were collected from literature [34-45], see Table B-1. These references show a substantial amount of test data, so a S-N curve could be fitted and a fatigue limit at 2 million cycles could be determined. The stress ratios of these fatigue data were $R=0.1$ or -1 . Fatigue data with a stress ratio $R=$ 0.1 were corrected to $R=-1$ (mean stress $S_{m}=0$ ) using Morrow's equation [25] for a mean stress correction, see Eq. 9. The collected fatigue data are summarized in Table B-1.

The physical properties for stainless steel AISI 316(L) and Al-6061-T6 were collected from the Metals handbook [46]. For AISI 316(L): density $\rho=8000 \mathrm{~kg} / \mathrm{m}^{3}$, Young's modulus, $\mathrm{E}=193 \mathrm{GPa}$, and Poisson's ratio $\mathrm{v}=0.30$, and for Al-6061-T6: density $\rho=$ $2700 \mathrm{~kg} / \mathrm{m}^{3}$, Young's modulus, $\mathrm{E}=69 \mathrm{GPa}$, and Poisson's ratio $v=0.33$. 
Table B-1. Fatigue life curves of AISI 316 austenitic stainless steel and aluminium 6061-T6 in air at $20^{\circ} \mathrm{C}$, collected from literature [34-45], and corrected, using Morrow's equation [25], to a stress ratio of $R=-1$.

\begin{tabular}{|c|c|c|c|c|c|c|c|}
\hline \multirow[t]{2}{*}{ Literature source } & \multirow[t]{2}{*}{ Material } & \multirow[b]{2}{*}{$\begin{array}{c}R_{m} \\
(\mathrm{MPa})\end{array}$} & \multicolumn{5}{|c|}{$\begin{array}{l}\text { Fatigue life } S_{\max }-N_{f} \text { curves } \\
\text { for } R=-1\left(S_{m}=0\right)\end{array}$} \\
\hline & & & Loading & $\begin{array}{c}f^{1)} \\
(\mathrm{Hz})\end{array}$ & $\begin{array}{c}\mathrm{S}_{\mathrm{f}, 0} \\
(\mathrm{MPa})\end{array}$ & $\begin{array}{l}m \\
(-)\end{array}$ & $\begin{array}{c}\mathrm{S}_{\mathrm{D}}^{2)} \\
(\mathrm{MPa})\end{array}$ \\
\hline \multicolumn{8}{|l|}{ Austenitic stainless steel AISI 316} \\
\hline Tokaji et al. [34], 2004 & Rod, $\varnothing 16 \mathrm{~mm}$ & 576 & bending & 19 & 1248 & 9.2 & 256 \\
\hline Kamaya et al. [35], 2011 & Bar, $\varnothing 34 \mathrm{~mm}$ & 612 & axial & 0.2 & 1232 & 8.0 & 201 \\
\hline Herrera et al. [36], 2017 & Plate, 5 mm & 592 & axial & 50 & 1071 & 9.9 & 247 \\
\hline Maruyama et al. [37], 2011 & Bar, $\varnothing 25$ mm, HT $^{3)}$ & 540 & axial & 20 & 1145 & 9.6 & 253 \\
\hline Van Leeuwen [38], 1995 & Plate, $3 \mathrm{~mm}$ & 597 & axial & 20 & 3113 & 4.8 & 152 \\
\hline Liljas et al. [39], 2002 & HR plate, $10-20 \mathrm{~mm}$ & 578 & axial & 20 & 1828 & 6.0 & 163 \\
\hline Mohammad et al. [40], 2012 & Tubular, OD = $28 \mathrm{~mm}$ & 673 & axial & 5 & 1459 & 7.4 & 203 \\
\hline \multicolumn{8}{|l|}{ Aluminium 6061-T6 } \\
\hline Krishna et al. [41], 2018 & Rod & & bending & 42 & 797 & 9.4 & 206 \\
\hline Wasekar et al. [42], 2011 & Rod & & bending & 42 & 729 & 9.0 & 179 \\
\hline Takahashi et al. [43], 2012 & Extruded rod & 379 & bending & 55 & 799 & 9.7 & 221 \\
\hline Scott et al. [44], 2010 & Plate, $3.1 \mathrm{~mm}$ & 405 & axial & 40 & 945 & 7.0 & 153 \\
\hline Mutombo et al. [45], 2011 & Plate, $6.4 \mathrm{~mm}, 102 \mathrm{HV}$ & & axial & 1 & 951 & 6.1 & 128 \\
\hline
\end{tabular}

\footnotetext{
1) Frequency,

2) Fatigue limit $S_{D}$ at 2 million cycles,

3) Heat treated.
} 
Patent proposal D 


\section{Sensing damage of protective coatings}

Inventors: Lun Kai Cheng, Jonathan van den Ham, Henk Slot \& Rob Jansen

TNO Stieltjesweg 1, Delft

Patent proposal description

\section{Background and context}

For many applications, coatings are applied to protect structures and systems from external influences such as the weather. Examples are coatings on ship (hulls), aircraft, space vehicles, cars, wind turbines, buildings and many other structures.

Impacting mechanical forces, such as rain droplets, hailstones, debris (in water or air), bird strike, or ballistics may damage the coating and/or structure underneath the coating. Later on, this can lead to erosion, corrosion, cracking or disrupted functioning of the structure underneath the coatings, depending on the environment and materials involved. This leads to cost related to diagnostics or preventive maintenance because the damage cannot be assessed at early stage.

Solutions to tackle the unknown damage are related to structural health monitoring in various ways, such as 'indicating coatings' [1] and 'signalling coatings' [2]. Although these cannot be regarded as (reversible) sensors, they allow sensing if damage has occurred after an impact event. However, these kinds of responsive coatings generally show the result but do not quantify the forces involved. In addition, these approaches do not allow real time sensing of impacting forces.

For real time and reversible sensing, electronic sensors are often applied for research purpose. For instance, continuous stress measurements or tension load measurements can be done with electronic sensors. Although widely spread and relatively low cost, this approach does not allow for distributed sensing, and electronic sensors are not always suitable for specific environments and length scales. Therefore, this technology is not expected to be suitable for the intended application under operation.

\section{Core idea}

Fibre optic sensors can be applied to measure mechanical strains of structures. Using fibre Bragg grating (FBG), quasi-distributed sensing with multiple sensors in a 
single optical fibre can be realized to reduce costs and improve system integration. The concept of FBG is well known. However, as far as known to us, measuring impact forces on protective coatings and calculation of the resulting effects on the occurrence of erosion has not been reported before. Hence, this invention shall be disclosed in a patent proposal, comprising of the following steps:

1. Integration of a FBG fibre in or below a protective coating, which is present on a large structure. The optical fibre may comprise of glass or a polymer (POF).

2. Connection of one or more FBG per fibre to realise a FBG array or several fibres to an interrogator for data acquisition and/or monitoring of real time events in operation. Dedicated high-speed FBG interrogation technology is required to detect the amplitude of impact waves at the location of the FBG and separate the different impacts (e.g. by rain drops) in time.

3. Data analysis to identify magnitude and frequency (number of impacts) and model predictive erosion quantification.

\section{Detailed description for wind turbine blade application}

Rain erosion of the blades is a major challenge in view of upscaling wind turbines. Since rain erosion is related to the number of drop impacts and the forces they apply, a sensor is required to track these impacts. With this invention, a FBG system is integrated in or below the leading edge protective coating of the wind turbine blade. This FBG system measures the stresses of the impact waves and does not involve coating erosion but mechanical deformation analysis.

While aware of the large difference in stiffness between the coating (flexible) and the fibre (stiff), smart solutions are required for integration. In order to achieve this, a buffer coating is introduced to create a gradient in stiffness from the coating to the FBG fibre. In this invention, the amplitude of the wavelength shift upon droplet impact can be related to the energy of such a droplet by using proper FBG interrogation technology. Hence, this invention allows to track: 1 ) the number, and 2 ) the energy of the impacts on the protective coating of a wind turbine blade by using an interrogation technology which has the required speed and sensitivity [3]. Based on statistical considerations, only a few FBGs are required to monitor large structures as a wind turbine blade, since the droplet distribution of a certain rain shower leads to an average impact distribution over the blade surface and as a function of time. Combining these results with the predictive model of Slot et al. [4], which is part of this invention, the measured droplet impact data is used to: 3 ) 
predict cumulative erosion behaviour of the protective coating with certain physical and mechanical properties.

This invention can also be used for other markets and applications e.g. erosion of protective coatings of airplanes.

\section{References}

[1] Barut S., Ferreira M., Maia F., Senani S., Tedim J., Zheludkevich M., Coating for Monitoring the Internal Integrity of a vehicle Structure Comprising Same, Patent: EP 3181644 B1, University of Aveiro, Airbus, 2018.

[2] Meulendijks-Kiggen N.M.M., Erich S.J.F., Eversdijk J., Papen-Botterhuis N.E., Salari J.W.O., A coating composition comprising a dye and a method to detect moisture in objects, Patent: WO 2015/016716 A1, TNO, 2015.

[3] Hof P.G. van 't, Cheng L.K., Scholtes J.H.G., Prinse W.C., Dynamic pressure measurement of shock waves in explosives by means of a fiber Bragg grating sensor, 27th International Conference on High-Speed Photography and Photonics, Proceedings of SPIE 6279, 2007.

[4] Slot H.M., Gelinck E.R.M., Rentrop C., Heide E. van der, Leading edge erosion of coated wind turbine blades: Review of coating life models, Renewable Energy 80, 2015, 837-848. 